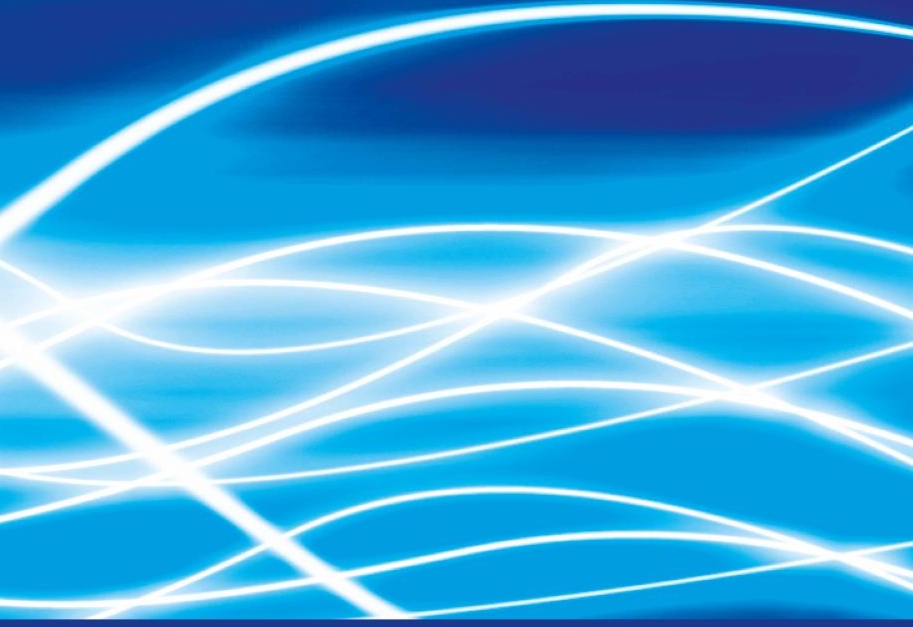

\title{
Modeling Public Policies in Latin America and
} the Caribbean

Carlos de Miguel José Durán Lima Paolo Giordano Julio Guzmán Andrés Schuschny Masakazu Watanuki Editors

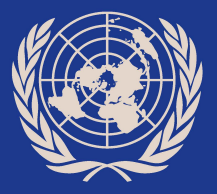

UNITED NATIONS

EC C A C
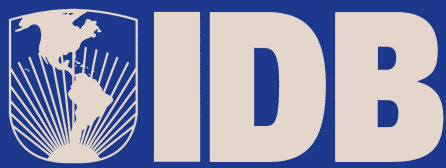


\section{Modeling Public Policies in Latin America and the Caribbean}

Carlos de Miguel

José Durán Lima

Paolo Giordano

Julio Guzmán

Andrés Schuschny

Masakazu Watanuki

Editors

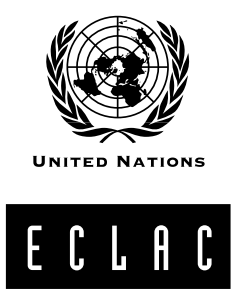

Santiago, Chile, September 2010 


\title{
Libros de la CEPAL
}

\section{9}

\author{
Alicia Bárcena \\ Executive Secretary \\ Antonio Prado \\ Deputy Executive Secretary \\ Osvaldo Rosales \\ Chief of the International Trade \\ and Integration Division \\ Joseluis Samaniego \\ Chief of the Sustainable Development \\ and Human Settlements Division \\ Susana Malchik \\ Officer-in-Charge \\ Documents and Publications Division
}

This book contains a selection of studies discussed at the first and second Regional Meetings on Computable General Equilibrium, which were held, respectively, in Santiago, Chile on 13 and 14 April 2007 with the collaboration of the Centre for International Prospective Studies and Information (CEPII), and San Jose, Costa Rica, from 24 to 25 November 2008, with the collaboration of the Central American Institute of Business Administration (INCAE). We are grateful to all the speakers and participants in both Regional Meetings for the detailed discussions and feedback which helped to enhance the papers presented in this book. Special thanks are owed to Robert Devlin, Antoni Estevadeordal, André Hofman, Mikio Kuwayama, José Luis Machinea, Osvaldo Rosales and Joseluis Samaniego for their generous support of the initiative.

Cover design: Andrés Hannach

United Nations Publication

ISBN: 978-92-1-121739-1

E-ISBN: 978-92-1-054519-8

LC/G.2461-P

Sales No. E.10.II.G.44

Copyright (C) United Nations, September 2010. All rights reserved

Copyright (C Inter-American Development Bank, September 2010. All rights reserved

Printed in United Nations, Santiago, Chile

Applications for the right to reproduce this work are welcomed and should be sent to the Secretary of the Publications Board, United Nations Headquarters, New York, N.Y. 10017, United States. Member States and the governmental institutions may reproduce this work without prior authorization, but are requested to mention the source and inform the United Nations of such reproduction. 


\section{Contents}

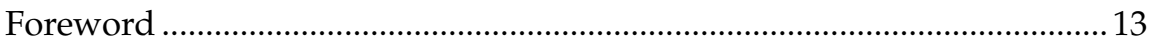

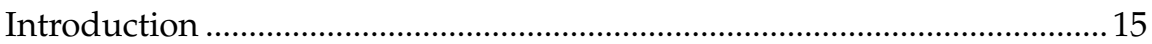

Chapter I

Are CGE models still useful for economic policymaking? ............................ 21

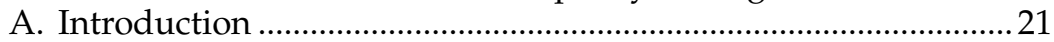

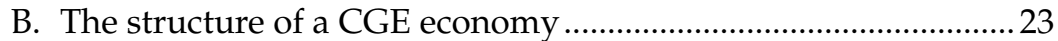

C. Better framing of CGE activities ...................................................... 25

D. A glimpse of the theoretical improvements needed .....................27

E. Conclusion ……............................................................................. 29

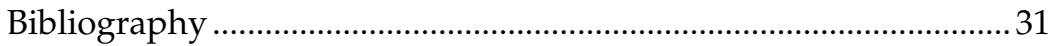

\section{Chapter II}

Andean countries at a crossroads:

evaluating pro-poor trade integration options ................................................. 33

A. Introduction ……............................................................................... 33

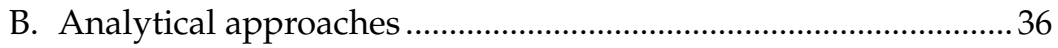

1. The IDB-INT Andean CGE model ..............................................37

2. Extensions and innovations of the CGE model ........................39

3. Microsimulation analysis ............................................................. 41

C. Overview of the Andean economies …………................................ 44

1. Macroeconomic indicators .......................................................... 44

2. Trade flows and barriers .......................................................... 45

3. Household income profile ......................................................... 51 
4. Poverty and extreme poverty …………………......................... 51

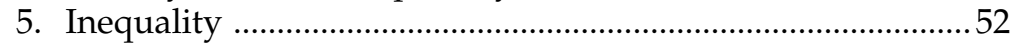

D. CGE simulations: macro and sectoral results ................................53

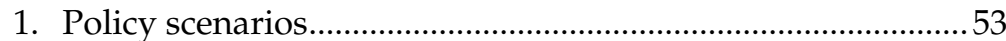

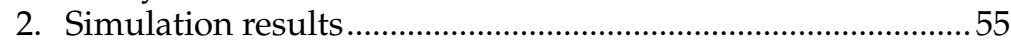

3. Opportunities and challenges for Andean industries..............62

E. Impact of trade and integration on poverty and inequality .......65

1. Impact on per capita household income,

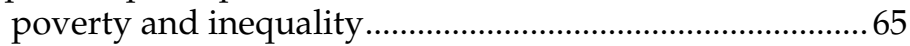

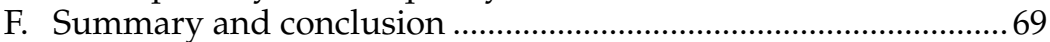

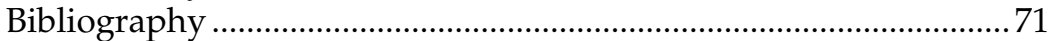

Annex 1: Regions and countries in the model....................................75

Annex 2: Sectoral classification in the model ..................................... 76

Annex 3: Impact on aggregate sectoral exports in the Andean

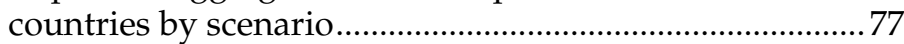

Annex 4: Structure of regional household income ............................... 82

Annex 5: Poverty and extreme poverty in Andean

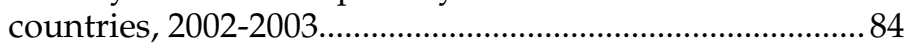

Annex 6: Household inequality in the Andean countries by region, 2002-2003.

Annex 7: Impact of Andean-United States trade agreements on income inequality

Chapter III

Central America - European Union Association Agreement:

an assessment using general and partial equilibrium ...................................8 87

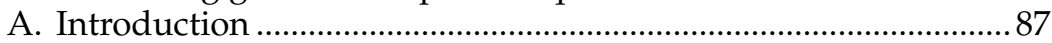

B. Regional integration, international integration patterns and trade policy developments ........................................................ 89

1. Regional integration and trade policy in Central America ..91

2. Central American trade patterns ................................................92

C. Trade relations with the European Union: common interests ...95

1. Tariff barriers being negotiated ..............................................100

2. Assessments of the possible effects of the free trade agreement and recent studies including the European Union

D. Data and analysis methodology ................................................... 102

1. Sectoral and regional aggregations in the computable general equilibrium ................................................................ 102

2. Amendment of the GTAP 7.0 database ..................................104

3. Sensitive products included in the simulations .....................105

4. Scenarios used in the simulations ............................................106

5. Methodology for partial equilibrium simulations .................108

6. Environmentally sensitive industries ...................................109

E. Analysis of the results ...................................................................111 
1. Macroeconomic results (output, trade, consumption and investment)

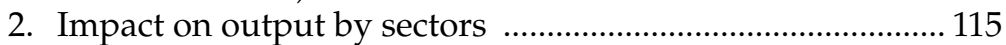

3. Foreign trade results (exports and imports) .......................... 116

4. Analysis of variations in welfare ............................................ 117

5. Results of partial equilibrium simulations (trade and welfare).

6. Changes in environmental sensitivity in Central America 122

F. Conclusions and trade policy recommendations ........................ 125

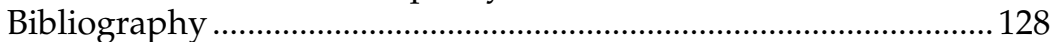

Annex 1: Trade and Reciprocal tariffs applied by Central America and the European Union

Annex 2: Global Trade Analysis Project (GTAP) database sectoral aggregation

Annex 3: Sensitive products in the free trade agreement between the Dominican Republic, Central America and the United States

Annex 4: Environmentally sensitive industries ................................ 134

Annex 5: Trade Agreements of European Union 27 ........................ 135

Annex 6: Impact assessment of the association agreement between Central America and the European Union, breakdown of the total value of exports of goods and services under several scenarios

\section{Chapter IV}

Fiscal policies and increased trade openness: poverty impacts in Ecuador

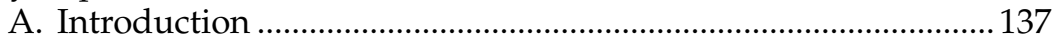

B. Overview of the Ecuadorian economy ……................................. 139

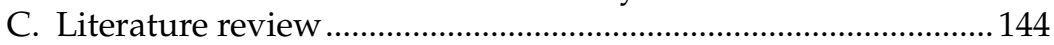

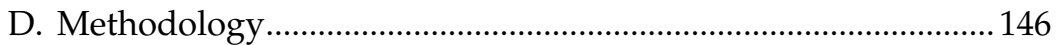

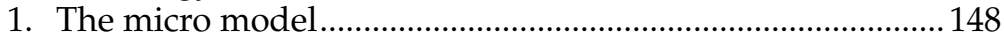

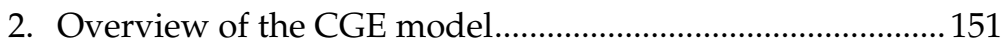

E. Data 157

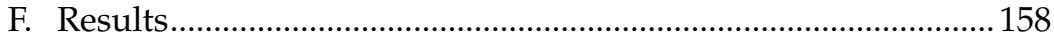

1. Micro model regression estimations........................................ 158

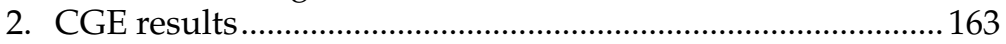

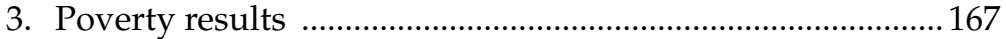

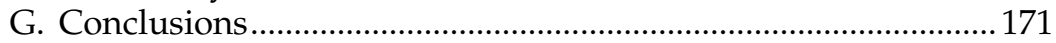

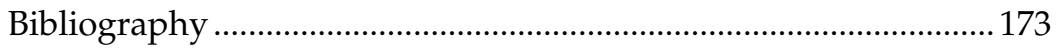

Chapter V

Poverty assessment from integration and employment policies in Uruguay: A CGE modelling analysis

A. Economic overview. 


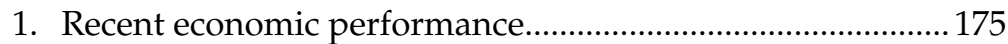

2. Recent trends in the Uruguayan labour market ....................178

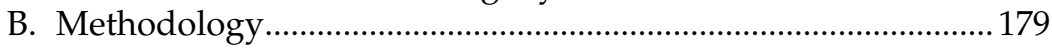

1. Labour market specification: wage curve ............................... 179

C. Simulation design and results ...................................................... 184

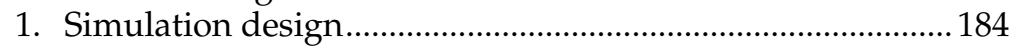

2. Simulations of regional shocks and results ............................186

3. Simulation of MERCOSUR deepening and results ...............189

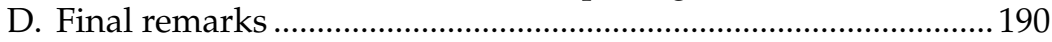

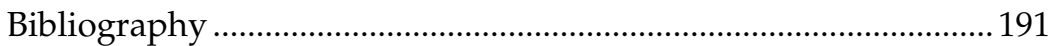

Appendix: Estimation of a wage curve ........................................... 194

Chapter VI

CGE lessons on liberalization of trade in services:

Argentina, Brazil and Uruguay..................................................................199

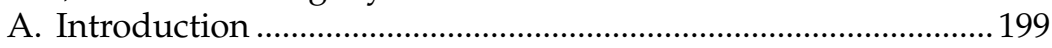

B. The literature on the liberalization of services in a computable general equilibrium..................................................2202

C. The basic economic model ............................................................204

D. The nature of liberalization exercises in the trade in services .209

E. Counterfactual experiments ......................................................... 211

1. A taxonomy of the main simulations in this study .............. 211

2. Productivity (PRO), efficiency (EFF) and quality (QUA) gains due to liberalization.......................................................... 214

3. Productivity, efficiency and quality under competition of technologies and international mobility of capital ...........216

4. Reduction in the implicit mark-up (MUP) on imports of services. Competition of technologies....................................... 218

5. Liberalization in trade of financial services (LIB) and regulations in Argentine portfolios .........................................219

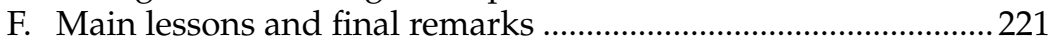

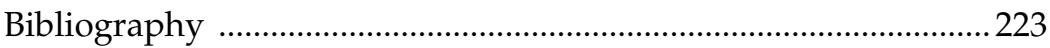

Appendix: The models..................................................................... 225

\section{Chapter VII}

World food price increases and Brazil: an opportunity for everyone? ....231

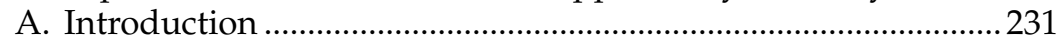

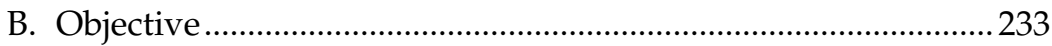

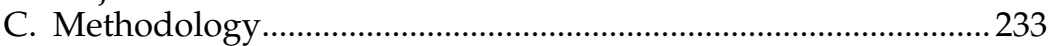

D. Poverty and income distribution in Brazil in the 2004

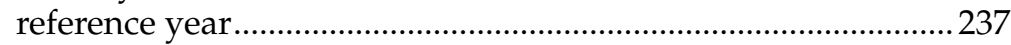

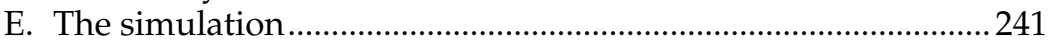

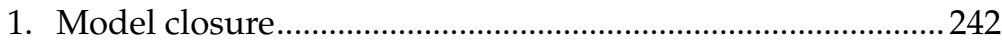

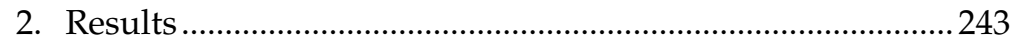

F. Poverty and income distribution results ......................................248 
G. Concluding remarks 251

Bibliography

Chapter VIII

Climate change in Latin America:

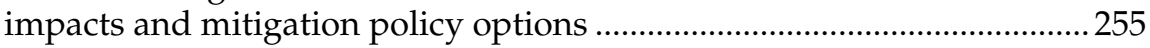

A. Introduction ……....................................................................... 255

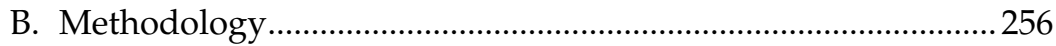

a. ENVISAGE: a global computable general

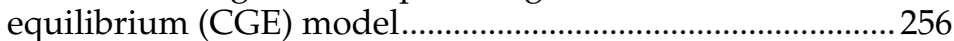

b. Global Income Distribution Dynamics (GIDD): a global micro-simulation model ..............................................2262

C. Macro results ………...................................................................... 264

1. Baseline: Business-as-usual (BaU) with climate-change damage .................................................................................... 264

2. Baseline with no damage from climate change ....................268

3. Mitigation policies: country-specific and global

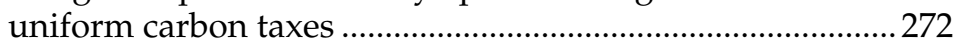

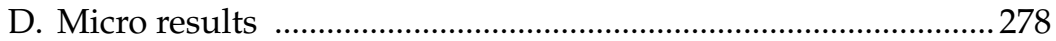

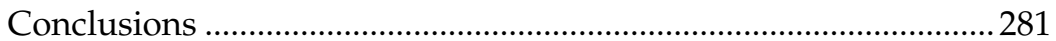

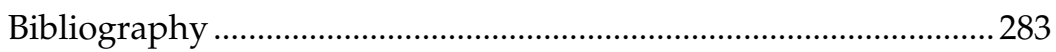

Chapter IX

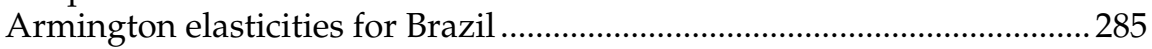

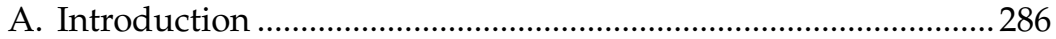

B. Armington elasticity and Brazilian trade

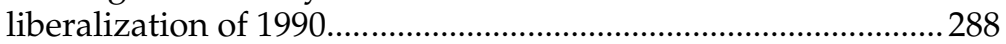

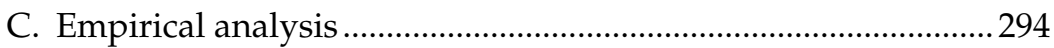

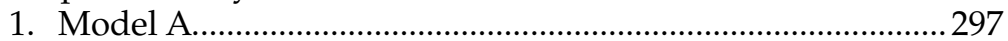

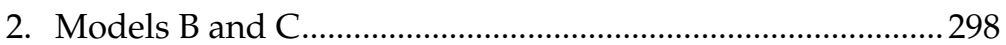

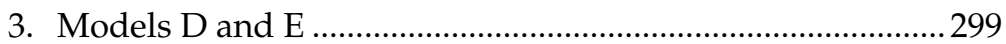

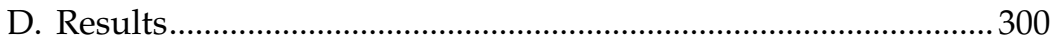

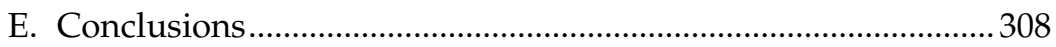

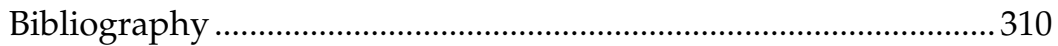

Annex A: Source and treatment of the data....................................... 311

Annex B: Determination of the order of integration of the price and quantum series ...................................................... 315

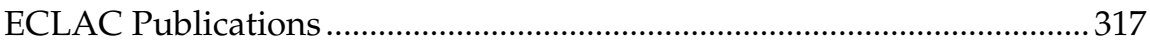

\section{Tables, figures and boxes}

\section{Tables}

II.1 Comparative macroeconomic statistics for the Andean countries, 2001

II.2 Market share of Andean trade by major partners, 2001 ................ 46 
II.3 Andean countries: Applied MFN tariffs by sector, 2001................. 48

II.4 Applied tariffs imposed on the Andean countries by major

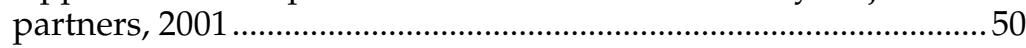

II.5 Policy scenarios simulated for Andean countries ………...............53

II.6 Impact of alternative scenarios on welfare and

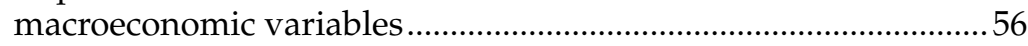

II.7 Sectoral winners and losers among Andean industries ..................64

II.8 Impact on poverty and extreme poverty in Andean countries ....67

III.1 Central American Common Market (CACM) and the European Union: Main macroeconomic and trade variables, 2007 and August 2008.

III.2 Central American Common Market (CACM): External relations. 92

III.3 Central American Common Market (CACM): Export pattern by main destinations, 2006

III.4 Barriers by groups of products in the European Union market, baseline GTAP 7.0

III.5 Regional aggregation of the GTAP database................................. 103

III.6 Sectoral aggregation of the GTAP database .................................... 107

III.7 Measures of trade creation and welfare variation using partial equilibrium

III.8 Environmentally Sensitive Industries (ESI) in Central American Common Market exports to the European Union and the world

III.9 Impacts of the association agreement between Central America and the European Union in real terms

III.10 Simulation of the association agreement between Central America and the European Union: Impacts on output and its components (three scenarios)

III.11 Breakdown of exports from the Central American Common Market (CACM) to the European Union, 2006

III.12 Assessment of the impact of an association agreement between Central America and the European Union:

Breakdown of the value of exports, various scenarios

III.13 Proposed free trade agreement between European Union and Central American Common Market: Changes in welfare (equivalent variation)

III.14 Central American Common Market (CACM): trade creation and welfare variations as a result of increased exports to the European Union market, full liberalization scenario

III.15 Central American Common Market (CACM): Trade creation and welfare variations as a result of increased exports in the European market, scenario of liberalization with only fruit and vegetables excluded by the European Union

III.16 Effects of an association agreement between the Central American Common Market (CACM) and The European 
Union on Environmentally Sensitive Industries (ESI)

III.17 Effects of total tariff elimination under an association agreement between the Central American Common Market (CACM) and the European Union on Environmentally Sensitive Industries (ESI).

IV.1 Ecuador: Exports and imports by country or region, 1998-2005 .. 141

IV.2 Non-financial public sector, selected operations, 1998-2005 ....... 141

IV.3 Central government budget deficit (-) or surplus (+), 1998-2005

IV.4 Ecuador: Poverty indices at the base, 2005 .................................. 143

IV.5 Number of workers, wages and earnings, 2005 ............................ 149

IV.6 Wage-worker regressions, OLS ……………..................................158

IV.7 Earnings regression for self-employment, OLS .............................159

IV.8 Wage-worker regressions, two-stage Heckman..............................160

IV.9 Earnings functions for self-employment, two-stage Heckman.. 161

IV.10 Occupational choice model.............................................................. 162

IV.11 Main macroeconomic results from the CGE simulations............. 164

IV.12 Percentage changes in income, by source, for urban and rural households.

IV.13 Percentage changes in real factor returns ..................................... 167

IV.14 Ecuador: Results on poverty incidence of trade liberalization

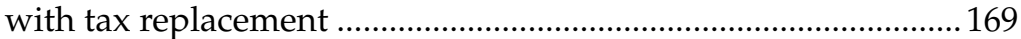

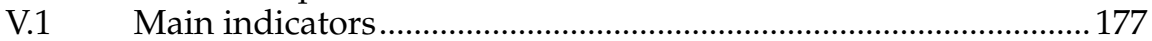

V.2 Coefficients on the unemployment variable in the estimation of a wage curve for groups of individuals.....................................180

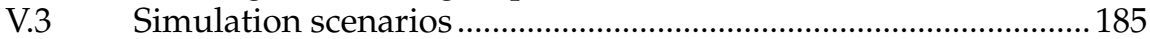

V.4 Macroeconomic variables for each simulation..............................186

V.5 Factor intensity of export by destination ........................................186

V.6 Specialization and factor intensity by sector..................................187

V.7 Output shares and variation by sector ........................................... 188

VI.1 Trade in services: Ad valorem equivalent barriers used in

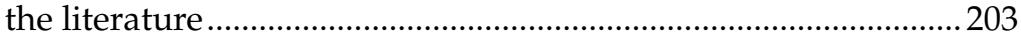

VI.2 Argentina, Brazil and Uruguay: Composition of costs and destination of sales

VI.3 Argentina, Brazil and Uruguay: Computable General Equilibrium model simulations. Results corresponding to productivity, efficiency and quality changes

VI.4 Argentina, Brazil and Uruguay: Computable General Equilibrium model simulations. Results corresponding to technological substitution and its effects on productivity, efficiency and quality changes

VI.5 Argentina, Brazil and Uruguay: Computable General Equilibrium model simulations. Results corresponding to mark-up reduction and technological substitution based on the methodology of DEE (2005) 
VI.6 Argentina: Financial services liberalization and regulations......220

VII.1 Poverty and income distribution in Brazil, 2004 …......................237

VII.2 Regional poverty and income inequality figures, Brazil, 2004 ...239

VII.3 Use of labor by each aggregated activity: Shares, Brazil, 2004 ...240

VII.4 Household income composition according to worker's wage class, Brazil, 2004 ……....................................................................... 240

VII.5 Shocks according to the model commodity classification............242

VII.6 Selected macroeconomic results.....................................................24

VII.7 Activity level variation by industry ………...................................224

VII.8 Selected macroeconomic results: Macro regions in Brazil............248

VII.9 Poverty and income distribution results.........................................249

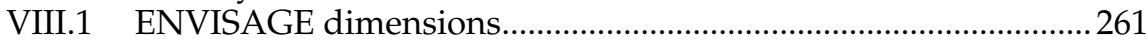

VIII.2 Population, GDP, and emissions in the baseline..............................266

VIII.3 Change in real income due to climate change damages................269

VIII.4 Change in the value of agricultural imports due to

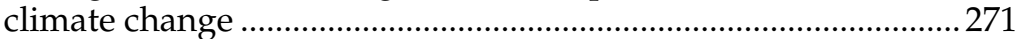

VIII.5 Carbon taxes in the uniform and country-specific

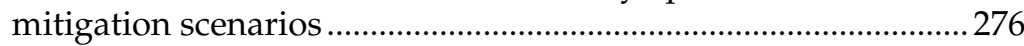

VIII.6 Change in real income relative to baseline .....................................277

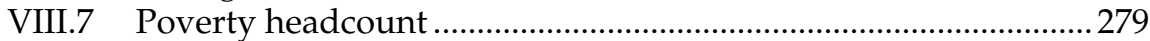

IX.1 Decision table for the type of model used in estimation ..............296

IX.2 Typology of quantum and price series............................................301

IX.3 Armington elasticities for Brazil, 1986-2002 …................................303

IX.4 Ranges of the estimated elasticities and international

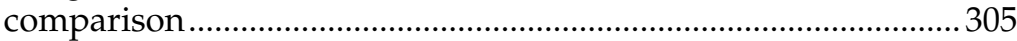

\section{Figures}

II.1 Labour force participation in the Andean countries by gender ... 45

II.2 Impact on per capita household income.

III.1 Central American Common Market: Trade pattern, main sectors by technological intensity and main destinations of total exports, 2006.

III.2 Central American Common Market (CACM): Trade with the European Union 27, 1986-2007

III.3 Central American Common Market: Tariff applied and pattern of imports from the European Union 27

III.4 Structure of Central American exports to the European Union and tariff applied at customs, 2006

III.5 Proposed free trade agreement between European Union and Central American Common Market: Breakdown of changes in GDP and total exports, by price and volume effect...

III.6 Proposed free trade agreement between European Union and Central American Common Market: Welfare changes under various simulated scenarios 
III.7 Proposed free trade agreement between European Union and Central American Common Market: changes in structure following liberalization with the European Union ....................... 122

IV.1 Export structure in the CGE model ………....................................153

IV.2 Import structure in the CGE model ..............................................153

VII.1 Regional poverty results, by type of shock (food and

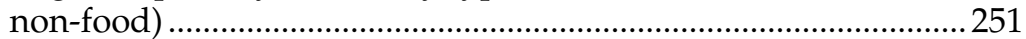

VIII.1 Production structure nesting ……………...................................25

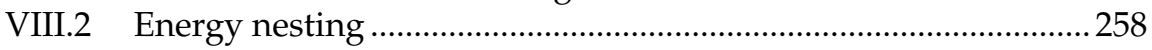

VIII.3 Domestic demand nesting ……………........................................259

VIII.4 Output, supply and trade ...........................................................2 260

VIII.5 GIDD methodological framework ................................................263

VIII.6 Atmospheric concentration of carbon, radiative forcing, and temperature in baseline ....................................................................2. 265

VIII.7 Composition of energy demand ………….....................................267

VIII.8 Reduction in global emissions and carbon taxes in the efficient mitigation scenario............................................................. 273

VIII.9 Growth incidence of climate change damages and mitigation policies in Latin America................................................................. 281

IX.1 Indifference curves between imports and domestic production

\section{Box}

III.1 Procedure for obtaining the new 2007 baseline and simulations applied. 



\section{Foreword}

In an increasingly integrated world where the pace of change is accelerating, policy decisions need to be taken with little hesitation. However, their development effectiveness requires that they are also based on solid analytical foundations.

The negotiation of an open rules-based global trading system, the eradication of poverty and inequality, and the adaptation to climate change are examples of complex policies featuring multiple direct and indirect effects, as well as economic, social and environmental ramifications that are difficult to assess in the absence of sophisticated analytical instruments.

Given the existence of information asymmetries and coordination failures, multilateral development institutions have an opportunity to support their member countries in the assessment of policies that require complex background analysis, particularly when their effects spill over beyond the border of any given country. The development and dissemination of cutting-edge knowledge and analytical toolkits should therefore be pursued as regional public goods.

In this context the Inter-American Development Bank (IDB) and the Economic Commission for Latin America and the Caribbean (ECLAC) have formed a partnership to promote a regional network of computable general equilibrium (CGE) modellers that facilitates the exchange of analytical findings, techniques and data, with the ultimate objective of better serving policymakers in policy formulation. 
The regional meetings of CGE modellers, held annually in a different country of the region, have been instrumental in promoting intraregional transfer of analytical technologies and in bringing the region closer to international best practices. As an outcome of this effort, the Global Trade Analysis Project (GTAP) selected ECLAC and IDB to host the $12^{\text {th }}$ Annual Conference on Global Economic Analysis, which provided an opportunity to showcase globally the work being done regionally.

This book includes a selection of studies discussed in past annual regional meetings on modelling. They deal with issues such as trade policy, regional integration, trade in services, fiscal policy, the impact of food price surges and climate change; are based on comparable methodologies; and shed light on the implications of crucial policy alternatives that Latin American regional policymakers are currently facing.

With this publication, ECLAC and IDB hope to disseminate the studies broadly among policymakers and to encourage new generations of modellers to further analytical work in this area. In doing so both organizations reaffirm their commitment to support this line of research so that stakeholders can take better informed policy decisions.

\author{
Alicia Bárcena \\ Executive Secretary \\ Economic Commission for Latin \\ America and the Caribbean
}

\author{
Santiago Levy \\ Vice-President for Sectors \\ and Knowledge \\ Inter-American Development Bank
}




\section{Introduction}

In response to scepticism over the supposed trickle-down effects of Latin American trade reforms, the region's policymakers are increasingly focusing attention on the distributive impacts of the reform measures and the channels through which they are transmitted. For their part, economists are developing cutting-edge quantitative methodologies and high-quality databases to support policy analysis in this inherently complex field.

A promising development in this regard is the growing use and sophistication of computable general equilibrium (CGE) analysis. This technique - which is particularly applicable to trade policy analysis, where distributive and cross-border impacts are significant- is increasingly being used to perform assessments at the national, regional and global levels.

In 2001, the Inter-American Development Bank (IDB) and the Centre d'Études prospectives et d'informations internationales (CEPII), acting through the Institute for the Integration of Latin America and the Caribbean (INTAL), sponsored a conference entitled "Impacts of Trade Liberalization Agreements on Latin America and the Caribbean", based on CGE models. This conference was held at IDB headquarters in Washington, D.C., and was a landmark event in the creation of the region's Computable General Equilibrium Modeling Network.

After developing parallel lines of research and in an effort to enhance the region's institutional capacity to perform trade policy analysis in a CGE framework, IDB and the Economic Commission for 
Latin America and the Caribbean (ECLAC) launched the Computable General Equilibrium Modeling Regional Network as an interactive platform for dialogue between CGE experts across the region. The objective of the initiative is twofold. First, it puts the Latin American region in the vanguard of knowledge about CGE modelling techniques, emphasizing - but not confined to- trade policy analysis. Second, it helps to create a dialogue between modellers and policymakers in which the former raise awareness of CGE while the latter identify relevant areas for analysis, research questions and simulation scenarios.

Subsequently, in 2007, IDB, ECLAC and CEPII organized the first Regional Meeting on Computable General Equilibrium. Held in Santiago, Chile, the event focused primarily on the link between trade and poverty, but also included CGE studies evaluating agricultural and fiscal policies, among others.

In 2008, in collaboration with the Central American Institute of Business Administration (INCAE), IDB and ECLAC held the second Regional Meeting in San José, Costa Rica. In addition to themes addressed at the Santiago conference, this event also examined the impact of increases in world food prices, the use of spatial models, and emerging areas for CGE analysis such as climate change and liberalization in the services sector.

These meetings have helped to promote a better understanding of policy issues, opportunities and challenges through the use of CGE models. They have also strengthened the analytical capabilities of governmental technical teams in Latin America responsible for policy formulation and implementation.

IDB and ECLAC are now collaborating on the publication of a selection of the papers presented at the last two meetings mentioned above. The selection process has been difficult, given the number of papers presented and their high quality. We feel that the sample included in this book represents the main areas discussed at the meetings and provides analysis of relevance to the Latin America and Caribbean region.

The papers included in this book can be categorized into four main groups. First, we review the usefulness of CGE models for policymakers and discuss the relevance of this tool for international organizations and governments. The second group consists of five papers that assess trade integration scenarios for Latin American countries, with a particular focus not only on macroeconomic indicators but also on socio-economic and welfare variables. One conclusion from this group of papers is that similar shocks do not have similar effects across countries, indicating the need for country-specific studies; i.e., results cannot be generalized. The third group of papers presents applications of CGE models in two 
new areas: climate change and liberalization of services. The final paper offers a practical contribution to general and partial equilibrium analysis by estimating a set of Armington elasticities for the Brazilian economy.

In chapter I, Flôres offers a brief but substantive review of the usefulness of CGE models for policymakers. He points out that CGE models, like other quantitative methods, have their drawbacks. However, as long as CGE is the "only ... technique providing a global, interrelated way of capturing economy-wide effects" of a policy reform, it is a useful methodology for policymakers. Flores also advocates building a relationship based on mutual trust between modellers and policymakers.

In chapter II, Giordano and Watanuki use a two-step approach to analyse the effects of trade agreements between the United States and European Union and the Andean countries (Ecuador, Colombia, Peru and the Plurinational State of Bolivia). The authors assess different integration scenarios, among them the possibility that the Plurinational State of Bolivia and Ecuador might not sign the agreement with the United States. The authors then complement the CGE analysis with microsimulations that assess the impact of the trade agreement with the United States on poverty and inequality. Their results show that the agreement with the United States would have positive effects in terms of GDP, exports, welfare and poverty alleviation for Colombia and Peru, and that Ecuador and the Plurinational State of Bolivia would forego potential opportunities if they did not sign. The authors also conclude that for the Andean countries, with the exception of the Plurinational State of Bolivia, an agreement with the European Union (with full or partial liberalization) is more advantageous than a full liberalization agreement with MERCOSUR.

In chapter III, Durán, Ludena, Alvarez and de Miguel use general and partial equilibrium analysis to assess the impact of an association agreement between the European Union and Central American countries. The authors model three different scenarios: one assuming full liberalization, another excluding sensitive products (e.g., fruit and vegetables, meat, dairy, sugar and vegetables oils, among others), and the last excluding vegetables and fruits. One of the main criticisms of CGE models mentioned by Flores in chapter II - the need for a large amount of data- appears to have been a constraint for the authors of this chapter. In the absence of specific data for El Salvador and Honduras, Duran and others aggregate these countries in the group labelled "rest of Central America" for the CGE analysis. However, the authors complement their CGE modelling with partial equilibrium analysis for these same two countries. The results reveal two conclusions that should be important for negotiators. First, the products included in the negotiations with 
the European Union do make a difference for Central America, and the exclusion of sensitive products would affect their terms of trade and GDP. Second, the impact of this agreement, whichever products are included, is nil for the European Union. The authors include a very innovative analysis of the impact of the agreement on environmentally sensitive products.

In chapter IV, Wong and Arguello assess the effects of eliminating tariffs between Ecuador and the United States. They also present a comparative analysis of changes in the value added tax (VAT) system and direct taxes as options for maintaining government revenue after tariffs are reduced. The analysis considers two scenarios: full employment and unemployment of unskilled labour. The results show that if the government compensates for revenue losses through changes in direct taxes, the poverty rate is reduced by more than it would be if this were done through changes in VAT (e.g., a higher rate, removal of exemptions or a flat rate on all goods).

In chapter V, Terra, Bucheli, Laens and Estrades use CGE and microsimulation analysis to assess the effects on the Uruguayan economy of price shocks in Argentina and Brazil, the country's main MERCOSUR partners. The research also estimates the effects on Uruguay of a foreign saving constraint and a reduction of the country's labour costs. The results indicate that Uruguay would be more affected by shocks in the Argentine economy than in Brazil. However, the authors emphasize that this outcome could be different if the composition of Uruguayan trade with its two neighbours were to change in the future.

In chapter VI, Chisari, Maquieyra and Romero continue to expand the CGE models' scope of analysis. The authors assess the effects of trade liberalization in the services sector in Argentina, Brazil and Uruguay. The analysis is performed by evaluating the impacts of improvements in the efficiency, productivity and quality of services on macroeconomic variables for these three economies. The services included in the assessment are telecommunications, finance and insurance. The findings indicate that liberalization of the service sector will produce a positive effect on real GDP and other macroeconomic indicators, such as investment. The authors also evaluate the change in results if the rest of the world lowers its barriers to the three countries' service sectors. They conclude that such a move would trigger an increase in domestic prices for services, bringing them into line with the international market. In addition, one consequence of multilateral liberalization of the services provided by the three countries would be a drop in living standards.

In chapter VII, Bento de Souza uses CGE and microsimulations to assess the effect of increases in world food prices on economic and distributional variables in Brazil. In the simulation, the author includes 
not only higher food prices but also price rises for other internationally traded commodities (e.g., oil and fertilizers). The price changes included in the simulations range from $0.94 \%$ to $212.82 \%$. The resulting estimates calculated by the author are for a $1.92 \%$ increase in Brazilian GDP and household consumption despite a $2.95 \%$ drop in real wages. The author also finds that the increase in food prices leads to a $1.04 \%$ rise in the poverty level. The results also demonstrate that the effects of food price rises are not homogeneous within a country; in the case of Brazil, their effect on poverty is shown to be most serious in the southern and south-eastern regions.

In chapter VIII, Medvedev and van der Mensbrugghe address social and economic impacts of climate change, a subject that will be on the agenda of policymakers in the coming decades. The authors develop this assessment by including feedback between changes in atmospheric temperature and economic activity. The paper compares the effects of two carbon reduction mechanisms: a country-specific carbon tax, where countries make the same percentage reduction in emissions, and a uniform global tax, where countries that can reduce emissions at a lower cost reduce them by more. In their analysis, the authors consider emissions resulting from changes in the intensities of existing technology use, population and economic growth that vary by region and country, with a focus on Latin America and the Caribbean. The authors' main conclusion is that a global tax would be preferable for Latin America because of the region's vulnerability to climate change and inability to cut emissions in the way other regions can, given that its carbon intensity is already below the average.

In chapter IX, Tourinho, Kume and de Souza estimate a set of Armington substitution elasticities for 28 Brazilian industrial sectors in the 1986-2002 period. Substitution elasticities are used in general and partial equilibrium analysis to measure levels of substitution between domestic and imported goods in a particular sector. The methodology developed by the authors measures the effects of trade restrictions that existed before 1990 and the impact of trade liberalization initiated that same year. The authors' estimates have the correct sign (positive) and are mostly significant at 5\%. Nevertheless, the substitution elasticity estimates for footwear and leather articles and mineral extraction have the incorrect sign (negative), although only the latter is statistically significant at the $95 \%$ confidence level.

IDB and ECLAC have three principal objectives in publishing this group of papers. First, the papers provide modellers and government technical teams with useful methodologies and evaluations. Second, they will motivate modellers to seek answers that policymakers need in order to address development issues. Finally, it is our goal to help practitioners understand the usefulness of CGE models in their decision-making. 



\section{Chapter I \\ Are CGE models still useful for economic policymaking? ${ }^{1}$}

Renato G. Flôres Jr. ${ }^{2}$

\section{A. Introduction}

This paper might be provocative, and sometimes even slightly dramatic. My purpose, before we delve into the many interesting applications of computable general equilibrium (CGE), is to put forward a few background considerations that will help us to better frame the results of a specific model. CGE - like any modelling tool- is plagued with problems and the first step to deal with them is to be aware of their

1 Paper based on the inaugural speech of the CGE Modelling Seminar, April 2007, delivered at ECLAC headquarters in Santiago, Chile. I am indebted to André Hofman, Andrés Schuschny, José Durán Lima, Paolo Giordano and Robert Devlin for the invitation and various incentives. Mr. Durán Lima and Mr. Schuschny were also fundamental in encouraging (and helping) me to produce this written version. I thank all participants in the seminar for their comments and responses to my presentation. Many of these ideas are the outcome of considerable work and debate in recent years, and have been presented at several centres and organizations in Latin America, Europe and the United States. This was made possible partly by the wise assistance of the Inter-American Development Bank (IDB), under Robert Devlin's leadership. Lastly, my (CGE) co-author and friend Masakazu Watanuki has been a stimulating alter ego, obliging me to refine and sharpen several of my views and arguments. I remain solely responsible for the entire text.

2 Graduate School of Economics (EPGE), Getulio Vargas Foundation (FGV), Rio de Janeiro, Brazil. 
existence and impacts. For professors, problems are in some ways their raison d'être, and they joyfully set about studying them and searching for solutions. However, for negotiators and policymakers, a poorly understood problem or a debatable approach may have serious consequences, ranging from wrong or inadequate measures to full-blown distrust of the technique.

Three main and serious criticisms are usually levelled at CGE efforts. First, they are said to be too aggregated, thereby reducing the value of their conclusions and failing to shed light on relevant sectors or issues. Such a general character often makes them a pointless exercise, as the fine print, be it in financial contracts or in economic disputes, is what matters.

At the same time, ironically, they require huge amounts of data; the combination of different sources, with varied reliability, being common currency in the applications. Timeliness, which is crucial for policy decisions, is frequently jeopardized by outdated sources and benchmarks referring to realities that may be five or more years old. As stakes, situations and interrelations change, we may often be dealing with bygones - and should let bygones be bygones.

Finally, even if the generality makes sense and the data are upto-date, results are meaningless if they answer wrong or ill-posed questions. Modelling demands so many shortcuts, simplifications and special assumptions that a rather artificial context is created, where the original questions lose their content.

I shall attempt to provide some views on these criticisms, and I shall begin with a positive outlook. I do not think the first point should give too much concern. Decisions on the aggregation level are inherent to any modelling effort; different levels answering different questions. Any model has its own limits on the explanations it can provide, and trying to push it beyond such limits is unwise, if not downright silly.

The second point, though important, is somewhat unfair. That data are a tough problem is common knowledge not only in the field of CGE, but in many other sophisticated applications as well. When I say this, I am proposing neither a global excuse, nor careless handling of data issues, but just a reminder that the problem pervades any quantitative exercise.

The crucial questions lie in the third point. I take this extremely seriously, and it requires due consideration to the meaning of what we produce. This will be dealt with in more detail in the next section. 


\section{B. The structure of a CGE economy}

The combination of the chosen assumptions of how the economy is described with the way key parameters are set in a CGE model may easily produce an extremely bad picture. Several concrete examples may be given.

The first and most telling one is the Social Accounting Matrix (SAM), the heart of any description of the economy. At the root of the SAM is the input-output (IO) matrix, a device with plenty of statistical limitations. A methodological revolution —and a Columbus' egg- at the time of its creation by Nobel prize winner Wassily Leontief, the IO matrix reflects a different, outdated view of the industrial sector, hardly to be found in any moderately sophisticated economy nowadays. ${ }^{3}$ Although some ingenious (partial) solutions were therefore found to the issue of many plants and multiple products in the $1970 \mathrm{~s},{ }^{4}$ the statistical instrument itself has long been "overdrawn" on its methodological account. In a world with fragmented production processes, too many plants with multiple outputs, diversified transnational firms activity, intense trade flows of different origins and kinds, the precision and usefulness of the matrix has, at the very least, decreased considerably.

Still within this context, it would be impossible not to mention the standard approaches for describing production sectors, in which although manufactures and agriculture may be sometimes reasonably portrayed, services usually fall foul of a mortal methodological sin. I have made this point in several other presentations and shall not repeat my frustration and annoyance with the way we see services modelled in most CGE versions. It is either poor or partial, as it does not encompass all relevant sectors, when not bluntly wrong. Yet, services dynamics are crucial in nearly all economies, from small countries such as Uruguay to the big and powerful United States.

Leontief started work on IO methods in the 1930s. In the 1950s, applications were already flourishing and it is perhaps fair to say that the technique reached its prime during the 1970s (Leontief himself received the Nobel prize in 1973). In the second half of the 1980s, it had already become clear that the amount of changes in production techniques was seriously threatening the reliability of the instrument. Nevertheless, for lack of a better alternative it is still widely used nowadays, being compiled by most national statistical offices (see also footnote 4).

4 The best known is perhaps the device created by Statistics Canada, and reproduced, in different adaptations, by other statistical offices. It uses two rectangular commodities $\mathrm{x}$ sectors matrices - nowadays called the Make (sector outputs) and Use (sector inputs) ones- which allow more flexibility and bypass some of the problems that emerged in the 1970s and 1980s. 
Moving on from production to the structure of demand, it is quite disturbing that, even now, we are all hostages to Paul Armington and the system he proposed in the late 1960s. The ultimate goal of Armington (1969), in keeping with the objectives of a serious international civil servant at the International Monetary Fund (IMF), was to produce a way of organizing massive amounts of data. At the same time, his hierarchical combination of constant elasticity of substitution (CES) functions (aggregators) provided a convenient way to account for cross-hauling in trade flows, which was a hot topic at the time. There is no comparative advantage in his scheme, simply because this was not originally intended. But then, no country/supplier disappears from an Armington tree, and why do we still use it nowadays to analyse the sweeping effect of Chinese exports in the world market?

Moreover, my colleagues who insist on sticking to perfect competition in their models, on the grounds of immaculate theoretical arguments and the illusion of being in a Hecksher-Ohlin framework, forget that the law of one price does not apply if they use the Armington system in their models.

Lastly, there is the question of welfare. The number of issues raised is very great, but I shall concentrate on a special subset of them, the one related to the many ways of performing welfare decompositions. These are important for the whole poverty debate, in order to identify which social classes are more affected by a given policy, as well as in arguments on the industrial structure, where a closer focus on the productive sector is needed. Such decompositions are not always performed in the best way, which adds to a lack of meaning for the results.

I do not think it necessary to pursue this list of problems to convince readers that we are often modelling something that does not exist. Were we in the field of literature, many of us would be serious candidates to the authorship of novels in the style of Adolfo Bioy-Casares or Gabriel García Márquez, ${ }^{5}$ to name but two outstanding Latin American writers whose novels are imbued with magic realism; but this is not the case, and we must address these shortcomings. Before doing so, I shall prepare the ground by making some comments on the current practice of CGE modelling.

Though completely off the subject of this paper, I dare to suggest El sueño de los héroes and La invención de Morel as sample masterpieces from Bioy and, of course, Cien años de soledad as regards García Márquez, for all CGE modellers who have not yet enjoyed the pleasure of these apparently odd, though fully consistent SGE (surreal general equilibrium) models of reality. 


\section{Better framing of CGE activities}

The first aspect that adds to the difficulty in theoretically, and practically, rescuing CGE from the above-mentioned sharp criticisms is the ignorance gap between policymakers on the one hand and modellers on the other. How and when should models be used?

Perhaps the gap is unavoidable, as negotiators and politicians are not obliged to master the subtleties of economic theory and data handling needed to implement a model. Nonetheless, this makes it much harder to build up a defence against negative arguments, as the counterarguments might sound too technical and ambivalent, lacking the power to change prejudices or previously opposing minds.

The only solution to this dilemma is to construct a trusting relationship between the two groups. This brings forward an old and often forgotten practical rule: the usefulness of CGE models increases in direct proportion to their use within the specific setting in question. A learning stage is essential, involving the modeller, technical modelbuilding personnel and users. CGE activity is not a one-shot operation like the production of hot dogs, it requires an enduring interaction among the whole team concerned, so that policymakers, even if they are unaware of the theoretical and statistical details, come to 'feel the model' and know how to use it, in the sense of which questions are fit for that tool. At the same time, the modeller, by progressively understanding the actual issues, becomes more able to formulate better, more realistic assumptions and improvements.

Unfortunately, at least half of the frustration with CGE models comes from a single trial, usually in haste, which often turns out to be both expensive and vapid. Government departments, domestic and international organisations, as well as private ventures should bear in mind that CGE modelling requires continuity; without allocating a minimum level of permanent staff to it, results are very likely to be disappointing.

Together with a steadier and more sustainable approach to the modelling activity, more concern should be given to interpretation and scenario building. This part of CGE activity is so crucial that it must go far beyond the technical staff, in order to add real meaning to the figures produced. Again, another source of disappointment and distrust is when one sees a similar pattern of results for Bolivia and, say, Denmark, receiving the same interpretation. Without creative, serious but rich interpretation, CGE results move even further away from reality. However, a good interpretation is often already contained in a wellposed and intelligent question: the scenario. 
The other point is that models are always a tool, translating a specific view, and so they should be coupled with other analyses. Which ones, in particular?

Here I confess that, until recently, I optimistically advocated the marriage of CGE efforts with correspondingly tailored partial equilibrium ones. Nowadays, unfortunately, such a marriage looks ever more like the impossible union of a schizophrenic bridegroom - the partial equilibrium model - with an overly general and absent-minded bride. Frequently, there is no way of seeing the links between a soundly based partial equilibrium aggregation level and the corresponding sectoral dynamics in the CGE experiment. One reason is the mismatch between assumptions; not only do really interesting specific disaggregations struggle to complement CGE sectors, but concepts and theories akin to both are usually not compatible.

This does not invalidate the use of very detailed analyses at the 6-digits product level, for instance. A galaxy of indicators and techniques, mostly shrewd variations on Balassa's revealed comparative advantages index, is now available, and can produce valuable exploratory answers. However, they have no theoretical background, standing more as a set of statistical findings.

How can we bring the partners in this fake marriage closer together? This task poses deeper theoretical challenges than previously imagined. Does this mean that there are no possible measures to deal with this gap? Should we throw both babies out with the (not very clean) bathwater?

I'm afraid that such questions call for a more relaxed, flexible attitude towards CGE modelling. One advantage of this standpoint is that we can devise less common uses for our models. I give one example from what I call a sequence, or combination of models.

It is well known that static CGE produces one-shot answers, which, from a starting point, yield a final - usually long-run- outcome. We do not know what happens between these two extreme points, which, even in life in general, is always the best part. Let us think, still in the economic context, of adjustment, i.e., all the pain and joy experienced by (intermediate) losing and winning sectors, respectively. Dynamic models can sometimes provide answers to this, but usually at the price of an even more aggregated and simplified model.

Why not then construct a set of sequenced scenarios that would, in a stepwise fashion, describe the more likely intermediate outcomes? The results of the previous scenario would be the 'base-year' configuration for the next one. Not only can a chain of scenarios be built up, but even one of models as well. If, in this path to the final equilibrium, it makes 
sense to suppose that some parameters or behavioural characteristics might change, why not modify the model accordingly, together with the sequence of scenarios?

The same more flexible attitude calls for an additional effort to include more effectively, or rather adapt, the spatial dimension to our models. This does not mean treating the different regions in an economy as individual "countries", connected by internal trade flows, but rather establishing true regional links. I suspect the importance of this, not only in huge countries like Argentina or Brazil, but even on a smaller scale, does not need to be emphasised.

In the same vein, there should ideally be many models for the same problem. Although we must endeavour to prevent waste, some redundancy in a technique with such a wide scope is positive. Different models help to improve our grasp of the mechanics of each one and often offer complementary views. I cannot avoid thinking of the Australian case, where quite a few models related to agriculture co-exist, contributing to a solid CGE culture in negotiations and policymaking. However, one could say that Australia, a wealthy country, is no example for our Latin American economies.

Finally, rather than trying to marry the CGE bride to a partial equilibrium groom, I think it more relevant to couple the model or its results with precise econometric models or characterizations. Econometrics, which for sometime was considered opposed to the CGE toolkit, can provide innovative and efficient ways to both extend and improve the quality of CGE results.

I turn now to providing a few answers to the theoretical shortcomings raised in section 2 .

\section{A glimpse of the theoretical improvements needed}

At this point, nobody would deny the dire need for theoretical improvements. The first area, where they have been urgently required for some time, is the previously mentioned services realm. Questions of regulation, or related to General Agreement on Trade in Services (GATS) mode 4 trade (movement of people), are but two examples of serious omissions. They, and most of the others, will have an impact on the data requirements, as the computation of barriers to trade in services is still in its infancy, beyond being conducted in a way that is usually unrelated to the needs and structure of CGE.

The theoretical approaches set forth by Markusen (1989) rank among the best I know to deal with services, but the number of experiments using them remains low. The work by Jensen and others (2004), for 
instance, contains interesting insights, although the methodology does not cover all sectors. The variety of services is one of the great problems in correctly dealing with them in a full CGE framework.

The second area encompasses the diversified treatment of welfare and welfare analysis. Here, interesting progress has taken place, though often disregarded.

In the context of a static CGE model, under imperfect competition, Smith and Venables have proposed a very interesting sectoral welfare decomposition. It comprises six different components, related to a direct effect -associated to scale economies, a competitiveness one - if firms in the sector become more competitive, a variety one- related, of course, to a love-of-variety effect (that usually presupposes a Spence-Dixit-Stiglitz utility), a diversion one - roughly related to classical trade diversion effects, and variations in the (sector) exports and imports terms of trade. In spite of its very enlightening and useful character, it is somewhat surprising to see that, apart from the original authors and the present one $^{6}$, nobody else seems to have used such decomposition.

Then, within the same area, there is the whole plethora of poverty studies coupled with CGE. Many people forget that, in the late 1970s, Piggott and Whalley, simulating the impact of fiscal policies, pointed to the right way of addressing such questions. They used a model with 100 household groups, each with a tree structure, where equilibrium was found simultaneously. Nowadays, it is much more common to see modellers importing the CGE results to feed what are known as microsimulations. This theoretically daring procedure, in my view, may work but may also not. It is often wrongly used, thanks to the sheer incompatibility between the assumptions of the two techniques. I feel much more comfortable advocating the approach originally proposed in Piggott and Whalley (1985), even if the household decomposition is sometimes more modest.

On a more theoretical note, I would like to draw attention to the very important, and again somewhat overlooked, welfare decompositions implicit in the proposal by Lloyd and Schweinberger (1988). They rely on the trade expenditure function, whose arguments are the vector of domestic prices, those of factor prices and of (household) factor endowments, and the utility level of consumers. Studied in different though similar guises by trade theoreticians - like Peter Neary, in Neary and Schweinberger (1986) and Anderson and Neary (1994) (his later proposal for a trade restrictiveness index)—, the trade expenditure

\footnotetext{
6 See, for instance, Gasiorek, Smith and Venables (1992) and Flôres (2003). The former contains a brief theoretical explanation of the welfare decomposition.
} 
function is a source of varied and interesting welfare decompositions, its possible interpretations lying at the heart of such procedures. Although Peter Lloyd has developed part of its potential applications in two subsequent (co-authored) papers, (Lloyd and MacLaren (2002), Lloyd and Schweinberger (1997)), ${ }^{7}$ it is far from having been fully exploited in the CGE context, and more efforts should be concentrated on this.

Improvements in the demand side of our models are, of course, another urgent need. I particularly favour a greater use of the Gorman polar form, but feel unable to strengthen my pledge, given the lack of empirical evidence. Those still attached to the Armington structure could perhaps combine it with different specifications for the utilities at lower levels of the tree, which might add more flexibility to this standard approach. ${ }^{8}$

Another difficult item that is missing from the static framework is investments. A hot topic in any modern trade agreement, though more suitable to a dynamic approach, it should not be absent in certain static contexts. Recent work by Grenadier (2000 and 2002), combining game and option theory to describe decisions to quit or invest in a given sector, can provide a clue to an innovative treatment of investment in static CGE. By grafting an option on investment within the sectoral game in the (imperfect competition) model, a dynamic and more realistic flavour can be added, even in a static setting.

The number of brand new areas of research will continue to rise, and I think that this shortlist can already serve as evidence that a massive research agenda lies in waiting.

\section{E. Conclusion}

After sketching this broad picture, which has not always been positive, maybe some could argue that the Seminar should stop here, as it makes no sense to present a diversified portfolio of applications if so many doubts and problems surround CGE modelling. Born optimists, on the other hand, may nurture the dream that, one day, CGE results will play the same role that the Black-Scholes option pricing model enjoys in derivatives markets, where people no longer care whether it is right or wrong, and take the implied volatility figure provided by the model as a key —and true! - market parameter.

The 1997 paper has a more theoretical goal, being related to generalizations of the Stolper-Samuelson theorem.

8 After this paper was first delivered, David Laborde reported on alternative new research being conducted on this subject at Centre for International Prospective Studies and Information (CEPII) (Paris, France). 
I would neither be too pessimistic nor optimistic, though I think that CGE models can come closer to reality. However, they are still too underused to produce a fruitful symbiosis between negotiations and simulation results. As to whether this is a valid prospect, maybe I have already answered that, in spite of the difficulties, they are still useful in policy making; but, exactly, why?

My reply is far from new, and can be found in any good textbook on the subject. As long as CGE continues to be the only available technique providing a global, inter-related way of capturing economy-wide effects of several different policies, it will stand as a useful methodology.

In fact, this is the sole reason why it remains precious; it is the only tool we have with such property. Until a better alternative appears, or we manage to implement a substantial part of the improvements outlined above, governments, national and international organisations wishing to use the technique should do so along the lines in section 3. Agencies as ECLAC, IDB or the World Bank can play a major role in supporting and encouraging multiple efforts. They are also uniquely positioned to enhance information and data sharing, as well as putting people from various origins and countries together, to share their experiences.

Different groups and different models, conceived in different units, either in government, or universities or the private sector, are a plus. A serious and complex task is, however, before us, if we wish to remedy at least the most dangerous current shortcomings of the technique. 


\section{Bibliography}

Anderson, J.E. and J.P. Neary (1994), "Measuring the restrictiveness of trade policy", The World Bank Economic Review, vol. 8, No. 2.

Armington, P.S. (1969), "A theory of demand for products distinguished by place of production", IMF Staff Papers, No. 16.

Flôres, R.G. (2003), "The case of Brazil. Costs and opportunities of different scenarios", The Costs of Opting Out: The EU-Mercosur Agreement and the Free Trade Area of the Americas, A.G.A. Valladão (ed.), Paris, Presses de Sciences-Po.

Gasiorek, M., A. Smith and A.J. Venables (1992), "'1992': trade and welfare - a general equilibrium model", Trade Flows and Trade Policy after '1992', L. Alan Winters (ed.), Cambridge, Cambridge University Press.

Grenadier, S. (2002), "Option exercise games: an application to the equilibrium investment strategies of firms, Review of Financial Studies, vol. 15, No. 3.

(2000), "Option exercise games: the intersection of real options and game theory", Journal of Applied Corporate Finance, vol. 13, No. 2.

Jensen, J., T. Rutherford and D. Tarr (2004), Economy-Wide and Sector Effects of Russia's Accession to the WTO, Washington, D.C., World Bank.

Lloyd, P.J. and D. MacLaren (2002), "Measures of trade openness using CGE analysis", Journal of Policy Modeling, vol. 24, No. 1.

Lloyd, P.J. and A.G. Schweinberger (1997), "Conflict generating product price changes: the imputed output approach", European Economic Review, vol. 41, No. 8. (1988), "Trade expenditure functions and the gains from trade", Journal of International Economics, vol. 24, Nos. 3-4.

Markusen, J. (1989), “Trade in producer services and in other specialized intermediate inputs", American Economic Review, vol. 79, No. 1.

Neary, J.P. and A.G. Schweinberger (1986), "Factor content functions and the theory of international trade", Review of Economic Studies, vol. 53, No. 3.

Piggott, J. and J. Whalley (1985), UK Tax Policy and Applied General Equilibrium Analysis, Cambridge, Cambridge University Press. 

Chapter II

\title{
Andean countries at a crossroads: evaluating pro-poor trade integration options ${ }^{1}$
}

\author{
Paolo Giordano and Masakazu Watanuki ${ }^{2}$
}

\section{A. Introduction}

The Andean countries are currently re-evaluating their trade integration strategies in the light of mounting social demands. The policy challenges thereby posed, which are now at the heart of the countries' development agendas, date back to the early 1990s when the Andean countries began to liberalize their trade regimes and participate in regional integration schemes. While moving forward in the area of trade and integration, however, these countries, like others in Latin

This study received support from the Trade and Poverty Trust Fund of the InterAmerican Development Bank (IDB). The authors are grateful to Juan S. Blyde, César Patricio Bouillon Buendia, Francesca Castellani, Eduardo Fernández-Arias, Fidel Jaramillo, Alberto Melo, Kim B. Staking, Antonio Guillermo Zoccali, Luiz A. Villela, Christian Volpe, Erick Zeballos and Jessica Luna for their contributions, suggestions and comments. Thanks also go to Maximiliano Méndez Parra for his inputs and preparation of the poverty analysis in our earlier version of this study, and to Jymdey Yeffimo for her superb research assistance. A first version of this paper was presented in November 2007 at the Regional Meeting on Computable General Equilibrium in Santiago, Chile. An updated version (June 2010) was prepared for inclusion in this publication.

2 The views expressed in this document are the authors' and do not necessarily reflect those of the Inter-American Development Bank or its member countries. The authors are responsible for any remaining errors and omissions. Paolog@iadb.org; Masakazuw@iadb.org. 
America, did not sufficiently examine the impact these policies would have on poverty, income inequality and social cohesion. In fact, despite significant economic growth resulting from trade in recent decades, the Andean countries are still grappling with persistent poverty and highly inequitable income distribution. Social benefits from integration policies have lagged relative to other Latin American countries (ECLAC, 2006). As a result, the challenge of maximizing the social benefits from trade and integration strategies now constitutes a major pillar of the countries' development agendas.

The Andean countries have made enormous efforts in the trade and integration process, and recent developments in globalization pose new challenges and opportunities. For one thing, these countries are currently negotiating bilateral trade agreements with the United States ${ }^{3}$ with a view to consolidating the preferential treatment they receive under the Andean Trade Promotion and Drug Eradication Act (ATPDEA), the centrepiece of trade policy between the Andean countries and the United States. ${ }^{4}$ They are also active in widening the integration process in Latin America and beyond. Jointly with MERCOSUR, the bloc is moving to create the South American Community of Nations, which would encompass all of South America. ${ }^{5}$ The Andean Community (the Plurinational State of Bolivia, Colombia, Ecuador and Peru) has launched the first round of negotiations for an association agreement with the European Union. Peru and Colombia concluded their negotiations in 2010.

The social agenda is also extremely important. Poverty has been declining over the past decades, but progress has been quite slow. Furthermore, the highly inequitable and inflexible distribution of income in the Andean countries is as detrimental to society as poverty

\footnotetext{
In May 2004, three countries of the Andean Community (Colombia, Peru and Ecuador) launched formal negotiations to create free trade agreements (FTAs) with the United States. Peru and Colombia signed their agreements in December 2005 and February 2006, respectively. Peru ratified its agreement in June 2006; the United States House of Representatives approved the agreement with Peru in November 2007 and it came into force in January 2009. However, the House of Representatives has not considered the agreement with Colombia as of yet.

4 ATPDEA was extended for eight months after expiring at the end of 2006, and had not been renewed at the time the scenarios included in this paper were modelled. The beneficiary countries were the Plurinational State of Bolivia, Colombia, Ecuador and Peru. In 2009, ATPDEA was renewed but excluded the Plurinational State of Bolivia.

5 Recently, Panama moved towards associate membership and Chile announced its intention of rejoining. The Bolivarian Republic of Venezuela withdrew from the community in 2006, but recently expressed its willingness to rejoin. Mexico has also expressed its interest in helping to further the Andean integration process.
} 
itself. Inequality undermines social stability and political cohesion. In addition, Ravallion (1997) finds that inequality tends to reduce the impact of economic growth on poverty reduction, while Rodrik (1997) argues that highly unequal income distribution masks economic growth over the long term. Thus, poverty and inequality are a paramount concern and a threat to development in the Andean countries (Giordano, 2010). The Plurinational State of Bolivia and Colombia are classified by ECLAC (2006) in the "very high inequality" group of Latin American countries. Ecuador and Peru are in the "mid-level" group.

In view of these development challenges, the key questions in international trade policy are the following:

- What impact will trade integration initiatives have?

- Which sectors will gain and which will lose?

- Do bilateral agreements with the United States generate divergent impacts between signing and non-signing countries?

- What economic costs will there be if the Andean countries lose ATPDEA preferential treatment?

Regarding the impact of trade policy on poverty, we primarily focus on bilateral trade agreements with the United States. Given that poverty and inequality are complex, multidimensional phenomena that depend on different transmission mechanisms, the main policy questions we assess are the following:

- Will the bilateral agreements with the United States reduce poverty and inequality?

- If so, what will the magnitude of the improvement be?

- Would the rural poor living in conditions of extreme poverty be better or worse off after an agreement with the United States?

- Will the agreements result in different social impacts for signing as opposed to non-signing countries?

We answer these policy questions by applying a two-step top-down computerized general equilibrium (CGE) model and microsimulation analysis in sequence. The first step is undertaken with a new global, multi-region comparative static CGE model. The second stage is carried out with a microsimulation methodology applied to the bilateral AndeanUnited States trade agreements. In this assessment, Colombia and Peru are modelled as signing partners and the Plurinational State of Bolivia as a non-signing country.

The CGE simulation results for the Andean countries indicate unambiguously that trade agreements generate small but positive effects on trade and production, as well as on other macro variables. 
Traditional agriculture and resource-based sectors emerge as winners, whereas capital-intensive manufacturing industries tend to experience competitive pressure. Bilateral trade agreements with the United States produce different economic outcomes between signing and non-signing countries. The costs of losing ATPDEA preferences are much larger than the negative effects of exclusion from a bilateral trade agreement with the United States. The transatlantic agreement with the European Union largely benefits agriculture and processed food industries. While they increase economic gains and promote global competitiveness, regional initiatives alone do not automatically generate export diversification, nor do they reinforce technology-intensive industries. To maximize social welfare, the Andean countries need to adopt complementary policy instruments in coordination with trade liberalization.

The microsimulation analysis demonstrates that trade integration is pro-poor, i.e., it increases social welfare and reduces poverty. As many studies have shown, income generation via labour market effects, particularly employment, is the dominant factor in reducing poverty. The impact on inequality is marginal but positive. Opting out of the trade agreement with the United States would be anti-poor and adversely affect income equality.

The rest of this paper is divided into sections as follows. Section B briefly presents the analytical approaches taken. The CGE model used in the first step, with key extensions and innovations incorporated into it, is followed in the second step by the microsimulation approach. Section $C$ presents an overview of the socio-economic features of the Andean economies as a background for understanding the subsequent CGE simulation results. Section D describes alternative scenarios for policy simulations and reports macroeconomic and sectoral impacts on trade. This section also evaluates the sectoral winners and losers. Section E presents the impact of the bilateral Andean-United States trade agreements on poverty and inequality. Lastly, Section F summarizes the main findings and conclusions.

\section{B. Analytical approaches}

In this study, we apply a two-step top-down approach that sequentially combines a CGE model and a microsimulation module, following Vos and de Jong (2003) and Ganuza and others (2006). First, a multi-region CGE model is used to evaluate trade integration options for the Andean countries. Second, a microsimulation employs household survey data to measure the impact of trade agreements on poverty and inequality. The following section briefly describes each methodology. 


\section{The IDB-INT Andean CGE model}

The IDB-INT Andean model is a global, multi-region, multisector static general equilibrium model with several salient extensions and innovations compared to standard trade-focused models. The model comprises 18 regions and countries (see annex 1), identifying all four Andean countries and their key partners with 30 sectors, which are aggregated into six macro sectors (see annex 2). All regions are fully endogenized and linked only through trade. Accordingly, the model deals only with the real side of the economy and does not consider the financial or monetary markets. The model is built on individual social accounting matrices for each region and country at base year 2001.

Each region in the model experiences circular flows of income through factor payments from producers to institutions (households, firms and government) and back to final demand for goods in commodity markets. These institutions represent economic agents whose behaviours and interactions are explicitly specified in the model. Consumption, intermediates, government consumption and investment are the four components of domestic demand. Households in each region choose commodity bundles for consumption in optimal quantities by maximizing their utility, subject to budget constraints and prices. The government collects various taxes and receives foreign transfers, spends revenue on goods and services, allocates subsidies to domestic institutions and amortizes payments to domestic and foreign lenders.

The model explicitly specifies output-supply and input-demand equations for each sector. Production consists of intermediate inputs, determined by Leontief fixed coefficients, and primary factors, which are specified in a constant elasticity of substitution (CES) function with a constant returns to scale technology. Producers are assumed to maximize profits, implying that each factor has a demand such that marginal value product exactly equals its corresponding marginal cost. The model also incorporates factor market rigidities or distortions, which exogenously fix the ratios between relative sectoral returns and the economy-wide average return for that factor at base year. Primary factors comprise labour, capital, land and natural resources.

The treatment of international trade follows the standard specifications of other trade-focused CGE models. The model specifies a set of export supply and import demand equations for traded sectors, allowing national product differentiation. Exports are modelled in a CES function. The optimal allocation of supply is determined by a revenue maximization choice between domestic sales and aggregate export 
supply at the upper stage, and among exports destined for different markets at the lower stage. However, the specification of imperfect substitutes for some products in certain regions or countries can be partially or entirely turned off, permitting perfect substitutes. Imports are modelled by a CES function, following the "Armington" assumption. The optimal allocation of demand is determined by a cost minimization choice between domestic demand and aggregate import purchases at the upper level, and imports from different markets at the lower stage.

In factor markets, the model applies different treatments that reflect certain peculiarities of the labour market due to geographic differences. For labour, the model incorporates six categories in the Andean countries, disaggregated by gender and skills. ${ }^{6}$ For non-Andean regions and countries, the model applies a single labour market. ${ }^{7}$ Labour is mobile across sectors within each region or country. In the Andean countries, the labour supply for skilled categories is fixed, but the supply of lowand semi-skilled groups is endogenized, while real wages are fixed. ${ }^{8}$ In non-Andean regions, the supply of labour is endogenous for developing regions, whereas it is fixed for developed regions. No international labour migration is allowed. Capital is mobile only within each region and its aggregate supply is fixed at the baseline. Land is used only in agriculture and is sector-specific in developed regions but mobile across sectors in developing regions. Natural resources are treated as fixed factors in all countries and regions.

The model includes three key macroeconomic closures: public finance, saving-investment, and external market. A large number of different choices are available. The key is which choice in each closure is the most appropriate and realistic. In this study, for the government balance variable, public saving is determined residually as the gap between current revenues and expenditures, while all transfers are fixed. This treatment allows fiscal surpluses or deficits to adjust to balance the

6 This is important, particularly for poverty and inequality analysis, because labour is the major source of income for the poor (see table 8). Therefore, it is extremely important to disaggregate the labour market in order to clearly capture the impact on household income generated through different labour categories.

7 In a single labour market there is no differentiation between workers by skill level.

8 These different treatments are due largely to labour market characteristics in the developing world, including the Andean countries. That is, the supply of skilled labour is relatively limited because countries cannot increase numbers of workers with high levels of skill and experience, while the supply is elastic for non-skilled groups because of high unemployment and underemployment. 
public finances. ${ }^{9}$ Moreover, to control possible welfare effects arising from variations in public spending, government consumption demand is fixed in real terms.

For the saving-investment closure, the current amount of (nominal) investment is fully financed by aggregate savings in each region owing to the static nature of the model and the absence of international capital mobility. The model applies the neoclassical "saving-driven" closure, so that private saving rates are fixed.

For the external market closure, there are two options: a fixed trade balance and a fixed exchange rate. The choice depends on the objective of the study. The former permits evaluation of the impact on (real) exchange rates associated with changes in trade flows. The latter measures the impact on the trade balance of changes in demand at home and abroad. Thus, the former adopts a long-term perspective, whereas the latter takes a short-term view. Thus trade, valued at world prices, is balanced for each country and region and exchange rates in each region are equilibrating variables. In other words, the initial balance of trade in goods and services remains constant.

\section{Extensions and innovations of the CGE model}

A dozen recent studies evaluate trade and integration and their impact on poverty in the Andean countries. Light (2003) examined the Free Trade Area of the Americas (FTAA) process, focusing on United States initiatives. Monteagudo and others (2004) analysed three hemispheric approaches for each of the Andean countries. The Latin American Integration Association (LAIA) General Secretariat (2003) assessed the FTAA. Duran, de Miguel and Schuschny (2007) analysed United Statescentred scenarios with some updated information on protection for 2004. Country studies focusing on bilateral trade agreements with the United States include Gracia and Zuleta (1997), Martín and Ramírez (2005) and Botero (2005) for Colombia, Carrasco, Reinoso and Hoyle (2004) and Tello (2005) for Peru and Morales, Parada and Torres (2005) for Ecuador, using a partial equilibrium agricultural trade policy model. With the combination of CGE modelling and microsimulation, Bussolo and Lay (2003) examined globalization and poverty in Colombia and Pardo and others (2005) evaluated the effect of the Colombia-United States bilateral agreement on poverty. Luduena and Wong (2006) present an analysis of the AndeanUnited States FTA and domestic policy for agriculture in Ecuador.

Fiscal neutrality assumptions adopted by, for instance, van der Mensbrugghe (2005) and Harrison, Rutherford and Tarr (2003) may not necessarily be realistic for some countries. For example, governments in poor countries rely heavily on tariffs and might not have the capacity to compensate for a drop in tariff collection. See Taylor and Von Arnim (2006). 
Nevertheless, few studies have rigorously evaluated current Andean trade policies in a comprehensive manner that takes into account recent medium- to long-term developments in the Western Hemisphere. To fill this gap and go beyond the standard modelling approaches used for many previous trade policy studies, the IDB-INT model is extended in several ways in order to more accurately reflect economic reality in the Andean countries.

First, the model accommodates a large number of agriculturerelated sectors: 10 in agriculture itself and five in food industries (see annex 2). This is because they are extremely important for the economies and employment of the Andean countries, with agriculture accounting for $10 \%$ to $15 \%$ and food industries for $12 \%$ to $18 \%$ of the countries' production, and between $33 \%$ and $54 \%$ of employment. Thus, agriculture is critical for many individuals and households, particularly in lowincome rural areas.

Second, the model includes several labour categories and household groups. Trade policy affects households largely through two main channels. One is income from wages, which is by far the dominant factor for many households. The second is the price channel, with trade policy affecting commodity prices, which in turn influence household consumption. The impact of the income and price channels on individual households is highly heterogeneous, as each household differs considerably in family structure, income sources, consumption patterns and so on. To capture this heterogeneity, particularly in the income channel, it is extremely important to identify the sources and mechanisms of labour income in greater detail. The model includes six labour categories decomposed by gender and skills. Households are grouped by location or geographic origin and similarity in income, sources of income, and consumption patterns.

Third, the model incorporates improvements in productivity that result from increased trade leading to greater production efficiency. It is widely acknowledged that trade liberalization or trade openness increases productivity, or total factor productivity (TFP). This effect results from economies of scale, externalities, technological spillovers, specialization, increased investment and other factors. Empirical studies show that developing countries can boost domestic productivity as they take advantage of technological spillovers by importing intermediate inputs and capital goods that incorporate knowledge from foreign exporters. This is crucial for Latin America, where trade is one of the major driving forces of growth and foreign currency earnings generated by improvements in the region's global competitiveness in production and exports. In order to capture these effects, we follow the structure used by Polaski (2006). Technically, TFP is modelled 
as an increasing function of aggregate imports of capital goods and technology-intensive products, multiplied by the share of intermediate inputs in sectoral imports. ${ }^{10}$

Fourth, the model is constructed on the basis of the IDB-INTRADE database, which provides an updated record of key regional trade agreements and preferential treatment in the Western Hemisphere and the European Union. ${ }^{11}$ Tariffs include ad valorem, ad valorem equivalents of specific and compound tariffs, and tariff-rate quotas (TRQs), estimated at the Harmonized Tariff Schedule (HTS) eight-digit level.

\section{Microsimulation analysis}

The microsimulation methodology uses a micro database to model the behaviour of individual agents (IDB Program for the Improvement of Surveys and the Measurement of Living Conditions in Latin America and the Caribbean - MECOVI). The poverty and inequality analysis models the income generation process at the individual household level. Household income includes factor incomes such as wages, capital and land rents as well as government transfers and remittances from both domestic and foreign sources. This income generation process is highly heterogeneous, however, depending on family structure, occupation, education, gender, marital status, age, location and other factors. As the literature shows, labour is by far the most important income source for the majority of households, particularly in rural areas. Many studies also show that important determinants of labour income are skill level and

10 While acknowledging the importance of the link between trade and productivity, some modellers criticize this concept on two grounds. First, applications of the CGE models are based on ad hoc methodology. Second, direct linkage between trade openness and productivity is not based on microeconomic theory. Yet Karacaovali (2006), for instance, provides a theoretical demonstration of the endogeneity of trade liberalization with respect to productivity, using a standard political economy model. Our idea is to estimate the policy impact as realistically as possible, basing our work on the evidence, empirical studies and the new trade theory paradigm. When the positive link between trade and productivity is ignored, all that are captured are traditional effects due to resource allocation while gains from increased efficiency are completely missed.

11 Seven regional trade agreements are included: the North American Free Trade Agreement (NAFTA), the Central America Common Market (CACM), the Caribbean Community (CARICOM) and Caribbean Common Market, the Andean Community (AC), the Southern Common Market (MERCOSUR), the G-3 (Mexico, Colombia and the Bolivarian Republic of Venezuela) and the new European Union (EU25). Four bilateral agreements are covered (MERCOSUR-PlurinationalState of Bolivia, MERCOSUR-Chile, Canada-Chile and MexicoChile). In addition to the most-favoured-nation (MFN) tariffs, the database also includes three important United States preferential treatments: the Caribbean Basin Initiative (CBI) for Central America and the Caribbean; the Andean Trade Promotion and Drug Eradication Act (ATPDEA) for four Andean countries (Colombia, Ecuador, Peru and the Plurinational State of Bolivia); and the Generalized System of Preference (GSP) for countries in the rest of Latin America. For this study, our database reflected the status of ATPDEA as of 2004. 
gender. The microsimulation analysis in this study examines the income generation process, with a particular focus on the labour market as the main transmission channel. The labour market in the Andean countries is decomposed into six categories segmented by skill and gender.

The two-step "top-down" CGE microsimulation adopts a sequential approach that translates the economy-wide impact of trade policy shocks into changes in households income. No rigorous attempt is made to account for feedback effects from changes in individual households back through returns in factor markets at the macro level. ${ }^{12} \mathrm{~A}$ major advantage of this top-down approach is that the analysis, based on household survey data, can be carried out separately from the top-tier CGE analysis. It is ideal, but not necessary, to reconcile the household data with the national data (Ganuza and others, 2006). In practice, the microsimulation analysis requires new vectors of prices, factor returns and employment simulated by the CGE model.

In the process, however, there is a crucial methodological issue: namely, how changes in the labour market are captured and reflected in the microsimulation analysis. For instance, wage workers will move from depressed industries to booming ones, may change occupation, or may lose their jobs. New workers, previously unemployed, may find jobs in expanding sectors. The issue is what methodology is appropriate to capture these labour market dynamics with precision.

There are two standard methodologies: a microeconomic household income generation model in a partial equilibrium framework, involving a system of equations that determine occupational choice, returns to labour and human capital, consumer prices and other household income components; and a random selection procedure as a proxy for occupational shifts within the segmented labour market.

Our specification uses the second methodology for two technical reasons. First, the modelling intensity in a CGE framework required by the models must ensure consistency between the CGE and the microsimulation. The second reason is the need to ensure convergence in modelling exercises that deal with 18 regions, 30 sectors and six segmented labour markets, with multiple regional households.

Poverty is measured using the familiar Foster-Greer-Thorbecke (FGT) indices ${ }^{13}$ of additively decomposable measures. The FGT poverty indices are generally expressed as:

12 As the CGE model includes a number of regional households, however, it implicitly captures feedback effects through income-expenditure linkages for factor returns and consumption behaviour for prices.

13 Foster, Greer and Thorbecke (1984). 


$$
P_{\alpha}=\frac{1}{n} \sum_{i=1}^{q}\left(\frac{z-y_{i}}{z}\right)^{\alpha}
$$

where $n$ is the population size, $q$ is the number of people below the poverty line, $y_{i}$ is the income of the $i$ th households and $z$ is the poverty line. The poverty aversion parameter $\alpha$ takes three values. The headcount index of poverty is expressed with $\alpha=0$. The poverty gap has $\alpha=1$, measuring the distance from the poverty line. The severity of poverty is measured as $\alpha=2$.

Using national statistics, poverty and extreme poverty lines are calculated by adjusting sampling weights on the basis of household sample sizes and population statistics for each region. In the policy simulations, both poverty lines are updated using the national consumer price index for each country. Poverty and inequality analysis uses the DAD 4.4 distributive analysis software developed by Duclos, Araar and Fortin (2004).

The microsimulation analysis is based on several key labour market assumptions. After a policy shock, workers may seek better wages by moving from one sector to another; they may change their occupational status or category, e.g., from low- to semi-skilled or from informal to formal; and some will move out of or into unemployment. All the above influence labour income, which is the primary source of household income. Due to the lack of complete information on the labour market, however, a process of random assignment is carried out to identify new employment or job losses at the household level. This random assignment was undertaken 20 times to increase probability. It is also assumed that labour does not change its skill category and does not move between regions.

Income inequality is measured by the popular Theil and Gini indices, which are given in the following formulas:

$$
\text { Theil index }=\frac{1}{n} \sum_{i} \frac{y_{i}}{\mu} \log \left(\frac{y_{i}}{\mu}\right)
$$

$$
\text { Gini index }=\frac{1}{\mu n(n-1)} \sum_{i>j} \sum_{j}\left|y_{i}-y_{j}\right|
$$

where $n$ is population size, $\mu$ is mean income and $y_{i}$ is the income of the $i$ th households. 


\section{Overview of the Andean economies}

This section briefly outlines the economic structures of the Andean countries at the benchmark and provides an overview of their trade links with key partners, protection regimes and social outlook.

\section{Macroeconomic indicators}

Table II.1, which presents key macroeconomic statistics for the four Andean countries, shows considerable differences in economic size. As indicated, the GDP of Colombia accounts for nearly half the total for the Andean bloc, while that of the Plurinational State of Bolivia represents only $5 \%$. Trade openness, measured as trade flows over GDP, is relatively moderate. Ecuador is the most open economy, with trade openness of $48 \%$. Peru is the least open, followed by Colombia.

Table II.1

COMPARATIVE MACROECONOMIC STATISTICS FOR THE ANDEAN COUNTRIES, 2001

\begin{tabular}{|c|c|c|c|c|}
\hline & Bolivia (Plur. State of) & Colombia & Ecuador & Peru \\
\hline \multicolumn{5}{|c|}{ GDP and trade flows ${ }^{a}$ (US $\$$ billion) } \\
\hline Exports & 1.3 & 11.8 & 4.9 & 7.0 \\
\hline Imports & 1.6 & 11.9 & 5.6 & 6.8 \\
\hline GDP & 8.1 & 82.1 & 21.8 & 54.2 \\
\hline \multicolumn{5}{|c|}{ Trade openness (trade/GDP as \%) } \\
\hline Exports/GDP & 16.6 & 14.4 & 22.5 & 13.0 \\
\hline Imports/GDP & 19.4 & 14.6 & 25.8 & 12.6 \\
\hline \multicolumn{5}{|c|}{ Factor share of value-added (\%) } \\
\hline Land & 4.9 & 5.1 & 2.3 & 3.6 \\
\hline Natural resources & 1.6 & 2.9 & 3.7 & 0.8 \\
\hline Labour & 61.9 & 50.0 & 62.2 & 59.1 \\
\hline Capital & 31.6 & 42.0 & 31.8 & 36.5 \\
\hline Value added & 100.0 & 100.0 & 100.0 & 100.0 \\
\hline
\end{tabular}

Source: Inter-American Development Bank (IDB), IDB-INT model database, 2001.

a Merchandise trade only.

Based on national household surveys, figure II.1 presents the proportions of labour in the workforce classified into six categories. ${ }^{14}$ It reveals several salient and heterogeneous features for each country. For

14 The national household surveys are the Encuesta Nacional de Hogares (2002) for the Plurinational State of Bolivia, the Encuesta Nacional de Calidad de Vida (2003) for Colombia, the Encuesta de Empleo, Desempleo y Subempleo for Ecuador (2003) and the Encuesta Nacional de Hogares (2003) for Peru. Sources are based on the Programme for the Improvement of Surveys and the Measurement of Living Conditions in Latin America and the Caribbean (MECOVI). 
example, since lower national income is associated with a higher share of low-skilled labour, low-skilled workers in the Plurinational State of Bolivia account for $70 \%$ of the nation's labour force; in more prosperous Ecuador, 58\% are unskilled. In another example, women account for $43 \%$ to $44 \%$ of the national workforce in Colombia and the Plurinational State of Bolivia, whereas in Ecuador and Peru male workers account for nearly two thirds of all labour. Colombia shows the least heterogeneous distribution of labour participation over skill categories, followed by Peru. The opposite is true of the Plurinational State of Bolivia, where the low-skilled category shows the highest concentration.

Figure II.1

LABOUR FORCE PARTICIPATION IN THE ANDEAN COUNTRIES BY GENDER

\begin{tabular}{|c|c|c|c|c|c|}
\hline \multirow[b]{2}{*}{ Low-skilled } & \multicolumn{2}{|c|}{ Bolivia (Plur. State of) } & Colombia & Ecuador & Peru \\
\hline & iोit & 蜜蜜 & ஜிர் & 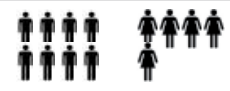 & 中ोi \\
\hline Mid-skilled & $\boldsymbol{i t |}$ & $\pi T^{\prime}$ & iो & †ி申 & †ो \\
\hline High-skilled & $\dot{\phi}$ & $\dot{\pi}$ & 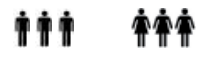 & $\boldsymbol{i t}$ & 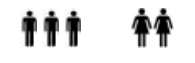 \\
\hline
\end{tabular}

Source: prepared by the authors on the basis of household surveys; 2001 for the Plurinational State of Bolivia, 2003 for Colombia, Ecuador and Peru.

Note: Each image represents about $4.6 \%$ of the labour force.

\section{Trade flows and barriers}

Trade flows and protection are the most important variables to consider in an examination of the impact of changes in trade and integration policies. In this study, tariff changes are the policy instrument affected by the CGE simulation shock.

\section{a) Market share by major partner}

The United States is the leading supplier and main destination for most Andean countries (see table II.2). However, dependence on the United States market varies greatly by country, with Colombia and Ecuador being the most dependent and the Plurinational State of Bolivia the least.

Despite an already liberalized market, the level of intra-bloc trade is fairly low compared with other subregional blocs in Latin America and the Caribbean. MERCOSUR is still an unexploited market for most Andean countries, the only exception being the Plurinational State 
of Bolivia, owing to the preferences it enjoys as an associate member. Regarding extra-hemispheric markets, the EU25 is the Andean countries' main destination and supplier. In fact, the EU25 represents the secondlargest market after the United States and is far larger than the intra-bloc market. Yet the countries' export dependence is fairly asymmetric. For Peru, the EU25 is presently the largest partner, with a market share of $26 \%$.

Table II.2

MARKET SHARE OF ANDEAN TRADE BY MAJOR PARTNERS, 2001

(Percentages)

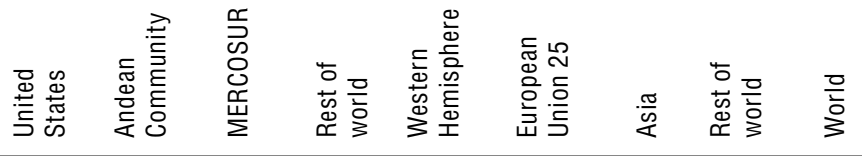

\section{Exports}

Bolivia (Plur. State of)

Colombia

Ecuador

13.6

39.1

Peru

Andean Community

38.4

24.9

\section{1}

\section{3}

\section{4}

12.8

$1.9 \quad 14.6$

11.9

33.6

5.0

3.8

20.1

67.6

45.5

66.0

\section{0}

17.5

18.2

\section{$4.5 \quad 13.6$}

$\begin{array}{lll}2.8 & 2.7 & 100.0\end{array}$

$\begin{array}{llll}18.2 & 8.4 & 5.8 & 100.0\end{array}$

$\begin{array}{lrrr}26.4 & 18.5 & 9.5 & 100.0\end{array}$

$\begin{array}{llll}19.8 & 8.4 & 5.8 & 100.0\end{array}$

\section{Imports}

\begin{tabular}{lrrrrrrrrr} 
Bolivia (Plur. State of) & 14.3 & 9.4 & 38.6 & 16.0 & 78.3 & 11.5 & 8.4 & 1.8 & 100.0 \\
Colombia & 32.5 & 5.5 & 7.1 & 18.5 & 63.5 & 17.9 & 14.1 & 4.4 & 100.0 \\
Ecuador & 24.4 & 16.1 & 5.8 & 18.2 & 64.5 & 14.6 & 15.9 & 4.9 & 100.0 \\
Peru & 21.2 & 9.6 & 12.1 & 19.9 & 62.8 & 14.8 & 15.9 & 6.5 & 100.0 \\
Andean Community & 26.6 & 9.1 & 10.0 & 18.7 & 64.4 & 16.0 & 14.6 & 4.9 & 100.0 \\
\hline
\end{tabular}

Source: Inter-American Development Bank (IDB), IDB-INT model database.

Note: Merchandise trade.

\section{b) Sectoral composition of trade with major partners}

Andean exports are highly resource-intensive. Energy products are the leading exports from Colombia and Ecuador to the United States market, with crude oil and gas alone accounting for a more than $40 \%$ share. In sharp contrast, heavy manufactures, represented mostly by metal products $(46 \%)$, are Peru's leading exports to the United States. For the Plurinational State of Bolivia, light manufactures, comprising lumber and labour-intensive products, are the major exports (59\%). Agriculture exports are also important for Ecuador (25\% share) and Colombia (19\%).

The composition of intraregional exports varies greatly by country. Capital-intensive products are the main exports for Colombia (chemicals) and Peru (chemical and metal products). Crude oil is the leading sector for Ecuador, and labour-intensive food products are a major export 
sector for the Plurinational State of Bolivia. The Andean countries' exports to MERCOSUR are concentrated in resource-based products. For the Plurinational State of Bolivia, natural gas alone accounts for three quarters of the country's exports to MERCOSUR. In the case of Colombia, energy and chemical products account for $80 \%$, while in that of Peru, minerals and metal products claim a $77 \%$ share. Ecuador is the only exception; its main exports to MERCOSUR are labour-intensive food products (52\%) and agricultural products (45\%).

In sharp contrast, agricultural products are the main exports of the Andean Group to the European Union market, followed by resource-based products. In particular, agriculture and processed foods account for $90 \%$ of exports from Ecuador. For Colombia, agriculture makes up one third of exports to the European Union, second to crude oil with a $38 \%$ share. Metal products dominate Peru's exports to the European Union, followed by processed foods. Two thirds of all exports from the Plurinational State of Bolivia to the EU25 consist of mineral and metal products.

\section{c) Applied tariffs of the Andean countries and their partners}

Table II.3 shows Andean sectoral tariffs. The Andean Group is still an incomplete customs union, as each member has applied slightly different MFN tariffs. The Plurinational State of Bolivia has the lowest and most uniform tariffs among the Andean countries - 10\% across the board. Other countries have established higher protection for a wide range of products, particularly labour-intensive goods (processed foods and light manufactures). For example, tariffs on processed foods are around $18 \%$ in the region, and Peru imposes a $23 \%$ tariff on dairy products. In contrast, intra-bloc trade is almost completely liberalized. The remaining protection in Peru is largely for processed foods. ${ }^{15}$ The Andean countries have set preferential tariffs for MERCOSUR on a bilateral basis. As an associate member, the Plurinational State of Bolivia applies the lowest preferences for MERCOSUR, with total tariffs of $4 \%$ versus $7 \%$ in Peru and $10.5 \%$ in Colombia.

15 The intra-Andean tariffs of Peru were updated for 2004/2005 on the basis of figures from the Ministry of External Trade and Tourism (MINCETUR). 


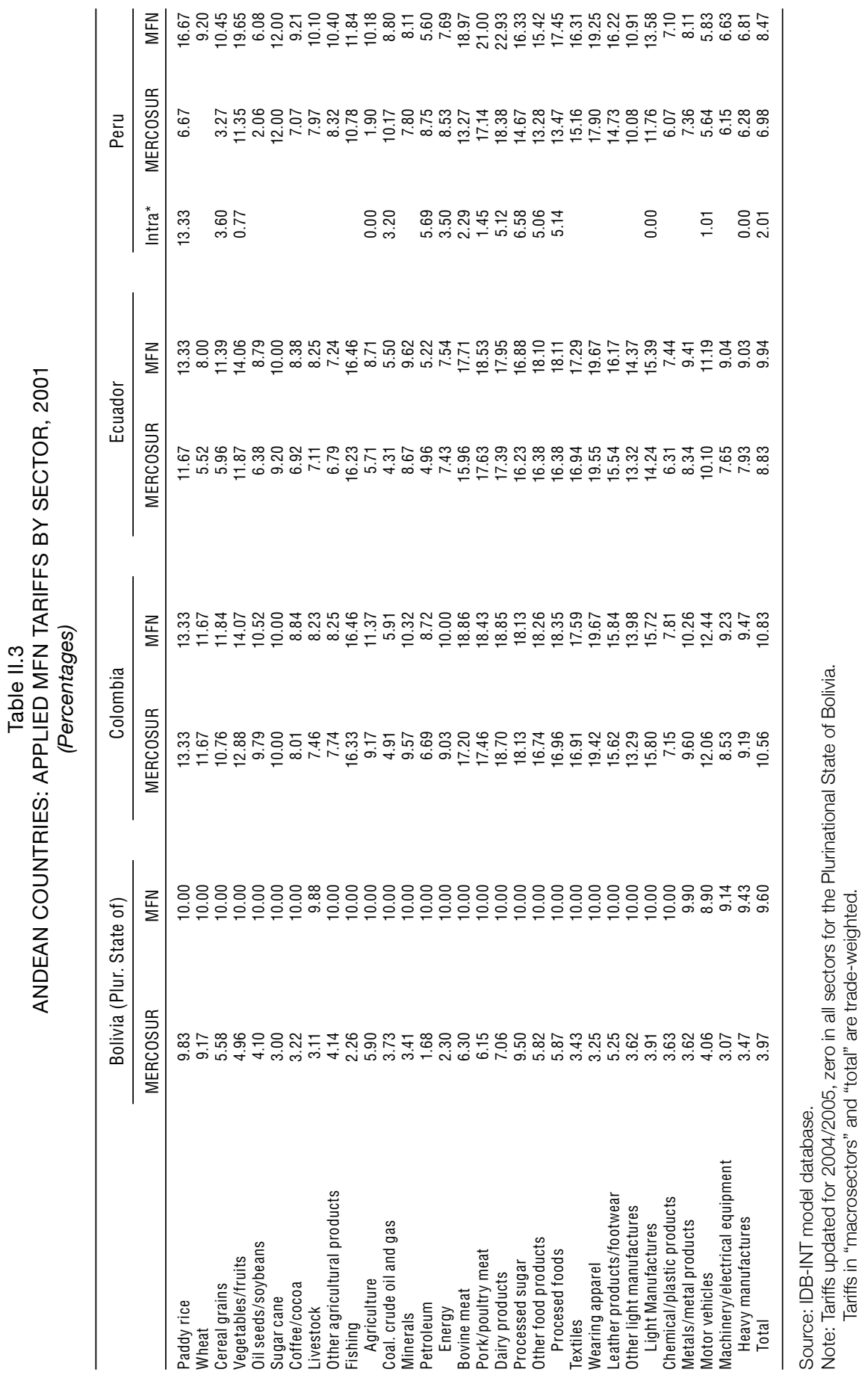


Table II.4 lists the tariffs imposed by the Andean countries' major trading partners. As beneficiaries of preferential treatment under ATPDEA, the Andean countries enjoy very low tariffs (1.1\%) in the United States market. Yet Andean countries still face moderate protection of $4 \%$ on their agricultural exports to the United States. Among commodities, coffee and cocoa, the Andean countries' leading agricultural exports, face $7 \%$ tariffs, the second highest after oilseeds and soybeans $(10.6 \%){ }^{16}$

The United States still maintains high protection on sensitive food products, especially dairy and processed sugar, with $10 \%$ tariffs on both. With the enactment of ATPDEA, the most notable benefits for the Andean countries have been substantially lowered tariffs on their exports of labour-intensive light manufacturing products. ${ }^{17}$ Textiles and wearing apparel are the main beneficiaries, facing modest tariffs of $3 \%$ and $1.2 \%$, respectively. The tariff differentials between MFN and ATPDEA are 11 percentage points for wearing apparel, leather and footwear, and 7 percentage points for textiles.

MERCOSUR applies preferential tariffs to the Andean countries, but imposes high protection for labour-intensive products such as foods and light manufacturing goods. ${ }^{18}$ At the sectoral level, wearing apparel faces the highest applied tariffs at $20 \%$, followed by dairy and processed sugar at $18 \%$. Tariffs on heavy manufacturing products are around 10\%, while sensitive automobiles face much higher protection. As an associate member of MERCOSUR, the Plurinational State of Bolivia enjoys lower tariffs than the other Andean members but still faces high protection on capital-intensive heavy manufacturing products, particularly automobiles (11\% to $12 \%)$.

In the EU25, protection is considerably distorted in favour of agriculture and processed foods. The aggregate tariff on agriculture is $10 \%$, but sensitive products are heavily protected: $57 \%$ for wheat, $53 \%$ for paddy rice and $50 \%$ for cereal grains. Processed foods are also heavily protected: $67 \%$ for bovine meat, $54 \%$ for processed sugar and $48 \%$ for dairy products. Due to high tariff protection on agriculture and food products, the aggregate trade-weighted tariff is $4.3 \%$, four times higher than that of the United States.

16 Coffee and cocoa are the main agricultural exports of Colombia, accounting for $77 \%$ of that country's agricultural exports to the United States. These products are also important for Ecuador and Peru, where the shares are $38 \%$ and $30 \%$, respectively.

17 ATPDEA was enacted in 2002, replacing the former Andean Trade Preference Act (ATPA).

18 MERCOSUR applies bilateral preferential treatment to each Andean country on the basis of economic complementarity agreements. Sectoral differentials for the Andean partners are marginal, however, except in the case of the Plurinational State of Bolivia. 


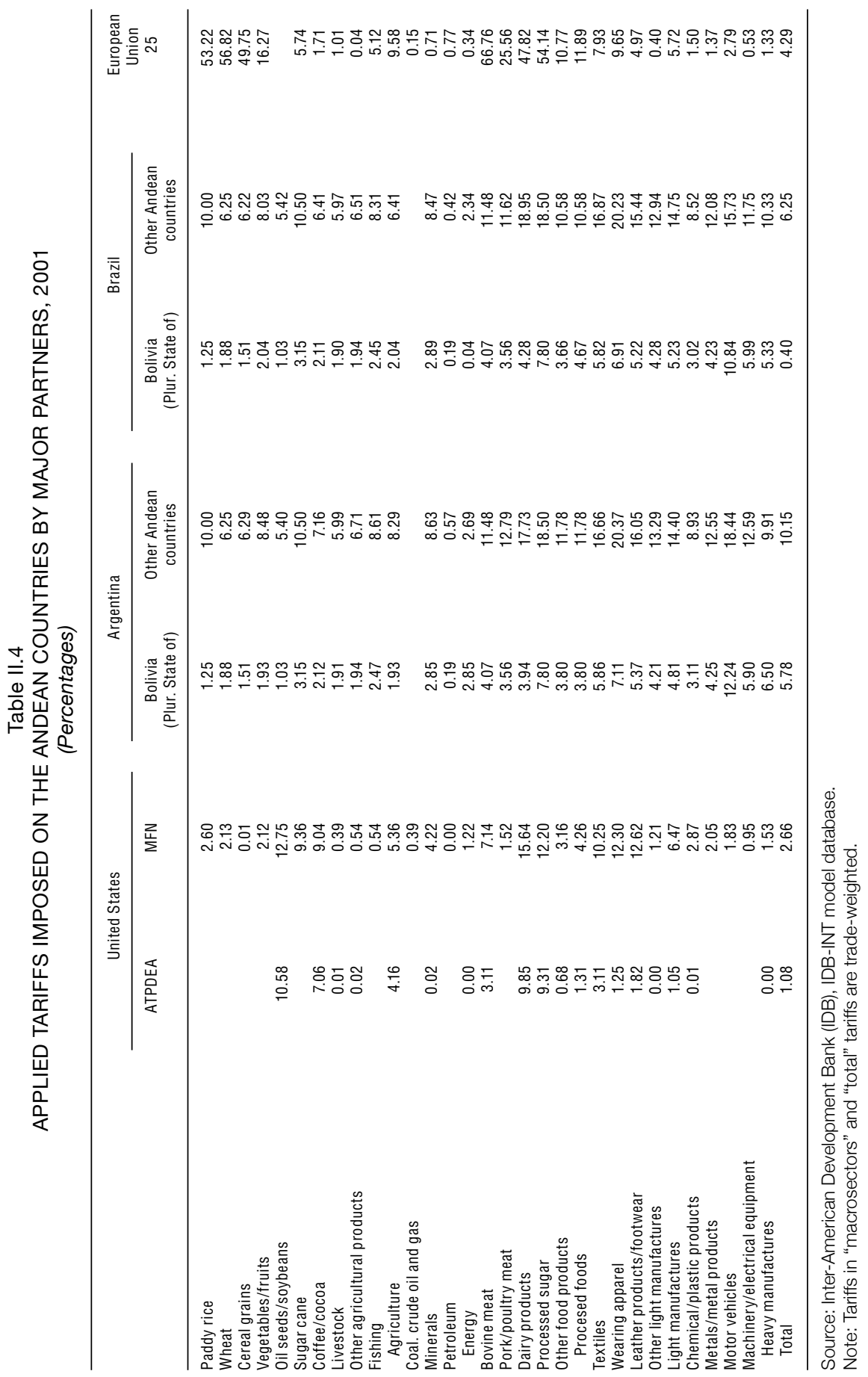




\section{Household income profile}

There is significant heterogeneity in the composition of household income within and between countries (see annex 4). ${ }^{19}$ First, rural households have a greater share of labour income and land rents than those in metropolitan or urban areas. Second rural households tend to have less capital income than urban households. Interestingly, rural households in the Plurinational State of Bolivia are more dependent on capital income than their equivalents in Colombia and Peru.

Third, there is a notable difference across countries in the structure of income transfers to households. In Colombia, government transfers constitute a substantial portion of household income, accounting for an average of $12 \%$. But government transfers play only a marginal role in Peru and the Plurinational State of Bolivia, where transfers from other institutions are more significant, primarily for urban residents.

The evidence implies that it is critical to carry out a thorough analysis of policy effects operating via labour market channels and among various transmission mechanisms, as examined in recent studies (Giordano, 2010; Winters, McCulloch and McKay, 2004; Ganuza, Paes de Barros and Vos, 2002).

\section{Poverty and extreme poverty}

On the basis of the familiar FGT indices, poverty and inequality are both evaluated on the basis of per capita household income (see annex 5). ${ }^{20}$ In Colombia, $51 \%$ of the population lives below the poverty line and $24 \%$ are in extreme poverty. Poverty is very high in rural regions. Household surveys show a strong correlation between the incidence of poverty and self-employed households. This indicates that poor families rely heavily on non-wage activities.

The national poverty rate in Peru is $55 \%$. As in Colombia, the problem is most severe in rural areas, where the highest levels of poverty and extreme poverty are found. In particular, rural mountain areas have the highest poverty and extreme poverty, followed by rural forest areas. In these two regions, income from self-employment is the main or nearly

19 Ecuador was dropped from the microsimulation analysis because household survey data did not provide full information of sufficient accuracy on income streams decomposed into labour categories, occupations by sector, and geographic locations.

20 The data on poverty and extreme poverty presented in this paper are estimates based on national household surveys: the Encuesta Nacional de Hogares (2002) for the Plurinational State of Bolivia, the Encuesta Nacional de Calidad de Vida (2003) for Colombia, the Encuesta de Empleo, Desempleo y Subempleo for Ecuador (2003) and the Encuesta Nacional de Hogares (2003) for Peru. Sources are based on MECOVI. 
the only income source, making up about $70 \%$ of poor households' income. In rural coastal areas, where irrigated cultivation and fishing are practised, poverty is high (73\%) but extreme poverty is relatively low $(25 \%)$ in comparison with other rural regions. In both urban and rural areas, the coastal region has the lowest poverty.

Among the Andean countries, the Plurinational State of Bolivia has the highest incidence of poverty: a $62 \%$ national poverty rate and a $37 \%$ extreme poverty rate. Santa Cruz, the country's largest city, has the lowest poverty and extreme poverty rates. Poverty is particularly serious in rural regions. More than $85 \%$ of residents in the rural highlands and valleys live below the poverty line, and nearly $70 \%$ of the population in these two regions is classified as extremely poor. Across the country, the majority of poor households rely on unskilled labour as their main source of income.

\section{Inequality}

In Colombia, the income gap across regions is very high. However, excluding the metropolitan area, disparities between urban and rural regions, and within each region, are relatively small. The national inequality coefficient is 0.78 on the Theil index and 0.6 on the Gini index, the highest among the three countries. Regional income inequality is strongly associated with mean income levels in each region. The metropolitan area, which has the highest mean income, also has the greatest inequality, followed by the urban coastal region. In general, there is less inequality in rural regions than in the cities.

Of the four countries, Peru has the lowest income inequality, reflected in its 0.52 Theil and 0.51 Gini coefficients. Inequality is less heterogeneous across regions in Peru than in Colombia, yet the metropolitan area has the country's greatest income inequality (after urban mountain areas). The mean income in the metropolitan area is $50 \%$ higher than the national average, which is almost the same as the national average for urban regions, with small regional deviations. In rural mountain areas the mean income is only $30 \%$ of the national average, the lowest in the country, followed by rural forest areas (36\%).

In the Plurinational State of Bolivia, regional mean income shows a clear dichotomy between urban and rural regions. Urban areas, including La Paz-El Alto and Santa Cruz, have incomes higher than the national average. In rural regions the average income falls below the national average, especially in rural highlands and valleys. In sharp contrast with Colombia and Peru, however, inequality in the Plurinational State of Bolivia has a unique and unfavourable feature. The lowest-income regions 
(rural highlands and valleys) have the highest regional disparities. The opposite is also true. Santa Cruz, with the highest mean income in the country, has the least regional income inequality.

\section{CGE simulations: macro and sectoral results}

\section{Policy scenarios}

Our policy variables are tariffs applied to merchandise trade. ${ }^{21}$ To measure the cumulative and overall effects in the long run, we consider the consequences of complete tariff elimination in each scenario. Table II.5 summarizes these alternative policy scenarios.

Scenario 1 examines bilateral trade agreements already concluded between Colombia and Peru and the United States. ${ }^{22}$ In these agreements, the two Andean countries and the United States undertook to reciprocally eliminate all tariffs on merchandise trade only. Under ATPDEA, more

Table II.5

POLICY SCENARIOS SIMULATED FOR ANDEAN COUNTRIES

\begin{tabular}{|c|c|c|}
\hline Scenario & Code & Description \\
\hline 1 & $A C^{a}-U S$ “ "2+1" FTA & $\begin{array}{l}\text { Two Andean countries (Colombia and Peru) and the United States } \\
\text { completely eliminate tariffs on a bilateral basis. }\end{array}$ \\
\hline 2-A & No ATPDEA & $\begin{array}{l}\text { Bolivia and Ecuador lose ATPDEA, and instead face MFN protection } \\
\text { in the United States. }\end{array}$ \\
\hline 2-B & $\begin{array}{l}\text { AC-US "2+1" FTA } \\
\text { plus No ATPDEA }\end{array}$ & Combination of scenarios 1 and 2-A. \\
\hline 3 & AC-US " $4+1$ " FTA & $\begin{array}{l}\text { Four Andean countries (Bolivia, Colombia, Ecuador and Peru) and } \\
\text { the United States completely eliminate tariffs on a bilateral basis. }\end{array}$ \\
\hline 4 & AC-MERCOSUR FTA & All five Andean countries and Mercosur completely eliminate tariffs. \\
\hline 5-A & AC-EU full FTA & All five Andean countries and the EU25 completely eliminate tariffs. \\
\hline $5-B$ & AC-EU partial FTA & $\begin{array}{l}\text { All five Andean countries and the EU25 eliminate tariffs, excluding } \\
\text { sensitive agricultural products in the EU market. }\end{array}$ \\
\hline
\end{tabular}

Source: Prepared by the authors.

a $\mathrm{AC}$ stands for the Andean countries.

21 Market access policy measures include tariffs and non-tariff barriers such as quotas, sanitary and phytosanitary regulations and import licensing, as well as safeguards and rules of origin, among others. However, owing largely to difficulties and lack of methodological consensus when it comes to quantifying ad valorem equivalents of these measures, we only include tariff reduction in the policy variable.

22 Under the bilateral agreements they have now concluded with the United States, Colombia and Peru will eliminate over $80 \%$ of tariffs as soon as the agreements come into force, followed by an additional $7 \%$ within five years and the rest within 10 years. 
than 6,000 products from Colombia and Peru were already entering the United States duty-free. The real gain for the Andean countries is that the agreements will make duty-free preferential treatment permanent. This scenario is also designed to evaluate the costs of excluding the Plurinational State of Bolivia and Ecuador from the agreement.

Scenario 2 evaluates the benefits of ATPDEA, which was provisionally extended after its expiration date of December 2006. The aim is to evaluate the costs of not negotiating agreements with the United States under two variant scenarios. Under scenario 2-A, Ecuador and the Plurinational State of Bolivia lose the ATPDEA preferences and move to MFN protection. This scenario measures the real costs of losing the ATPDEA preferences. Scenario 2-B combines scenario 1 and scenario 2-A. The United States applies two completely differentiated trade regimes to the Andean countries: bilateral FTAs with Colombia and Peru, and MFN tariffs for Ecuador and the Plurinational State of Bolivia.

Scenario 3 evaluates the effects of bilateral trade agreements between each of the four Andean countries (Colombia, Ecuador, Peru and the Plurinational State of Bolivia,) and the United States. This is a hypothetical scenario whereby the Andean countries and the United States liberalize trade by eliminating bilateral tariffs reciprocally, which is an extension of scenario $1 .{ }^{23}$ Comparing scenarios 1 and 2 shows how gains and costs would change for each country if they moved from " $2+1$ " to " $4+1$ " FTA formations.

Scenario 4 measures a biregional FTA between the Andean countries and MERCOSUR. Since 1997, the Plurinational State of Bolivia has been an associate member of MERCOSUR. In August 2003, MERCOSUR and Peru signed an agreement. MERCOSUR and the other Andean countries completed negotiations in April 2004, and an FTA is presently in an extended period.

Lastly, scenario 5 simulates two alternatives for the AndeanEU transatlantic FTA. Scenario 5-A measures the effects of a full FTA that completely eliminates tariffs in both groups of countries. Given agriculture's high political sensitivity and the reluctance in the European Union to conduct trade negotiations at the multilateral and regional levels, this scenario seems highly ambitious and hypothetical. It is useful, however, for evaluating the maximum possible gains Andean countries would reap from fully eliminating tariffs. Scenario 5-B is a

23 In November 2003, the United States announced its intention of opening free trade negotiations with Colombia, Peru, Ecuador and the Plurinational State of Bolivia, which are the ATPDEA beneficiary countries. Negotiations between the United States and Ecuador were suspended at the end of March 2006, and the Plurinational State of Bolivia has not joined the negotiating process. 
more realistic scenario that allows for non-reciprocal arrangements in agriculture. Here, Andean countries completely eliminate tariffs on imports of European Union origin, while the European Union eliminates protection on manufacturing products and partially on agriculture, but excludes sensitive agricultural products. ${ }^{24}$

\section{Simulation results}

This section summarizes the impact of the different scenarios on macroeconomic variables, and particularly the sectoral impact on trade. However, it is advisable to interpret the simulation results with caution. These results are cumulative effects generated over the long run by one-time changes in policy instruments (tariff elimination) in which countries fully adjust to the policy shocks. In actuality, the effects would be influenced by many more factors, including a combination of allround macroeconomic management and external and fiscal policies, and not just by trade policies.

\section{Macroeconomic results}

Table II.6 shows the aggregate effects on macroeconomic variables. The agreements are clearly expansionary in terms of real GDP, welfare, and trade flows. When the Andean countries create an FTA with the United States under a " $2+1$ " formula (scenario 1), signing members benefit from the agreements. ${ }^{25}$ The opposite is clearly the case with nonsigning members, which are excluded from the agreements and face a small but negative impact on all macroeconomic variables. In scenario 3, the positive impact on macroeconomic variables becomes slightly smaller for Colombia and Peru. This is due to stronger competition between Andean countries to penetrate the United States market. Ecuador and the Plurinational State of Bolivia become winners instead of losers, with modest gains in macro variables.

24 The agreement excludes seven agricultural products: paddy rice, wheat, cereal grains, bovine meat, pork and poultry meat, dairy products and processed sugar.

25 Regarding the impact of trade agreements with the United States, our aggregate results for trade are in accordance with other recent studies, such as Lima, de Miguel and Shuschny (2006). They find that these agreements generate clear positive impacts on trade. This does not necessarily produce positive effects on other economic variables because they apply the standard external market closure of the Global Trade Analysis Project (GTAP) model. In this closure, the current account balance is endogenized so that Andean countries worsen their current account positions by eliminating more tariffs than their partner. This is probably one of the reasons why the positive trade effects do not necessarily translate into gains in other macroeconomic variables in their study. 


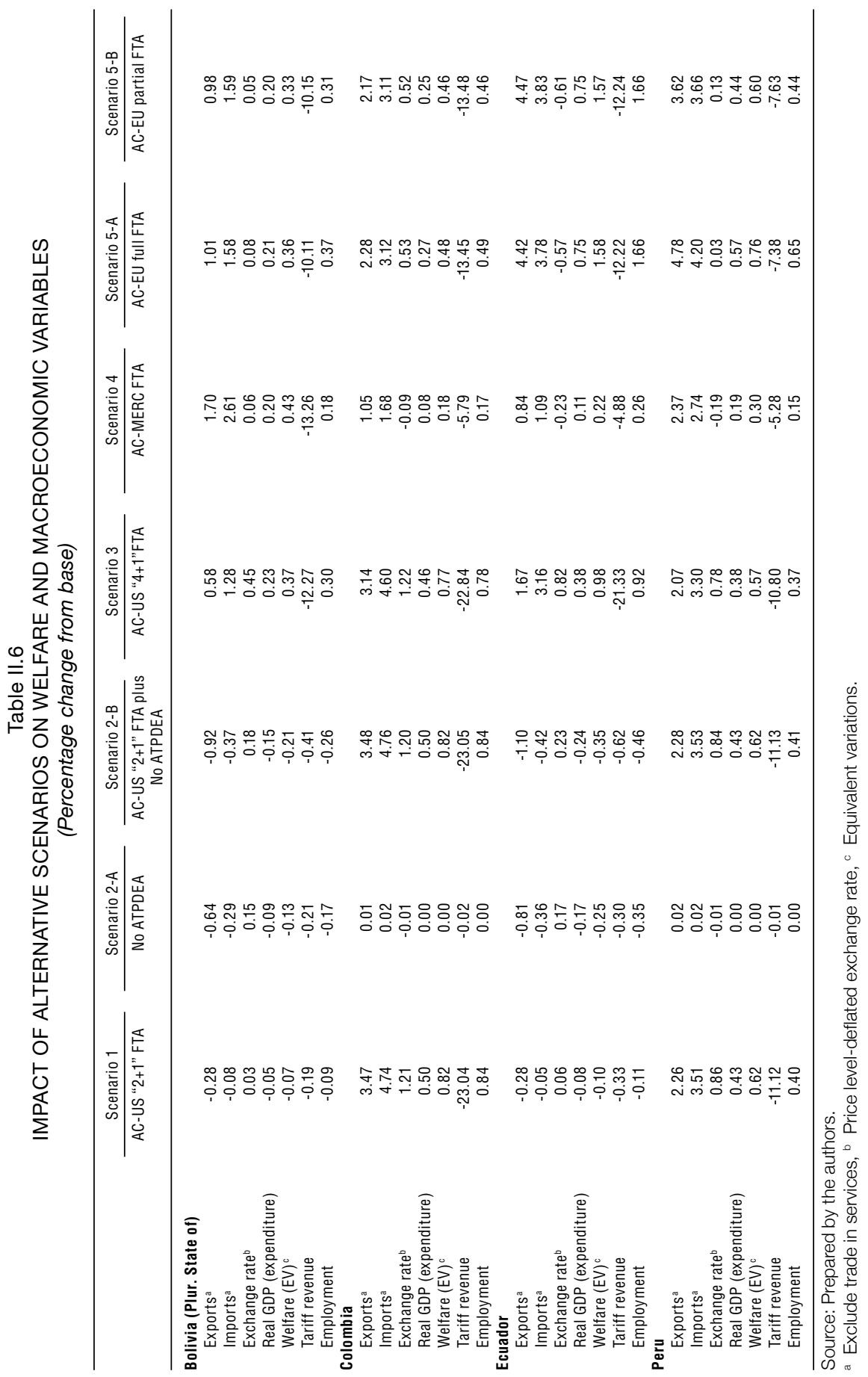


In scenario 2-A, the reduction in Bolivian and Ecuadorian exports to the United States is clear. Ecuador is more dependent on the United States than the Plurinational State of Bolivia, and thus experiences approximately $25 \%$ greater negative effects than the latter. For other Andean countries, the impact is negligible. This result indicates the critical importance of signing FTAs and consolidating current preferences into permanent agreements. Scenario 2-B amplifies the impact for both signing and nonsigning countries. The aggregate impact on macroeconomic variables is close to the sum measured in scenario 1 and scenario 2-A. In short, the signing countries increase their gains at the cost of non-signing members. This scenario is the best option for Colombia and the second best for Peru, but the worst for the Plurinational State of Bolivia and Ecuador.

In an FTA with MERCOSUR (scenario 4), Peru enjoys greater export growth. For the Plurinational State of Bolivia, which has already been granted greater market access, the effect is somewhat higher export growth and modest economic gains. The opposite is true for Colombia and Ecuador, where large-scale tariff elimination on its own cannot overcome the disadvantage of the countries' low export penetration prior to the agreements and their large trade deficits with MERCOSUR.

Integration with the EU25 (scenario 5-A) is an appealing option for the Andean countries. In fact, this scenario emerges as the best approach for each of the four countries except Colombia. Ecuador and Peru benefit the most from this strategy, while the Plurinational State of Bolivia receives the fewest gains owing to its limited trade and the low barriers its products face in the European Union market even now. Excluding sensitive agricultural products from the European Union market (scenario 5-B) does not essentially change the impact on the macroeconomic variables. The simulation results show that excluding sensitive products has greater consequences for welfare than for aggregate trade. This is due mainly to the unique production and labour market situation in the Andean countries: sensitive agricultural sectors account for significant shares of labour force participation $(11.3 \%$ in the Plurinational State of Bolivia and 5.3\% in Peru). As a result, European Union exclusion of these products directly reduces remuneration, which in turn reduces welfare.

One troubling finding is that the trade balance of the Andean countries with their partners would worsen under the principal scenarios, such as agreements with the United States and EU25, requiring the countries to depreciate their currencies to return to their initial positions. ${ }^{26}$ An FTA with the United States would transform the Peruvian trade surplus with that country into a small deficit. Meanwhile, Colombia would come to have a very large bilateral deficit owing to its

26 To keep the overall goods and services trade balance unchanged. 
heavy reliance on United States imports. As a result, the overall trade deficit on the goods account of Colombia would worsen, while the gross trade surplus of Peru would narrow. ${ }^{27}$ Likewise, integration with the EU25 would have a heterogeneous impact on bilateral trade positions. Peru would manage to maintain its trade surplus, while the surplus of Ecuador would disappear. The trade deficits of the other countries would widen. The Andean countries would have to achieve real depreciation or productivity gains larger than the expected depreciation; otherwise they would risk a loss of competitiveness in the international market. This situation would be particularly stressful for a dollarized economy like Ecuador, because the country cannot pursue its own monetary policies.

\section{b) The sectoral impact on trade}

This section reports the sectoral impact on trade, which is presented on an aggregate basis for each Andean country in annex 3.

\section{Scenario 1: Andean-United States "2+1" FTA}

In this scenario, bilateral agreements increase aggregate exports to the United States by 7\% for Colombia and 5\% for Peru. Export adjustment patterns are highly asymmetrical across sectors. The principal sectors for Colombia are coffee and cocoa, the country's traditional agricultural export commodities (30\%). Exports of textiles, wearing apparel, leather and footwear also expand strongly $(20 \%)$. Crude oil and gas exports increase by a small $2.3 \%$. This is also true for metal products from Peru, which expand by $2.6 \%$.

Colombia and Peru experience a sharp rise in imports for all product lines originating in the United States. Imports from the United States jump by $40 \%$ in Colombia and $36 \%$ in Peru. The sectoral impact on imports is fairly balanced in both countries, however. Capital-intensive goods comprise the bulk of new imports (about $60 \%$ of new purchases from the United States). In value terms, machinery and electronic equipment are the most important new products, capturing a $24 \%$ share in Colombia and 30\% in Peru.

Non-signing Andean members face negative impacts on trade, primarily as a result of trade diversion. While Colombia and Peru slightly expand their exports to other Andean members, they shift imports from

As was shown during the adjustment process after the Latin American economic crisis, in which exports played a significant role as an engine of strong recovery and growth, the Andean countries do have the potential to manage external shocks. If this were not the case, each country would be likely to lose global competitiveness and see its overall trade account position worsen. 
intra-bloc sources to imports originating in the United States. Colombia reduces its imports from its Andean partners by some $7 \%$ to $10 \%$. The effect on Peru is much less. Capital-intensive heavy industries are the most affected sectors because intra-industry trade in these products dominates Andean intra-bloc trade.

Scenario 2-A: No ATPDEA

Reversion by the United States from the ATPDEA preferences to the MFN tariff regime has formidable economic consequences for the Plurinational State of Bolivia and Ecuador, although the negative impact on their macroeconomic variables is small. For the Plurinational State of Bolivia, aggregate exports decline by $8 \%$, with wearing apparel particularly affected, and textile exports to the United States market fall sharply (by nearly 30\%). As a result, production drastically shrinks in these labour-intensive traditional industries. Metal exports also drop by $9 \%$. Labour-intensive light manufacturing products and metals account for $85 \%$ of lost exports to the United States.

Ecuador experiences a smaller impact than the Plurinational State of Bolivia, with aggregate exports declining by $3.4 \%$. While the patterns of sectoral shocks for exports are similar to those in the Plurinational State of Bolivia, the composition of the reductions in exports to the United States differs significantly. Vegetables and fruits, coffee and cocoa and other food products - the country's leading agricultural exports account for $80 \%$ of lost exports to the United States market.

\section{Scenario 2-B: Andean-United States "2+1" FTA plus no ATPDEA}

The overall impact of this scenario is close to the sum of the impacts simulated under scenario 1 (Andean-United States "2+1" FTA) and 2-A (No ATPDEA). Sectoral trade performance is amplified and accompanied by larger structural adjustments. Colombia and Peru further reinforce their traditional patterns of trade with the United States. Their leading export products - coffee and cocoa, textiles and crude oil in Colombia and metals in Peru - are the main beneficiaries. In return, these countries increase their purchases of capital-intensive products (largely machinery and electric equipment) from the United States. Yet the composition of new exports to, and new imports from, the United States is almost unchanged from the results produced by scenario 1 .

For the Plurinational State of Bolivia and Ecuador, exports deteriorate further in all sectors. Labour-intensive light manufactures suffer the most. Wearing apparel is hit the hardest, with exports to the United States market declining by more than $30 \%$, followed by $27 \%$ drops in textile exports for both countries. 
Where bilateral trade positions with the United States are concerned, Colombia slightly reduces its trade deficit, while in Peru the balance remains unchanged. The trade surplus of the Plurinational State of Bolivia with its Andean partners declines as signing countries shift their imports from intra-bloc to United States sources. For the same reason, the trade deficit of Ecuador with the Andean members worsens slightly.

\section{Scenario 3: Andean-United States "4+1" FTA}

When the four Andean countries sign FTAs on a bilateral basis, gains from the bilateral agreements extend to new signatory members. The aggregate impact and the patterns of adjustments remain almost unchanged for Colombia and Peru, but the Plurinational State of Bolivia expands its exports to the United States by 3.3\%, and those of Ecuador increase by $4.9 \%$.

Ecuadorian exports of coffee and cocoa (traditional agricultural products) and textiles increase by more than $20 \%$. Crude oil and gas, the country's leading exports, expand by a modest $1.7 \%$. These traditional products are the mainstay of the country's exports and its main foreign currency earners, accounting for more than $70 \%$ of new sales to the United States. The Plurinational State of Bolivia experiences different impacts across sectors compared to the other Andean Countries, but the composition of its exports is quite distinct. By contrast with the other Andean countries, labour-intensive textiles account for 30\% of new sales by the Plurinational State of Bolivia to the United States, followed by metal products with a $15 \%$ share.

Imports originating in the United States increase sharply in the Plurinational State of Bolivia and Ecuador. Some sensitive agricultural sectors experience significant growth in imports, particularly wheat in both countries and poultry meat in Ecuador. This is partly because initial imports are very low. In value terms, however, capital-intensive products easily dominate the new imports. For the Plurinational State of Bolivia, with its small industrial base, these products account for $80 \%$ of new imports from the United States. The composition of new imports for Ecuador is similar to that for Colombia.

Trade agreements change the pattern and composition of intrabloc trade flows. Trade declines owing to an increase in exports to the United States market, which diverts sales originally taking place within the Andean market, while the penetration of competitive United States goods replaces Andean products (e.g., machinery and electric equipment and metal products and chemicals). 


\section{Scenario 4: Andean-MERCOSUR FTA}

In this scenario, the biregional South-South agreement reinforces the Andean bloc's initial trade patterns. Each of the Andean countries increases its resource-based exports in exchange for capital-intensive goods from MERCOSUR.

Because the Andean countries' trade links with MERCOSUR are currently weak (with the exception of the Plurinational State of Bolivia), the impact of this scenario on trade is impressively dynamic. Peru experiences the greatest rise in exports to MERCOSUR, with a jump of more than $60 \%$, followed by Colombia and Ecuador. In contrast, Bolivian exports rise by only $7 \%$. Capital-intensive heavy manufacturing products register the second-highest export growth after light manufacturing goods, but they are key commodities in value terms for Colombia and Peru. The principal commodity exports show different results: chemicals dominate new sales in Colombia, while metal products are the main exports of Peru. For Ecuador, agriculture (vegetables and fruits) and food products account for $90 \%$ of new sales to MERCOSUR.

The impact of imports from MERCOSUR on the Andean countries is much larger, particularly in Colombia, where they jump by nearly $60 \%$, followed by Ecuador. In these countries, heavy manufacturing products dominate new purchases from MERCOSUR: chemical products and metal products in the Plurinational State of Bolivia and Ecuador and automobiles in Colombia and Ecuador. In this regard, Peru is the exception. Reflecting the initial structure of imports, processed foods and labour-intensive light manufacturing products continue to represent high shares of new imports from MERCOSUR, although heavy manufacturing products have the largest share at $37 \%$.

\section{Scenario 5-A: Andean-EU full FTA}

A full biregional agreement sharply boosts the Andean countries' exports to the European Union. Yet the sectoral impact differs significantly by country, as the composition of exports to the EU25 is highly asymmetrical. Ecuador enjoys the greatest export growth $(37 \%)$, followed by Peru (24\%). Large-scale tariff elimination in the European market explains more of the Andean countries' robust export performance than the bloc's resource-based comparative advantage. Processed foods are the largest gainers in Peru and Colombia. Agriculture also enjoys high export growth, with vegetable and fruit exports enjoying a powerful $40 \%$ expansion across the Andean countries. 
In value terms, agriculture and processed foods dominate new exports in Ecuador, Colombia and Peru. In the Plurinational State of Bolivia, crude oil and metal products are as important as agriculture and agricultural products.

There is a larger impact on imports than on exports. This is because the Andean bloc's tariff elimination commitments are greater than those of the European Union. Imports rise by almost 50\% in Colombia and Ecuador and by $40 \%$ in the Plurinational State of Bolivia and Peru. Compared with export performance, import patterns are relatively even across sectors and are similar to those of imports from the United States. In value terms, as seen in other scenarios, heavy manufacturing goods dominate imports $(75 \%$ in the Plurinational State of Bolivia, $70 \%$ in Ecuador and $60 \%$ in Peru).

\section{Scenario 5-B: Andean-EU partial FTA}

In this scenario, the partial agreement excluding sensitive agriculture in the European Union does not change trade gains in the aggregate, as is the case in scenario 5-A. However, the exclusion affects the sectoral performance of these products. Peru is the most affected: its exports of bovine meat to the European Union market almost disappear, and growth in the country's exports of processed foods to the European Union falls sharply from $91 \%$ to $39 \%$. Likewise, Colombia loses exports of bovine meat, pork and poultry meat and processed sugar. In the Plurinational State of Bolivia, cereals are the most affected sector, and agricultural export growth drops by almost 6 percentage points.

The trade surplus of Peru with the European Union narrows while its trade deficit with Colombia widens. The bilateral trade balances of Ecuador and the Plurinational State of Bolivia with the European Union barely change from the previous scenario.

\section{Opportunities and challenges for Andean industries}

Identifying winning and losing sectors is of crucial importance for trade negotiations and for the design of comprehensive trade, industrial and social policies. Industries are classified into four categories by the sectoral impact of policy scenarios on production (scenarios 3, 4 and 5-A):

(i) Winning $(\mathrm{W})$ : If at least one output variation is greater than $1 \%$, while others fall within the threshold range $(-1 \%, 1 \%)$.

(ii) Neutral $(\mathrm{N})$ : If variation is within the threshold range $(-1 \%, 1 \%)$.

(iii) Conflicting (C): If positive and negative variations appear outside the threshold range. 
(iv) Losing (L): If at least one variation is lower than $-1 \%$, while others are within the threshold range.

Table II.7 presents sectors sorted according to the above criteria. Clearly, most of the Andean countries' traditional resource-based industries emerge as obvious winners. In the Plurinational State of Bolivia, contrary to common belief, crude oil, gas and minerals, the country's leading industries, fall into the neutral category. These industries are closer to the winning sectors, however, particularly under the agreement with the European Union. Light manufactures have a mostly mixed status. While textiles are winners, leather and footwear fall into the conflicting and wearing apparel into the neutral category. Heavy industries other than metals tend to be losing sectors under the agreements with the United States and the European Union. These industries might find better opportunities through stronger trade and production linkages with MERCOSUR.

In Colombia, most agricultural sectors are losers, the exceptions being coffee and cocoa. Wheat in particular experiences serious challenges under both the United States and the European Union integration options. Only vegetables and fruits are winners under the agreement with the European Union. For food industries, the outcome is mixed. Bovine meat and processed sugar are winners, while pork and poultry meat emerge as losers. The outcome for light manufacturing industries is also mixed. Wearing apparel and leather and footwear are winners in all scenarios. The opposite is the case with textiles. Among heavy industries, chemicals are in the neutral category. Other capitalintensive industries such as motor vehicles and metals are more likely to experience competitive pressure.

In Ecuador, the situation is promising in agriculture, except for oilseeds and soybeans. Winners include vegetables and fruits and coffee and cocoa, among others. Processed food industries are also clear winners in all integration scenarios. Conversely, the outcome is challenging for most manufacturing industries. All sectors other than wearing apparel appear to be losers.

In Peru, the prospects are very promising. Agriculture is a clear winner over a wide range of products, particularly in the case of integration with the European Union. The same is true of food industries. Light manufacturing industries - textiles, wearing apparel and leather and footwear- are also winners. The exception is wheat, which appears to be a loser, as it was in the cases of the Plurinational State of Bolivia and Colombia. Among heavy industries, machinery and electrical equipment are also losers. 
Table II.7

SECTORAL WINNERS AND LOSERS AMONG ANDEAN INDUSTRIES

\begin{tabular}{|c|c|c|c|c|}
\hline & $\begin{array}{c}\text { Bolivia } \\
\text { (Plur. State of) }\end{array}$ & Colombia & Ecuador & Peru \\
\hline \multicolumn{5}{|l|}{ Agriculture } \\
\hline \multicolumn{5}{|l|}{ Paddy rice } \\
\hline \multicolumn{5}{|l|}{ Wheat } \\
\hline \multicolumn{5}{|l|}{ Cereal grains } \\
\hline \multicolumn{5}{|l|}{ Vegetables/fruits } \\
\hline \multicolumn{5}{|l|}{ Oilseeds/soybean } \\
\hline \multicolumn{5}{|l|}{ Sugar cane } \\
\hline \multicolumn{5}{|l|}{ Coffee/cocoa } \\
\hline \multicolumn{5}{|l|}{ Livestock } \\
\hline \multicolumn{5}{|c|}{ Other agricultural prod. } \\
\hline \multicolumn{5}{|c|}{ Fishing } \\
\hline \multicolumn{5}{|l|}{ Energy } \\
\hline \multicolumn{5}{|l|}{ Coal, oil and gas } \\
\hline \multicolumn{5}{|l|}{ Minerals } \\
\hline \multicolumn{5}{|l|}{ Petroleum } \\
\hline
\end{tabular}

\section{Processed foods}

Bovine meat

Pork and poultry meat

Dairy products

Processed sugar

Other food products

$\begin{array}{ll}0 & 0 \\ 0 & 0 \\ 0 & 0\end{array}$

\section{Light manufactures}

Textiles

Wearing apparel

Leather prod. and footwear (1)

Other light manufactures

\footnotetext{
Heavy manufactures

Motor vehicles

Note:
Winning
Losing
(1) Conflicting
Neutral

Chemical/plastic products

Metals/metal products
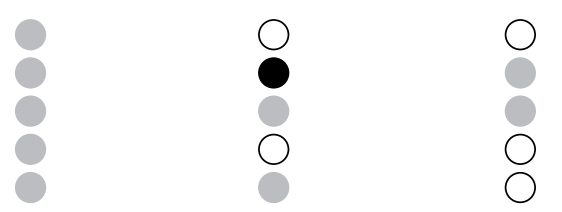

Machinery/electrical equip.

$\begin{array}{ll}0 & 0 \\ 1 & \bigcirc\end{array}$

Source: prepared by the authors. 


\section{E. Impact of trade and integration on poverty and inequality}

This section measures the impact of regional trade agreements on poverty and inequality. Specifically, we consider scenario 2-B (AndeanUnited States " $2+1$ " FTA plus the reversal of ATPDEA). Applying microsimulation analysis, we evaluate the impact of this policy scenario on poverty and inequality for three Andean countries: Colombia, Peru and the Plurinational State of Bolivia.

\section{Impact on per capita household income, poverty and inequality}

\section{Impact on per capita household income}

Figure II.2 displays the impact on per capita household income. Clearly, there are salient differences in the respective impact on signing and non-signing countries on the one hand, and common features for signing members on the other. First, in signing countries Colombia and Peru, income rises in all regions and nationally. Meanwhile, the Plurinational State of Bolivia, a non-signatory, suffers a decline in income both nationally and across regions. Second, the impacts (positive and negative) are generally greater in rural regions than in urban areas. This implies that the FTA with the United States would have the potential effect of reducing poverty in rural areas and narrowing regional disparities between urban and rural areas, although these effects are not necessarily guaranteed. Third, labour income is the main cause of the increase in income, followed by land rents. This is particularly true in rural regions.

\section{Impact on poverty and extreme poverty}

Trade and integration are beneficial to the poor, and income generation via the labour market (employment and wages) is the dominant factor in the subsistence of the poor.

In Colombia, the FTA generates small but positive pro-poor effects, ${ }^{28}$ national poverty, measured by headcount, declines by $0.29 \%$, which roughly equates to lifting 63,800 people out of poverty. The key factor behind this positive impact is job creation (1.15\%), particularly for lowskilled workers, followed by semi-skilled labour. Yet the impact is uneven

28 Using the Global Trade Analysis Project (GTAP) model with data from 2001 and household survey data from 2003, Pardo Reinoso and others (2005) estimate that the bilateral trade agreement with the United States reduces poverty in Colombia by $1 \%$ in terms of headcount. 
Figure II.2

IMPACT ON PER CAPITA HOUSEHOLD INCOME

(Percentage change from base)

\section{Colombia}
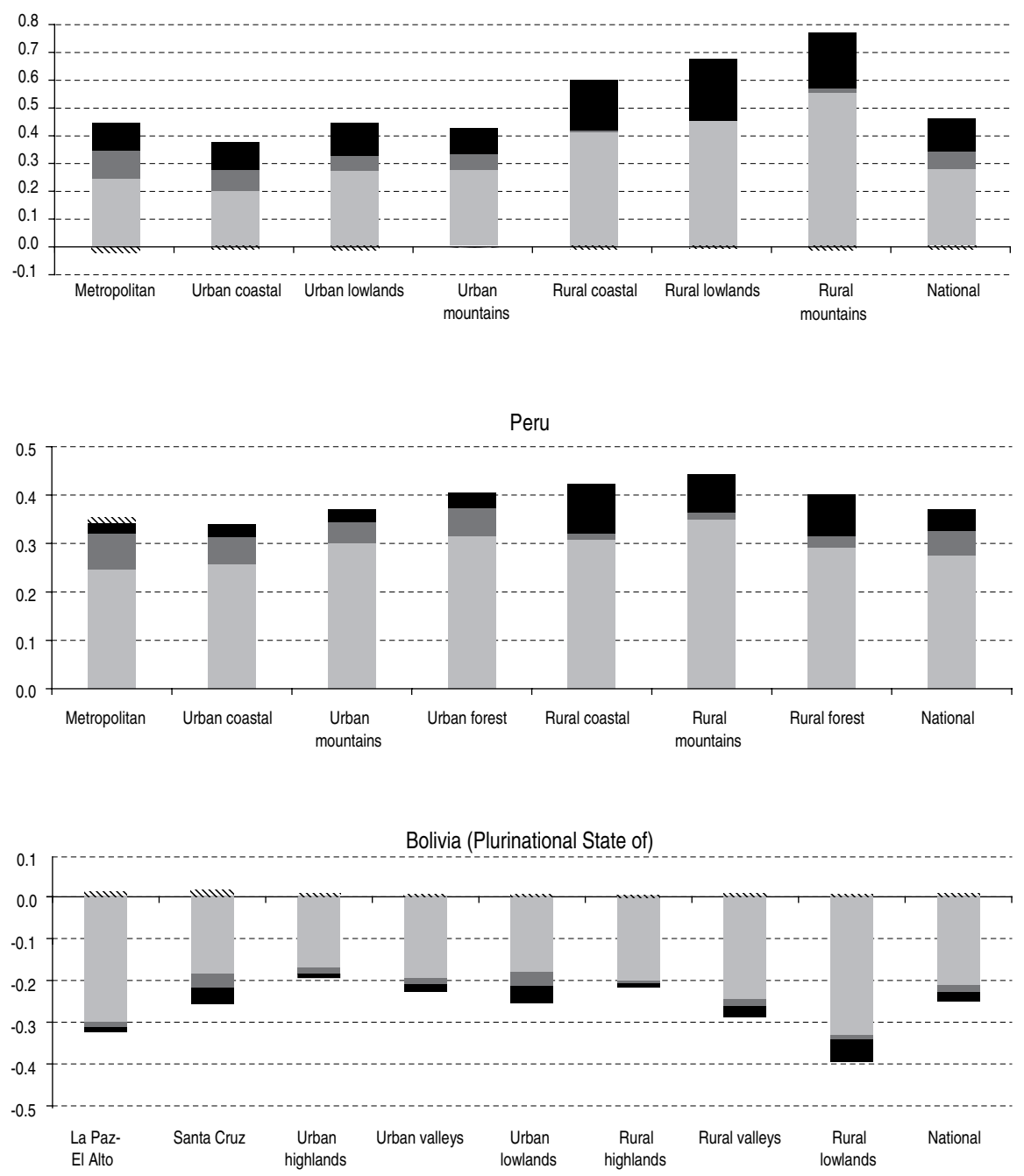

Labour Capital $\quad$ Land Transfers

Source: Inter-American Development Bank (IDB), IDB-INT CGE model and microsimulation. 
across regions. Poverty declines particularly in rural mountain areas as new jobs are created in the booming coffee industry. Poverty also declines in metropolitan and urban coastal regions, where booming industries such as apparel, leather products and footwear are located. The impact of the FTA on extreme poverty is even more pronounced. The headcount rate declines by $0.6 \%$ at the national level, equivalent to 63,200 people. In general, this positive impact is larger in rural than in urban regions.

Table II. 8

IMPACT ON POVERTY AND EXTREME POVERTY IN ANDEAN COUNTRIES (Percentage change from base)

\begin{tabular}{lcc}
\hline & Poverty & Extreme poverty \\
\hline Colombia & & \\
Metropolitan & -0.39 & -0.50 \\
Urban coastal & -0.34 & -0.50 \\
Urban lowlands & -0.21 & -0.59 \\
Urban mountains & -0.25 & -0.66 \\
Rural coastal & -0.15 & -0.51 \\
Rural lowlands & -0.20 & -0.60 \\
Rural mountains & -0.46 & -0.80 \\
National & -0.29 & -0.60 \\
& & \\
Peru & & \\
Metropolitan & -0.37 & -0.90 \\
Urban coastal & -0.34 & -0.76 \\
Urban mountains & -0.25 & -0.73 \\
Urban jungle & -0.18 & -0.69 \\
Rural coastal & -0.18 & -0.41 \\
Rural mountains & -0.12 & -0.29 \\
Rural jungle & -0.11 & -0.36 \\
National & -0.23 & -0.56 \\
Bolivia (Plurinational State of) & & \\
La Paz-El Alto & & \\
Santa Cruz & 0.99 & 2.22 \\
Urban highlands & 0.82 & 2.37 \\
Urban valleys & 0.75 & 0.96 \\
Urban lowlands & 0.78 & 1.26 \\
Rural highlands & 0.52 & 1.95 \\
Rural valleys & 0.43 & 0.38 \\
Rural lowlands & 0.37 & 0.71 \\
National & 0.45 & 1.09 \\
\hline
\end{tabular}

Source: Inter-American Development Bank (IDB) IDB-INT Andean model simulation and microsimulation.

Poverty and extreme poverty also decline in Peru, but at more modest rates than in Colombia. The headcount indices for poverty and extreme poverty drop by $0.22 \%$ and $0.56 \%$, respectively, roughly corresponding to 49,300 and 59,600 people. These positive pro-poor impacts are due largely 
to job creation for low- and semi-skilled workers and, to a lesser extent, the effects on wages. The effects are smaller than in Colombia, particularly regarding employment. The reason is mainly that agricultural benefits are lower than in Colombia. Poverty reduction is greatest in urban rather than rural regions, with the highest gains in the metropolitan area $(0.37 \%)$. Rural areas in the coastal region show slightly higher poverty reduction gains than the other regions. One of the reasons for this outcome is that job-creating industries such as light manufactures, energy and processed foods are mainly located in urban areas.

By opting out of the agreement, the Plurinational State of Bolivia experiences rising poverty at the national and regional levels. The national poverty headcount rises by $0.6 \%$, equivalent to some 31,100 people. Poverty generally worsens more in urban than rural areas because the greatest elimination of jobs occurs in light manufactures such as textiles and apparel, which are located in urban regions. Metropolitan La Paz-El Alto is hit the hardest, with the poverty headcount rising by $0.98 \%$. Extreme poverty nationwide follows the pattern of poverty, but at greater magnitude. Extreme poverty increases by more than $2 \%$ in $\mathrm{La}$ Paz-El Alto and Santa Cruz, and by almost $2 \%$ in urban lowlands.

\section{Effects on income inequality}

Ganuza, Paes de Barros and Vos (2002) find that the impact of trade liberalization is more ambiguous for income inequality than for poverty. Our results indicate that the impact is small, but positive, at the national level and for most regions in signing countries. The opposite is true for the non-signing country. Annex 7 includes the impact on income inequality, measured by mean income, and two inequality indices, the Theil and Gini coefficients.

In Colombia, because per capita household income increases faster in rural regions than in urban areas, income inequality narrows slightly: by $0.06 \%$ on the Theil index and by $0.07 \%$ on the Gini index. Inequality generally declines in rural areas relative to urban regions. Rural mountain areas, followed by rural lowlands, experience the most rapid decline in inequality.

As with Colombia, income inequality in Peru decreases, but at a lower rate. Mean income increases with relatively low regional variations. On average, the Gini and Theil indices decline by $0.03 \%$ and $0.11 \%$, respectively. Inequality falls by slightly more in rural regions than in urban areas, but the impact on regional inequality is mixed. Inequality declines in rural forest and rural mountain regions, but worsens slightly in rural coastal regions. In urban regions, the impact on regional inequality is also positive, but marginal. 
The Plurinational State of Bolivia faces rising inequality within and across regions. The country's national mean income falls by $0.25 \%$, and rural highlands, which already have the lowest income level, suffer the largest decline $(-0.43 \%)$. This leads to a significant increase in national and regional inequality. La Paz-El Alto suffers the greatest impact: the Gini coefficient rises by $0.63 \%$ and the Theil index by $0.36 \%$. In contrast, the deterioration is relatively small in Santa Cruz, which is where inequality is already below the national average. On the other hand, the rural highlands and valleys, where inequality is already high, experience the smallest (although still negative) impact within the rural regions category.

\section{F. Summary and conclusion}

The CGE simulation results presented here show that trade agreements improve living conditions and produce a clearly expansionary impact. Bilateral trade agreements with the United States generate different outcomes for signing and non-signing countries. The signing countries benefit by consolidating market access while the non-signatories suffer losses as they forfeit trade preferences and experience trade diversion. The costs of losing the ATPDEA preferences are much larger than the negative effects of being excluded from bilateral trade agreements alone. The transatlantic agreement with the European Union sharply increases Andean exports of agricultural and agroindustry products. The exclusion of sensitive agricultural products barely affects the aggregate impact, but it significantly reduces exports of these products.

The simulation results reveal important policy challenges. From a hemispheric viewpoint, the Andean countries increase exports of products for which they have a comparative advantage. Furthermore, most of the traditional resource-based industries appear to be clear winners, whereas the majority of capital-intensive heavy industries will face challenges. Trade liberalization alone does not automatically guarantee export diversification or changes in economic structure. Another challenge is the decline of intra-bloc trade due to trade diversion, which has a direct impact on economic performance. This is particularly true in the case of non-resource-based capital-intensive industries.

Trade liberalization has pro-poor benefits. Income generation via the labour market is the determining factor in increasing household income for the poor. The key element is the employment effect, particularly for low-skilled workers.

In Colombia and Peru, trade agreements have less of an effect on inequality than on poverty. By contrast with the impact of agreements on poverty, however, income inequality does not necessarily improve in all 
regions. Improvements at the national level do not guarantee, and are not necessarily accompanied by, improvements across the different regions. By opting out of these agreements, the Plurinational State of Bolivia suffers a negative impact on inequality.

As many studies indicate and theory predicts, trade and integration hold the potential for reducing poverty in the long run and in the aggregate. These gains are not always guaranteed for all, however, and the poor may be harmed in the short term. It is therefore important to sequence liberalization carefully and to support the poor during the adjustment process. 


\section{Bibliography}

ALADI General Secretariat (2004), "Impacto del ALCA sobre la economía de los países miembros de la ALADI: un análisis de equilibrio general" (ALADI/ SECdt 457).

Alatas, V. and F. Bourguignon (2005), "The evolution of income distribution during Indonesia's fast growth 1980-96", The Microeconomics of Income Distribution Dynamics in East Asia and Latin America, F. Bourguignon, F.H.G. Ferreira and N. Lusting (eds.), Oxford University Press.

Botero, J. (2005), "Estimación del impacto sobre el empleo de los tratados de libre comercio en Colombia; análisis de equilibrio general computable", Estudios y perspectivas series, No. 8 (LC/L.2366-P), Bogotá, Economic Commission for Latin America and the Caribbean (ECLAC). United Nations publication, Sales No. S.05.IIG.105.

Bourguingnon, F. (2003), "The growth elasticity of poverty reduction", Inequality of Growth, T. Eicher and S. Turnovsky (eds.), Cambridge, MIT Press.

Bourguignon, F., M. Fournier and M. Gurgand (2001), "Fast development with a stable income distribution: Taiwan, 1979-94", Review of Income and Wealth, vol. 47, No. 2, June.

Bourguignon, F., A. Robilliard and S. Robinson (2003), “Representative versus real households in the macro-economic modeling of inequality", DELTA Working Paper 2003-05, Washington, D.C., World Bank and IFPRI.

Bourguignon, F., L. Pereira da Silva and N. Stern (2002), "Evaluating the Poverty Impact of Economic Policies: Some Analytical Challenges", Washington, D.C., World Bank, unpublished.

Bussolo, M. and J. Lay (2003), "Globalization and poverty changes in Colombia", World Bank Working Paper, No. 28734, Washington, D.C., World Bank.

Cano, C.G. (2004), "El agro colombiano frente al TLC con Los Estados Unidos", Bogota, Ministry of Agricultural and Rural Development.

Carrasco, G.C., A.F. Reinoso and D.F. Hoyle (2004), "Escenarios de integración del Perú en la economía mundial: un enforque de equilibrio general computable", Red Latinoamericana de Política Comercial.

Coe, D.T. and E. Helpman (1995), "International R\&D spillovers", European Economic Review, No. 39.

Coe, D.T., E. Helpman and A.W. Hoffmaister (1997), "North-South R\&D spillovers", The Economic Journal, No. 107.

De Melo, J. and S. Robinson (1992), "Productivity and externalities: models of export-led growth", Journal of International Trade and Economic Development, No. 1.

Decaluwé, B., J.C. Dumon and L. Savard (1999), "Measuring poverty and inequality in a computable general equilibrium model", Cahier de recherché du CRÉFA, No. 99-20, Université Laval, Québec.

Decaluwé, B., A. Patry, L. Savard and E. Thorbecke (1999), "Poverty analysis within a General Equilibrium Framework", CRÉFAWorking Paper, No. 9909.

Devarajan, S., J.D. Lewis and S. Robinson (1993), "External shocks, purchasing power parity, and the equilibrium real exchange rate", World Bank Economic Review, vol. 7, No. 1.

Duclos, J., A. Arrar and C. Fortin (2004), “DAD: Distributive Analysis", Quebec, Laval University. 
Durán, J.E., C. de Miguel and A.R. Schuschny (2005), "Andean countries and USA: how much can be expected from FTAs?", Comercio Internacional series, No. 77 (LC/L.2678-P), Santiago, Chile, Economic Commission for Latin America and the Caribbean (ECLAC).

ECLAC (Economic Commission for Latin America and the Caribbean) (2006), Social Panorama of Latin America 2005 (LC/G.2288-P/I), Santiago, Chile. United Nations publication, Sales No.E.05.II.G.161.

Foster, J., J. Greer and E. Thorbecke (1984), “A class of decomposable poverty measures", Econometrica, vol. 52, No. 3.

Ganuza, E., R. Paes de Barros and R. Vos (2002), "Labor market adjustment, poverty and inequality during liberalization", Economic Liberalization, Distribution and Poverty, R. Vos, L. Taylor and R. Paes de Barros (eds.), Massachusetts, Edward Elgar Publishing Ltd.

Ganuza, E., S. Morley, S. Robinson and R. Vos (2006), “Are export promotion and trade liberalization good for Latin America's poor?", Who Gains from Free Trade?: Export-led Growth, Inequality and Poverty in Latin America, R. Vos, E. Ganuza and S. Morley (eds.), New York, Routledge.

Giordano, P. (2010), Trade and Poverty in Latin America, Washington, D.C., InterAmerican Development Bank (IDB).

Gracia, H. and O. Zuleta (1997), "The Free Trade Agreement between Colombia and USA: What can happen to Colombia?", unpublished.

Harrison, G.W., T.F. Rutherford and D.G. Tarr (2003), “Trade liberalization, poverty and efficient equity", Journal of Development Economics, No. 71.

Herrera, J. (2001), "Poverty dynamics in Peru, 1997-1999" (DT/2001/09), paper presented at the LACEA/IDB/World Bank Network on inequality and poverty, Rio de Janerio, 11 October 2000.

Karacaovali, B. (2006), "Productivity matters for trade policy: theory and evidence", Policy Research Working Paper, No. 3925, Washington, D.C., World Bank.

Lall, S., M. Albaladejo and M.M. Moreira (2004), "Latin American industrial competitiveness and the challenge of globalization", INTAL-ITD IECI Occasional Paper, No. 05, Washington, D.C., Inter-American Development Bank (IDB).

Light, M.K. (2003), "Acuerdo de Libre Comercio de las Américas: impactos económicos en la Comunidad Andina", document prepared for the Andean Secretariat.

Luduena, C. and S. Wong (2006), "Domestic policies for agriculture in Ecuador and the US-Andean Countries FTA: an applied General Equilibrium Assessment", paper presented at the ninth Annual Conference on Global Trade Analysis, Addis Ababa, 15-17 June.

Martín, C.P. and J.M. Ramírez (2005), "Impacto económico de un cuerdo parcial de libre comercio entre Colombia y Estados Unidos", Estudios y perspectivas series, No. 7 (LC/L.2362-P), Bogota, Economic Commission for Latin America and the Caribbean (ECLAC).United Nations publication, Sales No. S.05.II.G.101.

Monteagudo, J., L. Rojas, A. Stabilito and M. Watanuki (2004), "The New Challenges of the Regional Trade Agenda for the Andean Countries", unpublished.

Morales, C., S. Parada and M. Torres (2005), "Los impactos diferenciados del Tratado de Libre Comercio Ecuador-Estados Unidos sobre la agricultura de Ecuador", Recife, Editora Universitária UFPE. 
Nicita, A. and M. Olarreaga (2001), "Trade and productivity, 1976-99", Policy Research Paper, No. 2701, Washington, D.C., World Bank.

Pardo Reinoso, O., A.A. Perdomo Strauch, C. Delgado González and C. Lozano Karanauskas (2005), “Colombia y el TLC: efectos sobre la distribución del ingreso y la pobreza", Bogota, National Planning Department (DNP).

Polanski, S., (2006), "Winners and Losers: Impact of the Doha Round on Developing Countries", Washington, D.C., Carnegie Endowment for International Peace.

Ravallion. M. (1997), "Can high-inequality developing countries escape absolute poverty?", World Bank Policy Research Working Paper, No. 1775, Washington, D.C., World Bank.

Rodrik, D. (1997), Has Globalization Gone Too Far?, Washington, D.C, Institute of International Economics.

Schiff, M., Y. Wang and M. Olarreaga (2002), "Trade-related technology diffusion and the dynamics of North-South and South-South integration", Policy Research Working Paper, No. 2861, Washington, D.C., World Bank.

Schor, A. (2004), "Heterogeneous productivity response to tariff reduction: evidence from Brazilian manufacturing firms", Journal of Development Economics, vol. 75, No.2.

Tacone, J.J. and U. Nogueira (2002), "Andean Report, Andean Report 1, Volume 1", Buenos Aires, Institute for the Integration of Latin America and the Caribbean (INTAL), Integration and Regional Programs Department, Inter-American Development Bank (IDB).

Taylor, L. and R. von Arnim (2006), "Modeling the Impact of Trade Liberalization: A Critique of Computable General Equilibrium Model", Oxfam International Research Report, July.

Tello, M.D. (2005), "Estudio del impacto económico ex-ante del Tratado de Libre Comercio entre el Perú y los Estados Unidos", Lima, Centro de Negocios, Pontificia Universidad Católica del Perú.

Trybout, J.R., and M.D. Westbrook (1995), "Trade liberalization and the dimensions of efficiency changes in Mexican manufacturing industries", Journal of International Economics, vol. 39, No.1/2.

UDAPE (Unidad de Análisis de Políticas Sociales y Económicas) (2006), "Pobreza y desigualdad en Municipios de Bolivia: estimación del gasto de consumo combinando el Censo 2001 y las encuestas de hogares", La Paz, Economic and Social Policy Analysis Unit of the Plurinational State of Bolivia, second edition, January.

USITC (United States International Trade Commission) (2006), “U.S.-Peru Trade Promotion Agreement: Potential Economy-wide and Selected Sector Effects", Investigation, No. TA-2104-20, Washington, D.C.

Van der Mensbrugghe, D. (2005), "Linkage Technical Reference Document, Development Prospect Group", Washington, D.C., World Bank.

Vélez, C., J. Leibovich, A. Kugler, C. Bouillón and J. Núñez (2005), “The reversal of inequality trends in Colombia, 1978-95: a combination of persistent and fluctuating forces", The Microeconomics of Income Distribution Dynamics in East Asia and Latin America, F. Bourguignon, F.H.G. Ferreira and N. Lusting (eds.), Oxford University Press.

Vos, R. and N. de Jong, (2003), "Trade liberalization and poverty in Ecuador: a CGEmicrosimulation analysis", Economic Systems Research, vol. 15, No. 2, June. 
Winters, L.A., N. McCulloch and A. McKay (2004), “'Trade liberalization and poverty: the evidence so far", Journal of Economic Literature, vol. XLII, March.

WOLA (Washington Office on Latin America) (2004), "Rights and Development", Washington, D.C., October. 


\section{Annex 1}

REGIONS AND COUNTRIES IN THE MODEL

\begin{tabular}{ll}
\hline Region & Country/subregion \\
\hline Western Hemisphere & \\
Canada & Canada \\
United States & United States \\
Mexico & Mexico \\
Central America & Costa Rica, El Salvador, Guatemala, Honduras, Nicaragua \\
Bolivia (Plurinational State of) & Bolivia (Plurinational State of) \\
Colombia & Colombia \\
Ecuador & Ecuador \\
Peru & Peru \\
Venezuela (Bolivarian Republic of) & Venezuela (Bolivarian Republic of) \\
Argentina & Argentina \\
Brazil & Brazil \\
Chile & Chile \\
Rest of WH & Paraguay, Uruguay and countries in the Caribbean subregion \\
\hline Extra-hemispheric region & \\
European Union (25) & Raiwan, Viet Nam \\
& Rest of world \\
Rest of world & Fustria, Belgium, Czech Republic, Cyprus, Denmark, Estonia, \\
China & Latvia, Lithuania, Luxembourg, Malta, Netherlands, Poland, \\
Asia (3) & Portugal, Slovakia, Slovenia, Spain, Sweden, United Kingdom \\
Asia (7) & China \\
& Republic of Korea, Malaysia, Thailand \\
& Hong Kong SAR, Indippines, Singapore, \\
\hline & \\
&
\end{tabular}

Source: Prepared by the authors. 


\section{Annex 2}

SECTORAL CLASSIFICATION IN THE MODEL

\begin{tabular}{|c|c|c|}
\hline & No. Sector & Description \\
\hline \multirow[t]{11}{*}{ I. } & Agriculture & \\
\hline & 1 Paddy rice & Paddy rice \\
\hline & 2 Wheat & Wheat \\
\hline & 3 Cereal grains & Corn, cereal grains, maize, sorghum \\
\hline & 4 Vegetables and fruits & Vegetables and fruits \\
\hline & $5 \quad$ Oil seeds and Soybeans & Oilseeds, soybeans, sunflower \\
\hline & 6 Sugar cane & Sugar cane, sugar beet \\
\hline & 7 Coffee and cocoa & Coffee and cocoa \\
\hline & 8 Livestock & $\begin{array}{l}\text { Bovine cattle, sheep and goats, horses, animal products, } \\
\text { wool, silk-worm cocoons, raw milk }\end{array}$ \\
\hline & 9 Other agricultural products & Plant-based fibres, cotton, jute, raw milk, forestry \\
\hline & 10 Fishing & Fishing \\
\hline
\end{tabular}

\section{Energy}

11 Coal, crude oil and gas

12 Minerals

Coal, crude oil, gas

13 Petroleum

Mineral products (china, glass, cement), minerals (iron ores, tin ores, copper ores)

Petroleum, coal products

\section{Processed foods}
14 Bovine meat
15 Pork and poultry meat
16 Dairy products
17 Processed sugar
18 Other food products
Bovine meat
Pork and poultry meat
Dairy products
Processed sugar
Vegetable oils and fats, processed rice, beverages and tobacco products

\section{Light manufactures}

19 Textiles
20 Wearing apparel
21 Leather products and footwear
22 Other light manufactures

Textiles

Wearing apparel

Leather products, footwear, shoes

Wood products (furniture), paper products, publishing, books, magazines, manufactures nec, toys, jewels

\section{v. Heavy manufactures}

23 Chemical and plastic products

24 Metals and metal products

25 Motor vehicles

Chemical, rubber and plastic products, fertilizers, tyres

Ferrous metals, iron, steel, metal products, cutlery, tools

Motor vehicles and parts, transport equipment (aircraft, trains, ships)

26 Machinery and electrical equip. Electronic equipment, machinery and equipment

\section{Services}

27 Utilities and financial services

28 Construction

29 Trade and tourism

30 Transport and communication
Electricity, gas manufacture, distribution, water, financial services, insurance, business services, public administration, defence, education, health

Construction

Trade, recreational and other services, dwellings

Transport, water transport, air transport, communication

Source: Prepared by the authors.

Note: Sectoral classification follows Global Trade Analysis Project (GTAP). 
Annex 3

IMPACT ON AGGREGATE SECTORAL EXPORTS IN THE ANDEAN COUNTRIES BY SCENARIO

\begin{tabular}{lcccc}
\hline & $\begin{array}{c}\text { Bolivia } \\
\text { (Plur. State of) }\end{array}$ & Colombia & Ecuador & Peru \\
\hline
\end{tabular}

\section{Scenario 1: Andean-US “2+1” FTA}

Paddy rice

Wheat

Cereal grains

$-0.72$

$-4.97$

0.60

Vegetables/fruits

Oilseeds/soybeans

0.14

$-1.70$

$-0.01$

Sugar cane

Coffee/cocoa

0.26

$-0.78$

0.75

Livestock

Other agricultural products

$-5.14$

Fishing

Agriculture

Coal. oil and gas

Minerals

Petroleum

$$
\text { Energy }
$$

Bovine meat

Pork and poultry meat

Dairy products

Processed sugar

Other food products

Processed foods

Textiles

Wearing apparel

Leather products and footwear

Other light manufactures

Light manufactures

Chemical/plastic products

Metals/metal products

Motor vehicles

Machinery/electrical equipment

Heavy manufactures

Total

$-0.76$

0.20

0.21

0.21

$-7.12$

$-2.98$

$-0.06$

$-1.18$

$-1.23$

$-3.20$

0.25

0.15

0.27

$-0.16$

$-1.11$

0.44

0.38

$-0.27$

0.17

$-0.28$

13.02

0.66

0.40

0.65

9.18

1.77

1.33

1.24

1.67

1.27

1.12

1.93

5.73

1.90

2.58

4.40

6.45

4.00

1.76

4.05

2.13

2.86

3.83

0.77

2.25

3.47

0.22

$-5.36$

$-3.87$

$-0.56$

6.85

$-1.41$

2.89

0.28

0.71

0.17

$-0.05$

0.15

$-0.48$

0.18

0.14

0.52

3.75

1.09

1.41

0.69

1.29

2.24

$-7.30$

0.39

2.31

$-4.70$

$-0.10$

$-0.32$

$-4.90$

0.28

$-1.90$

$-0.59$

$-1.62$

$-2.58$

$-1.65$

$-1.56$

$-1.68$

$-1.99$

$-0.28$

25.83

1.36

1.74

6.10

4.73

2.67

0.95

3.85

0.93

2.39

1.33

$-0.02$

2.14

2.26

\section{Scenario 2-A: No ATPDEA}

Paddy rice
Wheat
Cereal grains
Vegetables/fruits
Oilseeds/soybeans
Sugar cane
Coffee/cocoa
Livestock
Other agricultural products
Fishing
$\quad$ Agriculture

Paddy rice

Wheat

Cereal grains
Vegetables/fruits

0.07

$-1.05$

0.20

0.03

$-0.79$

$-0.04$

$-0.78$

0.01

0.20

0.21

0.05

$-0.04$

0.06

$-2.44$

0.02

$-0.16$

$\begin{array}{ll}0.14 & 0.02\end{array}$

$-0.05$

$-0.66$

$-0.34$

0.02

0.05
$-0.04$

0.03

$-0.09$

$-0.43$

0.02

0.03 
Annex 3 (continued)

\begin{tabular}{lccrr}
\hline & $\begin{array}{c}\text { Bolivia } \\
\text { (Plur. State of) }\end{array}$ & Colombia & Ecuador & Peru \\
\hline Coal. oil and gas & 0.23 & 0.01 & 0.24 & 0.02 \\
Minerals & 0.03 & 0.00 & -3.59 & 0.01 \\
Petroleum & & 0.01 & 0.19 & 0.02 \\
$\quad$ Energy & 0.12 & 0.01 & 0.16 & 0.01 \\
Bovine meat & 0.34 & 0.02 & & 0.02 \\
Pork and poultry meat & & -0.14 & 0.44 & \\
Dairy products & 0.33 & 0.00 & 0.36 & 0.02 \\
Processed sugar & -5.92 & 0.00 & -1.95 & 0.03 \\
Other food products & 0.15 & -0.02 & -1.91 & 0.01 \\
$\quad$ Processed foods & 0.10 & -0.02 & -1.86 & 0.01 \\
Textiles & -9.82 & -0.05 & -1.91 & -0.01 \\
Wearing apparel & -15.77 & 0.03 & -16.57 & 0.02 \\
Leather products and footwear & 0.03 & 0.00 & 0.19 & -0.02 \\
Other light manufactures & -2.20 & -0.02 & -0.77 & 0.00 \\
$\quad$ Light manufactures & -4.18 & -0.01 & -2.50 & 0.01 \\
Chemical/plastic products & -0.50 & -0.02 & -0.05 & -0.05 \\
Metals/metal products & -1.13 & 0.02 & -0.53 & 0.03 \\
Motor vehicles & -2.31 & -0.02 & 0.47 & 0.02 \\
Machinery/electrical equipment & 0.32 & 0.00 & 0.38 & 0.00 \\
$\quad$ Heavy manufactures & -0.71 & -0.01 & 0.12 & 0.02 \\
$\quad$ Total & $-\mathbf{0 . 6 4}$ & $\mathbf{0 . 0 1}$ & $\mathbf{- 0 . 8 1}$ & $\mathbf{0 . 0 2}$
\end{tabular}

\section{Scenario 2-B: Andean-US “2+1" FTA plus reversal of ATPDEA}

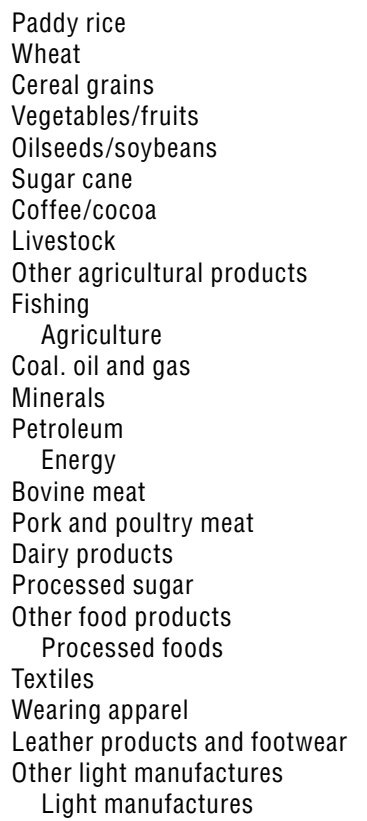

$\begin{array}{rrrr}-0.64 & & -5.01 & 0.61 \\ -0.91 & 0.02 & -0.56 & 0.80 \\ -1.50 & -1.56 & -5.16 & -3.90 \\ & & & \\ 0.24 & 13.10 & -2.96 & 6.89 \\ & 0.67 & -1.59 & 2.79 \\ -5.01 & 0.42 & 0.24 & 0.27 \\ & 0.67 & -0.50 & 0.54 \\ -1.10 & 9.24 & -1.17 & 3.79 \\ 0.43 & 1.78 & 0.39 & 1.11 \\ 0.24 & 1.33 & -4.10 & 1.43 \\ & 1.25 & 0.36 & 0.70 \\ 0.33 & 1.68 & 0.30 & 1.31 \\ -6.80 & 1.29 & & 2.26 \\ & 0.97 & -6.88 & \\ -2.66 & 1.92 & 0.75 & 2.33 \\ -5.98 & 5.73 & -6.69 & 25.87 \\ -1.04 & 1.88 & -2.02 & 1.38 \\ -1.13 & 2.56 & -2.19 & 1.76 \\ -13.20 & 4.35 & -6.93 & 6.09 \\ -15.54 & 6.48 & -16.31 & 4.75 \\ 0.18 & 3.99 & -1.71 & 2.66 \\ -1.93 & 1.74 & -1.37 & 0.95 \\ -4.37 & 4.04 & -4.15 & 3.86 \\ & & & \end{array}$


Annex 3 (continued)

\begin{tabular}{lcccr}
\hline & $\begin{array}{c}\text { Bolivia } \\
\text { (Plur. State of) }\end{array}$ & Colombia & Ecuador & Peru \\
\hline Chemical/plastic products & -1.62 & 2.11 & -2.65 & 0.89 \\
Metals/metal products & -0.69 & 2.89 & -2.19 & 2.42 \\
Motor vehicles & -1.94 & 3.81 & -1.10 & 1.35 \\
Machinery/electrical equipment & 0.06 & 0.73 & -1.30 & -0.02 \\
$\quad$ Heavy manufactures & -0.55 & 2.23 & -1.87 & 2.16 \\
Total & $\mathbf{- 0 . 9 2}$ & $\mathbf{3 . 4 8}$ & $\mathbf{- 1 . 1 0}$ & $\mathbf{2 . 2 8}$
\end{tabular}

Scenario 3: Andean-US “4+1" FTA

Paddy rice

Wheat

Cereal grains

$-0.42$

Vegetables/fruits

0.46

0.05

$-4.28$

$-4.84$

0.60

Oilseeds/soybeans

$-1.36$

0.87

0.72

Sugar cane

Coffee/cocoa

2.90

12.95

$-5.09$

$-4.10$

Livestock

Other agricultural products

0.73

13.44

6.70

Fishing

Agriculture

$-4.46$

0.48

$-0.02$

1.88

1.05

0.19

$-0.12$

0.69

0.51

Coal. oil and gas

9.14

3.63

0.42

1.75

Minerals

0.83

1.15

1.02

Petroleum

1.00

1.32

Energy

0.64

1.61

Bovine meat

$-6.14$

1.37

Pork and poultry meat

$-1.20$

0.55

0.20

1.19

0.45

2.13

Dairy products

$-1.89$

1.96

$-5.71$

Processed sugar

5.51
1.54

Other food products

24.87

2.20

$-0.80$

2.25

25.68

Processed foods

$-0.61$

3.32

Textiles

4.44

Wearing apparel

3.98

6.35

1.52

3.87

2.15

1.34

5.67

1.70

1.95

5.51

$-3.12$

4.58

1.25

0.94

2.37

Other light manufactures

3.49

4.95

0.62

1.92

$-0.32$

3.50

Chemical/plastic products

1.60

$-0.38$

0.12

2.44

2.68

2.22

Motor vehicles

0.28

2.74

1.27

$-0.18$

$-0.94$

-0.50
1.35

$-1.08$

$-1.29$

1.88

Heavy manufactures

1.49

$-0.99$

2.07

\section{Scenario 4: Andean-MERCOSUR FTA}

Paddy rice

Wheat

Cereal grains

0.07

3.14

1.67

Vegetables/fruits

Oilseeds/ soybeans

1.43

$-1.74$

0.67

0.35

0.02

0.50

Sugar cane

Coffee/cocoa

0.93

1.08

0.91

0.97 
Annex 3 (continued)

\begin{tabular}{lcccr}
\hline & $\begin{array}{c}\text { Bolivia } \\
\text { (Plur. State of) }\end{array}$ & Colombia & Ecuador & Peru \\
& & & & \\
\hline Livestock & & 0.23 & 0.06 & 1.29 \\
Other agricultural products & -1.11 & 0.83 & 0.78 & -1.76 \\
Fishing & & 0.58 & 0.56 & 0.59 \\
$\quad$ Agriculture & -0.04 & 0.95 & 1.16 & 0.78 \\
Coal. oil and gas & 0.98 & 0.72 & 0.46 & 0.63 \\
Minerals & 1.17 & 0.98 & 0.39 & 2.63 \\
Petroleum & & 0.75 & 0.48 & 0.72 \\
$\quad$ Energy & 1.08 & 0.75 & 0.46 & 2.26 \\
Bovine meat & -5.70 & 0.31 & & 0.75 \\
Pork and poultry meat & & 0.65 & 0.07 & \\
Dairy products & -0.53 & -1.33 & 0.91 & 1.21 \\
Processed sugar & 1.47 & 0.19 & 0.31 & 1.01 \\
Other food products & -0.68 & 0.48 & 1.79 & 0.95 \\
$\quad$ Processed foods & -0.68 & 0.34 & 1.73 & 0.94 \\
Textiles & -0.08 & 1.71 & -0.82 & 1.77 \\
Wearing apparel & 6.25 & 2.29 & 0.84 & 1.11 \\
Leather products and footwear & 0.62 & 0.29 & -1.18 & 0.48 \\
Other light manufactures & 2.35 & 1.51 & 0.55 & 2.42 \\
$\quad$ Light manufactures & 2.25 & 1.69 & 0.16 & 1.76 \\
Chemical/plastic products & 1.81 & 2.75 & 0.28 & 1.63 \\
Metals/metal products & 3.10 & 0.19 & -0.72 & 3.70 \\
Motor vehicles & 25.54 & -2.52 & -3.19 & -0.55 \\
Machinery/electrical equipment & 9.87 & 1.44 & 0.88 & 3.38 \\
$\quad$ Heavy manufactures & 6.00 & 1.34 & -0.60 & 3.50 \\
Total & $\mathbf{1 . 7 0}$ & $\mathbf{1 . 0 5}$ & $\mathbf{0 . 8 4}$ & $\mathbf{2 . 3 7}$ \\
& & & &
\end{tabular}

Scenario 5-A: Andean-EU full FTA

Paddy rice
Wheat
Cereal grains
Vegetables/fruits
Oilseeds/soybeans
Sugar cane
Coffee/cocoa
Livestock
Other agricultural products
Fishing
Agriculture
Coal. oil and gas
Minerals
Petroleum
Energy
Bovine meat
Pork and poultry meat
Dairy products
Processed sugar
Other food products
Processed foods

41.07

13.98

0.64

3.39

1.17

7.69

0.51

1.32

0.94

$-2.49$

$-4.87$

1.11

$-3.08$

$-3.08$
18.83

3.70

1.74

$-0.79$

0.60

2.22

6.08

1.17

0.55

1.00

1.08

152.67

61.18

7.84

$-0.86$

6.42

7.15
$-0.27$

15.59

60.43

$-0.53$

0.79

$-0.32$

$-1.36$

$-0.32$

3.10

4.64

0.43

0.27

1.72

11.21

5.93

$-0.29$

0.27

$\begin{array}{ll}-0.87 & 1.07\end{array}$

$\begin{array}{ll}-0.15 & 0.42\end{array}$

$-0.29$

$-5.04$

0.94

112.15

$0.05 \quad 1.31$

$-1.10$

1.35

7.46

6.60

14.28 
Annex 3 (concluded)

\begin{tabular}{lccrr}
\hline & $\begin{array}{c}\text { Bolivia } \\
\text { (Plur. State of) }\end{array}$ & Colombia & Ecuador & Peru \\
\hline Textiles & 4.61 & 2.79 & -1.97 & 5.47 \\
Wearing apparel & 4.38 & 3.60 & 8.30 & 6.16 \\
Leather products and footwear & 12.85 & 6.42 & -0.45 & 7.39 \\
Other light manufactures & 1.24 & -0.46 & -1.29 & -0.31 \\
$\quad$ Light manufactures & 3.16 & 2.18 & -0.50 & 3.76 \\
Chemical/plastic products & 0.57 & 0.41 & -2.97 & -0.37 \\
Metals/metal products & 4.29 & 2.05 & -2.49 & 2.76 \\
Motor vehicles & 1.10 & -1.56 & -5.96 & -0.28 \\
Machinery/electrical equipment & 0.20 & -1.51 & -1.59 & -1.01 \\
$\quad$ Heavy manufactures & 2.78 & 0.19 & -3.36 & 2.31 \\
$\quad$ Total & $\mathbf{1 . 0 1}$ & $\mathbf{2 . 2 8}$ & $\mathbf{4 . 4 2}$ & $\mathbf{4 . 7 8}$
\end{tabular}

Scenario 5-B: Andean-EU partial FTA without sensitive agriculture

$\begin{array}{lrrrr}\begin{array}{l}\text { Paddy rice } \\ \text { Wheat }\end{array} & & & & \\ \text { Cereal grains } & 0.42 & & -0.29 & 0.70 \\ \text { Vegetables/fruits } & 14.08 & 19.00 & 15.65 & 8.58 \\ \text { Oilseeds/soybeans } & 0.39 & 3.81 & -0.61 & 0.85 \\ \text { Sugar cane } & & & & \\ \text { Coffee/cocoa } & 3.55 & 2.00 & -0.27 & 3.37 \\ \text { Livestock } & & -0.76 & -1.48 & 4.39 \\ \text { Other agricultural products } & 0.65 & 0.64 & -0.26 & 0.41 \\ \text { Fishing } & & 2.36 & 0.32 & 1.81 \\ \quad \text { Agriculture } & 6.30 & 6.31 & 11.27 & 5.58 \\ \text { Coal. oil and gas } & 0.59 & 1.23 & -0.24 & 0.52 \\ \text { Minerals } & 1.40 & 0.63 & -0.82 & 1.39 \\ \text { Petroleum } & & 1.05 & -0.10 & 0.60 \\ \quad \text { Energy } & 1.02 & 1.14 & -0.24 & 1.23 \\ \text { Bovine meat } & 0.66 & -1.63 & & 1.61 \\ \text { Pork and poultry meat } & & -2.36 & -5.19 & \\ \text { Dairy products } & & -9.00 & 0.10 & 1.63 \\ \text { Processed sugar } & -5.12 & -0.79 & -1.11 & 1.45 \\ \text { Other food products } & 1.17 & 6.50 & 7.52 & 6.78 \\ \quad \text { Processed foods } & -3.08 & 4.23 & 7.11 & 6.31 \\ \text { Textiles } & -3.08 & 2.92 & -1.94 & 6.07 \\ \text { Wearing apparel } & 4.61 & 8.37 & 6.79 \\ \text { Leather products and footwear } & 4.46 & 3.71 & -0.47 & 7.76 \\ \text { Other light manufactures } & 12.92 & 6.52 & -1.26 & 0.16 \\ \quad \text { Light manufactures } & 1.32 & -0.38 & -0.47 & 4.32 \\ \text { Chemical/plastic products } & 3.22 & 2.28 & -2.98 & 0.00 \\ \text { Metals/metal products } & 0.53 & 0.51 & -2.50 & 3.35 \\ \text { Motor vehicles } & 4.42 & 2.17 & -5.91 & 0.35 \\ \text { Machinery/electrical equipment } & 1.20 & -1.45 & -1.56 & -0.47 \\ \quad \text { Heavy manufactures } & 0.27 & -1.41 & -3.34 & 2.87 \\ \quad \text { Total } & 2.88 & 0.29 & \mathbf{3 . 6 2} \\ \text { - } & \mathbf{0 . 9 8} & \mathbf{2 . 1 7} & \mathbf{4 . 4 7} & \end{array}$

Source: Inter-American Development Bank (IDB), IDB-INT Andean model simulations. 


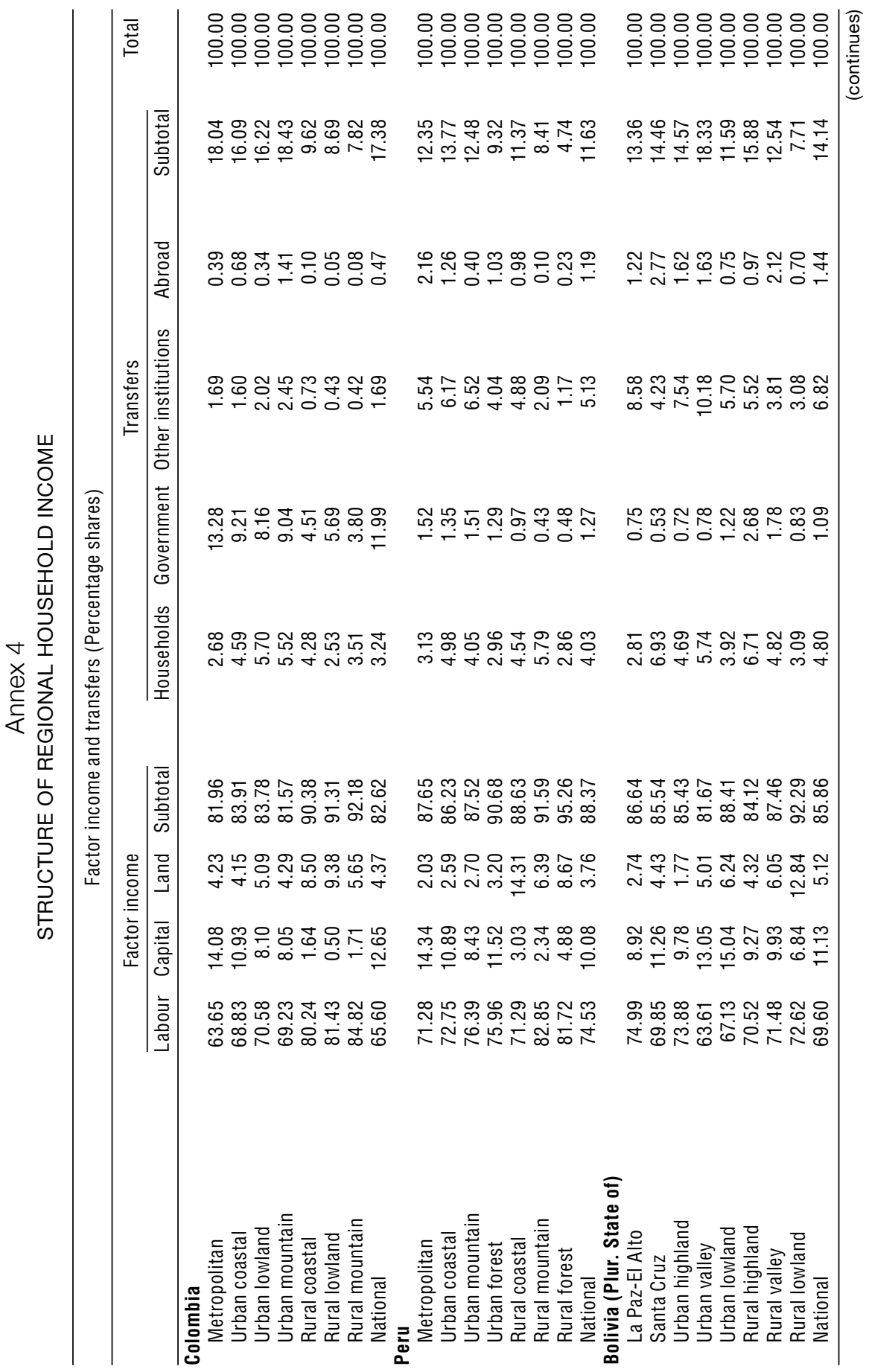




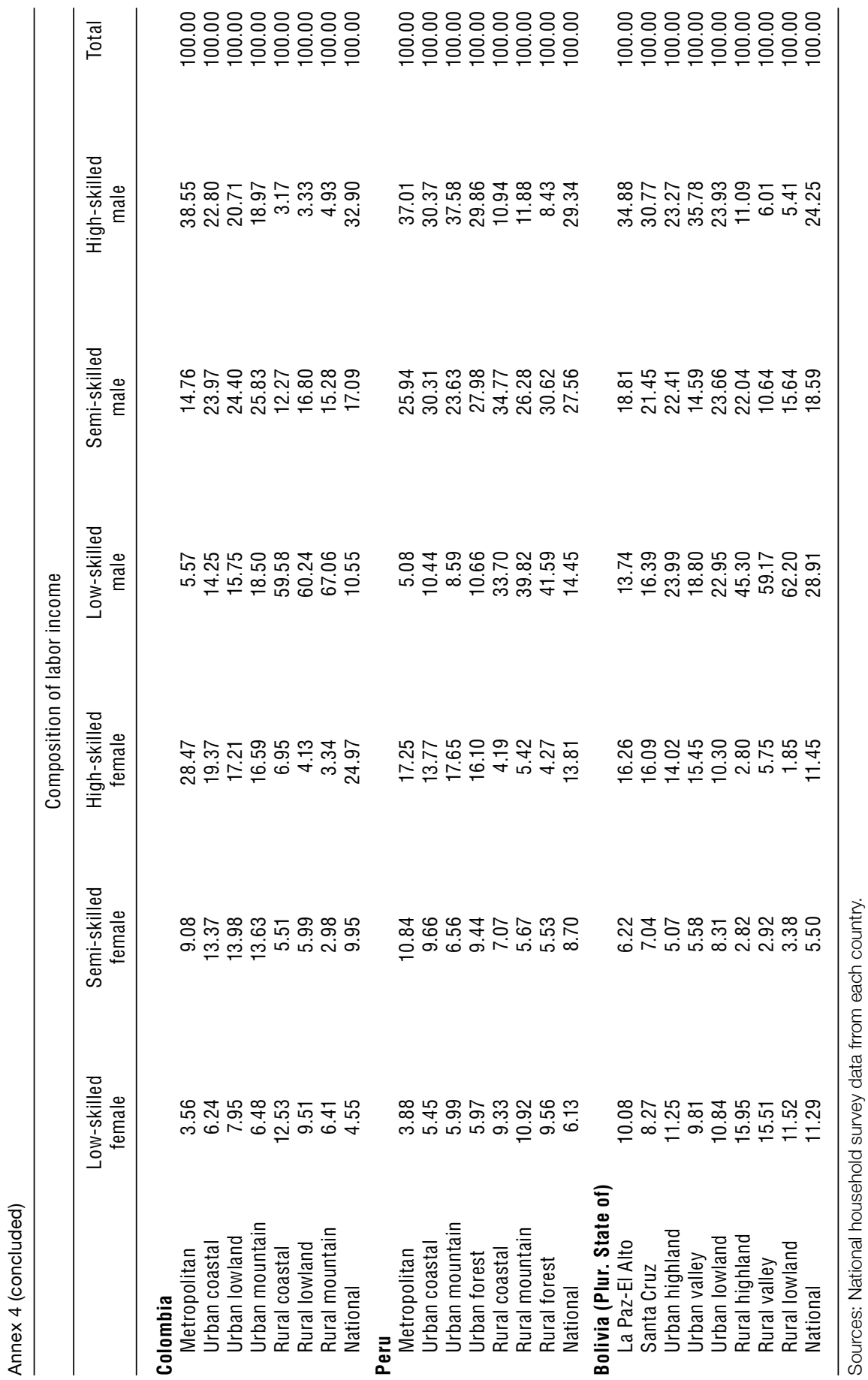




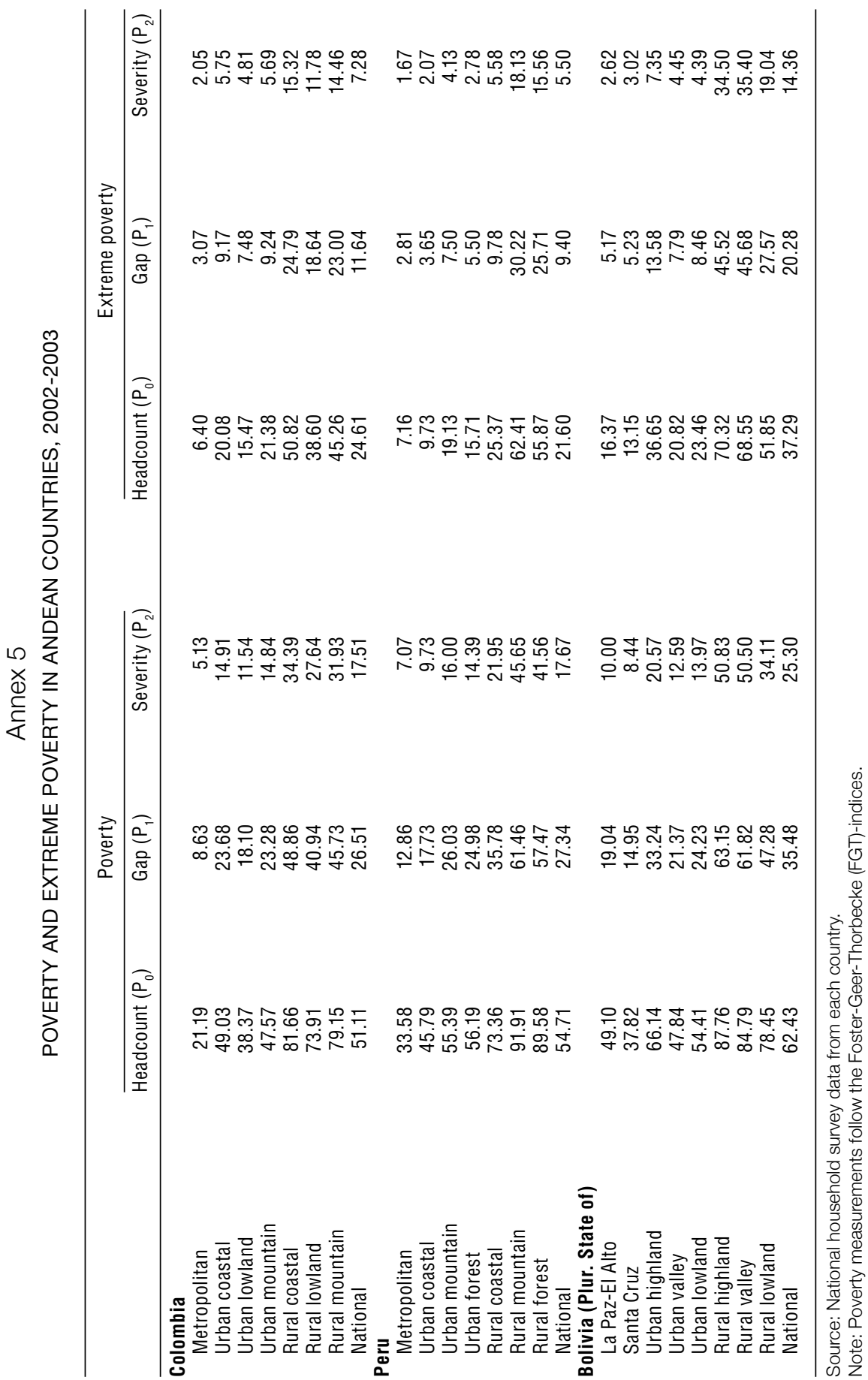


Annex 6

HOUSEHOLD INEQUALITY IN THE ANDEAN COUNTRIES BY REGION, 2002-2003

\begin{tabular}{|c|c|c|c|}
\hline & \multirow{2}{*}{$\begin{array}{l}\text { Mean income ratio } \\
\text { Regional vs. national }\end{array}$} & \multicolumn{2}{|c|}{ Inequality index } \\
\hline & & Theil & Gini \\
\hline \multicolumn{4}{|l|}{ Colombia } \\
\hline Metropolitan & 2.075 & 0.767 & 0.572 \\
\hline Urban coastal & 1.000 & 0.656 & 0.572 \\
\hline Urban lowland & 1.046 & 0.496 & 0.515 \\
\hline Urban mountain & 0.919 & 0.570 & 0.539 \\
\hline Rural coastal & 0.363 & 0.518 & 0.514 \\
\hline Rural lowland & 0.452 & 0.474 & 0.503 \\
\hline Rural mountain & 0.387 & 0.481 & 0.503 \\
\hline National & 1.000 & 0.779 & 0.600 \\
\hline \multicolumn{4}{|l|}{ Peru } \\
\hline Metropolitan & 1.498 & 0.454 & 0.478 \\
\hline Urban coastal & 1.066 & 0.345 & 0.426 \\
\hline Urban mountain & 0.952 & 0.453 & 0.484 \\
\hline Urban jungle & 0.905 & 0.361 & 0.446 \\
\hline Rural coastal & 0.624 & 0.415 & 0.430 \\
\hline Rural mountain & 0.323 & 0.435 & 0.474 \\
\hline Rural jungle & 0.360 & 0.408 & 0.465 \\
\hline National & 1.000 & 0.516 & 0.514 \\
\hline \multicolumn{4}{|c|}{ Bolivia (Plur. State of) } \\
\hline La Paz-El Alto & 1.388 & 0.591 & 0.524 \\
\hline Santa Cruz & 1.462 & 0.387 & 0.458 \\
\hline Urban highland & 0.832 & 0.439 & 0.479 \\
\hline Urban valley & 1.421 & 0.586 & 0.527 \\
\hline Urban lowland & 1.226 & 0.538 & 0.519 \\
\hline Rural highland & 0.420 & 0.823 & 0.630 \\
\hline Rural valley & 0.421 & 0.703 & 0.620 \\
\hline Rural lowland & 0.590 & 0.512 & 0.527 \\
\hline National & 1.000 & 0.666 & 0.576 \\
\hline
\end{tabular}

Source: National household survey data from each country.

Note: Average weighted by the population. 


\section{Annex 7}

IMPACT OF ANDEAN-UNITED STATES TRADE AGREEMENTS

ON INCOME INEQUALITY

(Percentage changes from base)

\begin{tabular}{lccr}
\hline & Mean income ratio & \multicolumn{2}{c}{ Inequality index } \\
\cline { 2 - 4 } & Regional vs. national & Theil & Gini \\
\hline Colombia & & & \\
Metropolitan & & 0.04 & -0.03 \\
Urban coastal & 0.36 & -0.05 & -0.06 \\
Urban lowland & 0.43 & -0.15 & -0.10 \\
Urban mountain & 0.42 & -0.11 & -0.10 \\
Rural coastal & 0.56 & -0.34 & -0.27 \\
Rural lowland & 0.60 & -0.40 & -0.31 \\
Rural mountain & 0.63 & -0.48 & -0.34 \\
National & 0.42 & -0.06 & -0.07 \\
Peru & & & \\
Metropolitan & & & -0.02 \\
Urban coastal & 0.36 & -0.11 & -0.01 \\
Urban mountain & 0.35 & -0.10 & -0.08 \\
Urban jungle & 0.37 & -0.24 & -0.04 \\
Rural coastal & 0.41 & -0.15 & 0.06 \\
Rural mountain & 0.43 & 0.24 & -0.08 \\
Rural jungle & 0.44 & -0.21 & -0.18 \\
National & 0.40 & -0.39 & -0.03 \\
Bolivia (Plur. State of) & 0.36 & -0.11 & \\
La Paz-El Alto & & & 0.36 \\
Santa Cruz & & & 0.14 \\
Urban highland & -0.32 & 0.63 & 0.21 \\
Urban valley & -0.12 & 0.28 & 0.12 \\
Urban lowland & -0.18 & 0.35 & 0.20 \\
Rural highland & -0.27 & 0.25 & 0.08 \\
Rural valley & -0.17 & 0.29 & 0.20 \\
Rural lowland & -0.43 & 0.28 & 0.23 \\
National & -0.28 & 0.39 & \\
& -0.39 & & \\
\hline
\end{tabular}

Source: Inter-American Development Bank (IDB) IDB-INT Andean model simulation and microsimulation. 
Chapter III

\section{Central America - European Union Association Agreement: an assessment using general and partial equilibrium}

José E. Durán Lima

Carlos Ludeña

Mariano Alvarez

Carlos J. de Miguel

\section{A. Introduction}

After the United States, the European Union is the main trading partner of Central American countries (Costa Rica, El Salvador, Guatemala, Honduras and Nicaragua). Since October 2007, the countries that make up the Central American Common Market have been working towards concluding an Association Agreement with the European Union. In recent years, Central American countries have stepped up the process of trade opening, with each State signing free trade agreements with the United States.

Between the end of 2007 and mid-2008, four rounds of negotiations were held, and the countries made significant progress in cooperation and political dialogue and reached agreements on topics such as democracy, good governance, human rights and the information society. In trade matters, and in terms of tariff reductions, Central American countries and the European 
Union exchanged two different lists. The Central American list covers around $80 \%$ of all tariff lines for the countries. The European Union, for its part, is hoping for the liberalization of up to $90 \%$ of all tariff lines, and is offering in exchange a full consolidation of its Generalised System of Preferences Plus (GSP+), except for a few products including ethanol, frozen shrimp, oranges, mandarins, lemons, tomatoes, pears, pulses and leather hides, among others.

This paper assesses the socio-economic and environmental impact of the agreement under negotiation, by applying the complementary economic approaches of computable general equilibrium (CGE) and partial equilibrium (PE). In the first approach, CGE, the cases of Costa Rica, Guatemala and Nicaragua are covered separately, while the rest of the countries are covered in aggregate form (including Belize, El Salvador and Honduras). The inclusion of the PE approach makes it possible to carry out analyses for El Salvador and Honduras, at least in terms of the potential effects of the trade generated by the agreement on welfare and trade.

Although computable general equilibrium and partial equilibrium exercises shed light on the changes resulting from trade policy through the simulated implementation of an Association Agreement, readers should be aware that the two approaches are not free from various criticisms and limitations. The results must therefore be analysed with caution when it comes to drawing general conclusions about the advantages and disadvantages of trade liberalization in each specific country. The results of this kind of exercise, based on ceteris paribus assumptions, could be skewed by the static nature of the scenarios simulated, most of the sectoral aggregation, the implicit assumption that governments will not attempt to take advantage of benefits or support losing sectors, as well as the exclusion of non-trade aspects such as investment, services, intellectual property and quality standards. The methodology is nonetheless relevant as a means of estimating the results of implementing this type of agreement.

To provide results that support the task of negotiators, shed light on the intersectoral realignment and the possible "winning" and "losing" sectors and identify the main products to benefit from the agreement, the sensitivities of the production sectors in both regions were considered. Three simulated scenarios were therefore analysed: full liberalization, liberalization with the exclusion of all sensitive products on both sides and liberalization with the European Union excluding "fruits and vegetables" from the agreement.

The results show that, in general, a full liberalization for all tariff lines would favour both regions by promoting the expansion of exports of all countries signing the agreement by between $1 \%$ and $5 \%$, and, 
especially, in the case of Central America, of agricultural products and to some extent light manufactures. The obtainment of such results is corroborated by those derived from the partial equilibrium approach. Full liberalization would improve welfare for all negotiating countries, and would be especially significant for Costa Rica. This improved welfare would stem from the improvement of terms of trade owing to higher export prices for Central American agricultural products, in particular fruits and vegetables and other crops. The scenario excluding sensitive products shows little change in trade, although any change would be positive. When the European Union excludes fruits and vegetables, results for trade and output remain positive, although less so than under full liberalization.

The aim of this study is to determine the effects of a free trade agreement between Central American countries (in particular, Costa Rica, Guatemala and Nicaragua) and the European Union, using the Global Trade Analysis Project (GTAP) computable general equilibrium model and a partial equilibrium model.

The document is organized as follows: First, the Central American integration process and the pattern of trade relations between Central America and the European Union are analysed. Then the methodologies and data used, including the trade liberalization scenarios and assumptions considered, are explained. Third, the results are presented, with an emphasis placed on macroeconomic and sectoral variables. Lastly, possible conclusions and trade policy recommendations are discussed.

\section{B. Regional integration, international integration patterns and trade policy developments}

The countries of Central America are small and medium-sized. Because of its particular characteristics, the region has been opening up to international trade and strengthening linkages with the global economy since the mid-1990s. Trade liberalization and openness to foreign direct investment have contributed to this process. Although five of the region's countries (Costa Rica, El Salvador, Honduras, Guatemala and Nicaragua) have had de jure integration since 1960, in the form of the Central American Common Market (CACM), in practice the wider process of liberalization only began to gather speed in the early 1990s, boosted by: (a) unilateral liberalization; (b) the conclusion of bilateral and multilateral agreements; and (c) preferential access conditions in industrialized countries, particularly the United States and the European Union, through their Generalized Systems of Preferences. 
All of these factors have shaped the trade policy structure of Central America as we know it, which includes 12 trade agreements currently in force, covering just over $73 \%$ of its total exports. Central American countries as a whole display an openness coefficient of $34 \%$, which is slightly higher than that of the 27 European Union countries. Table III.1 shows the differences in per capita output between the CACM and the European Union, as the former has a price level three times higher than the latter and an extremely low share of world exports. These small economies are thus price takers and more vulnerable than European Union countries, which account for almost a third of world exports.

Below is a chronological account of how these factors interact with the current trade pattern of the subregion of Central America.

Table III.1

CENTRAL AMERICAN COMMON MARKET (CACM) AND THE EUROPEAN UNION: MAIN MACROECONOMIC AND TRADE VARIABLES, 2007 AND AUGUST 2008

\begin{tabular}{|c|c|c|c|c|c|c|c|}
\hline Region/country & 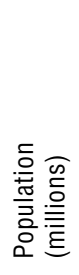 & 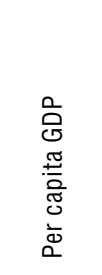 & 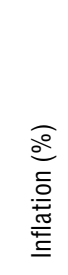 & 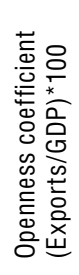 & 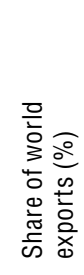 & 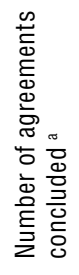 & 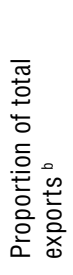 \\
\hline CACM & 37.7 & 2009 & 9.5 & 34.4 & 0.22 & 12 & 73.5 \\
\hline Costa Rica & 4.5 & 5041 & 10.1 & 42.1 & 0.08 & 8 & 56.9 \\
\hline El Salvador & 7.1 & 2249 & 6.2 & 25.0 & 0.03 & 6 & 89.3 \\
\hline Guatemala & 13.3 & 1658 & 9.6 & 31.3 & 0.06 & 6 & 80.8 \\
\hline Honduras & 7.2 & 1419 & 9.1 & 32.6 & 0.03 & 6 & 78.9 \\
\hline Nicaragua & 5.6 & 877 & 12.8 & 47.1 & 0.02 & 5 & 84.6 \\
\hline European Union (27) & 495 & 24800 & 2.3 & 31.6 & 32.37 & 20 & 75.3 \\
\hline
\end{tabular}

Source: Prepared by the author, on the basis of information from the Economic Commission for Latin America and the Caribbean (ECLAC), the Secretariat for Central American Economic Integration (SIECA), the European Commission and the Statistical Office of the European Communities (EUROSTAT).

a For CACM, this includes the following in addition to the integration agreement: Central America - Dominican Republic - United States (CAFTA-DR);Canada - Costa Rica; Central America - Panama; Central America Dominican Republic; Costa Rica - Mexico; Nicaragua - Mexico; El Salvador, Guatemala, Honduras - Mexico; Central America - Chile; Caribbean Community (CARICOM) - Costa Rica; Guatemala -Taiwan Province of China; Nicaragua -Taiwan Province of China; and El Salvador, Guatemala and Honduras -Taiwan Province of China. For the European Union 27, this includes the list of agreements in annex 5.

b Intra-European Union trade amounts to $68.1 \%$. 


\section{Regional integration and trade policy in Central America}

Because of their small size, as far back as the 1960s the countries of the CACM set out to achieve full regional integration by creating a free trade area and a common external tariff. Although the main objective was to establish a customs union, this did not come to fruition, and progress was made only in enhancing the free trade area.

In the early 1990s, the CACM and Panama set up and consolidated the Central American Integration System (SICA), an institutional initiative aimed at achieving Central American integration. ${ }^{1}$ From the mid-1990s, the Central American countries made progress with their strategy to receive broader preferences through free trade agreements. As a group, they concluded group negotiations with Chile, the Dominican Republic and Mexico. Costa Rica concluded negotiations with Canada, Trinidad and Tobago and the Caribbean Community (CARICOM). Lastly, in late 2003 and early 2004, the countries completed negotiations with their main trading partner, the United States. They have thus succeeded in extending preferences to just over $73 \%$ of their total exports (see table III.2), and negotiations are actively under way for them to increase by $12 \%$ the exports covered by preferences in the European Union, Canada and Andean countries.

In summary, then, the trade policy of Central American countries promotes a variable geometry (differentiated integration) system and seeks to open third markets to the subregion's products. It is thus understandable that the region should have adopted an attentive and active stance in multilateral negotiations and signed the various trade agreements referred to above. Consequently, the negotiations with the European Union are very important, given that this is an important source of capital goods and the destination of a tenth of total Central American exports.

On 13 December 1991, Costa Rica, El Salvador, Guatemala, Honduras, Nicaragua and Panama signed the Tegucigalpa Protocol to the Charter of the Organization of Central American States (ODECA). This Protocol defined the institutional structure of the regional bloc. For further information on regional integration developments, see: SIECA (2005 and 2008) and Durán and Maldonado (2005). 
Table III.2

CENTRAL AMERICAN COMMON MARKET (CACM): EXTERNAL RELATIONS (Up to August 2008)

\begin{tabular}{|c|c|c|}
\hline $\begin{array}{l}\text { Agreements concluded } \\
\text { and percentage of total exports }\end{array}$ & $\begin{array}{l}\text { Free trade agreements or } \\
\text { association agreements } \\
\text { currently under negotiation } \\
\text { (and projected \% of exports) }\end{array}$ & $\begin{array}{l}\text { Other types of } \\
\text { agreements }\end{array}$ \\
\hline $\begin{array}{l}\text { Canada - Costa Rica (2001) } \\
\text { Costa Rica - CARICOM (2003) } \\
\text { Costa Rica - Mexico (1994) } \\
\text { Costa Rica - Trinidad and Tobago (2002) } \\
\text { El Salvador and Honduras - Taiwan } \\
\text { Province of China (2008) } \\
\text { Guatemala - Taiwan Province of China } \\
\quad(2005) \\
\text { CACM - Chile (1999) } \\
\text { CACM - United States (2003 and 2004) } \\
\text { CACM - Panama (2002) } \\
\text { CACM - Dominican Republic (1998) } \\
\text { Mexico - Nicaragua (1998) } \\
\text { Nicaragua - Taiwan Province of China } \\
\text { (2008) } \\
\text { Northern Triangle (El Salvador, Guatemala, } \\
\text { Honduras) - Mexico (2000) }\end{array}$ & $\begin{array}{l}\text { El Salvador, Guatemala } \\
\text { and Honduras - Andean } \\
\text { Community (negotiated by } \\
\text { the General Secretariat of the } \\
\text { Andean Community, SGCAN, } \\
\text { and SIECA) } \\
\text { El Salvador, Guatemala, } \\
\text { Honduras and Nicaragua - } \\
\text { Canada } \\
\text { CACM - European Union } 27\end{array}$ & $\begin{array}{l}\text { CACM - CARICOM } \\
\text { (Cooperation } \\
\text { framework programme } \\
\text { since 1992) } \\
\text { CACM - European } \\
\text { Union (political } \\
\text { dialogue and } \\
\text { cooperation agreement } \\
\text { since December } \\
\text { 2003) } \\
\text { CACM - Andean } \\
\text { Community (with } \\
\text { a political dialogue } \\
\text { and cooperation } \\
\text { mechanism)c }\end{array}$ \\
\hline $73.5 \%$ & $12.1 \%$ & \\
\hline
\end{tabular}

Source: Prepared by the author, on the basis of information from the Latin American Integration Association (ALADI), the Secretariat for Central American Economic Integration (SIECA), the General Secretariat of the Andean Community and trade statistics from the United Nations Commodity Trade Database (COMTRADE).

a Includes intraregional preferences.

b Since 2007, the countries have been negotiating an Association Agreement with the European Union.

c An important issue in this partnership is cooperation between the Initiative for the Integration of Regional Infrastructure in South America (IIRSA) and the Puebla-Panama Plan, which was recently renamed the MesoAmerican Initiative.

\section{Central American trade patterns}

Over $60 \%$ of total exports from CACM countries are raw materials, and a significant proportion are natural-resource-based manufactures. These two types of products account for around 70\% of the group's total exports. Guatemala, Honduras and Nicaragua have the highest exports of raw materials and especially agricultural products such as coffee, bananas and fish products. The trade patterns of Costa Rica and El Salvador feature more manufactures, especially medium- and lowtechnology manufactures. This is particularly true of Costa Rica, which is replacing its export structure intensively based on raw materials with one based on electronics and medical equipment. However, most of these exports are attributable to the enterprise Intel (Rodríguez-Clare, 2001). 
The main destination market for Central American exports is the United States, which accounts for over $40 \%$ of the group's total exports. The United States is followed by Latin America and the Caribbean and the European Union (see figure III.1). As for the export pattern in the main target countries, a high portion of total exports are raw materials exports to various Latin American and Caribbean countries. The largest proportion of primary products goes to the European Union (see table III.3).

Figure III.1

CENTRAL AMERICAN COMMON MARKET: TRADE PATTERN, MAIN SECTORS BY TECHNOLOGICAL INTENSITY ${ }^{a}$ AND MAIN DESTINATIONS OF

TOTAL EXPORTS, 2006

(Percentages of the total)

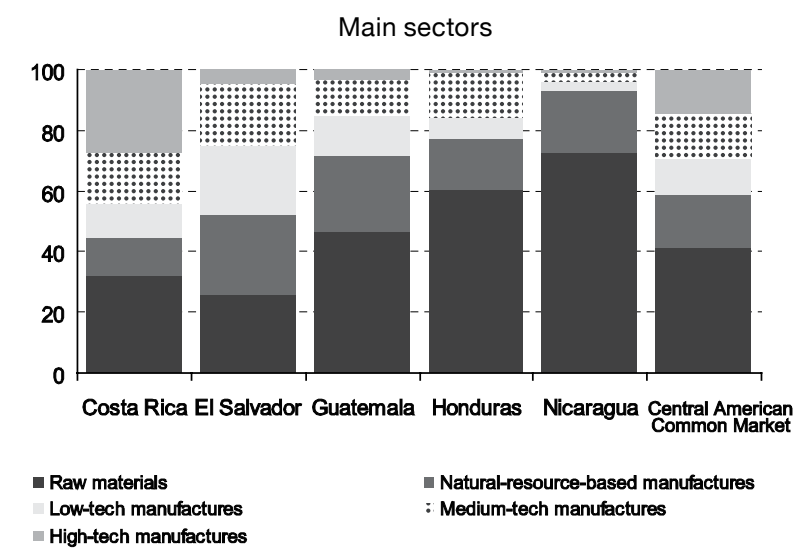

Main trading partners

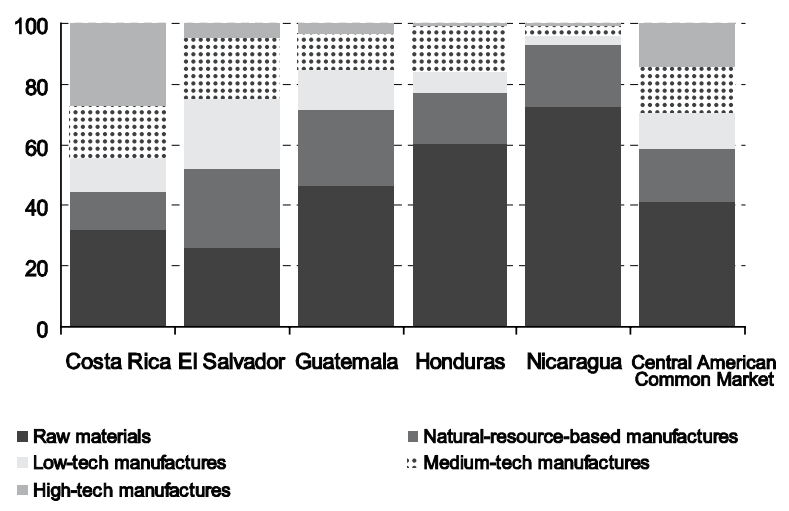

Source: Prepared by the authors, on the basis of data from the United Nations Commodity Trade Database (COMTRADE).

a Follows the classification of Lall (2000). 


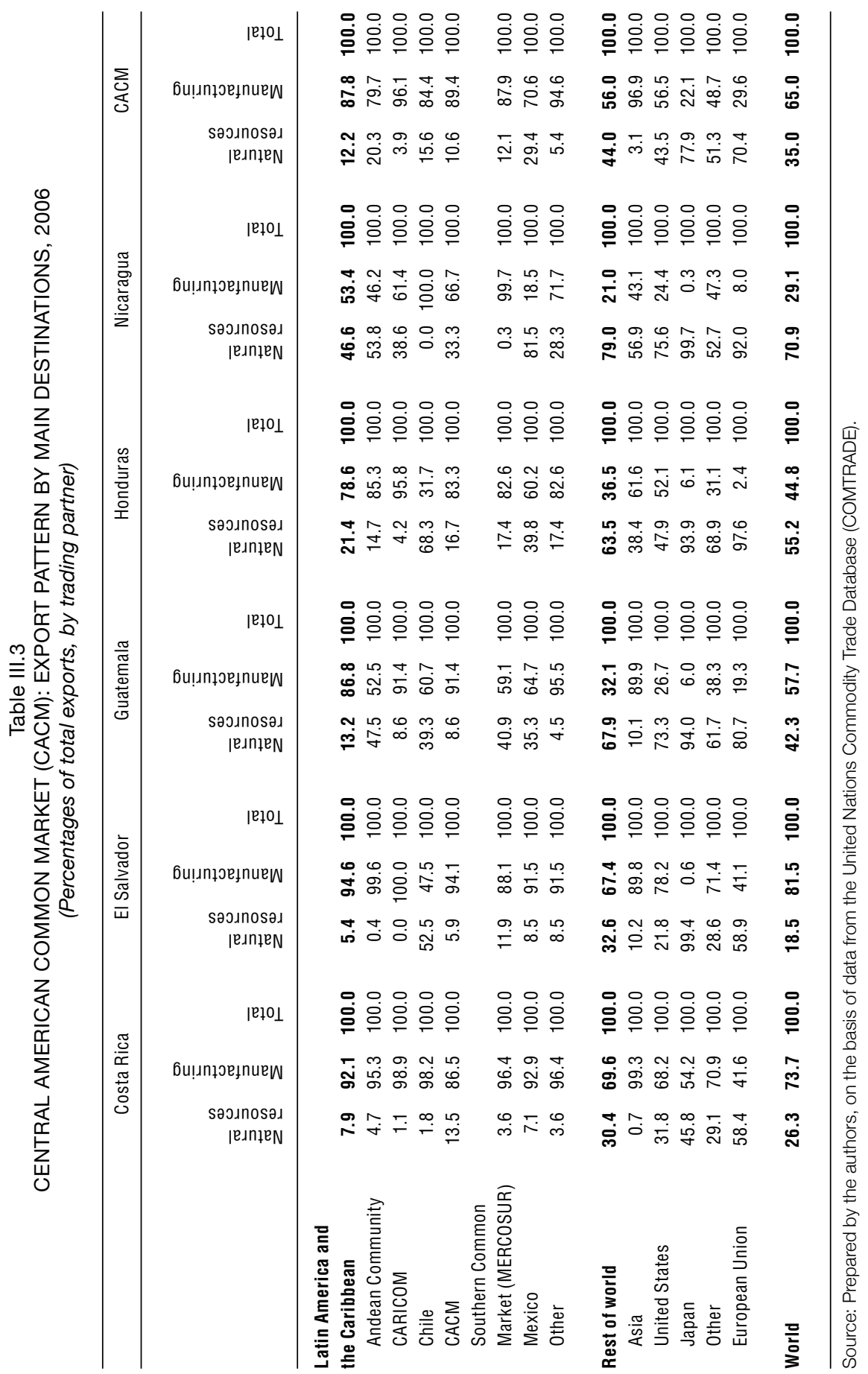




\section{Trade relations with the European Union: common interests}

The European Union has historically been an important trading partner for Central American countries. In the mid-1980s, the countries that now make up the European Union accounted for just over $16 \%$ of the subregion's exports and 30\% of its imports. Twenty years later, Central American exports to and imports from the European Union as a proportion of the subregion's total trade with the rest of the world had declined consistently, standing at $10 \%$ in 2007. Central America's trade deficit with the European Union has averaged around US\$ 900 million over the past five years (see figure III.2).

Figure III.2

CENTRAL AMERICAN COMMON MARKET (CACM): TRADE WITH THE EUROPEAN UNION 27, 1986-2007

Trade ratios

(CACM imports to and exports from the European Union 27 as a percentage of its total imports and exports)

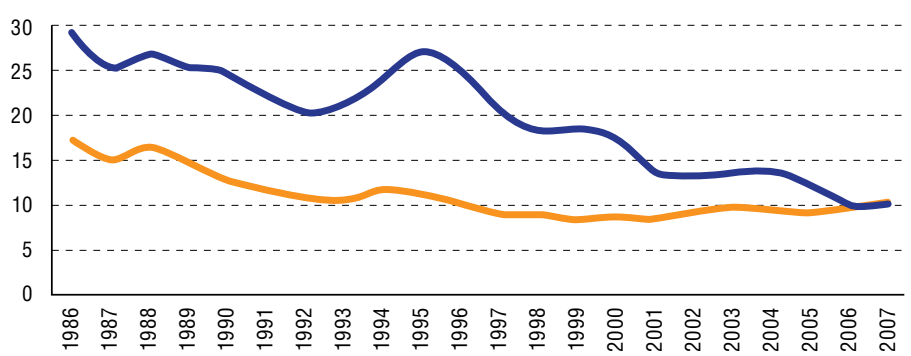

$\longrightarrow$ Exports Imports

Trade flows

(Millions of current US\$)

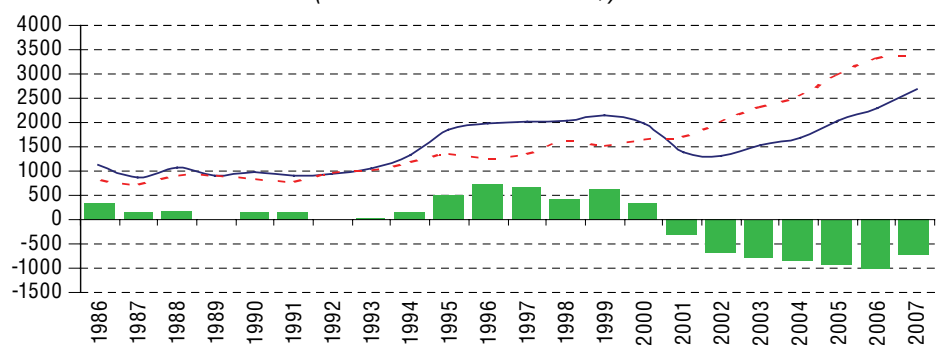

Trade Balance Exports - - - Imports

Source: Prepared by the authors, on the basis of data from the United Nations Commodity Trade Database (COMTRADE) and official information from the countries.

Note: Does not include the maquila sector. 
A review of the pattern of Central American exports to the European Union shows a marked predominance of "primary products" over manufactures. El Salvador, Guatemala, Honduras and Nicaragua have the highest proportion of primary products, with on average over $90 \%$ of their export baskets made up of commodities, especially coffee (just over $60 \%$ of the total). Another important product in Central America's export basket is bananas, especially in the case of Costa Rica. Neither coffee nor bananas are covered by the GSP or the GSP+, and the international prices of both products tend to fluctuate. ${ }^{2}$

Other important products in the basket of exports to the European Union are shellfish (shrimp and lobster), tuna and some non-traditional products such as pineapples, melon, flowers, sesame, moss and lichen. The Europe Union has high tariffs on these products.

In stark contrast to its exports, Central America's imports from the European Union are mainly made up of medium- and high-technology manufactures (see figure III.3).

Each Central American country's bilateral trade with the European Union consists of an inter-industry relationship dominated by exports of agricultural commodities in exchange for manufactures. This is confirmed by the fact that the Grubel-Lloyd index ${ }^{3}$ has never been above $0.09^{4}$ for any of the five countries and the European Union 27. This pattern directly affects the structure of countries' tariff protection in the framework of the Central American customs and economic union currently being set up (SIECA, 2007). This pattern protects intraregional trade flows and imposes high tariffs on the kind of products imported from the European Union. In the case of exports to the European Union, agricultural products not covered by the GSP+ encounter high barriers.

For Central American countries, the main objectives in pursuing negotiations with the European Union are to: (a) strengthen their trade policy of opening up new markets for their local exporters, as part of a variable geometry process in which more trade is viewed as better than less; (b) increase their export competitiveness vis-à-vis third countries; and (c) stimulate foreign direct investment in sectors that incorporate more value added.

2 After bananas, Costa Rica's main export products to the Eureopan Union are some electronic manufactures such as integrated circuits and electronic microstructures, computer parts and accessories and medical, surgical, dental and veterinary instruments and equipment.

3 The Grubel-Lloyd index measures trade at the level of the same branch of industry, that is, intra-industry trade. The index's results are expressed as a number from 0 to 1 , with values below 0.1 indicating inter-industry relations.

4 Authors' own calculations, based on United Nations Commodity Trade Database (COMTRADE). 
Figure III.3

CENTRAL AMERICAN COMMON MARKET: TARIFF APPLIED AND PATTERN OF
IMPORTS FROM THE EUROPEAN UNION 27

Average most-favoured-nation tariff charged, 1995-2007

(Percentages)

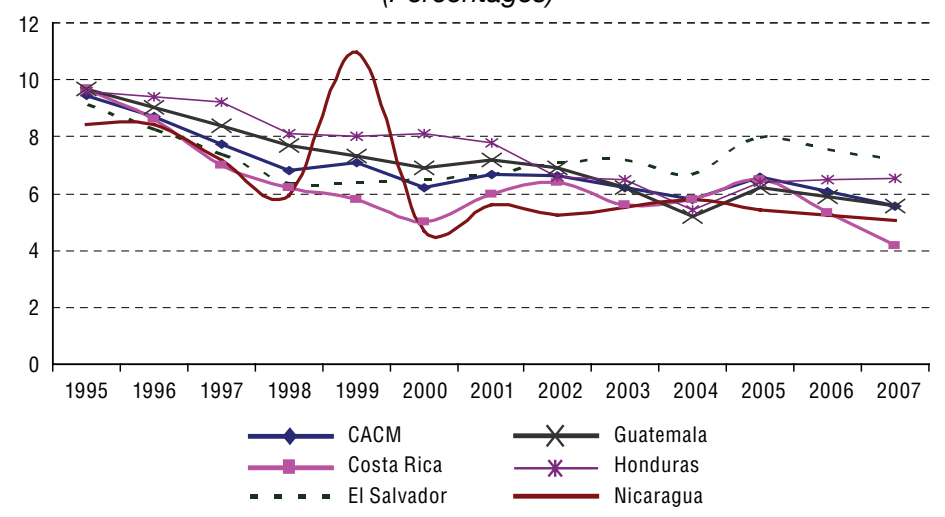

Structure of imports from European Union 27, 2006

(Percentages of total exports)

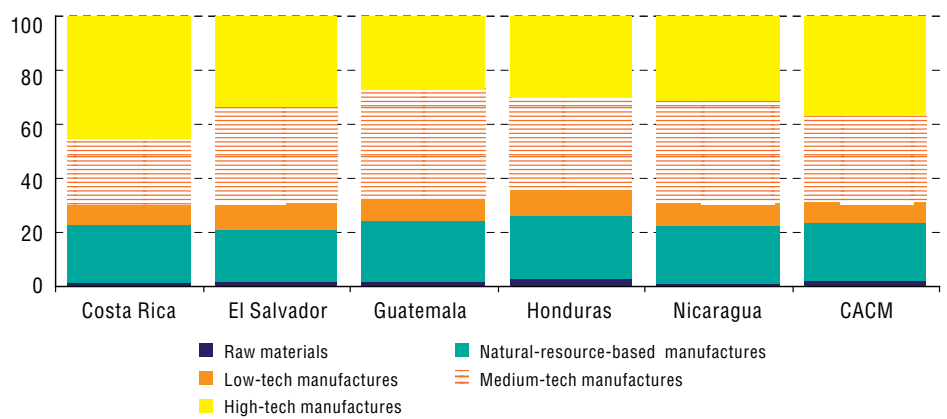

Source: Prepared by the authors, on the basis of official information from the countries and the Trade Analysis and Information System (TRAINS) of the United Nations Conference on Trade and Development (UNCTAD) as well as the United Nations Commodity Trade Database (COMTRADE), accessed through the World Bank's World Integrated Trade Solution (WITS).

For strengthening trade policy, the European Union is clearly an important partner. Although a high percentage of the European Union's imports come from developed countries (Japan, Norway, the Russian Federation and the United States), its imports from developing countries have risen considerably (tripling since 1980). In addition, the European Union is the world's largest importer of agricultural products.

Increasing competitiveness and reducing the costs of accessing the European market is another important incentive, especially because Central America's main competitors include China, India, Mexico, South 
Africa, the African, Caribbean and Pacific (ACP) countries, the countries of the Southern Common Market (MERCOSUR) (Argentina, Brazil, Paraguay and Uruguay) and the Andean countries. The main competition is in agricultural products, which is precisely where the ACP countries have an advantage over Central America, as exports by the former face lower barriers. This is the case, for instance, of bananas (Pardo, 2006a and 2006b). ${ }^{5}$ Figure III.4 lists Central American products that are subject to high tariffs in the European Union market.

Figure III.4

STRUCTURE OF CENTRAL AMERICAN EXPORTS TO THE EUROPEAN UNION AND TARIFF APPLIED AT CUSTOMS, 2006

Structure of exports to the European Union, by technological intensity

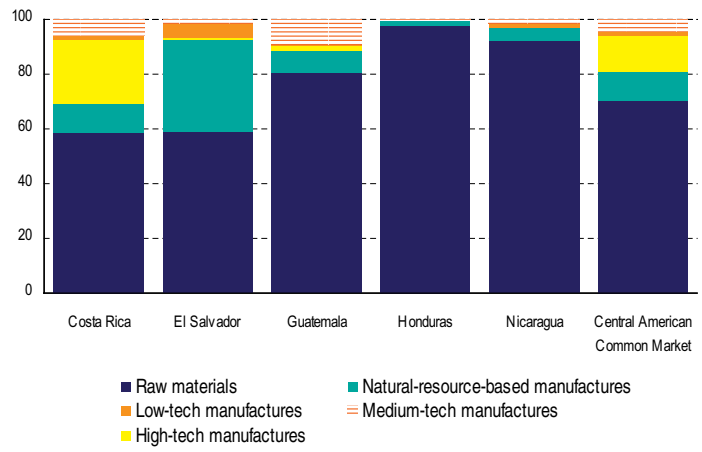

Barriers to certain sensitive products in the European Union market

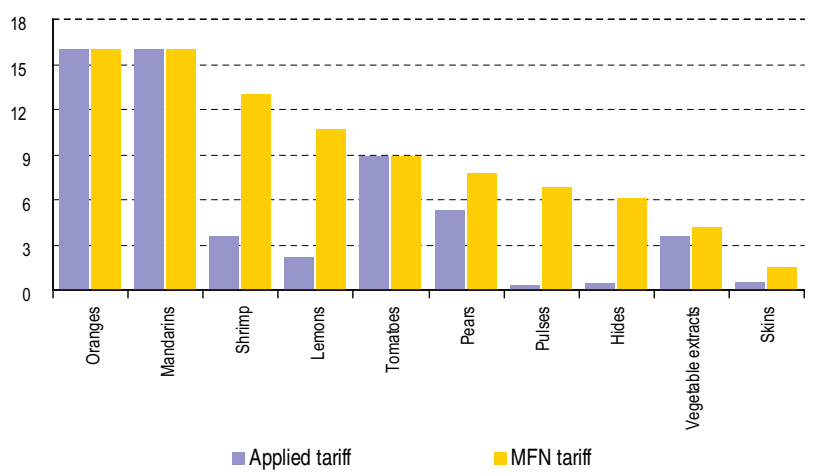

Source: Prepared by the authors, on the basis of Trade Analysis and Information System (TRAINS) of the United Nations Conference on Trade and Development (UNCTAD) and the United Nations Commodity Trade Database (COMTRADE), accessed through the World Bank's World Integrated Trade Solution (WITS).

5 From 2000 to 2006, raw materials exports grew at an annual rate of $4.2 \%$, or $3 \%$ less than the annual growth from 1990 to 2000 (authors' own calculations, based on data from the United Nations Commodity Trade Database (COMTRADE)). Easier access to the European Union market could lead to an increase in this type of exports. 
The record of most-favoured-nation tariffs charged, as of mid-2008, by European countries on products from countries not covered by GSP+ clearly shows the importance for Central American countries of being able to extend the tariff headings currently covered by zero tariffs to up to the 7,200 products of the general scheme. GSP+ is in force from January 2006 until the end of 2015. Although it is true that the system is unilateral and that it is generalized for countries with small and vulnerable economies, the European Commission reserves the right to periodically examine fulfilment of certain conditions, so as to determine if maintaining the preferences is justified. ${ }^{6}$

Boosting foreign investment in sectors with the highest value added is another of the main reasons for strengthening trade relations with the European Union. This will be possible if there are considerable reductions in the number of products currently covered by graduated tariffs. Although tariffs are not charged on products such as whole tuna, fresh fruit (including blackberry and pineapples) and unroasted coffee, the European Union applies higher tariffs on products covered by higher value added tariff headings, such as purées, prepared fruit or canned fish, which discourages investment in these industries.

The European Union's main motivations for moving forward in negotiations with Central American countries are to: (i) underpin its foreign trade policy with developing countries, in the framework of its cooperation programme with Latin America and Asia; (ii) recover its leadership in world trade, especially in Latin America and the Caribbean; and (iii) coordinate its international positions in the multilateral sphere, especially following the failure of the Doha Round.

The first highly significant reason is to maintain an active policy conducive to promoting free trade, thereby furthering the integration of developing countries in global trade. The policy vision is reflected in many of the official instruments signed by Brussels (European Commission, 2002). In countless studies and analyses of protectionism

GSP+ offers the elimination or reduction of tariffs for small economies that have ratified and effectively applied the international conventions on sustainable development, labour rights and good governance (see Articles 8 and 9 of European Council Regulation No. 980/2005). Countries do not have automatic access to GSP+ but must apply for it, and exporters must comply with the applicable sanitary and technical requirements as well as with the import rules of origin of the European counterpart. 
and market-access problems (especially in the agricultural sector), the European Union is portrayed as one of the most complicated markets in the world (van des Mensbrugghe, 2006; Tokarick, 2008).7

Recently, the United States has made great progress in terms of trade, signing free trade agreements with various countries and regions of the world, including many Latin American and Caribbean nations (such as those in Central America) (Bergsten, 2005). On a practical level, the increase in the United States' share of total Latin American exports has been at the expense of reduced Latin American trade with the European Union (ECLAC, 2007). It is therefore understandable that recovering this market is a major motivating factor for European negotiators, especially in Central America, whose relations with the United States have been strengthened by the Dominican Republic, Central America and the United States Free Trade Agreement (CAFTA-DR).

Coordinating its trade positions in the multilateral arena is also a significant incentive for the European Union to make decisive process in bilateral negotiations. As of June 2008, the European Union had concluded around 20 trade agreements, ${ }^{8}$ including free trade agreements, customs unions agreements and association agreements -almost double the number it had signed up to 2005 (Francois, McQueen and Wignaraja, 2005).

\section{Tariff barriers being negotiated}

A review of tariff levels prior to negotiations shows the barriers faced by Central American products in the European Union market and by European products in Central America. For Central American products, the highest barriers were for agricultural products, with Costa Rica and what are referred to as "other countries" (Belize, El Salvador and Honduras) facing the highest tariffs. Among fruits and vegetables, the products facing the highest barriers were bananas and coffee, and among light manufactures, the tightest restrictions were on sugar and prepared food (frozen fish, tuna, shrimp and prawns). Other product groups faced practically no barriers (see table III.4 and annex 1).

7 The European Union accounts for $45 \%$ of total support for farmers from countries of the Organisation for Economic Co-operation and Development (OECD) (US\$ 279.8 billion). The estimated ad valorem tariff for all agricultural products in the European Union in 2005 was $13.9 \%$ (van der Mensbrugghe, 2006)

8 Annex 5 lists all the agreements signed by the European Union that were in force in July 2008. It also lists seven legal instruments that will succeed the Cotonou Agreement with various groups of African, Asian and Caribbean countries. For a detailed review, see European Commission (2010). 
Table III.4

BARRIERS BY GROUPS OF PRODUCTS IN THE EUROPEAN UNION MARKET, BASELINE GTAP 7.0

\begin{tabular}{lccccc}
\hline Product group & Costa Rica & Guatemala & Nicaragua & $\begin{array}{c}\text { Other } \\
\text { countries }\end{array}$ & $\begin{array}{c}\text { Central } \\
\text { America }\end{array}$ \\
\hline Agricultural & 38.5 & 0.7 & 0.2 & 42.8 & 33.4 \\
Mining and extraction & 0.0 & 0.0 & 0.0 & 0.0 & 0.0 \\
Light manufactures & 4.7 & 3.1 & 2.6 & 33.5 & 17.5 \\
Heavy manufactures & 0.0 & 0.0 & 0.0 & 0.0 & 0.0 \\
Tariff (percentage) & 8.6 & 1.4 & 0.8 & 35.9 & 7.3 \\
\hline
\end{tabular}

Source: Prepared by the authors, on the basis of the "GTAP 7.0 Database" [online database] https://www.gtap. agecon.purdue.edu/databases/v7/default.asp

The weighted average tariffs by the European Union are, according to the available data, higher than those charged by Central American countries ( $7.3 \%$ and $4.3 \%$, respectively).

The main difference between the two tariff structures is that the European Union concentrates its protection in four groups - fruit and vegetables, meat, sugar and other foods- whereas Central America applies higher tariffs to practically all its import basket, including agricultural products. However, the average is pulled down by Central America's higher propensity to import manufactures such as transport equipment, machinery and equipment and chemicals with below-average tariffs (between 1\% and 2\%). Nonetheless, for European exporters these tariffs imply higher access costs if the negative effect of the distance between Europe and Central America is taken into account.

\section{Assessments of the possible effects of the free trade agreement and recent studies including the European Union}

As far as is known, no comprehensive studies have been carried out to assess the impacts of agreements being negotiated between the European Union and Central American countries since the talks began. There have been a few analytical studies on strategic elements to be considered in the negotiations and detailed reports on the trade relations between specific Central American countries and the European Union (Rivas, 2005; Pardo de León, 2006a and 2006b). 
There have been more studies on the possible effects of the CAFTADR than on relations with the European Union. The only paper to use a computable general equilibrium model, that of Francois, McQueen and Wignaraja (2005), focuses on the effects of free trade agreements between the European Union and developing countries without going into detail about Central American countries. The main reason for the absence of relevant studies is the lack of data from input/output matrices and detailed social accounting matrices.

\section{Data and analysis methodology}

This section describes the methodology used to simulate the possible effects of an Association Agreement between Central American countries and the European Union. The present study relies on two complementary methodologies: the computable general equilibrium approach, using the GTAP multi-country multi-product model and the standard model (Hertel, 1997), ${ }^{9}$ and a partial equilibrium approach, ${ }^{10}$ based on available trade data for the countries involved in negotiations. Details on the aggregations used and particular characteristics of each case are given in the subsections below.

\section{Sectoral and regional aggregations in the computable general equilibrium}

The sectors and countries selected for this study were the main sectors of the economies of Costa Rica, Guatemala, Nicaragua and the rest of Central America and the region's main trading partners. The GTAP database (version 7 pre-6) was aggregated into 33 sectors and 15 regions. Annex 2 lists the 33 sectors, which correspond to 12 primary sectors, 11 light manufacturing sectors, 9 heavy industry sectors and 1 aggregated services sector (see table III.6 for a summarized version). The classification used in this study is different from that used in previous ECLAC publications, in the sense that sectors were opened up and petroleum oils were grouped under manufactures. Paper products were also aggregated separately. ${ }^{11}$

Table III.5 lists the 15 countries/regions considered in this study. More emphasis has been placed on the disaggregation of Central America, which was previously considered a single entity consisting of the five

For details on the GTAP model, see Schushny, Durán and de Miguel (2007a).

10 The exercises follow the approximation developed by Cline and others (1978). See also Alvarez and Benavente (1997) and Reyes (2005).

11 For further details of changes in aggregation, see Schushny, Durán and de Miguel (2008, 2007a and 2007b), where 30 sectors were considered instead of the 33 included here. 
members of the Central American Common Market, Belize and Panama. The present study includes results for three countries in particular (Costa Rica, Guatemala and Nicaragua), ${ }^{12}$ and for the rest of the region in the aggregate (Belize, El Salvador and Honduras). This has been made possible by updates to those countries in the new version of the GTAP database (7.0). In the medium term, it is hoped that the other countries will be included separately, with a view to increasing understanding of the opportunities and difficulties for countries involved in trade negotiations with the European Union.

Table III.5

REGIONAL AGGREGATION OF THE GTAP DATABASE

\begin{tabular}{lll}
\hline No. Country/region & Description - original GTAP sectors \\
\hline 1 & Costa Rica & Costa Rica \\
2 & Guatemala & Guatemala \\
3 & Nicaragua & Nicaragua \\
4 & Panama & Panama \\
5 & Rest of Central America & Belize, El Salvador and Honduras \\
6 & United States & United States \\
7 & Mexico & Mexico \\
8 & Canada & Canada \\
9 & Andean Community & Plurinational State of Bolivia, Colombia, Ecuador and Peru \\
10 & Bolivarian Republic of Venezuela & Bolivarian Republic of Venezuela \\
11 & MERCOSUR & Argentina, Brazil, Paraguay and Uruguay \\
12 & Chile & Chile \\
13 & European Union 15 & Austria, Belgium, Denmark, Finland, France, Germany, Greece, \\
& & Ireland, Italy, Luxembourg, Netherlands, Portugal, Spain, \\
14 & Countries of Central and Eastern & Sweden, United Kingdom \\
& Europe (12) & Bulgaria, Cyprus, Czech Republic, Estonia, Hungary, Latvia, \\
15 & Asia & Lithuania, Malta, Poland, Romania, Slovakia, Slovenia \\
& & Cambodia, China, Indonesia, Japan, Laos, Malaysia, \\
16 & Rest of world & Philippines, Republic of Korea, Taiwan Province of China, \\
& Thailand, Viet Nam, Central Asia, South Asia \\
\hline
\end{tabular}

Source: Prepared by the authors, on the basis of 101 countries/regions of the "GTAP 7.0 Database" [online database] https://www.gtap.agecon.purdue.edu/databases/v7/default.asp.

12 The work of ECLAC and the United Nations Department of Economic and Social Affairs (DESA) and the financial support of the German Agency for Technical Cooperation (GTZ) made it possible to include Costa Rica, Guatemala and Nicaragua. In addition, the financial support of GTZ made it possible to transform country data from supply and use tables and social accounting matrices into the input/output matrix format required by GTAP. For further technical details on matrices, see Sánchez, Vos and Ludeña (2008); Sánchez and Ludeña (2008); and Ludeña, Durán and Schuschny (2008). 


\section{Amendment of the GTAP 7.0 database}

The main change to the GTAP database was the updating of tariffs. The GTAP 7.0 database was used, as it contains updates for the countries referred to above (Costa Rica, Guatemala, Nicaragua and Panama). This database also contains information on global trade and production structures, among others items, for 2004. However, the database does not include the tariff structure for agreements signed between 2004 and 2007, including CAFTA-DR, the recent agreements concluded by Chile and some Asian countries (Schushny, Durán and de Miguel, 2008) or the Eastern European countries that have been incorporated into the European Union.

Box III.1 contains a diagram of the process to update the database from base year 2004 to 2007, including the following two fundamental aspects: implementation of CAFTA and the expansion of the European Union from 15 to 27 members. These changes were introduced as shocks to the 2004 base year to be updated in 2007. The altertax algorithm was not used because the new GTAP 7.0 database includes tariffs for 2004, and the agreements simulated to filter through the impacts of the CAFTADR agreement in the second instance constitute, in and of themselves, an assessment of the impact of free trade agreements concluded between 2004 and 2007. This is not, however, an ex ante but rather an ex post assessment that attempts to realistically capture the scenario prior to negotiations of the Association Agreement with the European Union, which were initiated in the third quarter of 2007.

In the case of CAFTA, an attempt was made to ensure that the terms of the agreement were respected as closely as possible. This is important as it changes the tariff structure and trade flows between the United States and Central American countries, including Costa Rica, Guatemala, Nicaragua and the rest of the States in the subregion.

To reflect specific aspects of CAFTA, sensitive products were selected, which were defined as those with no immediate tariff reduction -that is, those with a tariff reduction that includes years of grace and linear reduction in periods of up to 20 years in the final trade agreement (Cordero, 2005). In this sense, tariffs were reduced to zero for all products in intraregional trade, except those considered sensitive. The list of sensitive products for Central America and the United States is included in table III.7.

Tariff information also included the 12 countries of Central and Eastern Europe incorporated into to the European Union (European Union 15). The tariffs between these two regions were therefore reduced to zero, and the tariffs of the 12 Central and Eastern European Countries 


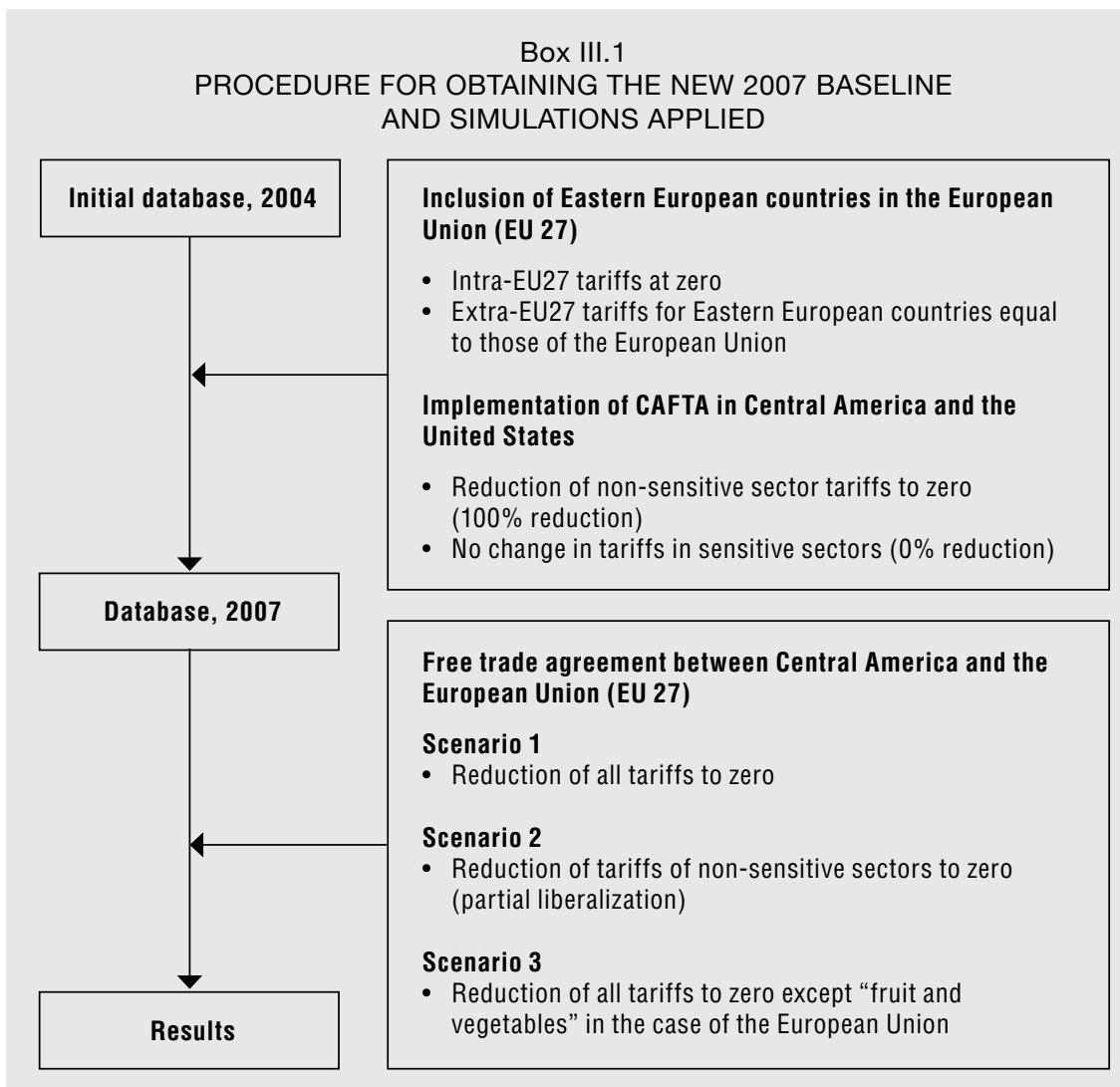

Source: Prepared by the author, on the basis of analyses of the structure of the "GTAP 7.0 Database" [online database] https://www.gtap.agecon.purdue.edu/databases/v7/default.asp.

to and from Central American countries were changed to the same levels as those applied by the European Union 15 in the baseline protection of GTAP version 7.0. Once the database was updated from 2004 to 2007, sensitive products and trade liberalization scenarios between Central America and the European Union were defined. These are examined in the sections below.

\section{Sensitive products included in the simulations}

Sensitive products are an important aspect of negotiations. This study therefore includes a list of sensitive products for Central America and the European Union. For Central America, the products defined as sensitive under CAFTA were assumed to be sensitive under the free trade agreement with the European Union. For the European Union, 
sensitivity was determined on the basis of tariffs and information available in the specialized trade press, ${ }^{13}$ as well as by consulting the European Union's official online customs tariff database, TARIC. A product is considered sensitive if the tariff is higher than the simple average tariff for all sectors.

On the basis of these two criteria, the following groups of products were defined as sensitive for Europe: 'fruit and vegetables', 'meat', 'dairy', 'sugar', 'beverages and tobacco', as well as 'other foods', examples of all of which are given in figure III.4. Table III.6 lists the sectors considered sensitive for the European Union. The same sectors will be considered sensitive for the partial equilibrium analyses.

\section{Scenarios used in the simulations}

Once the sensitive products had been established for Central America and the European Union, the following three scenarios were considered:

The first scenario is a full liberalization of products, with a $100 \%$ reduction of tariffs between Central America and the European Union.

The second scenario considers sensitive products as defined in table III.7 and excludes them from the free trade agreement.

The third scenario is similar to the second scenario but, rather than excluding all the sensitive products of the European Union, it excludes only fruit and vegetables from liberalization (as this is a category that developed countries usually consider sensitive).

See press releases on trade topics on the official website of the Secretariat for Central American Economic Integration (SIECA): http://www.noticias.sieca.org.gt/. 


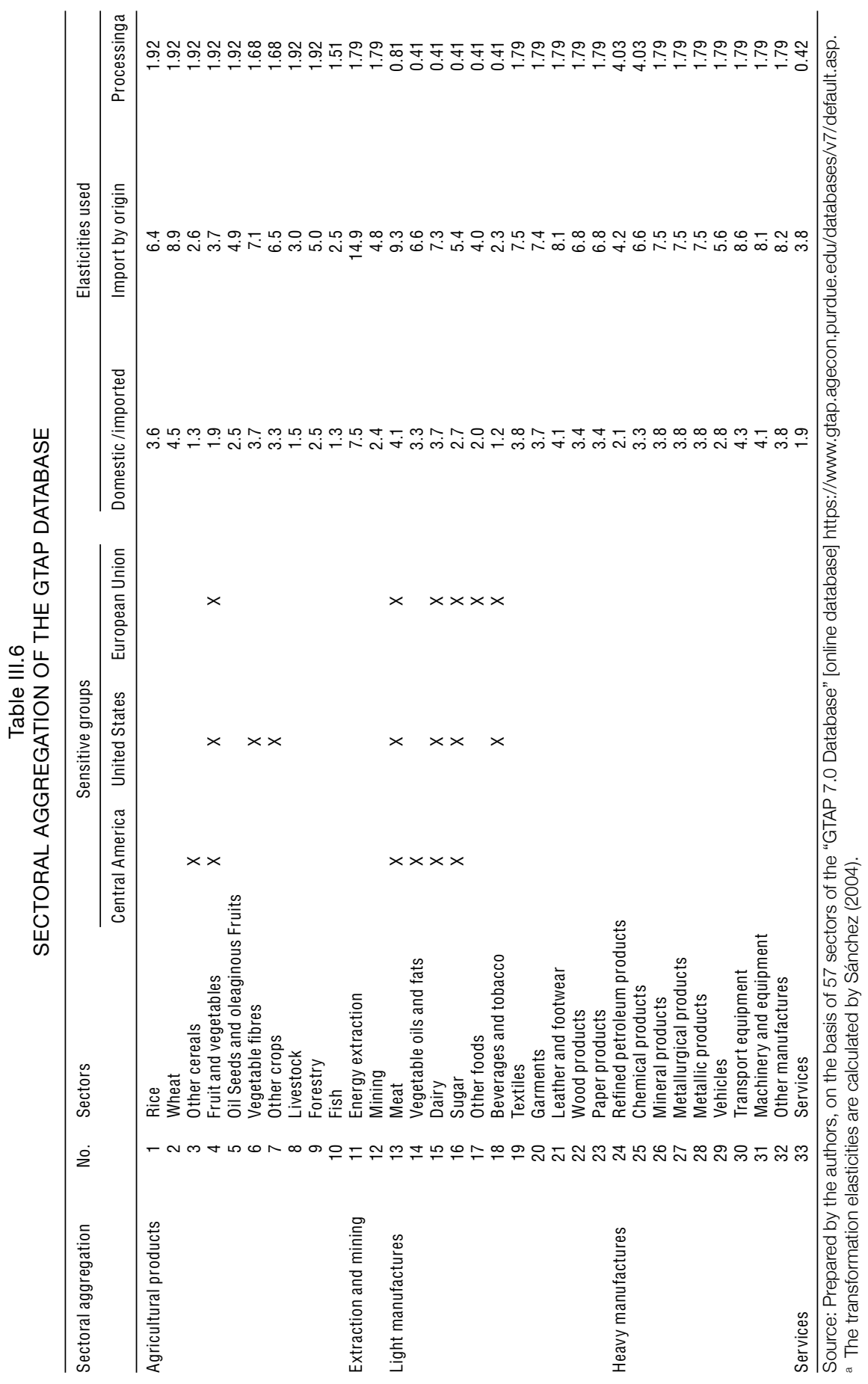




\section{Methodology for partial equilibrium simulations}

To complement the general equilibrium analysis, simulations were developed to calculate expected changes in the level of exports and imports of Central American countries, given the changes in the tariff structure of the base year. This methodology has the advantage of being simple and fast, as well as providing a fairly disaggregated assessment at the level of output, which is naturally impossible with CGE methodology.

As will be seen, the CGE analyses have a major limitation given the absence of specific data for El Salvador and Honduras, which appear as an aggregated single unit termed "Rest of Central America". These exercises provide a glimpse of which products and groups could benefit the most from the conclusion of an Association Agreement with the European Union.

The approach followed is one of trade creation, which consists in calculating the increase in exports and imports that would arise from a given change in tariffs. In practical terms, the percentage increase in imports, in this case, is equal to the percentage change in import prices resulting from the tariff reduction, multiplied by the price elasticity of import demand, with the result then multiplied by the level of the base year of imports. The percentage change in import prices, for its part, is equivalent to the tariff change divided by the original tariff, plus one. The same principle applies to exports, where the expected change in levels is determined by the tariff level in the base year and the price elasticity of exports. With the information on the price elasticities of demand, export elasticity, export and import levels in a given base year, tariffs charged and expected changes, it is also possible to calculate a way of measuring variations in welfare.

The simulated level of exports/imports will be equal to the sum of the base level plus the delta obtained by applying the formulae in table III.7. The results per baseline can then be used to aggregate by group. For a simple comparison, products were matched with the large sectoral groups of the GTAP database detailed in table III.6, which also indicates the elasticities used for the calculation.

The partial equilibrium simulations were carried out based on import and export information from the United Nations Commodity Trade Database, COMTRADE, accessed using the World Bank's World Integrated Trade Solution (WITS). The tariffs used were from the official European Union database (TARIC), and tariffication was performed on specific customs duties using methodologies 1 and 2 proposed by the United Nations Conference on Trade and Development (UNCTAD) 
Table III.7

MEASURES OF TRADE CREATION AND WELFARE VARIATION USING PARTIAL EQUILIBRIUM

\begin{tabular}{lcc}
\hline Type of simulation $\quad$ Imports & Exports \\
\hline $\begin{array}{l}\text { Trade } \\
\text { creation }\end{array}$ & $\Delta M=\varepsilon \cdot M_{0} \frac{\left(t_{1}-t_{0}\right)}{\left(1+t_{0}\right)}$ & $\Delta X=X_{0} t_{0} \cdot\left(1+\gamma+\gamma t_{0}\right)$ \\
\hline $\begin{array}{l}\text { Welfare } \\
\text { variation }\end{array}$ & $\Delta B=\frac{1}{2} \varepsilon \cdot \frac{\left(t_{1}-t_{0}\right)}{\left(1+t_{0}\right)} M_{0}\left(t_{1}+t_{0}\right)$ & $\Delta B=X_{0} t_{0} \cdot\left(1+\frac{1}{2} \cdot \gamma t_{0}\right)$ \\
\hline
\end{tabular}

where:

$\Delta M=$ variation in import volume

$\Delta X=$ variation in export volume

$\Delta B=$ variation in welfare

$\varepsilon=$ price elasticity of import demand

$t_{0}=$ tariff applied to a good for baseline import/export

$t_{1}=$ tariff applied to an imported/exported good following the conclusion of a trade agreement

$\gamma=$ export price elasticity

$M_{0}=$ level of baseline import volumes

$X_{0}=$ level of baseline export volumes

Source: Prepared by the authors.

for such cases (FAO, 2005; Stawowy, 2001). This exercise involved disaggregation to five digits of the Standard International Trade Classification (SITC) (Rev. 2), in accordance with the Harmonized System (2002) and the official database of the European Union.

\section{Environmentally sensitive industries}

For the best possible assessment of expected effects on environmental sensitivity, the definition of environmentally sensitive industries used is that given by Low and Yeats (1992) and Schaper (1999), who identified 40 industries from SITC Rev.1 and their equivalents in SITC Rev.2. This information was used to identify matches with the 57 GTAP codes, which were in turn grouped into the 33 sectors presented in this study. Of the 33 sectors, 9 were identified as having environmentally sensitive industries that account for exports totalling US\$ 88 million, or $3.9 \%$ of all CACM exports to the European Union. This type of industry therefore represents almost $10 \%$ of the subregion's total exports (see table III.8). 


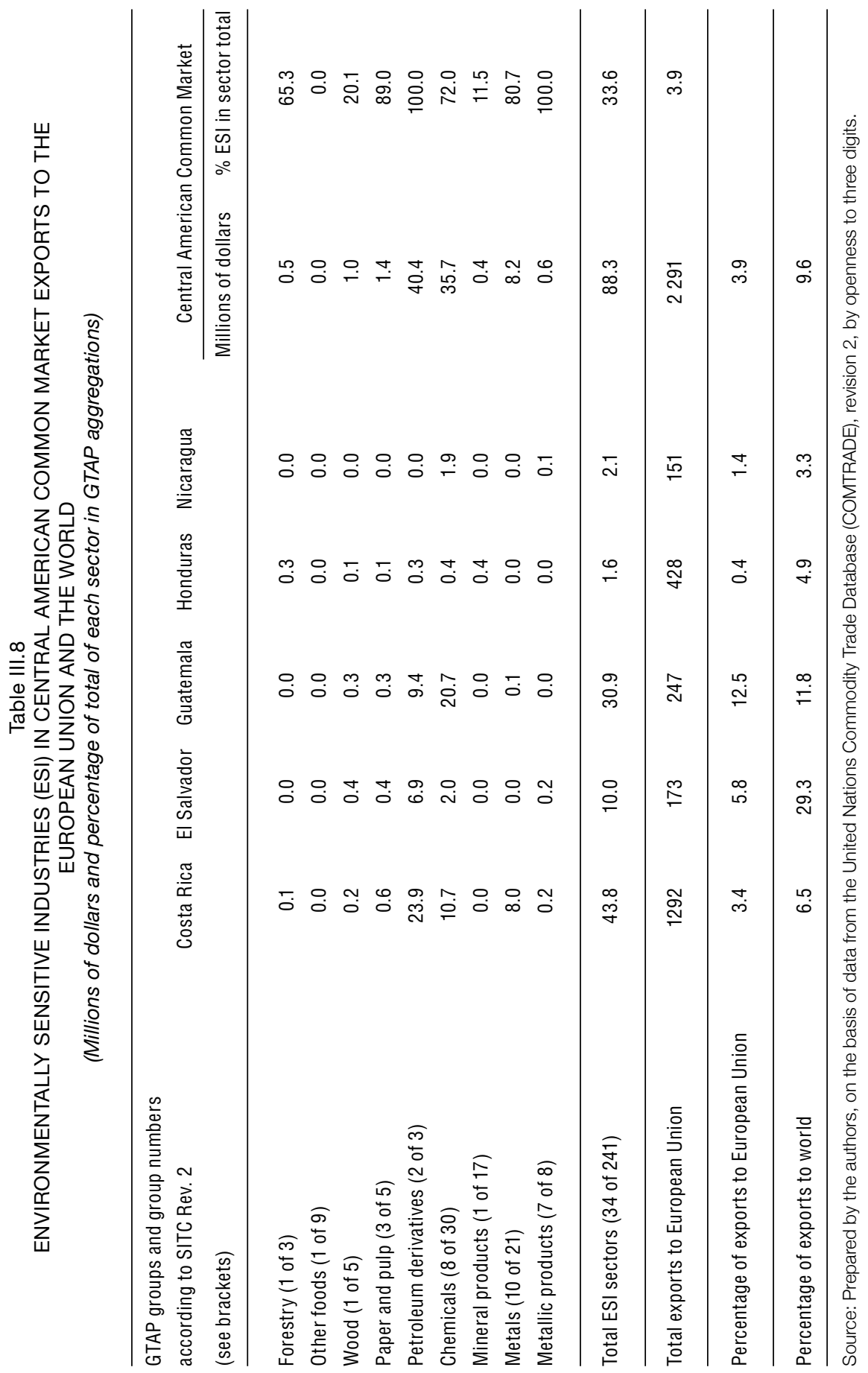


Analysis of exports from environmentally sensitive industries in the CACM as a whole to the European Union revealed that the majority of the exports originated in three countries: Costa Rica, El Salvador and Guatemala (with $96 \%$ of the total). For the other countries, the proportion was considerably lower. The pattern was the same for exports to the rest of the world, with a higher rate share for exports from El Salvador and Guatemala.

At the sector level, environmentally sensitive industries are concentrated in the petroleum derivatives, chemicals and metals groups, in terms of both percentages and value. Within each category, the most significant industries correspond to the following groups of SITC Rev. 2: 334 (petroleum derivatives), 512 (alcohols), and 699 (metallic manufactures). These correlations between environmentally sensitive groups and industries are higher than $70 \%$, with a figure of $100 \%$ for petroleum derivatives.

Despite slight differences among the countries of the subregion, there are other groups for which environmentally sensitive industries account for a considerable share of exports, such as paper and pulp, and forestry and metallic products. However, the share of these products in total exports is considerably less than $0.1 \%$ in each case (see table III.9).

As a proportion of total exports to the world, the percentage of environmentally sensitive industries is slightly higher for CACM countries as a whole $(9.6 \%)$, and especially for El Salvador and Guatemala.

Taking into account the above-mentioned pattern, this document will subsequently analyse possible changes in environmentally sensitive export industries, focusing in particular on exports to the European Union and the two methodologies put forward in previous sections.

\section{E. Analysis of the results}

This section presents the results of the scenarios described in the methodology section, both for the general equilibrium and for the partial equilibrium simulations. The baseline applied in the CGE exercises corresponds to a scenario close to 2007 that considers liberalization between Central American countries and the United States (CAFTADR), as well as the expansion of the European Union from 15 members to 25 and subsequently to 27 . As for the partial equilibrium simulations, the baseline corresponds to data from COMTRADE, through the World Bank's World Integrated Trade Solution (WITS), and the tariffs are those reported by the European Union in its online customs tariff database, TARIC. In some cases, specific tariffs were calculated. 
The analysis of the results will be presented in the following order: (a) analysis of the macroeconomic effects on output and its components; (b) analysis of foreign trade for the region as a whole and for Costa Rica, Guatemala, Nicaragua and the rest of Central America in CGE, plus partial equilibrium results for El Salvador and Honduras; (c) sectoral analysis in order to detect possible changes in the pattern of specialization and the output dimension; and lastly (d) the effects on welfare and the components of welfare.

\section{Macroeconomic results (output, trade, consumption and investment)}

Real GDP for Central American economies increases in the full liberalization scenario (scenario 1) and in the scenario where the European Union excludes only fruit and vegetables (scenario 3). However, GDP falls slightly when there is a partial liberalization with sensitive products (scenario 2). Per capita income increases in scenario 1, especially for Costa Rica $(4.52 \%)$ and the rest of Central America (12.48\%). For Guatemala and Nicaragua, income edges up slightly - by $0.46 \%$ and $0.33 \%$, respectively. The rise is smaller in scenario 3, especially for the rest of Central America, and income even drops for Guatemala. This is reflected in changes in welfare, which are discussed below in more detail.

Regarding trade volume, the exports of Costa Rica and the rest of Central America decrease in scenario 1 and those of Costa Rica decrease in scenario 3 and increase slightly in scenario 2 . Meanwhile, imports rise the most in scenario 1 , followed by scenario 3 then 2 . These results generate a positive change in the terms of trade of Costa Rica and the rest of Central America in scenarios 1 and 3, with a deterioration in scenario 2 (see table III.9). The causes of these results are discussed in more detail below.

A disaggregation of the quantum and price effects for the various simulations shows that most of the impacts under the three scenarios result from price improvements rather than from an increase in actual volume, especially in the case of full liberalization in scenario 1. Considering exclusively changes in terms of volume, scenario 2 appears to be the most advantageous, although the increases are very small. These statements are valid for the analysis of output and foreign trade (see figure III.5). The next analysis discusses how the values of the main macroeconomic variables vary from the baseline.

Table III.10 presents the results for the main macroeconomic variables for Central America and the European Union in terms of their value and relation to the baseline. The impact on GDP shows that the total liberalization scenario would have the greatest impact for Central 
Table III.9

IMPACTS OF THE ASSOCIATION AGREEMENT BETWEEN CENTRAL AMERICA AND THE EUROPEAN UNION IN REAL TERMS

(Changes in relation to the base year $=2007$ )

\begin{tabular}{lcccccc}
\hline & $\begin{array}{c}\text { Real } \\
\text { GDP }\end{array}$ & $\begin{array}{c}\text { Per capita } \\
\text { income }\end{array}$ & $\begin{array}{c}\text { Welfare } \\
\text { (M of dollars) }\end{array}$ & $\begin{array}{c}\text { Exports } \\
\text { (\% variat.) }\end{array}$ & $\begin{array}{c}\text { Imports } \\
\text { (\% variat.) }\end{array}$ & $\begin{array}{c}\text { Terms of } \\
\text { trade }\end{array}$ \\
\hline Costa Rica & 0.22 & 4.52 & 477 & -1.37 & 1.87 & 3.88 \\
Guatemala & 0.03 & 0.46 & 13 & 0.93 & 0.74 & 0.15 \\
Nicaragua & 0.06 & 0.33 & 4 & 0.17 & 0.35 & 0.23 \\
Rest of Central America & 0.38 & 12.48 & 1,386 & -4.94 & 6.40 & 9.41
\end{tabular}

Scenario 2: partial free trade agreement

$\begin{array}{lrrrrrr}\text { Costa Rica } & -0.01 & -0.33 & 0 & 0.45 & 0.57 & -0.04 \\ \text { Guatemala } & -0.01 & -0.46 & -32 & 1.01 & 0.30 & -0.25 \\ \text { Nicaragua } & -0.01 & -0.40 & -4 & 0.40 & 0.15 & -0.07 \\ \text { Rest of Central America } & 0.01 & -0.26 & -14 & 0.47 & 0.25 & -0.08\end{array}$

Scenario 3: European Union 27 excludes fruit and vegetables

$\begin{array}{lrrrrrr}\text { Costa Rica } & 0.20 & 4.31 & 462 & -1.39 & 1.76 & 3.78 \\ \text { Guatemala } & -0.00 & -0.27 & -23 & 0.89 & 0.33 & -0.17 \\ \text { Nicaragua } & 0.00 & -0.22 & -4 & 0.17 & -0.02 & -0.09 \\ \text { Rest of Central America } & 0.03 & 0.27 & 25 & 0.23 & 0.36 & 0.17\end{array}$

Source: Prepared by the authors, on the basis of results from the GTAP model, version 7.0.

Note: The variables of the model are: exports (qxwreg), imports (qiwreg) and income (yp).

America as a whole, especially for Costa Rica (3.7\%) and the rest of Central America (13.9\%), whereas for Guatemala and Nicaragua the increase is just over half a percentage point $(0.60 \%)$. The only partial liberalization scenario to have a positive effect is scenario 3, in which GDP would rise by $2.4 \%$ in Central America and 3.9\% in Costa Rica, with little impact for Nicaragua (0.2\%) and Guatemala (where the change is marginally negative).

For the European Union as a whole, changes in output are practically nil, in contrast with the larger increases for Central America. It makes no difference to the European Union if all the sensitive products or if only fruit and vegetables are excluded. This would not be the case for Central American countries, for which any increases in trade (exports and imports) would be much smaller, especially when the European Union excludes sensitive products from negotiations. This analysis highlights the considerable asymmetry in results, reflected in the scale effect, which means that for the European Union the results are practically irrelevant in relative terms, ${ }^{14}$ although in political terms this is clearly not the case -as mentioned previously.

14 The European Union's trade with CACM countries does not exceed $1 \%$ of its total trade, and the CACM accounts for just $0.18 \%$ of total European Union imports. 


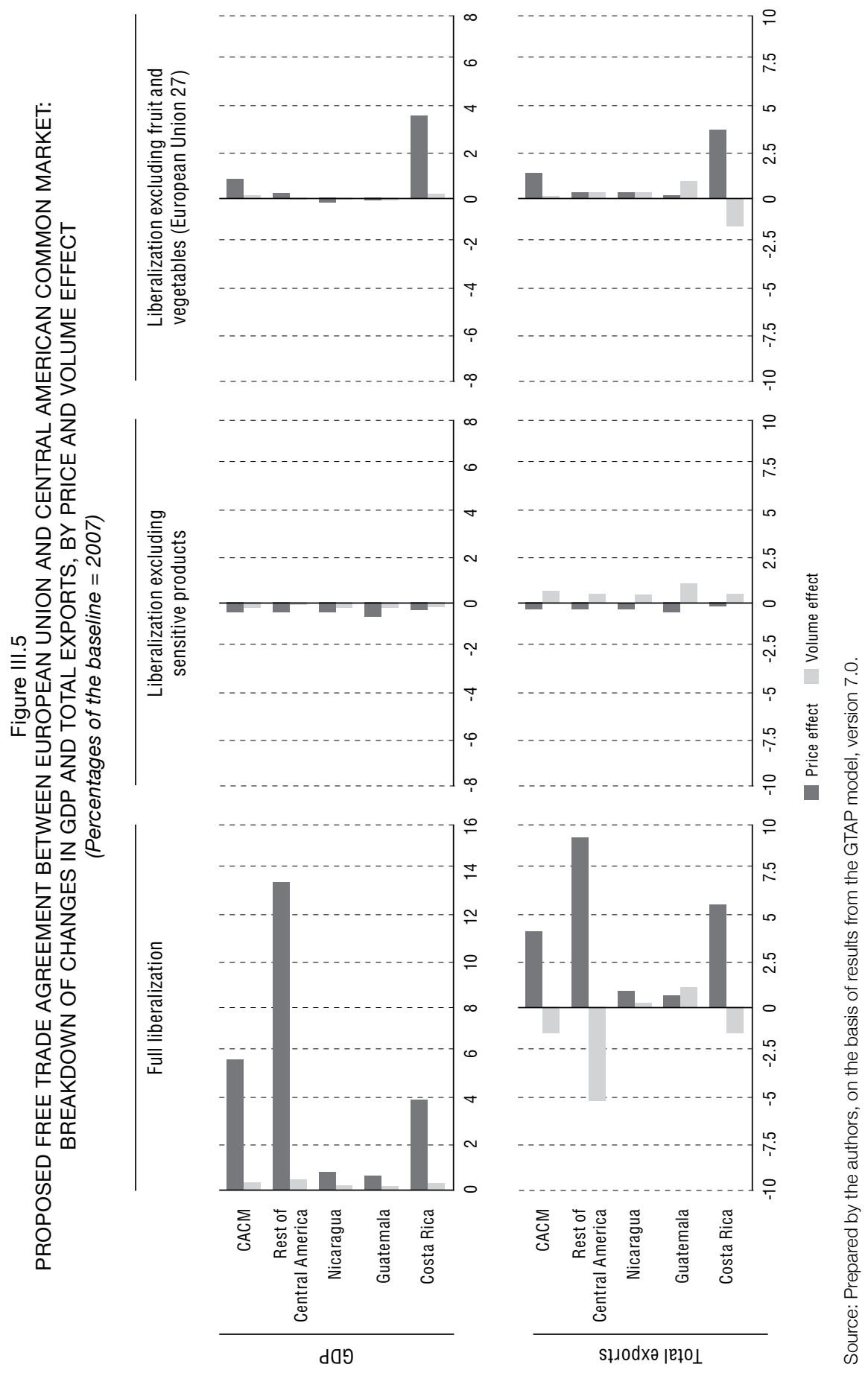


Table III. 10

SIMULATION OF THE ASSOCIATION AGREEMENT BETWEEN CENTRAL AMERICA AND THE EUROPEAN UNION: IMPACTS ON OUTPUT AND ITS COMPONENTS (THREE SCENARIOS)

(Percentage changes in relation to the base scenario $=2007$ )

\begin{tabular}{|c|c|c|c|c|c|c|}
\hline Simulations by country and region & GDP & C & 1 & G & $x$ & M \\
\hline \multicolumn{7}{|l|}{ Central America } \\
\hline Full liberalization & 5.9 & 5.4 & 8.0 & 6.9 & 2.9 & 3.6 \\
\hline Liberalization excl. sensitive products & -0.3 & -0.4 & 0.0 & 2.9 & 0.4 & 0.3 \\
\hline Liberalization excl. fruit and vegetables & 1.0 & 0.7 & 0.4 & 3.6 & 1.2 & 0.7 \\
\hline \multicolumn{7}{|l|}{ Costa Rica } \\
\hline Full liberalization & 4.1 & 4.4 & 1.8 & 4.3 & 2.5 & 2.0 \\
\hline Liberalization excl. sensitive products & -0.2 & -0.3 & 0.5 & 2.5 & 0.4 & 0.6 \\
\hline Liberalization excl. fruit and vegetables & 3.9 & 4.2 & 1.6 & 1.9 & 2.3 & 1.8 \\
\hline \multicolumn{7}{|l|}{ Guatemala } \\
\hline Full liberalization & 0.6 & 0.9 & 0.5 & 0.5 & 1.4 & 1.1 \\
\hline Liberalization excl. sensitive products & -0.4 & -0.3 & 1.4 & 1.4 & 0.7 & 0.3 \\
\hline Liberalization excl. fruit and vegetables & 0.0 & 0.2 & 1.1 & 1.1 & 0.8 & 0.5 \\
\hline \multicolumn{7}{|l|}{ Nicaragua } \\
\hline Full liberalization & 0.7 & 1.9 & 0.5 & 0.5 & 1.0 & 1.0 \\
\hline Liberalization excl. sensitive products & -0.2 & 0.2 & 1.4 & 1.0 & 0.3 & 0.1 \\
\hline Liberalization excl. fruit and vegetables & -0.1 & 1.1 & 1.1 & 1.0 & 0.4 & 0.4 \\
\hline \multicolumn{7}{|l|}{ Rest of Central America } \\
\hline Full liberalization & 13.8 & 12.5 & 20.2 & 12.6 & 4.3 & 6.7 \\
\hline Liberalization excl. sensitive products & -0.2 & -0.3 & 0.0 & 4.3 & 0.4 & 0.2 \\
\hline Liberalization excl. fruit and vegetables & 0.3 & 0.3 & 0.3 & 6.7 & 0.4 & 0.4 \\
\hline \multicolumn{7}{|l|}{ European Union 27} \\
\hline Full liberalization & 0.0 & 0.0 & 0.0 & 0.0 & 0.0 & 0.0 \\
\hline Liberalization excl. sensitive products & 0.0 & 0.0 & 0.0 & 0.0 & 0.0 & 0.0 \\
\hline Liberalization excl. fruit and vegetables & 0.0 & 0.0 & 0.0 & 0.0 & 0.0 & 0.0 \\
\hline
\end{tabular}

Source: Prepared by the authors, on the basis of simulations from "GTAP 7.0 Database" [online database] https://www.gtap.agecon.purdue.edu/databases/v7/default.asp.

C = Household consumption expenditures/Personal consumption expenditures

I = Gross private domestic investment

$G=$ Government consumption and gross investment expenditures

$X=$ Gross exports of goods and services

$M=$ Gross imports of goods and services

\section{Impact on output by sectors}

At the sectoral level, there are changes in output in the various sectors of the economy. For reasons of space, the results are not presented here. However, the most striking result is that, under the total liberalization scenario, Costa Rica sees its fruit and vegetable output increase by $38 \%$. The same occurs for the rest of Central America, where this sector's output rises by $41 \%$. These countries also see higher production of sugar $(982 \%)$ and other crops including coffee $(17 \%)$. 
Output of light manufactures and heavy manufactures, as well as other agricultural sectors, however, falls for these same countries. The changes are similar for scenario 3. Lastly, the partial liberalization scenario produces minimum production changes of less than $3 \%$.

\section{Foreign trade results (exports and imports)}

The results depend on countries' specific share of total exports to the European Union. Each country's export pattern largely determines the relative size of gains under the simulations. Table III.11 presents a matrix of each country's trade intensity in the total exports of the Central American Common Market by sector. This can be used to determine that the main gains in global terms are expected for exports from Costa Rica, especially in products such as light manufactures, heavy manufactures and agricultural products. Next in line is Honduras, where benefits would be concentrated in mining and extraction and the agricultural sector. Guatemala, El Salvador and Nicaragua would also benefit, although to a lesser degree (see table III.11).

Table III.11

BREAKDOWN OF EXPORTS FROM THE CENTRAL AMERICAN COMMON MARKET (CACM) TO THE EUROPEAN UNION, 2006

(Percentages of total by sector)

\begin{tabular}{lcccccc}
\hline Sector & Costa Rica & El Salvador & Guatemala & Honduras & Nicaragua & CACM \\
\hline Agricultural & 48.3 & 6.6 & 12.1 & 24.0 & 8.9 & 100.0 \\
Mining and extraction & 0.0 & 0.0 & 0.1 & 99.9 & 0.0 & 100.0 \\
Light manufactures & 58.4 & 30.7 & 2.8 & 3.0 & 5.1 & 100.0 \\
Heavy manufactures & 90.8 & 1.1 & 6.8 & 0.7 & 0.6 & 100.0 \\
Total & $\mathbf{5 6 . 7}$ & $\mathbf{7 . 4}$ & $\mathbf{1 0 . 1}$ & $\mathbf{1 9 . 1}$ & $\mathbf{6 . 8}$ & $\mathbf{1 0 0 . 0}$ \\
\hline
\end{tabular}

Source: Prepared by the authors, on the basis of data from the United Nations Commodity Trade Database (COMTRADE), accessed through the World Bank's World Integrated Trade Solution (WITS).

As shown above, the total liberalization scenario results in smaller export volumes for Costa Rica and the rest of Central America (down $1.37 \%$ and $4.94 \%$, respectively). Under scenario 3, exports drop by $1.39 \%$ for Costa Rica. For Guatemala and Nicaragua, exports increase in all scenarios. Under the partial liberalization scenario, exports rise for all Central American countries by between $0.4 \%$ and $1.0 \%$. When export volumes are analysed, increases are observed in all scenarios, and to a greater extent under complete liberalization. Again, the main explanation for this result lies in the larger price increases for exported products, which generates favourable increases in the terms of trade for all countries under the full liberalization scenario. 
In scenario 1, the sector of Costa Rica that posts the largest increase in exports is fruit and vegetables (49.4\%), while in the rest of Central America the only sector to increase production is sugar. For Guatemala and Nicaragua, there are increases in fruit and vegetables, livestock and various agro-industry sectors. This pattern of change in exports is similar in scenario 3. Export changes in scenario 2, on the other hand, are smaller than in the other simulations (with variations of less than $+/-5 \%$ ).

Table III.13 summarizes the main changes at the subsector level according to degree of technological intensity. Agricultural products and light manufactures are clearly vital for Central American countries. For both aggregates, a possible trade association agreement with the European Union would provide a greater boost to the subregion's total exports. The least favourable scenario is the one excluding sensitive products, and one in which the European Union excludes fruits and vegetables from the agreement is an intermediate situation.

The possible effects are practically nil in all sectors (except agricultural products). Despite this, in relative terms, there are practically no changes for European countries, as noted above (see table III.12).

The terms of trade improve in scenarios 1 and 3 but worsen under scenario 2. This is because in scenarios 1 and 3, the increase in export prices is greater than the improvement in export prices, whereas in scenario 2, export prices fall by more than import prices.

Import volumes increase in all scenarios, and to the greatest extent in scenarios 1 and 3 , in that order. In scenario 1, imports rise particularly for Costa Rica (1.9\%) and the rest of Central America (6.4\%). In scenario 3 , they rise by $1.8 \%$ for Costa Rica and by $0.4 \%$ for the rest of Central America. For Guatemala and Nicaragua, imports increase by between 0.1 and $0.8 \%$ in all scenarios. In scenarios 1 and 3 , the sectors that have the largest increases in imports for Costa Rica and the rest of Central America are agriculture and agro-industry. For Guatemala and Nicaragua, there is a larger increase in wheat and certain light manufactures and heavy manufactures. As with exports, the change for imports under scenario 2 is minimal. And as in the previous cases, the calculations show larger variations for total import values than for volume.

\section{Analysis of variations in welfare}

In terms of welfare, total liberalization is the most beneficial scenario for the region's countries. The net benefit for Costa Rica is US\$ 477 million, while the largest welfare increase is that recorded for the group of countries composed of Belize, El Salvador, Honduras and 
Table III.12

ASSESSMENT OF THE IMPACT OF AN ASSOCIATION AGREEMENT BETWEEN CENTRAL AMERICA AND THE EUROPEAN UNION: BREAKDOWN

OF THE VALUE OF EXPORTS, VARIOUS SCENARIOS

(Percentage variation in relation to the base scenario 2007

and each sector's contribution to the total)

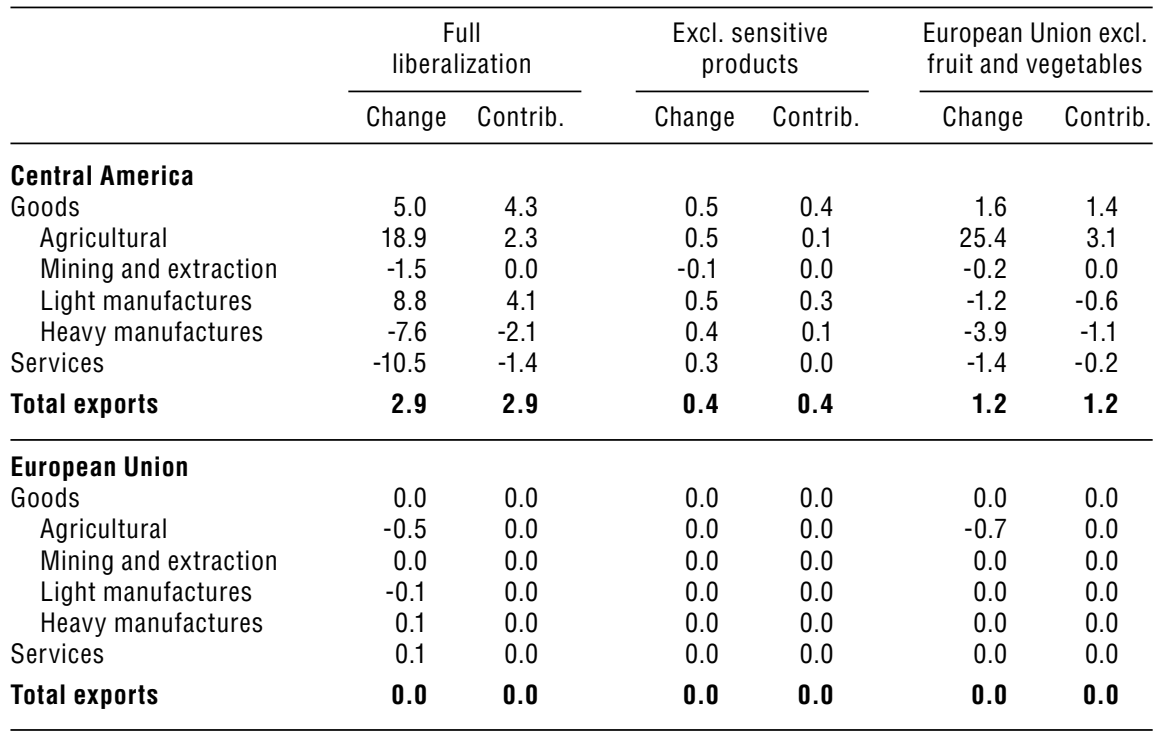

Source: Prepared by the authors, on the basis of simulations from "GTAP 7.0 Database" [online database] https://www.gtap.agecon.purdue.edu/databases/v7/default.asp.

Panama (totalling US\$ 1.386 billion). Welfare does increase for Guatemala and Nicaragua, although the rises are small (US\$ 13 million and US\$ 4 million, respectively).

These results stand in sharp contrast to those obtained under the scenario with sensitive products, where welfare falls in all Central American countries. This is mostly due to the worsening terms of trade for those countries. However, if only fruit and vegetables are considered sensitive products for the European Union, welfare gains are almost recovered for Costa Rica (US\$ 462 million) and recovered to a lesser extent for the rest of Central America (US\$ 25 million). The same cannot be said of Guatemala, where welfare still falls, and in Nicaragua where welfare remains the same in scenarios 2 and 3 (see figure III.6).

Table III.13 more clearly illustrates the effect on welfare by giving a breakdown of the changes. For the full liberalization scenario, most of the welfare gains for Costa Rica and the rest of Central America come from the improved terms of trade. This is because of the rise in export prices, especially for the following sectors: fruit and vegetables, 
Figure III.6
PROPOSED FREE TRADE AGREEMENT BETWEEN EUROPEAN UNION AND CENTRAL AMERICAN COMMON MARKET: WELFARE CHANGES UNDER VARIOUS SIMULATED SCENARIOS

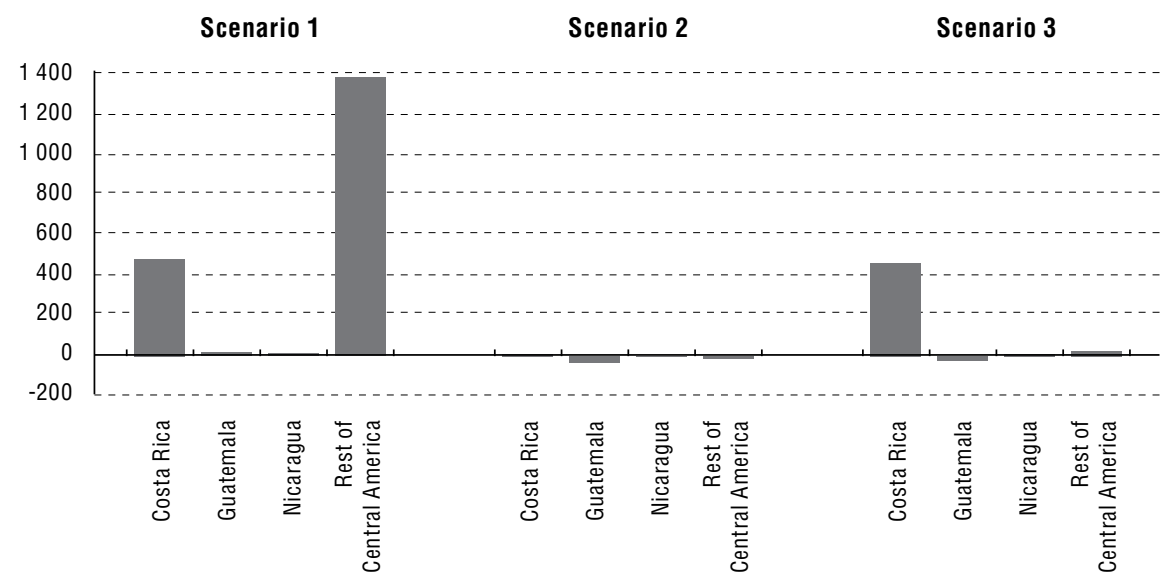

Source: Prepared by the author, on the basis of the results of simulations using the GTAP model.

Table III.13

PROPOSED FREE TRADE AGREEMENT BETWEEN EUROPEAN UNION AND CENTRAL AMERICAN COMMON MARKET: CHANGES IN WELFARE (EQUIVALENT VARIATION) (Millions of dollars)

\begin{tabular}{|c|c|c|c|c|}
\hline Scenario/Country & $\begin{array}{l}\text { Efficiency in factor } \\
\text { distribution }\end{array}$ & $\begin{array}{l}\text { Terms of } \\
\text { trade }\end{array}$ & $\begin{array}{l}\text { Savings and } \\
\text { investment }\end{array}$ & Total \\
\hline \multicolumn{5}{|l|}{ Scenario 1} \\
\hline Costa Rica & 44 & 456 & -23 & 477 \\
\hline Guatemala & 7 & -3 & 9 & 13 \\
\hline Nicaragua & 3 & -1 & 2 & 4 \\
\hline Rest of Central America & 103 & 1015 & 266 & 1386 \\
\hline European Union 27 & 957 & -1018 & -75 & -136 \\
\hline \multicolumn{5}{|l|}{ Scenario 2} \\
\hline Costa Rica & -1 & -6 & 7 & 0 \\
\hline Guatemala & -2 & -15 & -15 & -32 \\
\hline Nicaragua & -1 & -1 & -2 & -4 \\
\hline Rest of Central America & 2 & -9 & -7 & -14 \\
\hline European Union 27 & 54 & 89 & 7 & 150 \\
\hline \multicolumn{5}{|l|}{ Scenario 3} \\
\hline Costa Rica & 39 & 442 & -19 & 462 \\
\hline Guatemala & 0 & -12 & -11 & -23 \\
\hline Nicaragua & 0 & -3 & -1 & -4 \\
\hline Rest of Central America & 7 & 18 & 0 & 25 \\
\hline European Union 27 & 320 & -279 & 7 & 48 \\
\hline
\end{tabular}

Source: Prepared by the authors, on the basis of the results from "GTAP 7.0. Database" [online database] https://www.gtap.agecon.purdue.edu/databases/v7/default.asp. 
other manufactures and other crops, in the case of Costa Rica; and fruit and vegetables, services, textiles, garments and sugar, in the rest of Central America.

For the partial liberalization scenario, excluding sensitive products, the welfare losses are attributable both to worsening of the terms of trade and to a loss of efficiency in the use of economic resources.

An analysis of the scenario in which fruit and vegetables are excluded as a sensitive sector for the European Union shows the importance of this sector for welfare gains of Central America. Under this scenario, most of the benefits originate in the improved terms of trade. For Costa Rica and the rest of Central America, 70\% and 53\% (respectively) of the benefit from improved terms of trade comes from fruit and vegetables. These are precisely the sectors that are favourable to welfare in a complete liberalization scenario (scenario 1).

\section{Results of partial equilibrium simulations (trade and welfare)}

The results for trade creation and welfare variation in Central American countries follow the same pattern as the results from the general equilibrium model, in that the best scenario is full liberalization, under which all countries expand their export flows to the European Union. The magnitude of trade creation is determined by the composition of the export basket. Greater increases are expected in agricultural sectors, with Costa Rica and Guatemala posting the highest rises. In mining sectors the increases are nil, except for Guatemala and Honduras, in which the variations are minimal. This is due to the scarce endowment in mining and petroleum products in the subregion. Export creation has a positive effect on some light manufactures. Among this group all countries except Honduras would expand their exports. Total increases expected from a full liberalization scenario would be between $11.4 \%$ and $12 \%$ in agricultural products and $35.9 \%$ in light manufactures. The sector to benefit the most would be sugar (see table III.14).

The measure of welfare points to gains in all countries, with Costa Rica and Nicaragua posting the largest increases. These economies would see the greatest increases in welfare as a result of trade creation. In the partial equilibrium simulations, these gains are eliminated when the products that are sensitive for Europe are excluded, and are reduced by about a third in relation to the full liberalization scenario. Importantly, a European Union exclusion of only fruit and vegetables would have less impact on El Salvador and Nicaragua, which would maintain benefits in the light manufactures sector (where most of the increases are 
Table III.14

CENTRAL AMERICAN COMMON MARKET (CACM): TRADE CREATION AND WELFARE VARIATIONS AS A RESULT OF INCREASED EXPORTS TO THE EUROPEAN UNION MARKET, FULL LIBERALIZATION SCENARIO

(Changes to the baseline $=2006$ )

\begin{tabular}{lrrrrrr}
\hline Sector & Costa Rica & El Salvador & Guatemala & Honduras & Nicaragua & CACM \\
\hline Agricultural & 22.3 & 0.0 & 3.4 & 2.7 & 1.5 & 12.0 \\
Mining and extraction & 0.1 & 0.0 & 2.7 & 0.1 & 0.0 & 0.1 \\
Light manufactures & 7.7 & 22.1 & 57.6 & 0.9 & 454.3 & 35.9 \\
Heavy manufactures & 0.2 & 0.4 & 0.1 & 0.6 & 0.2 & 0.2 \\
Trade creation & 14.1 & 7.6 & 4.2 & 2.4 & 29.5 & 11.4 \\
Welfare variation a $^{2}$ & 64.86 & 5.55 & 3.62 & 3.98 & 19.6 & 97.61 \\
Percentage of total & 15.2 & 4.7 & 4.7 & 15.5 & 5.4 & 10.0 \\
\hline
\end{tabular}

Source: Prepared by the author, on the basis of partial equilibrium simulations.

a Millions of dollars.

attributable to sugar). In addition, Nicaragua and El Salvador maintain welfare increases at the same level as in the total liberalization scenario (see table III.15).

To assess the change in structure under the different scenarios simulated using partial equilibrium, a measure of the level of diversification was calculated for the base scenario and the full liberalization scenario. The indicator selected was the HerfindahlHirschman $(\mathrm{HH})$ index, which varies between 0 and 1 . Values below 0.10 indicate a high degree of diversification, while high values point to a greater concentration of the export basket. Rather than determining the level of the index and the extent of concentration, the aim of the

Table III.15

CENTRAL AMERICAN COMMON MARKET (CACM): TRADE CREATION AND WELFARE VARIATIONS AS A RESULT OF INCREASED EXPORTS IN THE EUROPEAN MARKET, SCENARIO OF LIBERALIZATION WITH ONLY FRUIT AND VEGETABLES EXCLUDED BY THE EUROPEAN UNION

(Changes to the baseline $=2006$ )

\begin{tabular}{lcccccr}
\hline Sector & Costa Rica & El Salvador & Guatemala & Honduras & Nicaragua & CACM \\
\hline Agricultural & 0.1 & 0.0 & 0.2 & 1.6 & 1.5 & 0.6 \\
Mining and extraction & 0.1 & 0.0 & 2.7 & 0.1 & 0.0 & 0.1 \\
Light manufactures & 5.5 & 22.1 & 57.6 & 0.9 & 454.3 & 34.6 \\
Heavy manufactures & 0.2 & 0.4 & 0.1 & 0.6 & 0.2 & 0.2 \\
Trade creation & 0.6 & 7.6 & 1.5 & 1.4 & 29.5 & 3.3 \\
Welfare variation a & 4.60 & 5.55 & 1.49 & 2.47 & 19.6 & 33.71 \\
\hline
\end{tabular}

Source: Prepared by the authors, on the basis of partial equilibrium simulations.

a Millions of dollars. 
analysis is to compare the value of the index in the base year and under the simulated scenario, in order to determine whether the level of concentration rises or falls following liberalization.

Figure III.7 shows that in all countries except Costa Rica, an agreement with the European Union would be conducive to a diversification of the basket of goods exported to the European Union. This trend would be markedly more favourable for Nicaragua and El Salvador (see figure III.7). Costa Rica's export basket to the European Union had already become more diversified in the period prior to the simulation exercises (Trejos, 2008; PROCOMER, 2008).

Figure III.7

PROPOSED FREE TRADE AGREEMENT BETWEEN EUROPEAN UNION AND CENTRAL AMERICAN COMMON MARKET: CHANGES IN STRUCTURE FOLLOWING

LIBERALIZATION WITH THE EUROPEAN UNION (Herfindhal-Hirschmann index)

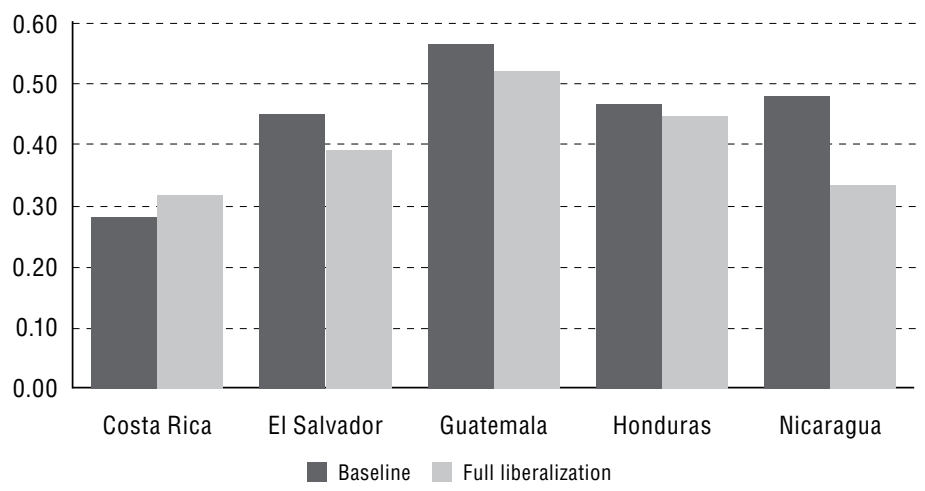

Source: Prepared by the authors, on the basis of partial equilibrium simulations.

A comparison of both scenarios makes it clear that full liberalization - that is, with the inclusion of fruit and vegetables - would be preferable for Central American countries. Indeed, the list of winning products includes many from this category (see table III.16).

\section{Changes in environmental sensitivity in Central America}

A complete examination of the possible macroeconomic and (especially) trade impacts of a potential trade agreement with the European Union should include some measurement of the change in the structure and the growth of the most environmentally sensitive 
Table III.16

EFFECTS OF AN ASSOCIATION AGREEMENT BETWEEN THE CENTRAL AMERICAN COMMON MARKET (CACM) AND THE EUROPEAN UNION ON ENVIRONMENTALLY SENSITIVE INDUSTRIES (ESI)

(Percentage variation from the base scenario $=2007$ )

\begin{tabular}{|c|c|c|c|c|}
\hline \multicolumn{5}{|c|}{ Total world exports (CGE results) } \\
\hline & $\begin{array}{c}\text { Scenario } 1 \\
\text { Ultraliberalized }\end{array}$ & $\begin{array}{l}\text { Scenario } 2 \\
\text { Excl. sensitive } \\
\text { goods }\end{array}$ & $\begin{array}{c}\text { Scenario } 3 \\
\text { European Union excl. } \\
\text { of fruit and veg. }\end{array}$ & $\begin{array}{l}\% \text { ESI } \\
\text { in total } \\
\text { exports }\end{array}$ \\
\hline $\begin{array}{l}\text { Costa Rica } \\
\text { Guatemala } \\
\text { Nicaragua } \\
\text { Rest of CACM }\end{array}$ & $\begin{array}{r}-3.3 \\
-1.0 \\
-0.7 \\
-18.3\end{array}$ & $\begin{array}{r}-0.3 \\
0.0 \\
-1.0 \\
-0.5\end{array}$ & $\begin{array}{l}-3.5 \\
-0.1 \\
-0.8 \\
-0.7\end{array}$ & $\begin{array}{r}6.5 \% \\
11.8 \% \\
3.3 \% \\
15.6 \%\end{array}$ \\
\hline CACM & -7.0 & -0.3 & -0.2 & $9.6 \%$ \\
\hline \multicolumn{5}{|c|}{ Total exports to the European Union (CGE results) } \\
\hline & $\begin{array}{c}\text { Scenario } 1 \\
\text { Ultraliberalized }\end{array}$ & $\begin{array}{l}\text { Scenario } 2 \\
\text { Excl. sensitive } \\
\text { goods }\end{array}$ & $\begin{array}{c}\text { Scenario } 3 \\
\text { European Union excl. } \\
\text { of fruit and veg. }\end{array}$ & $\begin{array}{l}\% \text { ESI } \\
\text { in total } \\
\text { exports }\end{array}$ \\
\hline Costa Rica & -1.6 & 0.8 & -1.2 & $3.4 \%$ \\
\hline Guatemala & -1.5 & 1.8 & 1.2 & $12.5 \%$ \\
\hline Nicaragua & -1.8 & 1.9 & 1.2 & $1.4 \%$ \\
\hline Rest of CACM & -10.0 & 0.3 & 0.0 & $1.3 \%$ \\
\hline CACM & -7.1 & 0.8 & -0.7 & $3.9 \%$ \\
\hline
\end{tabular}

Source: Prepared by the authors, on the basis of simulations using computable general equilibrium (CGE) with the "GTAP 7.0 Database" [online database] https://www.gtap.agecon.purdue.edu/databases/v7/default.asp.

sectors. This is one of the mechanisms for capturing the effects of a trade agreement on sustainable development and for assessing possible changes in the dependence of the export basket on environmentally sensitive industries as a result of liberalization.

With this in mind, the changes to "environmentally sensitive" exports were calculated, with the assumption that the weightings of each industry would be maintained following the trade agreement. In the central scenario, the results were very positive, with CACM countries as a whole showing a $7.90 \%$ reduction in environmentally sensitive exports to the world and a $7.1 \%$ reduction in those exported to the European Union (see table III.17). In general terms, this would indicate a reduced environmental sensitivity of Central American exports, not only as a result of a direct decrease associated with the European Union agreement but also because the agreement would lead to a larger relative reduction of such products in the subregion's production structure in favour of more environmentally friendly sectors. This is apparent in Costa Rica and the rest of the CACM. 
Table III.17

EFFECTS OF TOTAL TARIFF ELIMINATION UNDER AN ASSOCIATION AGREEMENT BETWEEN THE CENTRAL AMERICAN COMMON MARKET (CACM) AND THE EUROPEAN UNION ON ENVIRONMENTALLY SENSITIVE INDUSTRIES (ESI) (Percentage variation on the base scenario $=2007$ )

\begin{tabular}{|c|c|c|c|c|c|}
\hline & Costa Rica & Guatemala & Nicaragua & Rest of CACM & CACM \\
\hline \multicolumn{6}{|l|}{$\begin{array}{l}\text { Scenario } 1 \\
\text { (full liberalization) }\end{array}$} \\
\hline Forestry & 2.9 & -0.4 & 0.0 & -28.9 & 1.5 \\
\hline Other foods & 0.0 & 0.0 & 0.0 & 0.0 & 0.0 \\
\hline Wood & -1.3 & -1.0 & -0.1 & -6.4 & -3.7 \\
\hline Paper & -6.3 & -2.1 & -0.3 & -28.5 & -7.8 \\
\hline Petroleum derivatives & 0.3 & -1.6 & 0.0 & 0.0 & -7.7 \\
\hline Chemicals & -3.0 & -1.4 & -1.7 & -30.5 & -5.4 \\
\hline Minerals & 0.0 & 0.0 & 0.0 & -27.2 & -0.9 \\
\hline Metal & -4.8 & -1.1 & -0.3 & -1.9 & -12.4 \\
\hline Metallic products & -7.8 & -3.7 & -3.0 & -26.0 & -10.7 \\
\hline Total ESI & -1.6 & -1.5 & -1.8 & -10.0 & -7.1 \\
\hline \multicolumn{6}{|l|}{$\begin{array}{l}\text { Scenario } 2 \text { (excl. } \\
\text { sensitive products) }\end{array}$} \\
\hline Forestry & 3.5 & 0.4 & 0.0 & 0.2 & 3.3 \\
\hline Other foods & 0.0 & 0.0 & 0.0 & 0.0 & 0.0 \\
\hline Wood & -0.2 & 0.8 & 0.0 & 0.1 & 0.1 \\
\hline Paper & 0.3 & 1.2 & 0.1 & 0.7 & 0.6 \\
\hline Petroleum derivatives & 0.7 & 1.0 & 0.0 & 0.0 & 0.4 \\
\hline Chemicals & 0.7 & 2.2 & 1.9 & 1.3 & 1.2 \\
\hline Minerals & 0.0 & 0.0 & 0.0 & 0.4 & 0.1 \\
\hline Metal & 1.1 & 2.5 & 0.1 & 0.1 & 1.0 \\
\hline Metallic products & 0.8 & 1.6 & 0.9 & 1.3 & 1.0 \\
\hline Total ESI & 0.8 & 1.8 & 1.9 & 0.3 & 0.8 \\
\hline \multicolumn{6}{|l|}{$\begin{array}{l}\text { Scenario } 3 \\
\text { (European Union excl. of } \\
\text { fruit and vegetables) }\end{array}$} \\
\hline Forestry & 3.0 & 0.3 & 0.0 & -0.5 & 2.8 \\
\hline Other foods & 0.0 & 0.0 & 0.0 & 0.0 & 0.0 \\
\hline Wood & -1.1 & 0.4 & 0.0 & 0.0 & -0.3 \\
\hline Paper & -5.3 & 0.6 & 0.0 & -0.1 & -3.3 \\
\hline Petroleum derivatives & 0.3 & 0.5 & 0.0 & 0.0 & 0.1 \\
\hline Chemicals & -2.4 & 1.5 & 1.3 & 0.3 & -1.5 \\
\hline Minerals & 0.0 & 0.0 & 0.0 & -0.3 & -0.3 \\
\hline Metal & -3.9 & 1.9 & 0.0 & 0.0 & -0.8 \\
\hline Metallic products & -6.6 & 0.7 & 0.2 & 0.4 & -4.3 \\
\hline Total ESI & -1.2 & 1.2 & 1.2 & 0.0 & -0.7 \\
\hline
\end{tabular}

Source: Prepared by the authors, on the basis of simulations using computable general equilibrium (CGE) with the "GTAP 7.0 Database" [online database] https://www.gtap.agecon.purdue.edu/databases/v7/default.asp.

The alternative scenarios show little variation in environmental make-up of the export pattern, although excluding sensitive products from exports to the European Union would promote the development of the capacity to export products from dirty industries, and these products would also be diverted away from exports sold to the rest of the world. Excluding fruits and vegetables favours Costa Rica environmentally, 
whereas the other countries would divert environmentally sensitive exports from the rest of the world to Europe. In any event, the variations are limited, which was predictable given that the Central American basket of environmentally sensitive exports to the European Union is fairly small (3.9\% of the total) and represents less than $10 \%$ of the subregion's total exports.

As for the specific impact on the countries that make up the subregion, there are signs of a similar reduction of imports from environmentally sensitive industries for Europe in Costa Rica, Guatemala and Nicaragua, and a much clearer reduction for the rest of the CACM countries. In these three countries, the reduction in chemical exports has the greatest effect on the ultimate decline of environmentally sensitive industries, although reductions in paper and metallic products also play a role. The increase in forestry exports by Costa Rica (although their share of total exports is less than $1 \%$ ) - and the increase in all countries' environmentally harmful sectors when sensitive products are excluded from the agreement- is a cause for concern.

Guatemala is more dependent on environmentally sensitive industries and, like Nicaragua, its exports from this type of industry always increase under scenarios that do not amount to complete liberalization.

In any event, both the general equilibrium and partial equilibrium approaches show that, if exports associated with environmentally sensitive industries do not decline they will increase less than those products from other sectors, and hence their share in the pattern of exports will diminish.

\section{F. Conclusions and trade policy recommendations}

The European Union is the second largest trading partner of Central American countries, and one of the main providers of official development aid to the subregion. Since the mid-1990s, Central American exports to the European Union have dropped considerably, although they had been relatively flat in the first half of the 1990s. Also, imports from Europe declined in proportion to total imports. Given this situation, it was sensible for both sides to attempt to strengthen trade links, especially considering that tariff levels remain high in both directions. In 2007, formal talks were opened on concluding an Association Agreement between the European Union and Costa Rica, El Salvador, Guatemala, Honduras and Nicaragua.

This study assesses the socio-economic and environmental impact of the agreement by applying two complementary economic approaches: computable general equilibrium and partial equilibrium. 
The characteristics of the model and database used (GTAP) preclude an analysis of the impact on El Salvador and Honduras individually. The partial equilibrium analysis is therefore essential for those two countries.

To provide results that support the work of negotiators, it is vital to consider the sensitive production sectors of both regions and include them in the simulations. The study therefore analyses three scenarios: full liberalization on both sides, liberalization excluding sensitive products on both sides and liberalization with fruits and vegetables excluded by the European Union.

Generally speaking, the results point to a complete liberalization of all tariff lines being favourable to both regions, through export growth (of between $1 \%$ and $5 \%$ ) for all countries covered by the agreement, with agricultural products and to some extent light manufactures in particular benefitting in the case of Central America. These results are supported by those obtained using the partial equilibrium approach. In terms of welfare, full liberalization would generate increases for all countries involved, with significant rises for Costa Rica. This would be due to improved terms of trade associated with higher export prices for Central American agricultural exports (especially fruit and vegetables and other crops). Although the scenario excluding sensitive products shows little change in trade, any such changes would be positive. When the European Union excludes fruit and vegetables, results remain positive with regard to trade and output, although to a lesser extent than under the full liberalization scenario. It is striking that the scenario excluding sensitive products generates welfare losses associated with worsening terms of trade and lower efficiency in the use of factors.

Any full analysis of an agreement requires due consideration for its implications for environmental sustainability. Although this study has not attempted to carry out an exhaustive analysis on the subject, it has examined the dependence of the export pattern on environmentally sensitive industries. From that point of view, the agreement with the European Union is positive for the countries in question, provided that complete liberalization is achieved. In such a scenario, environmentally sensitive exports would fall for all countries, with the opposite happening should sensitive products be excluded. In any event, any positive effects for this type of industries are relatively small, and their share of the export pattern therefore diminishes. The low dependency of Central American countries on exports from environmentally sensitive industries means that the positive trade impacts of the agreement are not concentrated in these sectors. 
The results of the partial equilibrium simulations provided additional information on the type of products to benefit most from liberalization, and these were mainly agricultural products (including bananas, pineapples, lemons, oranges, nuts and shrimp). These simulations also confirmed the idea that the largest gains are achieved when levels of tariff protection are removed. The increase in welfare associated with higher exports was dominated (as in the CGE exercises) by Costa Rica, which is the largest Central American trading partner of the European Union (with full liberalization providing the best results).

It should be borne in mind that the two economic approaches were applied in a static context, and therefore do not incorporate potential dynamic impacts associated with the agreement, which are highly significant given the importance within the negotiations of issues such as investment, services, intellectual property and health and phytosanitary security.

Lastly, relatively little progress has been made in terms of multilateral liberalization at the global level, and there is a notable inequality of economic and social development between the two negotiating regions. Moreover, the gains and losses for the European Union are practically nil in all scenarios. Consequently, the European Union should reaffirm its commitment to combating poverty and maintaining an active policy in favour of fairer trade (that is, the Millennium Development Goals) by being more flexible and generous in consensus-building with a view to concluding the negotiations. 


\section{Bibliography}

Alvarez, Roberto and José Miguel Benavente H. (1997), "Impacto de un acuerdo de libre comercio: una revisión metodológica", Documentos de trabajo series, No. 145, Santiago, Chile, Department of Economics, Faculty of Economic and Administrative Sciences of the University of Chile.

Bergsten C. (2005), The United States and the World Economy, Washington, D.C., Institute for International Economics.

Cline, W. and others (1978), Trade Negotiations in the Tokio Round: a Quantitative Assessment, Washington, D.C., Brookings Institution.

Cordero, Martha (2005), "RD-CAFTA: características, impacto y perspectivas", México, D.F., sede subregional de la CEPAL en México, inédito.

Durán Lima, José E. and Raúl Maldonado (2005), “América Latina y el Caribe: la integración regional en la hora de las definiciones", Comercio internacional series, No. 62 (LC/L.2454-P), Santiago, Chile, Economic Commission for Latin America and the Caribbean (ECLAC). United Nations publication, Sales No. S.05.II.G.200.

(2003), "La ampliación de la Unión Europea hacia los países de Europa Central y Oriental: una evaluación preliminar del impacto para América Latina y el Caribe", Comercio internacional series, No. 45 (LC/L.2053-P), Santiago, Chile, Economic Commission for Latin America and the Caribbean (ECLAC). United Nations publication, Sales No. S.03.II.G.216.

ECLAC (Economic Commission for Latin America and the Caribbean) (2007), Latin America and the Caribbean in the World Economy, 2006. 2007 Trends (LC/G.2341-P), Santiago, Chile, October. United Nations publication, Sales No. E.07.II.G.85.

El Comercio (2008a), "Negociaciones de la Ronda de Doha fracasaron", Quito, 29 July.

(2008b), "UE rechaza firmar acuerdo del banano con América Latina", Quito, 29 de julio.

European Commission (2010), "European Commission trade" [online] http:// ec.eiropa.eu/trade.

(2002), "América Latina. La Comisión Europea adopta una estrategia para la cooperación regional 2002-2006", Brussels, April.

European Union (1993), "Framework Cooperation Agreement between the European Community and the Republics of Costa Rica, El Salvador, Guatemala, Honduras, Nicaragua and Panama. Exchange of letters on maritime transport: unilateral declarations" [online] http://eur-lex.europa.eu/LexUriServ/LexUriServ.do?u ri=CELEX:21999A0312(01):EN:HTML.

FAO (Food and Agriculture Organization of the United Nations) (2005), "Tariff reduction formulae: methodological issues in assessing their effects", FAO trade policy technical notes on issues related to the WTO negotiations on agriculture, No. 2 [online] ftp://ftp.fao.org/docrep/fao/007/j4019e/j4019e00.pdf.

Francois, J., M. McQueen and G. Wignaraja (2005), “EU - developing country FTA's: overview and analysis", document prepared for the United Nations trade taskforce on the Millennium Development Goals [online] http://www.ycsg. yale.edu/focus/gta/euDeveloping.pdf.

Hertel, T.W. (ed.) (1997), Global Trade Analysis: Modeling and Applications, Cambridge, Cambridge University Press. 
La Hora (2008), "La CAN buscará resolver insalvables", Quito, 1 August.

Lall, Sanjaya (2000), "The technological structure and performance of developing country manufactured exports, 1985-98", Oxford Development Studies, vol. 28, No. 3.

Low, P. and A. Yeats (1992), “Do 'dirty' industries migrate?", World Bank Discussion Papers, No. 159, Washington, D.C., World Bank.

Ludeña, Carlos, José E. Durán and Andrés Schushny (2008), "I-O Table: Guatemala", GTAP 7 Data Base Documentation, Global Trade Analysis Project (GTAP) [online] https://www.gtap.agecon.purdue.edu/resources/res_display. asp?RecordID=2917.

Mandelson, Peter (2008), "Final remarks by EUTradeCommissioner Peter Mandelson", press conference at the Geneva WTO ministerial, Geneva, 29 July [online] http:/ / trade.ec.europa.eu/doclib/docs/2008/july/tradoc_140012.pdf.

Pardo de León, Josefita (2006a), "Hacia un acuerdo de asociación entre Centroamérica y la Unión Europea: elementos para la definición de la estrategia de negociación" [online] http:/ /www.gtz.de/en/dokumente/sp-sl-acuerdo-de-asociacion-entrecentroamerica-y-la-union-europea.pdf.

(2006b), “El mercado de la Unión Europea: retos y oportunidades para las exportaciones no tradicionales de Guatemala" [online] http: / / www.negociosgt. com/archivos/RetosyOportunidadesUE.pdf.

(2006c), "Hacia un acuerdo de asociación entre Centroamérica y la Unión Europea" [online] http://www.incae.com/ES/clacds/seminario/pdfs/josefitapardo.pdf.

PROCOMER (Foreign Trade Corporation of Costa Rica) (2008), Estadísticas de comercio exterior de Costa Rica, 2007, San José, May.

Reyes Reyes, Mauricio (2005), Efectos en los sectores agropecuarios y agroindustrial chileno del tratado de libre comercio entre Chile y Costa Rica, Santiago, Chile, University of Chile.

Rivas, Christian (2005), "Informe de relaciones comerciales Nicaragua-Unión Europea año 2003-2004", Managua, April [online] http://www.sice.oas.org/ TPD/CACM_EU/Studies/RelNicUE0304_s.pdf.

Rodríguez-Clare, Andrés (2001), "Costa Rica's development strategy based on human capital and technology: how it got there, the impact of Intel, and lessons for other countries", United Nations Development Programme (UNDP) [online] http:/ /hdr.undp.org/en/reports/global/hdr2001/papers/rodriguez-clare.pdf.

Salazar, Alexander, Kattia Bermúdez and Randall Cordero (2007), "TLC de Centroamérica con socios extrarregionales" [online] http:/ /www.elfinancierocr. com/accesolibre/2007/noviembre/18/TLC1.swf.

Sánchez-C., M.V. (2004), Rising Inequality and Falling Poverty in Costa Rica's Agriculture during Trade Reform. A Macro-micro General Equilibrium Analysis, Mastricht, Shaker.

Sánchez, Marco and Carlos Ludeña (2008), "I-O Table: Costa Rica", GTAP 7 Data Base Documentation, Global Trade Analysis Project (GTAP) [online] https:// www.gtap.agecon.purdue.edu/resources/res_display.asp?RecordID=2913.

Sánchez, Marco, Rob Vos and Carlos Ludeña (2008), "I-O Table: Panamá", GTAP 7 Data Base Documentation, Global Trade Analysis Project (GTAP) [online] https:/ / www.gtap.agecon.purdue.edu/resources/res_display.asp?RecordID=2912. 
Schaper, Marianne (1999)," Impactos ambientales de los cambios en la estructura exportadora en nueve países de América Latina y el Caribe: 1980-1995“, Medio ambiente y desarrollo series, No. 19 (LC/L.1241-P), Santiago, Chile, Economic Commission for Latin America and the Caribbean (ECLAC), October. United Nations publication, Sales No. S.99.II.G.44.

Schuschny, A., José E. Durán Lima and Carlos J. de Miguel (2008), “Política comercial de Chile y los TLC con Asia: evaluación de los efectos de los TLC con Japón y China", Estudios estadísticos y prospectivos series, No. 66 (LC/L.2951-P), Santiago, Chile, Economic Commission for Latin America and the Caribbean (ECLAC), September. United Nations publication, Sales No. S.08.II.G.

(2007a), "El modelo GTAP y las preferencias arancelarias en América Latina y el Caribe: reconciliando su año base con la evolución reciente de la agenda de liberalización regional", Manuales series, No. 53 (LC/L.2679-P), Santiago, Chile, Economic Commission for Latin America and the Caribbean (ECLAC), February. United Nations publication, Sales No. S.07.II.G.29.

(2007b), "Acuerdos de libre comercio entre los países andinos y los Estados Unidos: ¿cuánto se puede esperar de ellos?", Comercio internacional series, No. 77 (LC/L.2678-P), Santiago, Chile, Economic Commission for Latin America and the Caribbean (ECLAC). United Nations publication, Sales No. S.07.II.G.27.

SIECA (Secretariat for Central American Economic Integration) (2009a), "Estado de situación de la integración económica centroamericana" [online] http:/ / www. sieca.int/site/Cache/17990000002915/17990000002915.pdf.

(2009b), "La unión aduanera centroamericana" [online] http://www.sieca.int/ site/VisorDocs.aspx?IDDOC=Cache/17990000003052/17990000003052.swf.

(2007), Informe Centroamericano. Período 2004-2006, Buenos Aires, InterAmerican Development Bank (IDB)/Institute for the Integration of Latin America and the Caribbean (INTAL).

Stawowy, Wojciech (2001), "Calculation of ad valorem equivalent of non-ad valorem tariffs. Methodology notes", United Nations Conference on Trade and Development (UNCTAD) [online] http://wits.worldbank.org/witsweb/ download/docs/AVEmeth.doc.

Tokarick, Stephen (2008), "Dispelling some misconceptions about agricultural trade liberalization", Journal of Economic Perspectives, vol. 22, No. 1.

Trejos, Alberto (2008), "Evaluación del impacto de acuerdos comerciales internacionales: aplicaciones y consideraciones para países pequeños en América Latina", Documento de trabajo, Mexico City, ECLAC subregional headquarters in Mexico, February, unpublished.

Van der Mensbrugghe, Dominique (2006), "Estimating the benefits: why numbers change", Trade, Doha, and Development. A Window into the Issues, Richard Newfarmer (ed.), Washington, D.C., Word Bank. 


\section{Annexes}

\section{Annex 1}

TRADE AND RECIPROCAL TARIFFS APPLIED BY CENTRAL AMERICA AND THE EUROPEAN UNION

(Baseline $=2004)$

\begin{tabular}{|c|c|c|c|c|c|c|}
\hline \multicolumn{2}{|c|}{ No. Product } & \multirow{2}{*}{$\begin{array}{c}\text { Exports }^{a} \\
0\end{array}$} & \multirow{2}{*}{$\begin{array}{c}\begin{array}{c}\text { Barriers in European } \\
\text { Union } 27 \\
(\% \text { of prod. value })^{\text {a }}\end{array} \\
0.0\end{array}$} & \multirow{2}{*}{$\begin{array}{c}\text { Imports }^{\mathrm{a}} \\
0 \\
0\end{array}$} & \multirow{2}{*}{$\begin{array}{c}\begin{array}{c}\text { Barriers in } \\
\text { Central America } \\
\text { (\% of prod. value) }^{\circ}\end{array} \\
0.0\end{array}$} & \multirow{2}{*}{$\begin{array}{r}\begin{array}{c}\text { Trade } \\
\text { balance }\end{array} \\
0\end{array}$} \\
\hline 1 & Rice & & & & & \\
\hline 2 & Wheat & 0 & 0.0 & 0 & 0.0 & 0 \\
\hline 3 & Ocereales & 4 & 0.0 & 0 & 0.0 & 4 \\
\hline 4 & FruitsVeg & 1091 & 33.2 & 5 & 15.2 & 1086 \\
\hline 5 & Oilseeds & 25 & 0.0 & 0 & 0.9 & 25 \\
\hline 6 & VegFibers & 1 & 0.0 & 0 & 0.0 & 0 \\
\hline 7 & Ocrops & 593 & 0.1 & 15 & 1.4 & 578 \\
\hline 8 & Livestock & 14 & 0.0 & 3 & 4.2 & 11 \\
\hline 9 & Forestry & 103 & 0.1 & 1 & 1.3 & 101 \\
\hline 10 & Fishing & 4 & 0.0 & 2 & 0.7 & 2 \\
\hline 11 & EnergyExt & 1 & 0.0 & 1 & 0.0 & 0 \\
\hline 12 & Mining & 27 & 0.0 & 4 & 1.6 & 23 \\
\hline 13 & Meat & 23 & 0.4 & 6 & 13.3 & 16 \\
\hline 14 & VegOils & 5 & 0.0 & 11 & 10.6 & -6 \\
\hline 15 & Dairy & 11 & 0.0 & 30 & 14.4 & -18 \\
\hline 16 & Sugar & 49 & 15.4 & 1 & 28.5 & 48 \\
\hline 17 & OtrFood & 340 & 1.6 & 82 & 9.2 & 257 \\
\hline 18 & DrinkTobac & 26 & 0.0 & 74 & 16.7 & -48 \\
\hline 19 & Textiles & 62 & 0.0 & 65 & 10.5 & -2 \\
\hline 20 & Apparel & 53 & 0.0 & 27 & 15.9 & 26 \\
\hline 21 & LeathShoes & 34 & 0.0 & 18 & 11.3 & 15 \\
\hline 22 & Wood & 21 & 0.0 & 26 & 12.3 & -4 \\
\hline 23 & Paper & 26 & 0.0 & 134 & 3.3 & -108 \\
\hline 24 & PetrolD & 8 & 0.0 & 131 & 9.5 & -123 \\
\hline 25 & Chemicals & 76 & 0.0 & 597 & 2.8 & -521 \\
\hline 26 & MineralProds & 9 & 0.0 & 58 & 10.2 & -49 \\
\hline 27 & Metal & 4 & 0.0 & 108 & 2.0 & -103 \\
\hline 28 & MetalProds & 13 & 0.0 & 93 & 5.4 & -80 \\
\hline 29 & Autop & 14 & 0.0 & 193 & 10.7 & -179 \\
\hline 30 & TranspEq & 12 & 0.0 & 290 & 1.0 & -278 \\
\hline 31 & MachinEq & 115 & 0.0 & 792 & 1.3 & -677 \\
\hline \multirow[t]{4}{*}{32} & OtrManuf & 2389 & 0.0 & 300 & 2.2 & 2089 \\
\hline & Total goods & 5153 & 7.3 & 3068 & 4.3 & 2086 \\
\hline & Total services & 3401 & & 1879 & & 1522 \\
\hline & Total Trade & 13707 & & 8014 & & 5693 \\
\hline
\end{tabular}

Source: Prepared by the authors, on the basis of "GTAP 7.0 Database" [online database] https://www.gtap. agecon.purdue.edu/databases/v7/default.asp.

Note: Includes re-exports.

${ }^{a}$ Millions of dollars.

b Authors'calculation, on the basis of weighted tariffs for individual countries and product groups. 
Annex 2

GLOBAL TRADE ANALYSIS PROJECT (GTAP) DATABASE SECTORAL AGGREGATION

\begin{tabular}{llll}
\hline No. Sector & Description & Aggregates \\
\hline 1 & Rice & Rice husk & Agricultural \\
2 & Wheat & Wheat & and livestock \\
3 & Other Cereals & Corn, Barley, etc. & \\
4 & Fruits and vegetables & Fruits, vegetables & \\
5 & Oil seeds and oleaginous fruits & Soya, sunflower, oil palm & \\
6 & Plant fibers & Cotton, jute & \\
7 & Other Crops & Sugarcane, coffee, cocoa, flowers, etc. & \\
8 & Livestock & Cattle, pigs, birds, etc. & \\
9 & Forestry & Forestry and logging & \\
10 & Fishing & Fishing & \\
\hline
\end{tabular}

\begin{tabular}{lll}
\hline 11 Energy Extraction & $\begin{array}{l}\text { Extraction of coal, crude oil and natural gas } \\
\text { Extraction of minerals }\end{array}$ & $\begin{array}{l}\text { Extraction and } \\
\text { mining }\end{array}$ \\
\hline 13 Meat & Meat products from cattle, swine, and poultry & $\begin{array}{l}\text { Light } \\
\text { manufactures }\end{array}$ \\
14 Vegetable oils and fats & Vegetable oils and fats & \\
15 Dairy & Dairy products (milk, yogurt, cheese) & \\
16 Sugar & Refined sugar & \\
17 Other Foods & Milled rice, bakery products, confectionery, etc. \\
18 Drinks and snuff & Drinks and snuff products \\
19 Textiles & Textiles & \\
20 Apparel & Apparel & \\
21 Leather and footwear & Footwear and leather products \\
22 Wood products & Wood products, furniture & \\
23 Paper products & Paper products, printing, etc.. &
\end{tabular}

24 Refined oil products

25 Chemicals

26 Mineral products

27 Metallurgical products

28 Metal products

29 Vehicles

30 Transport equipment

31 Machinery and equipment

32 Other articles
Refined petroleum prod. (gas., naphtha, etc.). Heavy Chemicals and pharmaceuticals

Glass, stone products

Steel sheets

Metal products

Vehicles and parts

Transport equipment

Machinery and equipment

33 Services

Electricity, water, transportation, construction, Services financial services, real estate, government (education, health, etc.), etc.

Source: Prepared by the authors, on the basis of 57 sectors of the "GTAP 7.0 Database" [online database] https://www.gtap.agecon.purdue.edu/databases/v7/default.asp. 


\section{Annex 3}

SENSITIVE PRODUCTS IN THE FREE TRADE AGREEMENT BETWEEN THE DOMINICAN REPUBLIC, CENTRAL AMERICA AND THE UNITED STATES

\begin{tabular}{lllll}
\hline $\begin{array}{l}\text { Central America and the Dominican Republic } \\
\text { Global Trade Analysis Project }\end{array}$ & & \multicolumn{2}{l}{$\begin{array}{l}\text { United States } \\
\text { Global Trade Analysis Project }\end{array}$} \\
\cline { 1 - 2 } Sector & Product & & Sector & Product \\
\hline Other cereals & Maize & & Fruits and vegetables & Peanuts \\
Fruits and vegetables & Potatoes, beans, vegetables & Meat & Meat \\
Meat & Meat & & Dairy & Dairy (cheese) \\
Oils and fats & Vegetable oils & Sugar & Sugar \\
Dairy & Dairy & & Drinks and snuff & Snuff and ethyl alcohol \\
Sugar & Sugar & Other crops & Sugarcane \\
Other foods & Flour, fructose & Plant fibers & Cotton \\
\hline
\end{tabular}

Source: Prepared by the authors, on the basis of the Dominican Republic - Central America - United States Free Trade Agreement (CAFTA-DR). 
Annex 4

ENVIRONMENTALLY SENSITIVE INDUSTRIES

\begin{tabular}{|c|c|c|}
\hline $\begin{array}{l}\text { Standard International } \\
\text { Trade Classif. } \\
\text { Rev.1 }\end{array}$ & Description & $\begin{array}{l}\text { Standard International } \\
\text { Trade Classif. } \\
\text { Rev.2 }\end{array}$ \\
\hline 251 & Pulp and paper waste & 251 \\
\hline 332 & Petroleum products & $334+3351$ to 3354 \\
\hline 512 & Organic chemicals & $511-516$ \\
\hline 513 & Inorganic chemicals & 522 \\
\hline 514 & Other inorganic chemicals & 523 \\
\hline 515 & Radioactive materials & 524 \\
\hline 521 & Coal tar & 3352 \\
\hline 561 & Fertilizers, manufactured & 562 \\
\hline 599 & Insecticides, fungicides, etc. & $591+592+598$ \\
\hline 631 & Veneer and plywood & 634 \\
\hline 632 & Articles of wood & 635 \\
\hline 641 & Paper and paperboard & 641 \\
\hline 642 & Articles of pulp, paper and paperboard & 642 \\
\hline 661 & Lime, cement and other building materials & 661 \\
\hline 671 & Pig iron & 671 \\
\hline 672 & Ingots of iron or steel & 672 \\
\hline 673 & Bars of iron or steel & 673 \\
\hline 674 & Slabs of iron or steel & 674 \\
\hline 675 & Iron or steel strapping & 675 \\
\hline 676 & Rails of iron or steel & 676 \\
\hline 677 & Wire of iron or steel & 677 \\
\hline 678 & Iron or steel pipes & 678 \\
\hline 679 & Mold parts and forging of iron or steel, not work & 679 \\
\hline 681 & Silver and platinum & 681 \\
\hline 682 & Copper & 682 \\
\hline 683 & Nickel & 683 \\
\hline 684 & Aluminum & 684 \\
\hline 685 & Lead & 685 \\
\hline 686 & Zinc & 686 \\
\hline 687 & Tin & 687 \\
\hline 688 & Uranium & 688 \\
\hline 689 & Other non-ferrous minerals & 689 \\
\hline 691 & Finished structural parts & 691 \\
\hline 692 & Metal containers for transport and storage & 692 \\
\hline 693 & Wire products and fencing and trellises & 693 \\
\hline 694 & Nails, bolts, nuts, etc. & 694 \\
\hline 695 & Tools & 695 \\
\hline 696 & Cutlery & 696 \\
\hline 697 & Household & 6973 to 6975 \\
\hline 698 & Manufactures of base metal & 699 \\
\hline
\end{tabular}

Source: Prepared by the authors, on the basis of P. Low and A. Yeats, "Do 'dirty' industries migrate?", World Bank Discussion Papers, No. 159, Washington, D.C., World Bank, 1992 and Marianne Schaper," Impactos ambientales de los cambios en la estructura exportadora en nueve países de América Latina y el Caribe: 1980-1995“, Medio ambiente y desarrollo series, No. 19 (LC/L.1241-P), Santiago, Chile, Economic Commission for Latin America and the Caribbean (ECLAC), October 1999. United Nations publication, Sales No. S.99.II.G.44. 


\section{Annex 5}

\section{TRADE AGREEMENTS OF EUROPEAN UNION $27^{\mathrm{a}}$}

\begin{tabular}{|c|c|c|c|}
\hline Partner & Nature of Agreement & Entry into Force & Comments \\
\hline Faroe Islands (Denmark) & Free Trade Agreement & 1 Jan. 1997 & $\begin{array}{l}\text { Replaces earlier treaty } \\
(1991)\end{array}$ \\
\hline Switzerland & Free Trade Agreement & 1 Jan. 1973 & $\begin{array}{l}\text { Included Lichtenstein, now a } \\
\text { member of the EU }\end{array}$ \\
\hline Macedonia & Stabilization and Association Agreement & 1 May 2004 & $\begin{array}{l}\text { Provisions applied first as an } \\
\text { Interim Agreement }\end{array}$ \\
\hline Croatia & Stabilization and Association Agreement & 1 Feb. 2005 & $\begin{array}{l}\text { Provisions applied first as an } \\
\text { Interim Agreement }\end{array}$ \\
\hline Albania & Stabilization and Association Agreement & 1 Dec. 2006 & $\begin{array}{l}\text { Entry into force of Interim } \\
\text { Agreement is pending }\end{array}$ \\
\hline Montenegro & Stabilization and Association Agreement & 1 Jan. 2008 & $\begin{array}{l}\text { Entry into force of Interim } \\
\text { Agreement is pending }\end{array}$ \\
\hline Bosnia-Herzegovina & Stabilization and Association Agreement & 1 Jul. 2008 & $\begin{array}{l}\text { Entry into force of Interim } \\
\text { Agreement is pending }\end{array}$ \\
\hline Algeria & Partnership Agreement & 1Sep. 2005 & $\begin{array}{l}\text { Supplants the Euro- } \\
\text { Mediterranean Cooperation } \\
\text { Partnership, } 1976\end{array}$ \\
\hline Egypt & Partnership Agreement & 1 Jun. 2004 & $\begin{array}{l}\text { Supplants the Euro- } \\
\text { Mediterranean Cooperation } \\
\text { Partnership, } 1977\end{array}$ \\
\hline Israel & Partnership Agreement & 1 Jun. 2000 & $\begin{array}{l}\text { Euro-Mediterranean } \\
\text { Agreement. Originally } \\
\text { applied trade arrangements } \\
\text { under the } 1995 \text { Agreement }\end{array}$ \\
\hline Jordan & Partnership Agreement & 1 May 2002 & $\begin{array}{l}\text { Euro-Mediterranean } \\
\text { Agreement of } 1997\end{array}$ \\
\hline Lebanon & Interim Agreement & 1 Mar. 2003 & $\begin{array}{l}\text { Supplants the Euro- } \\
\text { Mediterranean Cooperation } \\
\text { Partnerships, } 1977\end{array}$ \\
\hline Morocco & Partnership Agreement & 130 ct. 2000 & $\begin{array}{l}\text { Euro-Mediterranean } \\
\text { Agreement }\end{array}$ \\
\hline Palestinian Authority & Partnership Agreement & 1 Jul. 1997 & $\begin{array}{l}\text { Euro-Mediterranean Interim } \\
\text { Agreement }\end{array}$ \\
\hline Tunisia & Partnership Agreement & 1 Mar. 1998 & $\begin{array}{l}\text { Euro-Mediterranean } \\
\text { Agreement }\end{array}$ \\
\hline \multicolumn{4}{|l|}{ Overseas countries and } \\
\hline Territories & Partnership Agreement & 1 Oct. 1971 & $\begin{array}{l}\text { As provided in Part IV of the } \\
\text { Treaty of Rome }\end{array}$ \\
\hline Chile & Partnership Agreement and Protocol & 1 Feb. 2005 & $\begin{array}{l}\text { Partnership Agreement } \\
\text { signed on November } 2002\end{array}$ \\
\hline Mexico & $\begin{array}{l}\text { Socioeconomic, Political Coordination and } \\
\text { Cooperation Agreement }\end{array}$ & 25 Jul. 2000 & $\begin{array}{l}\text { Decision } 2 \text { of } 2000 \text { on trade } \\
\text { liberalization in the context } \\
\text { of overall agreement of } 1997\end{array}$ \\
\hline South Africa & Trade Development and Cooperation & 2 Nov. 2000 & $\begin{array}{l}\text { Exchange of Letters; terms } \\
\text { of FTA in goods are } \\
\text { provisionally applied since } \\
2000 \text {. }\end{array}$ \\
\hline
\end{tabular}

CARIFORUM

Economic Partnership Agreement

Central Africa

East African Community

Eastern and Southern Africa

Pacific

Community Southern African Development

West Africa
Interim Economic Partnership Agreement

Interim Economic Partnership Agreement

Interim Economic Partnership Agreement

Interim Economic Partnership Agreement

Interim Economic Partnership Agreement

Interim Economic Partnership Agreement
Comprehensive Economic Partnership Agreement, with conditions on trade in goods, services and development cooperation. Negotiations under way on a Comprehensive Economic Partnership Agreement Negotiations under way on a Comprehensive Economic Partnership Agreement Negotiations under way on a Comprehensive Economic Partnership Agreement Negotiations under way on a Comprehensive Economic Partnership Agreement

Negotiations under way on a Comprehensive Economic Partnership Agreement Negotiations under way on a Comprehensive Economic Partnership Agreement

Source: Prepared by the authors, on the basis of European Commission, "European Commission trade" [online] http://ec.europa.eu/trade, 2010.

a The agreements among Member States of the European Union, and customs unions with Andorra, San Marino and Turkey are omitted. 


\section{Annex 6}

IMPACT ASSESSMENT OF THE ASSOCIATION AGREEMENT BETWEEN CENTRAL AMERICA AND THE EUROPEAN UNION, BREAKDOWN OF THE TOTAL VALUE OF EXPORTS OF GOODS AND SERVICES UNDER SEVERAL SCENARIOS

(Percentage change with respect to the 2007 baseline and contribution of each sector in the total)

\begin{tabular}{|c|c|c|c|c|c|c|}
\hline & \multicolumn{2}{|c|}{$\begin{array}{c}\text { Full } \\
\text { liberalization }\end{array}$} & \multicolumn{2}{|c|}{$\begin{array}{l}\text { Sensitive products } \\
\text { excluded }\end{array}$} & \multicolumn{2}{|c|}{$\begin{array}{c}\text { European Union } \\
\text { excl. of fruits and veg }\end{array}$} \\
\hline & Change & Contrib. & Change & Contrib. & Change & Contrib. \\
\hline \multicolumn{7}{|l|}{ Costa Rica } \\
\hline Property & 3.65 & 3.13 & 0.46 & 0.40 & 3.33 & 2.85 \\
\hline Agricultural & 50.32 & 6.89 & 0.73 & 0.10 & 50.80 & 6.96 \\
\hline Mining and extraction & -0.12 & 0.00 & -0.88 & 0.00 & -0.72 & 0.00 \\
\hline Light manufactures & -4.37 & -0.68 & -0.03 & -0.01 & -8.67 & -1.36 \\
\hline Heavy manufactures & -5.48 & -3.08 & 0.54 & 0.30 & -4.90 & -2.76 \\
\hline Services & -4.02 & -0.58 & 0.05 & 0.01 & -3.49 & -0.50 \\
\hline Total exports & 2.55 & 2.55 & 0.40 & 0.40 & 2.35 & 2.35 \\
\hline \multicolumn{7}{|l|}{ Guatemala } \\
\hline Property & 1.74 & 1.48 & 0.73 & 0.62 & 0.85 & 0.72 \\
\hline Agricultural & 0.91 & 0.18 & 0.43 & 0.08 & 1.27 & 0.25 \\
\hline Mining and extraction & -0.55 & -0.02 & -0.12 & 0.00 & -0.21 & -0.01 \\
\hline Light manufactures & 2.82 & 1.31 & 1.15 & 0.53 & 1.00 & 0.47 \\
\hline Heavy manufactures & 0.05 & 0.01 & 0.02 & 0.00 & 0.05 & 0.01 \\
\hline Services & -0.40 & -0.06 & 0.92 & 0.14 & 0.49 & 0.08 \\
\hline Total exports & 1.41 & 1.41 & 0.76 & 0.76 & 0.79 & 0.79 \\
\hline \multicolumn{7}{|l|}{ Nicaragua } \\
\hline Property & 1.23 & 1.09 & 0.28 & 0.25 & 0.25 & 0.22 \\
\hline Agricultural & 3.08 & 0.44 & -0.03 & 0.00 & 0.98 & 0.14 \\
\hline Mining and extraction & -0.91 & 0.00 & -0.33 & 0.00 & -0.83 & 0.00 \\
\hline Light manufactures & 1.25 & 0.82 & 0.39 & 0.26 & 0.17 & 0.11 \\
\hline Heavy Manufactures & -2.09 & -0.17 & -0.04 & 0.00 & -0.34 & -0.03 \\
\hline Services & -1.26 & -0.15 & 0.56 & 0.06 & 0.30 & 0.03 \\
\hline Total exports & 0.95 & 0.95 & 0.31 & 0.31 & 0.26 & 0.26 \\
\hline \multicolumn{7}{|l|}{ Rest of Central America } \\
\hline Property & 8.48 & 7.47 & 0.40 & 0.35 & 0.58 & 0.51 \\
\hline Agricultural & -17.78 & -1.08 & 0.16 & 0.01 & 16.16 & 0.98 \\
\hline Mining and extraction & -6.33 & -0.02 & 0.12 & 0.00 & 0.02 & 0.00 \\
\hline Light manufactures & 14.55 & 10.93 & 0.49 & 0.37 & -0.53 & -0.40 \\
\hline Heavy Manufactures & -36.36 & -2.36 & -0.43 & -0.03 & -1.08 & -0.07 \\
\hline Services & -26.51 & -3.17 & 0.28 & 0.03 & -0.37 & -0.04 \\
\hline Total exports & 4.29 & 4.29 & 0.38 & 0.38 & 0.47 & 0.47 \\
\hline
\end{tabular}

Source: Prepared by the authors, on the basis of simulations from "GTAP 7.0 Database" [online database] https://www.gtap.agecon.purdue.edu/databases/v7/default.asp. 


\section{Fiscal policies and increased trade openness: poverty impacts in Ecuador}

Sara Wong and Ricardo Arguello

\section{A. Introduction}

We use a combined micro-simulation and computable general equilibrium model of the Ecuadorian economy to measure the impact on poverty of changes in fiscal policy in response to trade openness in Ecuador. This study is part of a growing branch of the empirical economics literature that seeks to examine the effects on poverty in countries that have opened their markets to global competition. We also study fiscal policies that the Government could use to compensate for tariff revenue loss. Analysing the impact of changes in trade and fiscal policies on poverty is a very important issue for a country such as Ecuador - a dollarized economy where poverty rates are high, particularly in the rural sector.

Ecuador is immersed in a process of economic policy changes that began in the early 1990s, spearheaded by changes in trade policy. Trade policy changes included tariff reform, major reductions in import restrictions, export promotion laws, the modernization of trade institutions and the simplification of trade procedures. Policy

Sara Wong (Escuela Superior Politécnica del Litoral, ESPOL, Guayaquil, Ecuador), sawong@espol.edu.ec.

2 Ricardo Arguello (Universidad del Rosario, Bogotá, Colombia), arguello@urosario.edu.co. 
developments have also included changes in the tax system. The ultimate goal of these changes is to create jobs, foster economic growth and reduce poverty in Ecuador. However, little has been done to study the impact of changes in fiscal and trade policies on poverty in Ecuador.

Currently, while Ecuador has put off negotiations for a free trade agreement with the United States, its main trade partner, negotiations for free trade agreements with the European Union are under way. The changes in tariff collection that these free trade agreements will bring about could spell reduced Government revenues, and, if that is the case, the latter will eventually have to be compensated for by increasing other taxes or reducing expenditure. Given the rigidities in the Ecuadorian government budget, it is more likely that an increase in taxes will be adopted. Some proposals have suggested an increase in value-added tax (VAT). The elimination of current VAT exemptions has also been proposed, which will affect agricultural income and food expenditure the most. VAT rate increases and the elimination of VAT exemptions could both significantly influence poverty, since poverty tends to be concentrated in the rural sector, and the poor in general spend a large share of their income on food.

The analysis of fiscal policy changes is a key issue for the Ecuadorian economy, since Ecuador adopted the United States dollar as its currency in 2000 as a way to halt the deep economic crisis that hit its economy in the late 1990s. With dollarization, the authorities lost out on the monetary and exchange rate policy instruments that had previously enabled them to deal with economic imbalances.

This study differs from previous CGE studies of Ecuador because (a) it links fiscal and trade policy changes to poverty effects, through changes in prices, wages, and employment, using a single-country CGE model and a micro simulation model; (b) it links macroeconomic variables to income distribution across different labour groups (according to area and education level; for wage earners and the self-employed).

The main research questions we pose in this study are: (i) What would be the macroeconomic effects of a policy of partial trade liberalization ${ }^{3}$ (zero tariff rates, with a key trade partner) and changes in the value added tax rates and/or income tax rates designed to keep the government deficit unchanged? (ii) What would be the changes to poverty rates resulting from these policy changes?

Through this study, we document the main domestic prices and labour market effects of a free trade agreement with the United States in Ecuador and establish the links between the CGE and the micro-model

As tariffs vis-à-vis the rest of the world will not be removed. 
regarding these prices and labour market effects; document the changes in poverty resulting from combined freer trade and changes in value added tax policies; and, establish the main links and mechanisms by which these trade and fiscal policies affect poverty across and within different labour types (wage, self-employment; rural, urban; and, skilled, unskilled).

The main results suggest that the impact of these policy changes on the economy is small. Extreme poverty or indigence (poverty incidence using the one-dollar-a-day poverty line) is reduced, albeit by a small percentage. There are mixed results on poverty (poverty incidence using the two-dollar-a-day poverty line). The best poverty reduction outcomes are attained when only direct taxes are used for making up tariff revenue losses and the worst outcomes occur when a flat VAT rate is introduced, including the elimination of current VAT exemptions (mostly for agricultural goods). A key contribution of this research is to illustrate the significance for poverty of policy choices available to the government.

The remainder of this report is organized as follows. Section B presents an overview of the Ecuadorian economy; section $C$ discusses relevant work on CGE modelling and micro-simulation models; sections D and E, lay out methodology and scenarios, and applied data, respectively. Section F discusses the main research results, while section $G$ features the conclusions.

\section{B. Overview of the Ecuadorian economy}

Ecuador is a small, middle-income, oil-revenue dependent economy which, since the late 1980s, has turned away from a policy of import substitution - a widespread policy in Latin America in the previous decades. Trade liberalization policies have been pursued as a means to foster growth and reduce poverty. However, high poverty rates, particularly in rural areas, persist in the economy. More recently, a free trade agreement was sought with the United States, but this was later scrapped on the grounds that it would have a negative impact on employment, particularly in rural areas (Morales and others, 2005). Another negative impact of a free trade agreement with the United States would be on the revenue side. A revenue loss from tariffs, in a dollarized economy such as that of Ecuador, imposes a constraint on the budget. Changes in taxes might be needed if tariff revenue had to be compensated for. Changes in trade and tax policies would, in turn, have an impact on poverty.

In 2006, Ecuadorian GDP totalled US\$ 41.4 billion, whereas GDP per capita stood at US\$3,088 (or US\$1,608 in dollars of 2000). Ecuadorian exports as a share of GDP represented an annual average of $25 \%$ in the period 2002-2006. 
In the late 1980s, Ecuador began a turnaround in trade policy, from an import-substitution policy to an export-oriented trade policy - a key component of which was tariff reform. These reforms brought down the tariff range from between $29 \%$ and $290 \%$ in 1989 to between $0 \%$ and $40 \%$ in 1994 (the highest tariff rate was applied to vehicle imports) (Tamayo, 1997). However, there remain sectors with high protection rates (nominal and effective). These generally include agricultural sectors, where a sizeable fraction of the Ecuadorian poor is concentrated.

As a result, Ecuador experienced a great increase in trade openness in the last decade. Openness - measured as imports plus exports as a percentage of gross domestic product - of the Ecuadorian economy increased from 37\% in 1993 to $43 \%$ in 1999 and 54\% in 2005. The consolidation of agreements in contexts such as the Andean Community, the opening-up of new markets (for example, Canada, the Russian Federation, and China), and the continuation of trade preferences that Ecuador receives from the United States (the Andean Trade Preference Act (ATPA), later called the Andean Trade Promotion and Drug Eradication Act (ATPDEA)) may have contributed to this result.

The United States, Andean Community and European Union markets purchase around $70 \%$ of all Ecuadorian exports. Similarly, Ecuador receives over $55 \%$ of its total imports from the same partners (see table IV.1).

To compensate for revenue lost in the form of potential tariff reductions/elimination in the wake of free trade agreements, the Government is likely to raise taxes. Tariff income represented an average of almost $2 \%$ of GDP for the non-financial public sector (which comprises the Central Government and non-financial public enterprises) for the period 2001-2005 (see table IV.2).

Although higher oil prices may seem a good source of extra revenue for a central government characterized by a high dependence on oil revenues (around 30\% annual average for the period 2001-2005), high spending on fuel imports and subsidies offsets revenues. Thus, deficits also characterize the Ecuadorian central government budget - an annual average of $0.7 \%$ of GDP for the period 2001-2005 (even larger deficits were common before the year 2000, when Ecuador adopted the United States dollar as the official currency) (see table IV.3).

Unless the Government reduces its current expenditure or generates more revenue from sources other than taxes, it will have to decide how to compensate for its tariff revenue loss. Such fiscal impacts have even more relevance in a dollarized economy like Ecuador's (having surrendered other key instruments of economic policy such as monetary and exchange rate policies). Fiscal policies in Ecuador are a unique and 
Table IV. 1

ECUADOR: EXPORTS AND IMPORTS BY COUNTRY OR REGION, 1998-2005

\begin{tabular}{lrrrrrrrr}
\hline & \multicolumn{7}{c}{ Exports as a percentage share of total exports } \\
\cline { 2 - 9 } Country / Region & 1998 & 1999 & 2000 & 2001 & 2002 & 2003 & 2004 & 2005 \\
\hline U.S.A. & 39 & 38 & 38 & 38 & 41 & 41 & 43 & 50 \\
Andean Community & 13 & 11 & 14 & 18 & 16 & 17 & 13 & 15 \\
European Union & 21 & 18 & 12 & 14 & 16 & 17 & 13 & 13 \\
Asia & 8 & 11 & 12 & 10 & 9 & 6 & 5 & 2 \\
Central America and Caribbean & 2 & 3 & 3 & 9 & 8 & 4 & 2 & 3 \\
Rest of America and the world & 17 & 19 & 21 & 11 & 10 & 15 & 24 & 17 \\
Total & $\mathbf{1 0 0}$ & $\mathbf{1 0 0}$ & $\mathbf{1 0 0}$ & $\mathbf{1 0 0}$ & $\mathbf{1 0 0}$ & $\mathbf{1 0 0}$ & $\mathbf{1 0 0}$ & $\mathbf{1 0 0}$ \\
\hline
\end{tabular}

\begin{tabular}{lrrrrrrrr}
\hline & \multicolumn{7}{c}{ Imports as a percentage share of total imports } \\
\cline { 2 - 9 } Country / Region & 1998 & 1999 & 2000 & 2001 & 2002 & 2003 & 2004 & 2005 \\
\hline U.S.A. ${ }^{a}$ & 30 & 30 & 25 & 25 & 23 & 21 & 21 & 20 \\
Andean Community & 18 & 20 & 23 & 22 & 22 & 23 & 25 & 22 \\
European Union & 15 & 14 & 11 & 12 & 14 & 12 & 10 & 10 \\
Asia & 14 & 11 & 15 & 16 & 15 & 15 & 16 & 20 \\
Central America and Caribbean & 0 & 1 & 0 & 1 & 0 & 1 & 0 & 1 \\
Rest of America and the world & 23 & 24 & 26 & 25 & 26 & 28 & 28 & 27 \\
Total & $\mathbf{1 0 0}$ & $\mathbf{1 0 0}$ & $\mathbf{1 0 0}$ & $\mathbf{1 0 0}$ & $\mathbf{1 0 0}$ & $\mathbf{1 0 0}$ & $\mathbf{1 0 0}$ & $\mathbf{1 0 0}$ \\
\hline
\end{tabular}

Source: Prepared by the authors, on the basis of data from the Central Bank of Ecuador.

a U.S. import data include Puerto Rico.

Table IV.2

NON-FINANCIAL PUBLIC SECTOR, SELECTED OPERATIONS, 1998-2005a (Percentage of GDP)

\begin{tabular}{|c|c|c|c|c|c|c|c|c|}
\hline Transaction & 1998 & 1999 & 2000 & 2001 & 2002 & 2003 & 2004 & 2005 \\
\hline Total revenues ${ }^{\mathrm{b}}$ & 17.32 & 21.08 & 25.90 & 23.57 & 26.16 & 25.40 & 26.92 & 25.06 \\
\hline Oil & 3.93 & 6.29 & 9.16 & 6.43 & 5.73 & 6.12 & 6.99 & 6.06 \\
\hline Non-oil & 13.32 & 14.0 & 15.79 & 16.63 & 19.67 & 18.95 & 19.15 & 18.83 \\
\hline Value Added Tax (VAT) & 3.58 & 3.54 & 5.61 & 6.93 & 6.87 & 6.39 & 6.23 & 6.78 \\
\hline Income taxes & 1.52 & 0.86 & 1.97 & 2.57 & 2.45 & 2.71 & 2.91 & 3.25 \\
\hline Tariff collections & 2.55 & 1.86 & 1.36 & 1.69 & 1.70 & 1.46 & 1.55 & 1.54 \\
\hline Others & 4.90 & 5.17 & 5.18 & 4.70 & 7.71 & 7.52 & 7.57 & 7.26 \\
\hline Total expenditures ${ }^{c}$ & 22.13 & 24.98 & 24.41 & 23.53 & 25.35 & 24.21 & 24.66 & 24.33 \\
\hline Current expenditures & 17.16 & 18.98 & 19.42 & 16.83 & 18.84 & 18.85 & 19.35 & 19.32 \\
\hline Capital expenditures & 4.97 & 6.00 & 4.99 & 6.70 & 6.51 & 5.37 & 5.31 & 5.02 \\
\hline Balance & -4.81 & -3.9 & 1.49 & 0.04 & 0.82 & 1.67 & 2.26 & 0.73 \\
\hline
\end{tabular}

Source: Prepared by the authors, on the basis of data from the Central Bank of Ecuador and the Ministry of Finance.

a Non-financial public sector includes the Central Government, public enterprises, local government, and other non-financial institutions of the government. " "Others" includes social security contributions and other revenues; other small revenues, excluded from this table, are: special consumption taxes, taxes on exits from the country, and taxes no longer applied after 2000 (like the tax on purchases and sales of foreign currency, and on circulation of capital). ${ }^{c}$ In this table government expenditures are expenditures already accrued. 
Table IV.3

CENTRAL GOVERNMENT BUDGET DEFICIT (-) OR SURPLUS (+), 1998-2005

\begin{tabular}{lrrrrrrrr}
\hline Transaction & 1998 & 1999 & 2000 & 2001 & 2002 & 2003 & 2004 & 2005 \\
\hline GDP (US\$ millions) & 23255 & 16674 & 15934 & 21250 & 24899 & 28636 & 32636 & 36489 \\
Oil revenues (\% tot. rev.) & 28 & 37 & 43 & 33 & 30 & 33 & 30 & 26 \\
Deficit or surplus (US\$ mill.) & -959.2 & -475.7 & 19.3 & -222.3 & -184.6 & -108.5 & -319.2 & -180.4 \\
Deficit or surplus (\% GDP) & -4.1 & -2.9 & 0.1 & -1.0 & -0.7 & -0.4 & -1.0 & -0.5 \\
Deficit or surplus (\% tot. rev.) & -29.7 & -17.7 & 0.6 & -5.8 & -4.0 & -2.3 & -6.2 & -3.0 \\
\hline
\end{tabular}

Source: Prepared by the authors, on the basis of data from the Central Bank of Ecuador and the Ministry of Finance.

key instrument in managing the economy. Changes in fiscal policies may, in turn, have an effect on poverty. Despite the importance of analysing trade, fiscal and poverty effects in Ecuador, there has been little research on the subject.

According to the 2005-2006 household survey data, there are $3,264,866$ households in Ecuador, $66 \%$ of which are in urban areas. The average household size is four people. Only a small percentage (21\%) of household heads are women. There is a significant percentage of household heads with no education $(7 \%)$ or just primary education $(47 \%)$, while $29 \%$ of all household heads have secondary education. Only $17 \%$ of household heads have higher education or beyond.

As shown in table IV.4, poverty is widespread in Ecuador, particularly in rural areas where $12 \%$ of households are under the one dollar a day poverty line (indigence) and $47 \%$ are under the two dollar a day poverty line (poverty), when measured by aggregate consumption (aggregate consumption includes food, non-food items, durables, utilities, and rent). ${ }^{4}$ There are differences in poverty incidence when households are headed by males or females. Households headed by women tend to experience lower incidence rates, when poverty is measured by consumption, but they tend to be further beneath the two dollar a day yardstick when poverty is measured by the aggregate income indicator (aggregate income includes wages and salaries, income from agricultural activities, income from household-owned businesses, remittances and aid).

\footnotetext{
4 Expenditure on durables was calculated as the flow of services from durable goods. It was calculated using data on durable spending and age of durable goods, as reported in the Ecuadorian household survey. See Deaton and Zaidi (2002) for details on the estimation of aggregate consumption and its components.
} 
Table IV.4

ECUADOR: POVERTY INDICES AT THE BASE, $2005^{\text {a b }}$

(Percentages)

\begin{tabular}{lcccccc}
\hline \multirow{2}{*}{ Households } & \multicolumn{2}{c}{ Measured by aggregate consumption } & & \multicolumn{2}{c}{ Measured by aggregate income } \\
\cline { 2 - 3 } \cline { 6 - 6 } & Below 1 dollar/day & Below 2 dollars/day & & Below 1 dollar/day & Below 2 dollars/day \\
\cline { 2 - 3 } \cline { 6 - 7 } & FGT (0) & FGT (0) & & FGT (0) & FGT (0) \\
\hline Total & 4.85 & 26.05 & & 14.87 & 35.28 \\
Rural & 11.57 & 47.09 & & 22.72 & 49.55 \\
Urban & 1.33 & 15.05 & & 10.78 & 27.82 \\
Headed by male & 5.19 & 27.41 & & 13.64 & 33.91 \\
Headed by female & 3.54 & 20.88 & & 19.57 & 40.46 \\
\hline
\end{tabular}

Source: Prepared by the authors, on the basis of National Statistics and Census Institute of Ecuador (INEC), Household Survey 2005-2006, Quito.

a Excludes households that do not show any data on income.

b As stated in the Introduction, this study uses the customary poverty measure of poverty incidence or Foster, Greer and Thorbecke (FGT) (0), which is the percentage of individuals whose consumption (or income) falls under the poverty line.

It is important to note that the poverty lines used are the customary one dollar and two dollar a day poverty lines, so that the reader may compare the baseline poverty situation in Ecuador and the poverty situation in other developing countries.

Sanchez-Páramo (2005) points out two key problems with social expenditure in Ecuador: it is highly volatile and poorly targeted. Some social expenditure is progressive - primary and secondary education, for instance. However, some is regressive, as is the case of subsidies for cooking gas, the elimination of which has been recommended on several occasions (Mayorga, 2004). Several governments have tried to reform or eliminate the gas subsidy, but it has proven a thorny political issue to deal with. The elimination of this subsidy could be a way to compensate for tariff revenue loss, but the high political cost makes the adoption of this expenditure-reduction measure unlikely.

A likely candidate for the tax increase is value-added tax (VAT). The current VAT rate stands at $12 \%$, with a few significant exemptions rated at $0 \%$. VAT exemptions include raw food products, basic food items, agricultural inputs and equipment, transport and other services. These products constitute either an important income source for rural households - where poverty is concentrated- or are important expenditure items in poor urban and rural households. For details on the VAT structure and exemptions in Ecuador, see the Law and Rules of Domestic Taxes in Ecuador by the Internal Revenue Service of Ecuador 
(2001) and reforms (2007) that currently apply. VAT in Ecuador is levied on domestic sales and import sales of goods and services. Export sales of goods and services have a zero VAT rate. There is a rebate for intermediate and investment purchases, so we can see VAT as administered using the "invoice method": all transactions are taxed, and firms deduct taxes paid on intermediate inputs as well as on purchases that add to their assets. The tax amount is reported on the invoices for inputs.

\section{Literature review}

There are various ways to approach the analysis of the impact on poverty of changes in economic policies within a combined CGE-microsimulation framework. These approaches are classified according to the interrelation between the CGE and the micro model or data they apply (top-down, bottom-up, both top-down and bottom-up; layered, fullyintegrated; representative, extended representative or real household data). Two recent surveys (Bourguignon, Pereira and Stern, 2006; Davies, 2004) highlight the main characteristics, applications, advantages and disadvantages of these approaches. Löfgren, Robinson and ElSaid (2003) explain the representative household approach. Cockburn (2005) is an example of a fully-integrated CGE-micro-simulation model. Bourguignon, Robilliard and Robinson (2003) follow a top-down layered or sequential approach. Savard (2003) designed a top-down/bottom-up approach. The present study uses a sequential approach with a CGE and a micro model along the lines of Bourguignon, Robilliard and Robinson (2003), with some variations that will be explained subsequently.

A recent study on the impact of trade liberalization on poverty in Ecuador using the CGE micro-simulation framework is Vos and De Jong (2003). However, this study involved no change in fiscal policy, and the micro modelling was approached as a random process. Ours is a departure from this approach, and attempts to model earnings and occupational choice (households' decisions) by building a system of equations as in Bourguignon, Robilliard and Robinson (2003) (See Bourguignon, Robilliard and Robinson (2005 and 2008), and Bussolo and Lay (2005)). A key contribution is identifying the central links between the CGE and micro models and carrying out the micro simulation analysis with real household data.

We build up a CGE model for Ecuador based on Löfgren, Harris and Robinson (2002). This model has the basic desired characteristics we need, plus the potential inclusion of household consumption of non-marketed commodities, transaction costs and activities generating multiple commodities and vice versa. All these are attractive features for 
a more realistic modelling of poverty impacts, especially for rural areas, where poverty is more concentrated in Ecuador. We model the VAT and other indirect and direct tax changes, as well as trade policy changes.

Fargeix and Sadoulet (1990) present one of the first applications of a CGE model for Ecuador. These authors analyse the impact on growth, inflation, and income distribution of alternative scenarios of adjustment programmes in Ecuador. These adjustment programmes follow a series of crises that hit the Ecuadorian economy in the 1980s. The study emphasizes the importance of a healthy fiscal stance for an economy's stability. Nonetheless, fiscal deficits continued to be a problem in Ecuador in the 1990s. Fiscal deficits, besides other economic imbalances and negative shocks, preceded the economic crisis of 1999 that the Ecuadorian authorities halted in 2000 with the adoption of the United States dollar as the new currency (see table IV.3). ${ }^{5}$

A more recent CGE model for Ecuador was developed by Castillo and Ramírez (2004). The authors apply a standard static CGE to analyse the impacts on GDP, imports, and exports of the FTA with the United States. Castillo and Ramírez, in contrast with other applied general equilibrium studies that also focus on the production and trade impacts of the FTA (Wong, 2006), find that GDP increases (1.58\%), imports from the United States decrease $(-1.32 \%)$, while exports to the United States increase by $1.7 \%$ as a result of the FTA (with the full liberalization of tariffs applied to the United States). We find it hard to believe that imports from the United States would actually decrease in an FTA scenario of full liberalization. Castillo and Ramírez use data from input-output tables for 1993-2001 to construct a Social Accounting Matrix with nine sectors.

Wong (2006) applies the GTAP model with Ecuador input-output data included for the first time as a separate region. ${ }^{6}$ This author finds that a free trade agreement with the United States (based on full liberalization) increases imports from the United States by $44 \%$ (total imports increase by $1.8 \%$ ). The main sectors that experience large increases in imports from the United States are meat, dairy, rice, oils and fats, textiles and apparel, wood and wood products, and other manufactures. Exports to the United States increase by $2.3 \%$ (total

5 In 1999, Ecuador endured a currency-debt-banking crisis. According to statistics of the Central Bank of Ecuador, that year GDP fell by $6.3 \%$ in real terms, inflation stood at $52 \%$, imports fell $46 \%$, unemployment was $15.1 \%$ and the central government deficit represented $2.9 \%$ of GDP (in 1998 the deficit was $4.1 \%$ ).

6 The GTAP model refers to a standard general equilibrium model of GTAP (the Global Trade Analysis Project) coordinated by the Center of Global Trade Analysis and housed in the Department of Agricultural Economics at Purdue University. See GTAP version 6.2 at www.agecon.gtap.purdue.edu. 
exports increase by $1 \%$ ). The increase in exports would not preclude a fall in GDP by $-1.4 \%$, once the FTA enters into force. It is important to note that Ecuador already exports most of its products to the United States with a zero tariff. This is because of the unilateral trade preferences the United States gives to Ecuador through the Andean Trade Preferences and Drug Eradication Act (ATPDEA).

None of these recent studies of the FTA with the United States analyses the impact on poverty in Ecuador, except for Vos and De Jong (2003). These authors, as mentioned above, analyse the impact on income distribution of a free trade agreement of the Americas (FTAA) scenario, as opposed to just an FTA with the United States. The CGE model of these authors predicts that, with an FTAA type of trade liberalization (that adjusts for changes in world prices using GTAP results), Ecuadorian imports would increase by $3.4 \%$, exports would increase by $0.3 \%$ and GDP would increase by just $0.4 \%$.

\section{Methodology}

To assess the impact on poverty of a combined policy of trade liberalization and a change in the VAT system to keep the government deficit unchanged, we combine a CGE model with an occupational choice and earnings model that simulates changes in earnings, prices and employment at the individual and household levels. This approach enables us to pass on to households changes in domestic prices and resource reallocation expected from trade liberalization that may have a key influence on household poverty. It also allows us to analyse the full distribution of real household income within households and not just between households, which is a criticism levelled at models that use a representative household approach with few groups. The approach with real household data we follow is not free from criticism either. The main criticisms of this approach cite the lack of feedback from households' results back into the main macro model (the CGE country model, in our case), and the ad-hoc nature of the micro-model equations as problems.

The method includes four main stages, and has a sequential approach, given that the macro and the micro modelling parts are developed separately. These modelling stages are:

- Linking, in a consistent way, the micro and the CGE models. Broady, this stage involves three steps:

(i) Checking for and ensuring consistency between the data used in the CGE model and the data used in the micro model; 
(ii) Obtaining a set of parameter shares on household characteristics that will be used to calibrate the CGE model, and

(iii) Running a benchmark simulation in the CGE model so that the model is calibrated in a consistent way to the micro model dataset.

- $\quad$ Solving the trade and fiscal policy changes in the CGE country model for Ecuador (which seek to raise revenues in response to the revenue lost due to tariff elimination, so as to keep the government deficit unchanged), and obtaining a new set of variables (a vector of appropriate earnings, wages, prices, and aggregate employment variables) that are used to communicate with the micro model. An overview of the CGE model is presented in section 4.2 below.

- $\quad$ Estimating the coefficients of the micro-simulation model and then using them to generate changes in variables that account for heterogeneity in the household data (individual wages, selfemployment income, and changes in employment) so that the results are consistent with the post-policy-change macro variables generated by the CGE model. We partly follow consistency rules provided by Bourguignon, Robilliard and Robinson (2003) that require changes in the variables of the micro model equations to be equal to changes in similar variables of the CGE model.

- $\quad$ Evaluating the impact of the policy changes on poverty, with due regard for the marginal impact of the fiscal policy changes.

Prior to the modelling stages, a good deal of data work is necessary. The data work includes:

(i) Cleaning up the rural and urban household survey data;

(ii) Constructing poverty indicators using the (initial) rural and urban household survey data, and,

(iii) Calibrating the CGE model with the make and use table and Social Accounting Matrix (SAM) data.

A key issue in this research is how to make the proper links between the CGE country model and the micro-simulation model to ensure consistency between them. To analyse whether there is consistency (at the benchmark equilibrium) between the data in the micro model and the data in the CGE model, we compare the two sets of data. According to the data comparison between the 2005-2006 household survey data and the 2004 Social Accounting Matrix of Ecuador, there are no significant differences between aggregate total income in the two data sets (the difference between aggregate income data amounts to $2 \%$ ). Differences in aggregate consumption are 
higher (15\%). Following a rule to deal with discrepancies between the household survey and the Social Accounting Matrix data, we keep total income data as provided in the SAM but re-balance consumption data in the SAM. The following section explains the micro model and the links between the micro and the CGE models.

\section{The micro model}

The micro model is based on a set of reduced form equations that describe wages, self-employment income, and the occupational choices of individuals in the household survey (inactive or unemployed, selfemployed, or wage worker).

The wage earnings equation follows the standard semilogarithmic equation of the logarithm of wages of individual $i$ in household $m\left(\log \mathrm{w}_{\mathrm{mi}}\right)$ with independent variables $\left(\mathrm{x}_{\mathrm{mi}}\right)$ : age, years of schooling, years of schooling squared (to account for non-linearity in income generation), number of children under 18 years of age, and dummies for: gender, marital status and head of household. See for instance, Mincer (1974) and Heckman, Lochner and Todd (2003).

$$
\log \mathrm{w}_{\mathrm{mi}}=\alpha_{\mathrm{g}(\mathrm{mi})}+\mathrm{x}_{\mathrm{mi}} \cdot \beta_{\mathrm{g}(\mathrm{mi})}+v_{\mathrm{mi}}
$$

The function $g(\cdot)$ is an index function that indicates the labour market segment to which member $i$ (a wage worker) in household $m$ belongs. There are four wage-labour market segments: urban skilled, urban unskilled, rural skilled, and rural unskilled.

The self-employment income or earnings equation is a semilogarithmic equation of the logarithm of self-employment income of household $m\left(\log \mathrm{y}_{\mathrm{m}}\right)$, with independent variables $\left(\mathrm{Z}_{\mathrm{m}}\right)$ : age of head of household, years of schooling and years of schooling squared of the head of household, land size of the farm field of those households that have farm income, and dummies for: gender and marital status of the head of the household. This self-employment income equation also includes a variable for the number of household members actually involved in self-employment $\left(\mathrm{N}_{\mathrm{m}}\right)$.

$$
\log \mathrm{y}_{\mathrm{m}}=\gamma_{\mathrm{f}(\mathrm{m})}+\mathrm{Z}_{\mathrm{m}} \cdot \delta_{\mathrm{f}(\mathrm{m})}+\lambda_{\mathrm{f}(\mathrm{m})} \cdot \mathrm{N}_{\mathrm{m}}+\eta_{\mathrm{m}}
$$

The index function $\mathrm{f}(\cdot)$ denotes whether a household with selfemployment income is located in a rural or urban area.

We estimate both total wages and earnings equations first by Ordinary Least Squares (OLS) and then by Heckman two-stage to account 
for sample selection bias, which may arise given that the wage and selfemployment income are observed only for those who actually participate in the labour market.

The occupational choice equation is a multinomial logit of the three occupational alternatives already mentioned: inactive or unemployed (benchmark, not estimated), self-employed, or wage earner.

Table IV.5 presents data on the number of workers and their wages and earnings. There are fewer self-employed (41\%) than wage earners $(59 \%)$, and the latter have a larger share of total wages and earnings (55\%) than the self-employed people. These differences hold for urban and rural areas, although in rural areas the share of wage-worker earnings (44\%) is lower than the share of self-employed earnings (56\%) in total wages and earnings (data on total wages and earnings should be interpreted with precaution as they may be subject to problems of under-reporting and omission).

Table IV.5

NUMBER OF WORKERS, WAGES AND EARNINGS, 2005

\begin{tabular}{|c|c|c|c|c|c|c|}
\hline \multirow[b]{2}{*}{ Description } & \multicolumn{2}{|c|}{ Total } & \multicolumn{2}{|c|}{ Urban } & \multicolumn{2}{|c|}{ Rural } \\
\hline & Value & $\%$ & Value & $\%$ & Value & $\%$ \\
\hline Numbers of wage workers & 3270907 & 59 & 2254662 & 62 & 1016245 & 54 \\
\hline Numbers of self-employed & 2279,231 & 41 & 1401,028 & 38 & 878203 & 46 \\
\hline Total & 5550138 & 100 & 3655690 & 100 & 1894448 & 100 \\
\hline Wages, annual millions of US\$ & 10800 & 55 & 8750 & 52 & 2050 & 44 \\
\hline Earnings, annual millions of US\$ & 8830 & 45 & 6260 & 48 & 2570 & 56 \\
\hline Total & 19630 & 100 & 15010 & 100 & 4620 & 100 \\
\hline
\end{tabular}

Source: Prepared by the authors, on the basis of National Statistics and Census Institute of Ecuador (INEC), Household Survey 2005-2006, Quito.

In the occupational choice model, individuals decide whether to be inactive, self-employed, or a wage worker, based on the utility associated with each choice. The base category is "inactive", and its associated utility is zero. For the other two categories, the multinomial equations we apply $\left(\mathrm{IW}_{\mathrm{mi}}, \mathrm{N}_{\mathrm{m}}\right)$ include as independent variables $\left(\mathrm{z}_{\mathrm{mi}}\right)$ : years of schooling, years of schooling squared, the number of children under 18 years, other income (exogenous, such as remittances and aid) and dummies for: gender, marital status, and for somebody in the household who owns a family business. 
$\mathrm{IW}_{\mathrm{mi}}=\operatorname{Ind}\left[\mathrm{a}_{\mathrm{h}(\mathrm{mi})}^{\mathrm{w}}+\mathrm{z}_{\mathrm{mi}} \cdot \mathrm{b}_{\mathrm{h}(\mathrm{mi})}^{\mathrm{w}}+\mathrm{u}_{\mathrm{mi}}^{\mathrm{w}}>\operatorname{Sup}\left(0, \mathrm{a}_{\mathrm{h}(\mathrm{mi})}^{\mathrm{s}}+\mathrm{z}_{\mathrm{mi}} \cdot \mathrm{b}_{\mathrm{h}(\mathrm{mi})}^{\mathrm{s}}+\mathrm{u}_{\mathrm{mi}}^{\mathrm{s}}\right)\right]$

where IW ${ }_{\mathrm{mi}}$ stands for members who work as wage workers as established by the 'Ind' indicator function. This equation states that an individual will be wage-employed if the utility associated with wageemployment is higher than the utility of being self-employed or inactive.

$$
\mathrm{N}_{\mathrm{m}}=\Sigma_{\mathrm{i}} \operatorname{Ind}\left[\mathrm{a}_{\mathrm{h}(\mathrm{mi})}^{\mathrm{s}}+\mathrm{z}_{\mathrm{mi}} \cdot \mathrm{b}_{\mathrm{h}(\mathrm{mi})}^{\mathrm{s}}+\mathrm{u}_{\mathrm{mi}}^{\mathrm{s}}>\operatorname{Sup}\left(0, \mathrm{a}^{\mathrm{w}}{ }_{\mathrm{h}(\mathrm{mi})}+\mathrm{z}_{\mathrm{mi}} \cdot \mathrm{b}_{\mathrm{h}(\mathrm{mi})}^{\mathrm{w}}+\mathrm{u}_{\mathrm{mi}}^{\mathrm{w}}\right)\right] i=1, . . \mathrm{k}_{\mathrm{m}}(4)
$$

where, as before, $\mathrm{N}_{\mathrm{m}}$ is the number of household members working in self-employment activities. This equation states that an individual $i$ of household $m$ will prefer self-employment if its associated utility is higher than the utility of wage-employment or inactivity. The index function $\mathrm{h}(\cdot)$ in equations (3) and (4) assigns the individual to a demographic group (head, spouse, or other household member).

An income accounting equation $\left(Y_{m}\right)$ complements the earnings and occupational choice model.

$$
\mathrm{Y}_{\mathrm{m}}=\Sigma_{\mathrm{i}} \mathrm{W}_{\mathrm{mi}} \mathrm{IW}_{\mathrm{mi}}+\mathrm{y}_{\mathrm{m}} \operatorname{Ind}\left(\mathrm{N}_{\mathrm{m}}>0\right)+\mathrm{y}_{\mathrm{om}}
$$

where, $Y_{m}$ is total household income, $y_{o m}$ is exogenous income such as government transfers, remittances, aid, etc., and $\mathrm{w}_{\mathrm{mi}^{\prime}} \mathrm{IW}_{\mathrm{mi}^{\prime}}$ and $\mathrm{y}_{\mathrm{m}}$ are defined as above.

\section{a) Linking the micro-simulation model with the CGE model}

To ensure consistency in the model simulations, percentage changes in household data should match percentage changes in the CGE model data after applying the policy changes to the CGE. The microsimulation model is linked with the CGE model through a set of aggregate percentage changes in wage employment, wages, and self-employment income. This is referred to as the "consistency" of the micro model with the CGE model. In summary, the general post-simulation consistency rules imply that percentage changes in summary figures from household data are equal to percentage changes in aggregates in the CGE model.

More specifically, for wages, the percentage change of total wages based on household survey data (by wage-labour market category) should be equal to the percentage change in the total wage bill, by wage-labour market segment, as arising from the CGE model simulations. For self-employment income, the percentage change in earnings by category of urban and rural self-employed households should equal the percentage change in selfemployed earnings from the corresponding category in the CGE model.

For the number of wage earners, the percentage change in the number of all wage earners from the household survey (the sum over 
each individual, whether heads, or other members in a household, and then sum over all households) equals the percentage change of total wage employment by wage-labour market segment arising from the CGE simulations. This consistency rule applies for the case of unemployment, where adjustments are expected in the number of unskilled wage workers. To choose which worker moves out of (or into) wage employment, we order wage workers according to their probability, given by the multinomial logit occupational choice model regressions, of being inactive (wage worker), with workers with the highest probability being chosen first.

To ensure consistency with income data in the baseline from the Ecuadorian household survey, we follow recent literature and add back estimated residuals into the estimated household behaviour equations.

We simulate changes in wages and earnings via changes in intercepts, that is, we do not re-estimate micro-equations behaviour. Consistency checks are performed in each simulation result.

\section{Overview of the CGE model}

We use a static CGE model based on Löfgren, Harris and Robinson (2002). We acknowledge that a dynamic model could also tackle interesting medium- and long-term developments in the economy, such as labour market dynamics, trade balance, capital formation and the rate of growth, which all have an impact on poverty. However, our focus is the impact effects, not the extremely long-term effects of trade and fiscal policies and this purpose is well served by a static model. Our concern for the fiscal implications of trade liberalization policy is justified by a number of studies that conclude that fiscal deficits should be corrected early in the trade reform process. "Since trade taxes are a major revenue source for most developing countries, careful planning is needed to ensure that revenue reducing effects of rate reduction do not upset the fiscal balance, but it is also necessary to look at ways of shifting away from trade taxes to less distortionary forms of taxation, such as VAT." (Hood, 1998, pp. 186-187). See also IMF (2005).

The basic structure of the model can be summarized as follows. Technology is modelled at the top by a Leontief function of value added and aggregate intermediate input. Value added is a CES function of primary factors (labour and capital) and the aggregate intermediate input is a Leontief function of disaggregated intermediate inputs. Each activity can produce more than one commodity following fixed yield coefficients. Also, a commodity can be produced by more than one activity. There are 27 sectors, nine primary or extractive, eight agro-industrial, seven industrial, and three services. These sectors produce 27 commodities, 17 of which are produced by more than one activity. 
There are several institutions in the model. Households receive income from factors (labour and capital) and transfers from other institutions; consumption is the residual after paying taxes, savings, and transfers to other institutions, and is spent according to LES demand functions derived from a Stone-Geary utility function. Households are split into urban and rural. Self-employment also generates income for households, but no attempt is made to distinguish between labour and capital due to the lack of reliable data for doing so - a treatment that is consistent with the structure of the micro-simulation model. Enterprises only obtain income from capital. This income is allocated between corporate taxes and transfers to households. The Government collects all tax-generated income and derives no income from resources at its disposal. Its expenditure comprises of acquisitions (basically services), transfers to households, payments to other regions and savings. Government consumption is fixed in real terms, while transfers to domestic institutions are CPI-indexed, and savings is a residual.

As for factor markets, we have six labour types, four wage-labour types and two self-employed types. Wage workers are organized by educational level and area of residence. Educational levels comprise of no formal education and primary (unskilled), and secondary (whether complete or not) and higher (skilled). Each of these wage-worker types is split into rural and urban, according to their area of residence. Self-employed labour is divided into urban and rural, according to the location of the household residence. The other factor included is capital. There is no distinction as to capital types. There is no land in this model due to lack of land data in the original SAM. We use two alternative assumptions for labour markets: (i) full employment, therefore, changes in wages and earnings clear the market, and (ii) unemployment only in unskilled wage-labour, so that changes in their employment clear their market. In this way, we have two "extreme" scenarios for analysing the likely impact of a foreign trade agreement with the United States and fiscal policies. As we look at the impact effects, capital is assumed to be immobile.

Aggregated domestic output is allocated between domestic consumption and export through a CET function. Export demands and supplies are infinitely elastic.

We have three foreign regions in the model: the United States, the Andean Community, and the rest of the world. These are incorporated in a nested structure that allows for a richer modelling of the trade liberalization scenarios considered, since it first splits preferential from non-preferential markets and then distinguishes between preferential markets, as shown in figure IV.1. 
Figure IV.1

EXPORT STRUCTURE IN THE CGE MODEL
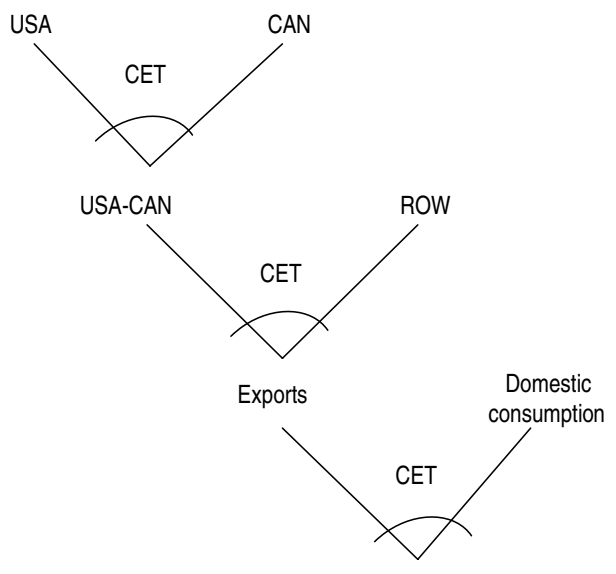

Source: Prepared by the authors.

Figure IV.2

IMPORT STRUCTURE IN THE CGE MODEL

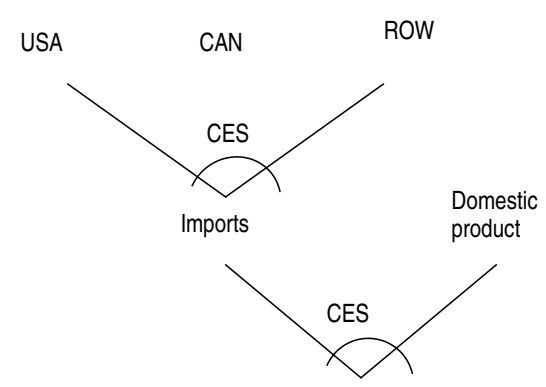

Source: Prepared by the authors.

Aggregate composite imported commodities and domestic output are imperfect substitutes in demand (using a CES function) and imports are differentiated by region of origin using a single nest structure, as illustrated in figure IV.2.

As mentioned below, we model different alternatives for the tax replacement. Effective tax rates are redefined for each tax type. These are the product of the original effective tax rates and a newly defined variable that may be adjusted. The latter, when allowed to vary endogenously, 
enables us to modify the effective tax rate so that the desired constraint is met (in this case, government income).

The general form of the approach is:

$\operatorname{TAXAD}(\mathrm{S})=$ taxrate $(\mathrm{S}) * \mathrm{TAXADJ}$

where, taxrate is the effective tax rate calculated from SAM data (indexed on the appropriate set), TAXADJ is the endogenously determined adjustment parameter for the corresponding tax rate type, and TAXAD is the resulting effective tax rate. Furthermore, in order to implement the tax replacement mechanism, when VAT and direct taxes are jointly used, we use a new variable, MMULTI, that links the tax types as shown in the equations below.

TINS $($ INSDNG $)=\operatorname{tins} 0($ INSDNG $) *$ TINSADJ * MMULTI

$$
\operatorname{TVAD}(\mathrm{A})=\mathrm{tva}(\mathrm{A}) * \text { TVADADJ } * \text { MMULTI }
$$

where TINS is the effective direct tax rate and TVAD is the effective value added tax rate, while TINSADJ and TVADADJ are the specific forms of TAXADJ for income taxes and the value added tax. In this way, for instance, by setting MMULTI $=1$ and TINSADJ $=1$, and letting TVADADJ vary endogenously, the tax replacement mechanism would only use VAT to keep government income from changing. Appropriate setting of these three variables allows the modeller to build the desired combination of taxes to be used in the tax replacement mechanism.

To model VAT rates that may differ among commodities, we have to resort to auxiliary external calculations to take this feature into account. Under the original Löfgren, Harris and Robinson (2002) model structure, VAT is linked to activities instead of to commodities. We therefore use data from the original Ecuadorian SAM to derive an effective VAT rate for each activity based upon the commodities' VAT rates and the I-O matrix. This allows us to externally recalculate the VAT rate that accrues to each activity when individual commodity VAT rates change. Then the new VAT rates are fed back into the model to carry out the simulations. For this, we use the following equation:

TVADSIM('A','escenario') = factor $(A)$ * tva ('A'),

where TVADSIM defines the VAT rate applied to activity $\mathrm{A}$ in each particular scenario, factor(A) is the activity specific factor that adjusts the VAT rate to the desired level (given the changes sought for the commodities' VAT rates), and tva is the effective VAT rate obtained from SAM data.

An additional aspect regarding the tax structure of the model is that we consider government subsidies for household domestic gas consumption. In Ecuador, while output prices of gas for domestic consumption are fixed by the Government, the purchases of such gas 
(all imported) are at international prices. While there is no practical way of targeting the specific destination of the subsidy (anecdotal evidence suggests that sizeable deviations to other uses of this commodity occur), we simply account for the implicit subsidy to the oil sector as a whole. This approach is convenient and suits our purposes in this study.

Lastly, while foreign savings are originally the difference between foreign currency spending and receipts, in our version of the model, we simply split factor transfers to the three foreign regions, on the spending side, and foreign transfers (from each region) to domestic institutions, while foreign savings are kept aggregated.

\section{a) Scenarios, closures, and calibration}

The alternative simulations that serve to analyse poverty effects of a combined policy of bilateral trade liberalization with changes in the value added tax system designed to compensate for government's tariff revenue loss in Ecuador are as follows:

(i) Tariff elimination vis-à-vis Ecuador's main trade partner, the United States, plus alternative changes in the VAT system (tax replacement policy) to keep government income unchanged. The alternatives for implementing this tax replacement mechanism are:

- Adjustments to the VAT rate, preserving its current structure. That is, all commodities that are currently exempted continue to be so and the tax rate is adjusted only for taxed commodities.

- Adjustments to the VAT rate, eliminating current exemptions. Currently taxed commodities are charged at a higher rate than those currently exempted.

- Adjustments to the VAT rate, using a flat rate for all goods and services.

(ii) For scenario (i.a), a tax replacement is implemented using a combination of the change in the VAT system and an increase in direct taxes. The adjustment shares are equal for both tax types.

(iii) Alternatively, the change in the VAT system is replaced by a (sole) change in direct taxes to make up for tariff revenue loss.

For each of these scenarios, we consider two alternative behaviours for the labour market. First, we look at full employment in all labour (and capital) markets so that changes in factor returns clear the corresponding markets (the classical trade model closure). While this is a commonly used assumption in trade models, it may be considered as lacking in realism, at least in the context of a developing country. In this sense, the scenarios where this assumption is used 
must be taken as a "lower bound" for the effects of trade liberalization on poverty, since only factor returns are affected and no change is brought about in employment levels.

Alternatively, we assume unemployment amongst the unskilled wage workers - both rural and urban - and that any adjustment takes place by movements in this factor usage, leaving the current nominal wage level unchanged; the rest of factor markets clear through changes in return. The basic rationale behind this assumption is that there is relative excess labour supply of unskilled wage workers and other characteristics in the labour market, leading to their opportunity cost being low enough to make wages for this labour segment unresponsive to changes in the quantity of factors required. This is reflected, for instance, in the relative size of the informal sector that, according to varying definitions, is estimated to represent between $60 \%$ and $65 \%$ of total employment in Ecuador (Perry and others, 2007). This is also shown in persistent wage differences, unrelated to compensating differentials, between formal and informal salaried workers, a fact that may be interpreted as "queuing" for formal salaried sector jobs, lack of flexibility of the labour market, or other sources of potential labour segmentation (as shown for other Latin American countries in Perry and others, 2007, chapter 3).

The closure rules reflect the relevant conditions in the Ecuadorian economy before we model the shocks. First of all, as the economy uses the United States dollar as its official currency, the nominal exchange rate is fixed. Second, the current account is fixed too, so as to avoid the "free lunch" effect that arises when foreign savings adjust to fill the current account gap. The nominal exchange rate is used as the numeraire and the consumer price index is allowed to vary so that the real exchange rate can adjust too.

Regarding the savings-investment closure, the adjustment is attained by means of proportional changes in the savings and investment sides. Therefore, the marginal propensity of households to save and the shares of investment and of government consumption in nominal total final demand (valued gross of sales taxes) are all endogenous (as also are these shares in real terms). Household savings adjust by means of adding an endogenous variable (DMPS) to the exogenous savings rate -mps0, given by the ratio of household savings to household expenditure net of direct taxes, from social accounting matrix data (i.e. marginal propensity to save $=\mathrm{mps} 0$ * DMPS).

As for the government closure, government savings are exogenous and government income is also fixed, while, as mentioned, government consumption is endogenous (but government transfers to households are fixed). For scenarios (i.a) to (i.c) implementing alternative ways 
of adjusting the VAT system, total government income is fixed, but income from sources other than VAT (such as direct taxes to domestic institutions, factor income taxes, activity taxes, etc.) is allowed to vary while the corresponding rates are kept fixed. Meanwhile, government income from VAT is also allowed to vary but the VAT rate adjusts endogenously. For scenario (ii), implementing the mix between VAT and direct taxes to make up for tariff revenue losses, household disposable income is fixed and government income from all sources is allowed to vary. The tax rate adjustment factor common to VAT and to direct taxes to domestic institutions (MMULTI) is allowed to adjust, while the rest of tax rates are kept fixed. As mentioned, the tax rate adjustment factors for VAT and direct taxes are exogenously set to accommodate for the desired tax mix in the tax replacement mechanism (i.e., TINSADJ and TVADADJ are set to values between zero and one while their sum is one). Lastly, for implementing scenario (iii), in which only direct taxes are used to compensate for tariff revenue losses, only the corresponding tax rate is allowed to vary. In all cases, government income from foreign transfers is exogenous.

Additionally, as we consider the short-term impacts of trade liberalization, capital is fully used and sector specific, so there is no capital mobility between sectors.

As mentioned in the section on the consistency between the macro and micro models, the CGE model is calibrated in such a way that its data are consistent with data coming from the household survey employed. In particular, total household income is consistent in the SAM and in the micro model database, the sectoral division of income comes from the original SAM, and the split between urban and rural households, both in terms of factor income and from self-employment, is consistent with that in the household survey.

\section{E. Data}

We use an input-output table and a social accounting matrix for Ecuador for the year 2004, both developed by the Central Bank of Ecuador. We also use the 2005-2006 survey of urban and rural households' living standards, collected by the National Institute of Statistics and Censuses (INEC). This survey follows the same methodology and format as the World Bank's Living Standards Measurement Study (LSMS) household surveys. The survey includes data on income and occupational choices at the individual level, as well as income from agricultural and business activities and expenditure at the household level. The unit of study of the survey is the household and its members. 


\section{F. Results}

\section{Micro model regression estimations}

The wage and earnings equations are estimated by OLS for each of the labour market categories indexed by g (urban skilled, urban unskilled, rural skilled, and rural unskilled) and f (urban, rural), respectively. Tables IV.6 and IV.7 show the results of these two regressions. The regressions for wages and earnings show, in general, expected signs and significant effects. Working-age male household members command higher wages than female ones; age has a positive and significant effect on wages and earnings (except in the equation for urban self-employment income, where age is not significant); married members show higher wages than unmarried members (except in the equation for rural skilled wage workers, and urban self-employed, where marital status is not significant); and the heads of household have a higher wage than the rest of working-age household members.

Table IV.6

WAGE-WORKER REGRESSIONS, OLS

(Dependent variable is log of annual wage income for wage earners)

\begin{tabular}{|c|c|c|c|c|}
\hline \multirow[b]{2}{*}{ Variables } & \multirow[b]{2}{*}{ Urban skilled } & \multicolumn{2}{|c|}{ Labour market categories } & \multirow[b]{2}{*}{ Rural unskillec } \\
\hline & & Urban unskilled & Rural skilled & \\
\hline Gender & $\begin{array}{c}0.19926{ }^{b} \\
{[4.59]}\end{array}$ & $\begin{array}{c}0.32284^{b} \\
{[6.65]}\end{array}$ & $\begin{array}{c}0.24373^{\mathrm{a}} \\
{[2.17]}\end{array}$ & $\begin{array}{c}0.381422^{\mathrm{b}} \\
{[7.82]}\end{array}$ \\
\hline Schooling (years) & $\begin{array}{c}0.25296 \\
{[2.8]}\end{array}$ & $\begin{array}{c}0.12832 \mathrm{~b} \\
{[4.25]}\end{array}$ & $\begin{array}{r}-0.13948 \\
{[-0.81]}\end{array}$ & $\begin{array}{c}0.07368 \text { b } \\
{[4.02]}\end{array}$ \\
\hline Schooling squared & $\begin{array}{r}-0.00408 \\
{[-1.34]}\end{array}$ & $\begin{array}{c}-0.00619 \mathrm{~b} \\
{[-2.61]}\end{array}$ & $\begin{array}{r}0.01075 \\
{[1.78]}\end{array}$ & $\begin{array}{r}-0.00347 \\
{[-1.93]}\end{array}$ \\
\hline Head & $\begin{array}{c}0.26063 \text { b } \\
{[5.84]}\end{array}$ & $\begin{array}{c}0.31975 \text { b } \\
{[6.84]}\end{array}$ & $\begin{array}{c}0.27353 \mathrm{a} \\
{[2.53]}\end{array}$ & $\begin{array}{c}0.20495 \mathrm{~b} \\
{[4.36]}\end{array}$ \\
\hline Marital status & $\begin{array}{c}0.267988^{b} \\
{[6.45]}\end{array}$ & $\begin{array}{c}0.17500^{\mathrm{b}} \\
{[3.96]}\end{array}$ & $\begin{array}{r}0.16093 \\
{[1.32]}\end{array}$ & $\begin{array}{c}0.20488^{\mathrm{b}} \\
{[4.82]}\end{array}$ \\
\hline Nchild18 & $\begin{array}{r}-0.03864 \\
{[-2.47]}\end{array}$ & $\begin{array}{c}-0.03791 b \\
{[-3.07]}\end{array}$ & $\begin{array}{r}-0.00618 \\
{[-0.24]}\end{array}$ & $\begin{array}{r}-0.00963 \\
{[-1.19]}\end{array}$ \\
\hline Age (years) & $\begin{array}{c}0.02379 \text { b } \\
{[13.42]}\end{array}$ & $\begin{array}{c}0.01286{ }^{b} \\
{[8.50]}\end{array}$ & $\begin{array}{c}0.02920^{\mathrm{b}} \\
{[5.28]}\end{array}$ & $\begin{array}{c}0.00515 \text { b } \\
{[3.55]}\end{array}$ \\
\hline Constant & $\begin{array}{c}4.17123 \text { b } \\
{[6.29]}\end{array}$ & $\begin{array}{c}5.968366^{b} \\
{[47.46]}\end{array}$ & $\begin{array}{c}6.25778^{\mathrm{b}} \\
{[5.41]}\end{array}$ & $\begin{array}{l}6.14757^{\text {b }} \\
{[68.25]}\end{array}$ \\
\hline Sample size & 4,101 & 3,630 & 913 & 4353 \\
\hline R-square & 0.30 & 0.14 & 0.29 & 0.11 \\
\hline
\end{tabular}

Source: Prepared by the authors, on the basis of National Statistics and Census Institute of Ecuador (INEC), Household Survey 2005-2006, Quito.

Notes: Values of t statistics in brackets.

a Significant at $5 \%$.

b Significant at $1 \%$. 
Table IV.7

EARNINGS REGRESSION FOR SELF-EMPLOYMENT, OLS (Dependent variable is log of annual earnings for self-employed income earners, by household)

\begin{tabular}{|c|c|c|}
\hline \multirow{2}{*}{ Variables } & \multicolumn{2}{|c|}{ Labour market categories } \\
\hline & Urban & Rural \\
\hline Gender, head & $\begin{array}{c}0.50307{ }^{\mathrm{a}} \\
{[6.11]}\end{array}$ & $\begin{array}{c}0.24877^{a} \\
{[3.29]}\end{array}$ \\
\hline Age, head (years) & $\begin{array}{r}0.00348 \\
{[1.77]}\end{array}$ & $\begin{array}{c}0.00656^{\mathrm{a}} \\
{[4.1]}\end{array}$ \\
\hline Schooling, head (years) & $\begin{array}{c}0.07465{ }^{\mathrm{a}} \\
{[3.77]}\end{array}$ & $\begin{array}{c}0.065344^{\mathrm{a}} \\
{[3.92]}\end{array}$ \\
\hline Schooling squared, head & $\begin{array}{r}0.00150 \\
{[1.52]}\end{array}$ & $\begin{array}{r}-0.00061 \\
{[-0.53]}\end{array}$ \\
\hline Marital status, head & $\begin{array}{r}-0.07593 \\
{[-0.98]}\end{array}$ & $\begin{array}{c}0.31457 \text { a } \\
{[4.31]}\end{array}$ \\
\hline Landsize & $\begin{array}{r}0.00413 \\
{[1.59]}\end{array}$ & $\begin{array}{r}0.00023 \\
{[0.68]}\end{array}$ \\
\hline N_m ${ }^{b}$ & $\begin{array}{c}1.24003 \text { a } \\
{[30.07]}\end{array}$ & $\begin{array}{l}1.09157 \text { a } \\
{[34.55]}\end{array}$ \\
\hline Constant & $\begin{array}{c}4.66665{ }^{a} \\
{[30.12]}\end{array}$ & $\begin{array}{c}4.87521 \text { a } \\
{[39.7]}\end{array}$ \\
\hline Sample size & 4,617 & 5,330 \\
\hline R-square & 0.31 & 0.29 \\
\hline
\end{tabular}

Source: Prepared by the authors, on the basis of National Statistics and Census Institute of Ecuador (INEC), Household Survey 2005-2006, Quito.

Notes: Values of $t$ statistics in brackets.

a Significant at $1 \%$.

b $\mathrm{N} \_\mathrm{m}$ is the number of household members who work as self-employed.

c Significant at 5\%.

Education benefits wage workers in the form of a higher wage for urban-skilled, urban-unskilled, and rural-unskilled wage workers. In this way, for the urban-skilled group each additional year of education would imply a $25 \%$ increase in wages; for the urban-unskilled group, one additional year of education increases wages by $12 \%$; and, for the ruralunskilled category, one more year of education raises wage earnings by $7 \%$. The effect of formal education on the wages of rural-skilled workers is negative, although not significant.

For self-employed individuals, higher education also has a positive and significant effect on earnings. For urban self-employed individuals one more year of education increases earnings by $7.5 \%$, and for rural households one more year of education raises self-employment earnings by $6.5 \%$.

The problem with applying OLS estimations is that the regression uses observed data, or the wages and earnings of those individuals who actually work (observable), which may produce inconsistent 
estimates of the coefficients of the wage $(\alpha, \beta)$ and earnings $(\gamma, \delta, \lambda)$ equations (see section 4.1 above). This situation should be less of a problem in large samples.

Econometricians have dealt with this problem of sample selection using the omitted variable approach. For those variables that appear in the equation that determines the sample selection (where the dependent variable is a dummy for observed or non-observed), the marginal effect of that independent variable on wages (or earnings, as may be the case) in the observed sample includes two components: the direct effect (as estimated in the observed sample) and the effects stemming from the influence of that independent variable on the probability of being in the sample. The Heckman two-step estimators account for this sample selection bias. We apply this estimator to the wage and earnings equations. Results for the Heckman two-step estimations are shown in tables IV.8 and IV.9.

The Heckman two-step estimates present similar effects as those in the OLS regressions, for both the wage and earnings equations. That is, our samples are large enough, so we can use the OLS estimates. The OLS estimates for the wages and earnings regressions are later used in the micro simulation that communicates the survey data (from the micro model) with the SAM data (from the CGE model).

Table IV.8

WAGE-WORKER REGRESSIONS, TWO-STAGE HECKMAN

\begin{tabular}{|c|c|c|c|c|}
\hline \multirow[b]{2}{*}{ Variables } & \multicolumn{4}{|c|}{ Labor market categories } \\
\hline & $\begin{array}{c}\text { Urban skilled } \\
\text { log wage }\end{array}$ & $\begin{array}{l}\text { Urban skilled } \\
\text { dummy wage a }\end{array}$ & $\begin{array}{l}\text { Urban unskilled } \\
\text { log wage }\end{array}$ & $\begin{array}{l}\text { Urban unskilled } \\
\text { dummy wage a }\end{array}$ \\
\hline Gender & $\begin{array}{l}-0.1559 \text { ** } \\
{[-3.33]}\end{array}$ & $\begin{array}{l}0.38744^{* *} \\
{[16.68]}\end{array}$ & $\begin{array}{l}0.3444 \text { ** } \\
{[7.15]}\end{array}$ & $\begin{array}{l}0.7536 \text { ** } \\
{[31.18]}\end{array}$ \\
\hline Schooling (years) & $\begin{array}{r}0.1073 \\
{[1.25]}\end{array}$ & $\begin{array}{l}0.0840 \\
{[16.63]}\end{array}$ & $\begin{array}{l}0.1282 \\
{[4.25]}\end{array}$ & $\begin{array}{r}-0.0035 \\
{[-0.7]}\end{array}$ \\
\hline Schooling squared & $\begin{array}{r}-0.0018 \\
{[-0.62]}\end{array}$ & & $\begin{array}{l}-0.0062{ }^{* *} \\
{[-2.61]}\end{array}$ & \\
\hline Head & $\begin{array}{l}0.2630 \\
{[6.33]}\end{array}$ & & $\begin{array}{l}0.3193 \text { ** } \\
{[6.82]}\end{array}$ & \\
\hline Marital status & 0.2389 ** & $\begin{array}{r}-0.0181 \\
{[-0.7]}\end{array}$ & $\begin{array}{l}0.1838 \text { ** } \\
{[4.18]}\end{array}$ & $\begin{array}{l}0.3140 \text { ** } \\
{[11.57]}\end{array}$ \\
\hline Nchild18 & $\begin{array}{c}-0.0385 \text { ** } \\
{[-2.66]}\end{array}$ & & $\begin{array}{l}-0.0379 * * \\
{[-3.07]}\end{array}$ & \\
\hline Age (years) & $\begin{array}{l}0.0251 \\
{[13.49]}\end{array}$ & $\begin{array}{l}-0.0048 \text { ** } \\
{[-4.96]}\end{array}$ & $\begin{array}{l}0.0126 \text { ** } \\
{[8.37]}\end{array}$ & $\begin{array}{l}-0.0078 \text { ** } \\
{[-11.6]}\end{array}$ \\
\hline Constant & $\begin{array}{l}6.9323 \\
{[10.96]}\end{array}$ & $\begin{array}{l}-1.2126 \\
{[-16.45]}\end{array}$ & $\begin{array}{l}5.9152 \\
{[46.81]}\end{array}$ & $\begin{array}{l}-0.8018 \\
{[-16.6]}\end{array}$ \\
\hline Sample size & 8,348 & & 12,646 & \\
\hline
\end{tabular}


Table IV.8 (concluded)

\begin{tabular}{|c|c|c|c|c|}
\hline \multirow[b]{2}{*}{ Variables } & \multicolumn{4}{|c|}{ Labor market categories } \\
\hline & $\begin{array}{l}\text { Urban skilled } \\
\text { log wage }\end{array}$ & $\begin{array}{l}\text { Urban skilled } \\
\text { dummy wage a }\end{array}$ & $\begin{array}{l}\text { Urban unskilled } \\
\text { log wage }\end{array}$ & $\begin{array}{l}\text { Urban unskilled } \\
\text { dummy wage }\end{array}$ \\
\hline Gender & $\begin{array}{c}-0.4332 \text { ** } \\
{[-4.35]}\end{array}$ & $\begin{array}{l}0.54544^{\star *} \\
{[10.36]}\end{array}$ & $\begin{array}{l}0.3809{ }^{*} \\
{[7.65]}\end{array}$ & $\begin{array}{l}1.0600 \text { ** } \\
{[43.74]}\end{array}$ \\
\hline Schooling (years) & $\begin{array}{c}-0.2744 \\
{[-1.99]}\end{array}$ & $\begin{array}{l}0.0743^{* *} \\
{[6.72]}\end{array}$ & $\begin{array}{l}0.07377^{* *} \\
{[4.03]}\end{array}$ & $\begin{array}{l}-0.0222 \text { ** } \\
{[-4.53]}\end{array}$ \\
\hline Schooling squared & $\begin{array}{l}0.0120 \text { * } \\
{[2.49]}\end{array}$ & & $\begin{array}{r}-0.0035 \\
{[-1.93]}\end{array}$ & \\
\hline Head & $\begin{array}{l}0.2508 \text { ** } \\
{[2.81]}\end{array}$ & & $\begin{array}{l}0.2050 \text { ** } \\
{[4.37]}\end{array}$ & \\
\hline Marital status & $\begin{array}{r}0.2044 \\
{[1.8]}\end{array}$ & $\begin{array}{r}-0.0785 \\
{[-1.36]}\end{array}$ & $\begin{array}{l}0.2048 \text { ** } \\
{[4.85]}\end{array}$ & $\begin{array}{c}0.2462 \text { ** } \\
{[9.17]}\end{array}$ \\
\hline Nchild18 & $\begin{array}{c}-0.0428 \\
{[-2.35]}\end{array}$ & & $\begin{array}{r}-0.0096 \\
{[-1.19]}\end{array}$ & \\
\hline Age (years) & $\begin{array}{l}0.0263 \text { * * } \\
{[4.96]}\end{array}$ & $\begin{array}{r}0.0039 \\
{[1.58]}\end{array}$ & $\begin{array}{l}0.0052 \text { ** } \\
{[3.63]}\end{array}$ & $\begin{array}{l}-0.0134 \text { ** } \\
{[-17.87]}\end{array}$ \\
\hline Constant & $\begin{array}{l}9.6066 \\
{[10.22]}\end{array}$ & $\begin{array}{l}-1.4384 * * \\
{[-9.55]}\end{array}$ & $\begin{array}{l}6.1484 * * \\
{[65.27]}\end{array}$ & $\begin{array}{l}-0.6845 \\
{[-15.27]}\end{array}$ \\
\hline Sample size & 1,989 & & 15,334 & \\
\hline
\end{tabular}

Source: Prepared by the authors, on the basis of National Statistics and Census Institute of Ecuador (INEC), Household Survey 2005-2006, Quito.

Notes: Values of $t$ statistics in brackets.

* Significant at $5 \%$.

** Significant at $1 \%$.

a Dummy variable takes the value of 1 if the individual is wage earner, 0 otherwise.

Table IV.9

EARNINGS FUNCTIONS FOR SELF-EMPLOYMENT, TWO-STAGE HECKMAN

\begin{tabular}{|c|c|c|c|c|}
\hline \multirow[b]{2}{*}{ Variables } & \multicolumn{4}{|c|}{ Labor market categories } \\
\hline & $\begin{array}{c}\text { Urban } \\
\text { log earnings }\end{array}$ & $\begin{array}{c}\text { Urban } \\
\text { dummy earnings a }\end{array}$ & $\begin{array}{c}\text { Rural } \\
\text { log earnings }\end{array}$ & $\begin{array}{c}\text { Rural } \\
\text { dummy earnings a }\end{array}$ \\
\hline Gender, head & $\begin{array}{l}0.42355^{* *} \\
{[4.93]}\end{array}$ & $\begin{array}{r}0.0694 \\
{[1.85]}\end{array}$ & $\begin{array}{l}0.3849^{* *} \\
{[5.04]}\end{array}$ & $\begin{array}{l}-0.22499^{\star *} \\
{[-5.06]}\end{array}$ \\
\hline Age, head (years) & $\begin{array}{c}-0.0083 \text { ** } \\
{[-4.09]}\end{array}$ & $\begin{array}{l}0.0116 \text { * * } \\
{[16.69]}\end{array}$ & $\begin{array}{r}0.0025 \\
{[1.55]}\end{array}$ & $\begin{array}{l}0.0116 \\
{[14.2]}\end{array}$ \\
\hline Schooling, head (years) & $\begin{array}{l}0.0808 \\
{[4.33]}\end{array}$ & $\begin{array}{l}-0.01422^{* *} \\
{[-5.97]}\end{array}$ & $\begin{array}{l}0.0718 \text { ** } \\
{[4.38]}\end{array}$ & $\begin{array}{l}-0.03466^{* *} \\
{[-9.27]}\end{array}$ \\
\hline Schooling squared, head & $\begin{array}{c}0.0021 \\
{[2.3]}\end{array}$ & & $\begin{array}{r}0.0004 \\
{[0.39]}\end{array}$ & \\
\hline Marital status, head & $\begin{array}{c}-0.4077 \quad * * \\
{[-5.11]}\end{array}$ & $\begin{array}{l}0.3392 \text { ** } \\
{[9.62]}\end{array}$ & $\begin{array}{r}0.0080 \\
{[0.11]}\end{array}$ & $\begin{array}{c}0.5918 \text { ** } \\
{[13.3]}\end{array}$ \\
\hline landsize & $0.0060 *$ & & $\begin{array}{r}0.0003 \\
{[0.81]}\end{array}$ & \\
\hline N_m (1) & $\begin{array}{l}1.1101 \\
{[26.54]}\end{array}$ & & $\begin{array}{l}1.0624 \text { ** } \\
{[33.11]}\end{array}$ & \\
\hline Constant & $\begin{array}{l}6.5991 \text { ** } \\
{[39.03]}\end{array}$ & $\begin{array}{c}-0.39744^{* *} \\
{[-7.73]}\end{array}$ & $\begin{array}{l}5.4234 \text { ** } \\
{[44.67]}\end{array}$ & $\begin{array}{c}0.5240 \text { ** } \\
{[9.4]}\end{array}$ \\
\hline Sample size & 7,422 & & 6,017 & \\
\hline
\end{tabular}

Source: Prepared by the authors, on the basis of National Statistics and Census Institute of Ecuador (INEC), Household Survey 2005-2006, Quito.

Notes: Values of $t$ statistics in brackets.

* Significant at $5 \%$.

** Significant at $1 \%$.

a Dummy variable takes the value of 1 if the individual is self-employed, 0 otherwise. 


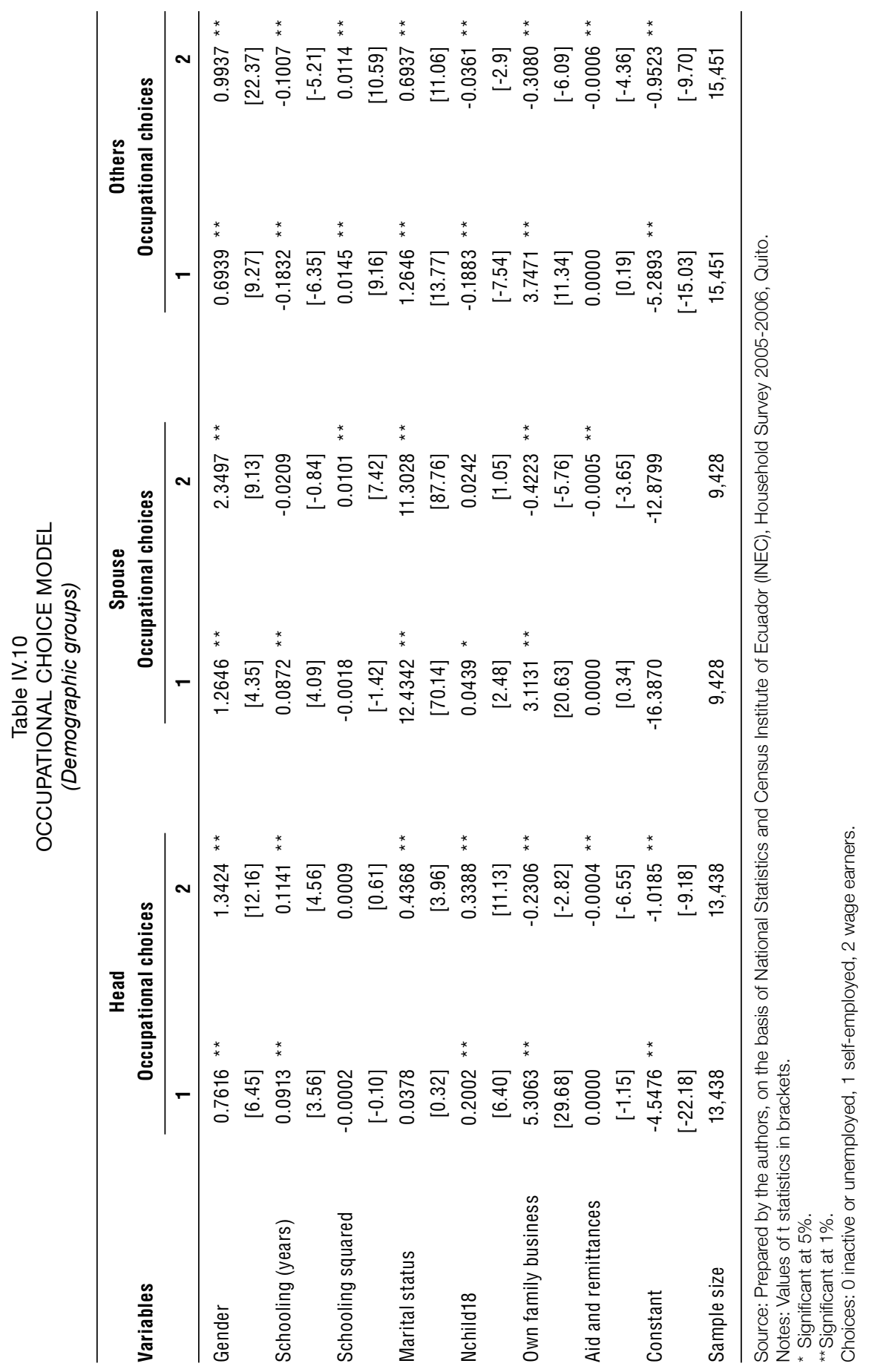


Table IV.10 presents results for the occupational choice model of working-age household members for the three demographic groups considered (head, spouse, and other household members). The base category is inactive (its coefficients of direct effects are zero). The depicted coefficient estimates show the effects of the independent variables (gender, schooling, marital status, number of children under 18 year-old, exogenous income (aids and remittances), and a dummy for own family business) in the underlying expected utility equations of an occupational choice model. These estimates of $\mathrm{a}^{\mathrm{w}}, \mathrm{b}^{\mathrm{w}}, \mathrm{a}^{\mathrm{s}}, \mathrm{b}^{\mathrm{s}}$, and their correspondent residuals will later be applied to the micro simulation that connects the micro model with the CGE model results.

\section{CGE results}

The Ecuadorian economy registers imports in all sectors considered in the model, with the exception of the sector comprised of banana, coffee, and cocoa. The main commodities imported are machinery and equipment $(23.4 \%)$, chemical, rubber, and plastic products $(17.1 \%)$, other services $(12.2 \%)$ and mineral products and refined oils (10.9\%). For these commodities, the share of trade with the United States is $45.3 \%, 22.6 \%$, $25.5 \%$, and $7.1 \%$, respectively, so the impact of trade liberalization vis-à-vis the United States is potentially important. As a matter of fact, the average change (weighted by the base year's share in imports) in quantities of imported commodities ranges between $0.41 \%$ and $0.65 \%$ across scenarios (individually considered, changes in quantities imported range between $-2.4 \%$ and $14.4 \%$ ). The average price change (weighted by the base year's share in imports) for imports is $-1.6 \%$, while individual changes range between $0 \%$ and $-15.5 \%$.

In the light of these changes, the quantum of domestic production tends to decrease. It falls by between $-0.01 \%$ and $-0.15 \%$ as an average (weighted by the base year's share in quantity produced), while it increase by $0.18 \%$ under scenario i.c (that is, tariff elimination on United States imports plus adjustment in the VAT rate using a flat rate for all goods). Average nominal prices (weighted by the base year's share in quantity produced) for the activities decrease under all scenarios; the decrease ranges between $-0.16 \%$ and $-0.34 \%$. The decrease in prices under scenario i.c. is $-0.16 \%$, so there is a negligible increase in the value of domestic production.

As for value added, the quantity of value added increases under scenarios i.b and ii (0.016 percent and $0.009 \%$, respectively) while it decreases under the rest of the scenarios (from $-0.004 \%$ to $-0.043 \%$ ). Meanwhile, the price of value added (which comprises of VAT) decreases 
under all scenarios but scenario i.c. The decrease ranges from $-0.128 \%$ to $-0.371 \%$ while the increase under scenario i.c is $0.432 \%$. This implies that the nominal value added decreases in all cases except scenario i.c. due to the fact that this scenario implies not only the elimination of all exemptions to VAT, but also the use of a flat VAT rate on commodities, which implies the largest average increase in VAT as applied to the activities $(0.008 \%)$.

The main macroeconomic results arising from the CGE model are summarized in table IV.11. From there it can be appreciated that, in nominal terms, absorption decreases under all scenarios, while private consumption decreases between $0.143 \%$ and $1.155 \%$. However, as the CPI decreases between $0.332 \%$ and $0.804 \%$ across scenarios, absorption and private consumption increase in real terms under scenario (i.c) and absorption alone increases again under scenario (iii). Fixed investment and stock changes decrease modestly in nominal terms, as shown in the table, but remain unchanged in real terms. The nominal value of exports and imports increases under all scenarios, and the same is true for their real value. Finally, the nominal GDP (value added) decreases in all cases between 0.339 and 0.944 percentage points, while in spending terms it decreases between 0.046 and 0.7 percentage points; in real terms, GDP remains practically unchanged.

Table IV.11

MAIN MACROECONOMIC RESULTS FROM THE CGE SIMULATIONS (Nominal terms, percentage changes)

\begin{tabular}{|c|c|c|c|c|c|c|}
\hline Variable & Labour market & $\begin{array}{l}\text { Scenario } \\
\text { i.a }\end{array}$ & $\begin{array}{l}\text { Scenario } \\
\text { i.b }\end{array}$ & $\begin{array}{c}\text { Scenario } \\
\text { i.c }\end{array}$ & $\begin{array}{c}\text { Scenario } \\
\text { ii }\end{array}$ & $\begin{array}{c}\text { Scenario } \\
\text { iii }\end{array}$ \\
\hline Absorption & $\begin{array}{l}\text { Full employment } \\
\text { Unemployment (unskilled) }\end{array}$ & $\begin{array}{l}-0.772 \\
-0.924\end{array}$ & $\begin{array}{l}-0.702 \\
-0.855\end{array}$ & $\begin{array}{l}-0.330 \\
-0.428\end{array}$ & $\begin{array}{l}-0.656 \\
-0.672\end{array}$ & $\begin{array}{l}-0.620 \\
-0.596\end{array}$ \\
\hline Private consumption & $\begin{array}{l}\text { Full employment } \\
\text { Unemployment (unskilled) }\end{array}$ & $\begin{array}{l}-0.931 \\
-1.155\end{array}$ & $\begin{array}{l}-0.764 \\
-0.989\end{array}$ & $\begin{array}{l}-0.143 \\
-0.281\end{array}$ & $\begin{array}{l}-0.756 \\
-0.781\end{array}$ & $\begin{array}{l}-0.702 \\
-0.671\end{array}$ \\
\hline Fixed investment & $\begin{array}{l}\text { Full employment } \\
\text { Unemployment (unskilled) }\end{array}$ & $\begin{array}{l}-0.832 \\
-0.862\end{array}$ & $\begin{array}{l}-0.998 \\
-1.033\end{array}$ & $\begin{array}{l}-1.002 \\
-1.043\end{array}$ & $\begin{array}{l}-0.789 \\
-0.785\end{array}$ & $\begin{array}{l}-0.770 \\
-0.756\end{array}$ \\
\hline Stock change & $\begin{array}{l}\text { Full employment } \\
\text { Unemployment (unskilled) }\end{array}$ & $\begin{array}{l}-0.806 \\
-0.789\end{array}$ & $\begin{array}{l}-0.745 \\
-0.731\end{array}$ & $\begin{array}{l}-2.219 \\
-2.231\end{array}$ & $\begin{array}{l}-1.166 \\
-1.161\end{array}$ & $\begin{array}{l}-1.279 \\
-1.269\end{array}$ \\
\hline Exports & $\begin{array}{l}\text { Full employment } \\
\text { Unemployment (unskilled) }\end{array}$ & $\begin{array}{l}0.428 \\
0.278\end{array}$ & $\begin{array}{l}0.413 \\
0.260\end{array}$ & $\begin{array}{l}0.669 \\
0.573\end{array}$ & $\begin{array}{l}0.510 \\
0.492\end{array}$ & $\begin{array}{l}0.538 \\
0.559\end{array}$ \\
\hline Imports & $\begin{array}{l}\text { Full employment } \\
\text { Unemployment (unskilled) }\end{array}$ & $\begin{array}{l}0.399 \\
0.259\end{array}$ & $\begin{array}{l}0.385 \\
0.243\end{array}$ & $\begin{array}{l}0.624 \\
0.535\end{array}$ & $\begin{array}{l}0.476 \\
0.459\end{array}$ & $\begin{array}{l}0.502 \\
0.522\end{array}$ \\
\hline GDP (value added) & $\begin{array}{l}\text { Full employment } \\
\text { Unemployment (unskilled) }\end{array}$ & $\begin{array}{l}-0.790 \\
-0.944\end{array}$ & $\begin{array}{l}-0.718 \\
-0.874\end{array}$ & $\begin{array}{l}-0.339 \\
-0.439\end{array}$ & $\begin{array}{l}-0.672 \\
-0.688\end{array}$ & $\begin{array}{l}-0.634 \\
-0.610\end{array}$ \\
\hline GDP (factor cost) & $\begin{array}{l}\text { Full employment } \\
\text { Unemployment (unskilled) }\end{array}$ & $\begin{array}{l}-0.302 \\
-0.458\end{array}$ & $\begin{array}{l}-0.543 \\
-0.700\end{array}$ & $\begin{array}{r}0.055 \\
-0.046\end{array}$ & $\begin{array}{l}-0.169 \\
-0.185\end{array}$ & $\begin{array}{l}-0.127 \\
-0.103\end{array}$ \\
\hline
\end{tabular}

Source: Prepared by the authors, on the basis of computable general equilibrium (CGE) results.

Scenarios: i.a: tax replacement with VAT under current structure; i.b: tax replacement with differential VAT for formerly exempted commodities; i.c: tax replacement with flat VAT; ii: tax replacement with a mix of VAT and direct taxes; iii: tax replacement with direct taxes only. 
As for wages and income generation, unskilled-waged urban workers obtain their income mostly from other services, transport and storage services, and the cultivation of flowers; skilled-waged urban workers mostly depend on other services, oil extraction, refining, and mining, and transport and storage services; rural-unskilled salaried workers mostly depend on other services, banana, coffee, and cocoa cultivation, and the cultivation of flowers; rural-unskilled salaried workers derive their income mainly from other services, oil extraction, refining, and mining, and bananas, coffee, and cocoa cultivation. Income generation for urban self-employed workers depends upon other services, transport and storage services, and textiles and leather products, while rural self-employed workers mainly depend on other services, animal rearing and transport and storage services.

All in all, the sector 'other services' determines to a large extent the impact on workers' income as it represents the most important source of wages and income generation for the six labour categories (between $38.8 \%$ and $77.7 \%$ of total wages or income). The effective VAT rate for this sector increases (when it is allowed to) from $0.001 \%$ to $0.011 \%$, the latter corresponding to scenario i.c. As the sector accounts for $55.8 \%$ of the quantity of valued added, and its value added decreases under all scenarios (ranging from $-0.2 \%$ to $-0.4 \%$ ), except for scenario i.c. (in which case it increases by $0.2 \%$ ), it is understandable that nominal wages and income decrease.

Table IV.12 presents percentage changes in urban and rural households' factor income with respect to the base year. Under both the full employment and the unskilled labour unemployment sets of scenarios, all urban labour returns fall and the same happens with income from selfemployment. As a result, as shown in the table, urban households' income from all sources decreases. The same trend is observed regarding rural households. As seen in the table, rural households' income from skilled labour and from self-employment decreases in all cases. Meanwhile, income from rural unskilled labourers' wages decreases under scenarios (i.a)-(i.c), but increases under scenarios (ii) and (iii). A common feature of scenario (i) is that under full employment all percentage changes are lower than under unskilled labour unemployment. The pattern breaks as we move to scenarios (ii) and (iii). Under scenario (ii), percentage changes continue being lower for skilled labour income and self-employment income under full employment, but are higher for unskilled labour income. In contrast, under scenario (iii) all percentage changes are higher under full employment

As the above changes are nominal and are driven by changes in factor returns, it is useful to factor in the effect of consumer price changes on factor returns. This is done in table IV.13, where real factor return 
Table IV.12

PERCENTAGE CHANGES IN INCOME, BY SOURCE, FOR URBAN AND RURAL HOUSEHOLDS

\begin{tabular}{llccccc}
\hline Labour market & $\begin{array}{l}\text { Household type } \\
\text { Income source }\end{array}$ & $\begin{array}{c}\text { Scenario } \\
\text { i.a }\end{array}$ & $\begin{array}{c}\text { Scenario } \\
\text { i.b }\end{array}$ & $\begin{array}{c}\text { Scenario } \\
\text { i.c }\end{array}$ & $\begin{array}{c}\text { Scenario } \\
\text { ii }\end{array}$ & $\begin{array}{c}\text { Scenario } \\
\text { iii }\end{array}$ \\
\hline Full employment & Urban unskilled & -1.025 & -0.993 & -0.280 & -0.308 & -0.070 \\
& Urban skilled & -1.053 & -0.855 & -0.147 & -0.372 & -0.146 \\
& Urban self-employed & -0.917 & -0.793 & -0.917 & -0.366 & -0.184 \\
Unemployment & Urban unskilled & -1.047 & -1.023 & -0.367 & -0.269 & -0.028 \\
& Urban skilled & -1.257 & -1.060 & -0.274 & -0.390 & -0.123 \\
& Urban self-employed & -1.125 & -1.003 & -1.053 & -0.386 & -0.157 \\
Full employment & Rural unskilled & -0.624 & -0.659 & -0.732 & 0.070 & 0.300 \\
& Rural skilled & -0.975 & -0.819 & -0.337 & -0.311 & -0.090 \\
& Rural self-employed & -1.132 & -1.558 & -2.008 & -0.419 & -0.183 \\
Unemployment & Rural unskilled & -0.848 & -0.883 & -0.822 & 0.023 & 0.293 \\
& Rural skilled & -1.218 & -1.064 & -0.495 & -0.333 & -0.059 \\
& Rural self-employed & -1.442 & -1.874 & -2.213 & -0.448 & -0.142 \\
\hline
\end{tabular}

Source: Prepared by the authors, on the basis of computable general equilibrium (CGE) results.

Scenarios: i.a: tax replacement with VAT under current structure; i.b: tax replacement with differential VAT for formerly exempted commodities; i.c: tax replacement with flat VAT; ii: tax replacement with a mix of VAT and direct taxes; iii: tax replacement with direct taxes only.

changes are presented. From there it can be seen that, under the full employment set of scenarios, scenarios (i.a) and (i.b) tend to show decreases in all factor returns, with the only exception being rural unskilled labour under scenario (i.a); scenario (i.c) favours urban skilled and unskilled labour; and, scenarios (ii) and (iii) generate increases in all factor returns. As for the unemployment set of scenarios, the main difference with the former under scenarios (i.a)-(i.c) is that changes in returns to unskilled labour (urban and rural) are now positive under scenarios (i.a) and (i.b). This is due to fact that, in this case, nominal wages for these two labour types are constant and the consumer price index decreases in all cases. Lastly, under scenarios (ii) and (iii) all factor returns increase.

As for the policy choices that are embodied in the scenarios considered, judging by their effects on real factor returns, it seems that increasing VAT under its current structure (scenario (i.a)) or eliminating its exemptions (scenario (i.b)), in the way it is done here, tend to be detrimental for the majority of labour types. Using a flat VAT rate, eliminating exemptions to its application, tends to favour urban labour income and worsen the rest of factor returns. Mixing changes in the VAT system and direct taxes to compensate for revenue losses (scenario (ii)), leads to increases in all real factor returns, and the same happens if only direct taxes are used to make up for revenue losses (scenario iii). Among these last two, the better results tend to be attained when only direct taxes are used and under the more realistic scenario with unemployment. 
Table IV.13

PERCENTAGE CHANGES IN REAL FACTOR RETURNS

\begin{tabular}{llccccc}
\hline Labour market & Household type & $\begin{array}{c}\text { Scenario } \\
\text { i.a }\end{array}$ & $\begin{array}{c}\text { Scenario } \\
\text { i.b }\end{array}$ & $\begin{array}{c}\text { Scenario } \\
\text { i.c }\end{array}$ & $\begin{array}{c}\text { Scenario } \\
\text { ii }\end{array}$ & $\begin{array}{c}\text { Scenario } \\
\text { iii }\end{array}$ \\
\hline Full employment & Urban unskilled & -0.306 & -0.414 & 0.052 & 0.358 & 0.579 \\
& Urban skilled & -0.334 & -0.276 & 0.185 & 0.294 & 0.503 \\
& Urban self-employed & -0.198 & -0.214 & -0.585 & 0.300 & 0.465 \\
Unemployment & Urban unskilled & 0.780 & 0.641 & 0.380 & 0.668 & 0.634 \\
& Urban skilled & -0.477 & -0.419 & 0.106 & 0.278 & 0.511 \\
& Urban self-employed & -0.345 & -0.362 & -0.673 & 0.282 & 0.477 \\
Full employment & Rural unskilled & 0.095 & -0.080 & -0.400 & 0.736 & 0.949 \\
& Rural skilled & -0.256 & -0.240 & -0.005 & 0.355 & 0.559 \\
& Rural self-employed & -0.413 & -0.979 & -1.676 & 0.247 & 0.466 \\
& Rural unskilled & 0.780 & 0.641 & 0.380 & 0.668 & 0.634 \\
& Rural skilled & -0.438 & -0.423 & -0.115 & 0.335 & 0.575 \\
& Rural self-employed & -0.662 & -1.233 & -1.833 & 0.220 & 0.492 \\
\hline
\end{tabular}

Source: Prepared by the authors, on the basis of computable general equilibrium (CGE) results.

Scenarios: i.a: tax replacement with VAT under current structure; i.b: tax replacement with differential VAT for formerly exempted commodities; i.c: tax replacement with flat VAT; ii: tax replacement with a mix of VAT and direct taxes; iii: tax replacement with direct taxes only.

\section{Poverty results}

The main mechanisms by which a zero-tariff policy with the United States in Ecuador translates into poverty effects are through impacts on growth, prices, factor markets and fiscal policy (the latter as a reaction to - presumably - lower revenue). Of these mechanisms, this study emphasizes transmission through the labour market and fiscal policies.

Although there are many contentious debates on how to measure the growth-poverty link, it is generally accepted that growth, on average, reduces poverty. See for instance Ravallion (2001), Dollar and Kraay (2002), Winters (2002), and Winters, McCulloch and McKay (2004) and the references therein. The evidence for growth reducing inequality is less clear (Fields, 1989). However, Winters (2004) warns that the initial conditions also matter, in particular the initial level of inequality: the lower the level of inequality (of a population centred around the poverty line), the greater the poverty impacts (either positive or negative). On the other hand, the literature stresses that the labour market is one of the main mechanisms by which foreign trade shocks can impact on poverty (Winters, 2002; Winters, McCulloch and McKay, 2004), and that the way in which these shocks impact on poverty depends on the structure of the labour market. The present study highlights the effects observed through segmented labour markets. 
Assuming unemployment amongst the unskilled wage workers (that is, wage workers with a fixed nominal wage, so that adjustments in this segment of the labour market take place through employment levels), a labour market feature that is thought to prevail in the Ecuadorian labour market —as mentioned above-, we obtain poverty reducing impacts under scenario i.a.(of a combined zerotariff policy of Ecuador with the United States and an adjustment in the VAT rate preserving its current structure to keep the government deficit unchanged). A point estimate of the incidence of indigence would fall from the baseline of $14.87 \%$ to $14.51 \%$, and the incidence of poverty would decrease from $35.28 \%$ to $34.96 \%$ (see table IV.14). Trade liberalization and taxes act in the same direction (reducing poverty), but to a different degree in rural and urban areas. Urban poverty benefits from a larger reduction (from $27.82 \%$ to $27.47 \%$ ) than rural poverty (from $49.55 \%$ to $49.30 \%$ ) (See table IV.14).

If the adjustment in the VAT rate includes also the elimination of current exemptions with differential VAT for formerly exempted commodities (scenario i.b), similar results for poverty still hold, but with lower reductions in poverty-incidence rates (except for a slight increase in rural poverty, from $49.55 \%$ to $49.66 \%$ ).

If the VAT adjustment uses a flat rate for all goods (scenario i.c), there are more differentiated effects in both the indigence and poverty rates between rural and urban areas. In rural areas, indigence and poverty rates rise from $22.72 \%$ to $22.98 \%$ and from $49.55 \%$ to $49.94 \%$, respectively. In urban areas, both indigence and poverty rates fall, from $10.78 \%$ to $10.47 \%$ and from $27.82 \%$ to $27.74 \%$, respectively. At the national level, this differentiated impact induces a fall in the indigence rate, but a rise in poverty.

The mixed result on poverty (reduced indigence, but increased poverty) under the third VAT scenario could be explained by the effects on employment as well as by where the different wage levels lie with respect to the poverty line (Winters, McCulloch and McKay, 2004). From table 13, under the unemployment scenarios for unskilled wage workers, we can see that trade liberalization increases unskilled real wages (in urban and rural areas), which may lead to reduced employment in this labour market segment, and may worsen poverty. Apparently, the increase in real wages of those who remain or become employed may be enough to lift some out of indigence but the loss of employment may throw others into poverty. Besides, the rest of wage-labour workers and self-employed individuals experience a small fall in (nominal and real) income (except for the increase in real wage of urban skilled workers, under scenario i.c), thereby contributing to higher poverty. 


\section{Table IV.14 \\ ECUADOR: RESULTS ON POVERTY INCIDENCE OF TRADE LIBERALIZATION WITH TAX REPLACEMENT}

\begin{tabular}{lcccccc}
\hline Assuming unemployment for unskilled wage-workers • Below one dollar a day \\
& Base line & $\begin{array}{c}\text { Scenario } \\
\text { i.a }\end{array}$ & $\begin{array}{c}\text { Scenario } \\
\text { i.b }\end{array}$ & $\begin{array}{c}\text { Scenario } \\
\text { i.c }\end{array}$ & $\begin{array}{c}\text { Scenario } \\
\text { ii }\end{array}$ & $\begin{array}{c}\text { Scenario } \\
\text { iii }\end{array}$ \\
\hline Total households & $14.87 \%$ & $14.51 \%$ & $14.59 \%$ & $14.76 \%$ & $14.41 \%$ & $14.38 \%$ \\
Rural households & $22.72 \%$ & $22.32 \%$ & $22.53 \%$ & $22.98 \%$ & $22.11 \%$ & $22.01 \%$ \\
Urban households & $10.78 \%$ & $10.43 \%$ & $10.44 \%$ & $10.47 \%$ & $10.39 \%$ & $10.39 \%$ \\
Household headed by male & $13.64 \%$ & $13.32 \%$ & $13.40 \%$ & $13.56 \%$ & $13.21 \%$ & $13.16 \%$ \\
Household headed by female & $19.57 \%$ & $19.05 \%$ & $19.12 \%$ & $19.34 \%$ & $19.01 \%$ & $19.02 \%$
\end{tabular}

\begin{tabular}{lcccccc}
\hline Assuming unemployment for unskilled wage-workers • Below two dollars a day & & \\
\hline & Base line & $\begin{array}{c}\text { Scenario } \\
\text { i.a }\end{array}$ & $\begin{array}{c}\text { Scenario } \\
\text { i.b }\end{array}$ & $\begin{array}{c}\text { Scenario } \\
\text { i.c }\end{array}$ & $\begin{array}{c}\text { Scenario } \\
\text { ii }\end{array}$ & $\begin{array}{c}\text { Scenario } \\
\text { iii }\end{array}$ \\
\hline Total households & $35.28 \%$ & $34.96 \%$ & $35.17 \%$ & $35.36 \%$ & $34.95 \%$ & $34.90 \%$ \\
Rural households & $49.55 \%$ & $49.30 \%$ & $49.66 \%$ & $49.94 \%$ & $49.21 \%$ & $49.07 \%$ \\
Urban households & $27.82 \%$ & $27.47 \%$ & $27.60 \%$ & $27.74 \%$ & $27.50 \%$ & $27.50 \%$ \\
Household headed by male & $33.91 \%$ & $33.60 \%$ & $33.83 \%$ & $34.00 \%$ & $33.55 \%$ & $33.51 \%$ \\
Household headed by female & $40.46 \%$ & $40.15 \%$ & $40.27 \%$ & $40.50 \%$ & $40.30 \%$ & $40.22 \%$
\end{tabular}

\begin{tabular}{lcccccc}
\hline Assuming full employment • Below one dollar a day & & & & & \\
\hline & Base line & $\begin{array}{c}\text { Scenario } \\
\text { i.a }\end{array}$ & $\begin{array}{c}\text { Scenario } \\
\text { i.b }\end{array}$ & $\begin{array}{c}\text { Scenario } \\
\text { i.c }\end{array}$ & $\begin{array}{c}\text { Scenario } \\
\text { ii }\end{array}$ & $\begin{array}{c}\text { Scenario } \\
\text { iii }\end{array}$ \\
\hline Total households & $14.87 \%$ & $14.56 \%$ & $14.65 \%$ & $14.86 \%$ & $14.43 \%$ & $14.40 \%$ \\
Rural households & $22.72 \%$ & $22.32 \%$ & $22.57 \%$ & $23.15 \%$ & $22.10 \%$ & $22.01 \%$ \\
Urban households & $10.78 \%$ & $10.50 \%$ & $10.52 \%$ & $10.53 \%$ & $10.42 \%$ & $10.42 \%$ \\
Household headed by male & $13.64 \%$ & $13.36 \%$ & $13.46 \%$ & $13.66 \%$ & $13.22 \%$ & $13.18 \%$ \\
Household headed by female & $19.57 \%$ & $19.13 \%$ & $19.18 \%$ & $19.43 \%$ & $19.01 \%$ & $19.01 \%$
\end{tabular}

Assuming full employment $\bullet$ Below two dollars a day

\begin{tabular}{lcccccc}
\hline & Base line & $\begin{array}{c}\text { Scenario } \\
\text { i.a }\end{array}$ & $\begin{array}{c}\text { Scenario } \\
\text { i.b }\end{array}$ & $\begin{array}{c}\text { Scenario } \\
\text { i.c }\end{array}$ & $\begin{array}{c}\text { Scenario } \\
\text { ii }\end{array}$ & $\begin{array}{c}\text { Scenario } \\
\text { iii }\end{array}$ \\
\hline Total households & $35.28 \%$ & $35.12 \%$ & $35.25 \%$ & $35.44 \%$ & $34.95 \%$ & $34.90 \%$ \\
Rural households & $49.55 \%$ & $49.47 \%$ & $49.68 \%$ & $50.09 \%$ & $49.14 \%$ & $49.07 \%$ \\
Urban households & $27.82 \%$ & $27.62 \%$ & $27.72 \%$ & $27.79 \%$ & $27.54 \%$ & $27.50 \%$ \\
Household headed by male & $33.91 \%$ & $33.73 \%$ & $33.88 \%$ & $34.09 \%$ & $33.55 \%$ & $33.51 \%$ \\
Household headed by female & $40.46 \%$ & $40.41 \%$ & $40.49 \%$ & $40.57 \%$ & $40.28 \%$ & $40.22 \%$
\end{tabular}

Source: Prepared by the authors, on the basis of National Statistics and Census Institute of Ecuador (INEC), Household Survey 2005-2006, Quito.

Scenarios: i.a: tax replacement with VAT under current structure; i.b: tax replacement with differential VAT for formerly exempted commodities; i.c: tax replacement with flat VAT; ii: tax replacement with a mix of VAT and direct taxes; iii: tax replacement with direct taxes only. 
Clearly, to assess the poverty impacts of trade shocks, the effects of those trade shocks on labour demand and the elasticity of labour supply are key. It is also important to take into account the differences in labour market segments, as the factors mentioned may vary across labour market segments. Other factors that should be taken into account are supply side effects (trade should first have an effect on output) which, as pointed out by Winters, depend on the structure of the goods markets and on the substitutability between imports, exports and domestic production.

It is worth noting that the worst effects on (nominal and real) income and poverty incidence are amongst the self-employed, under scenario i.c. - trade liberalization combined with a flat VAT rate to make up for revenue losses. This is explained because the rural self-employed (mostly farmers), who are likely to make up the poorer section of society, account for a larger share of food consumption. Food, a product category currently mostly exempt from VAT, would be subject to VAT under this proposed tax replacement scheme. Besides, the loss in real income coming from self-employed households in rural areas may offset the increase in the real rural unskilled wage.

Finally, and still assuming unemployment, if either direct taxes are applied in combination with changes in the VAT rate, or if just changes in direct taxes are used to make up for tariff revenue loss (scenarios ii, and iii, respectively) the impacts on poverty reduction are positive. Poverty incidence falls from $35.28 \%$ to $34.95 \%$ if tax replacement using changes in VAT and increases in direct taxes are used, and poverty rates fall from $35.28 \%$ to $34.90 \%$ if tax replacement is only based on changes in direct taxes to make up for tariff revenue loss. An income tax replacement scheme has been progressive.

These differences in the poverty impact coming from different tax replacement scenarios highlight what other CGE studies find, namely that welfare impacts of "tariff revenue losses depend on the nature of the replacement taxes introduced" (Winters, McCulloch and McKay, 2004).

Assuming full employment and similar scenarios, the adjustments in income of all wage workers and self-employed that now take place, imply - in almost all cases - slightly smaller effects on the incidence rates of indigence and poverty, but the directions of the changes are, in general, the same as those in the previous scenarios (table IV.14).

It is important to note that both the poverty line and the indigence line have been adjusted by changes in prices (resulting from trade liberalization and tax replacement) using the CPI index that results for each scenario. The CPI seems to be the most suitable price index as the prices of the main goods and services in the consumption basket of the households are determined in the domestic markets. 


\section{G. Conclusions}

In this paper we explore the impact of trade and fiscal policy changes on poverty and income distribution in the context of the Ecuadorian economy. Trade policy changes result from the implementation of a free trade agreement with the United States, while fiscal policy changes arise from the implementation of several alternatives to compensate for revenue losses stemming from tariff elimination. In particular, both VAT and direct taxes are used as tax replacement mechanisms under several arrangements.

As follows from previous sections, partial trade liberalization has relatively modest effects at the macro level. GDP, measured as value added, decreases in nominal terms in the range of 0.9 to 0.3 percentage points while, measured at factor costs, it falls between $0.05 \%$ and $0.70 \%$. Private consumption decreases by between $0.14 \%$ and $1.2 \%$ in nominal terms. Additionally, fixed investment, which is allowed to adjust endogenously while the current account and government income and savings are kept fixed, nominally decreases in the range of $0.76 \%$ and $1.03 \%$. Changes in real terms for the above variables follow the same direction as nominal changes.

In real terms, under full employment urban and rural wages and income from self-employment tend to decrease when only the VAT is used in the tax replacement mechanism. Decreases tend to be higher for urban skilled and unskilled wages, as compared to rural ones, and for rural self-employment income. When it is considered that the unskilled labour segment is characterized by unemployment, urban and rural unskilled wages increase while urban and rural skilled wages and income from self-employment decrease. Regarding wages, the urban sector is the most negatively affected, while with respect to selfemployment income the rural sector posts the worst outcome. When the tax replacement is based on changes in direct taxes, for both the full employment and the unskilled labour unemployment scenarios, wages and self-employment income for all segments increase in real terms. In all cases, changes in wages and income are small, ranging from $-1.8 \%$ and $0.95 \%$.

These factor return changes, being small in relative terms, suggest that the impact on poverty must be small too. In effect, this is what the micro simulation results show.

Under the full employment scenarios, the indigence rate (US\$ $1 \mathrm{a}$ day adjusted by post-simulation changes in CPI) at the national level falls between $0.01 \%$ and $0.48 \%$ (the smallest fall happens when using only changes in VAT to make up for tariff revenue loss). The largest decreases 
tend to be associated with rural poverty and poverty for households headed by a female. In contrast, the national poverty rate (US\$ 2 a day adjusted by post-simulation changes in CPI) increases $(0.17 \%)$ or decreases (between $0.02 \%$ and $0.37 \%$, the largest fall happens when changes in direct taxes are used to make up for tariff revenue loss). The largest increases and decreases in poverty correspond to rural households.

In the case of the scenarios with unemployment in the unskilled labour market segment, the national indigence rate falls between 0.11 and $0.49 \%$. Again, in general, it is rural households, and households headed by females that show the largest decreases in indigence. Moving to the national poverty rate, poverty incidence decreases slightly, by around $0.11 \%$ to $0.37 \%$, or it increases $(0.08 \%)$ in the case of adjustments that include only changes in the VAT rate.

From the standpoint of the alternative tax replacement mechanisms, results indicate that compensating for tariff revenue loss with changes in direct taxes would yield a better outcome for rural and urban indigence and poverty alleviation. In contrast, implementing a flat VAT for all goods would lead to the worst outcome for rural and urban poverty and indigence alleviation (both under unemployment and full employment assumptions).

Interestingly, in the case of the scenarios in which VAT is used in the tax replacement mechanism, the same forces that lead to slight decreases in indigence rates, may also lead to slight increases in poverty rates.

Overall, our research results indicate that, from the standpoint of poverty alleviation, the best path that the government can take is to resort to direct taxes for making up tariff revenue losses. This is, of course, also true regarding changes in wages and self-employment income, in which case the rural sector experiences the highest real increases.

This differentiated poverty impact of changes in trade and tax policies, pinpoints the potential of policy changes to simultaneously create both beneficial and harmful effects. Unless specific policy measures are taken in order to assure that trade-induced growth is pro-poor, there is no assurance that an improved resource allocation - resulting from increased openness - would yield the desired outcomes in terms of poverty alleviation and a more egalitarian distribution of income.

It is also important to note that the results shown here are static and that adjustments take time. Short-term results should differ from long-term effects. This is particularly important for labour market effects. It is important to stress that efficiency gains arising from capital reallocation in a post-trade shock are expected to contribute to growth and have poverty reducing effects in the long-run. 


\section{Bibliography}

Bourguignon, F., L. Pereira da Silva and N. Stern (2006), "Evaluating the poverty impact of economic policies: some analytical challenges", Macroeconomics Policies and Poverty Reduction, A. Mody and C. Patillo (eds.), London, Routledge.

Bourguignon, F., A. Robilliard and S. Robinson (2008), "Examining the social impact of the Indonesian financial crisis using a macro-micro model", The Impact of Macroeconomic Policies on Poverty and Income Distribution: Macro-Micro Evaluation Techniques and Tools, F. Bourguignon, M. Bussolo and L.A. Pereira da Silva (eds.), Washington, D.C., World Bank. (2005), "The social impact of a WTO agreement in Indonesia", World Bank Policy Research Working Paper, No. 3747, Washington, D.C., World Bank. (2003), "Representative versus real households in the macro-economic modeling of inequality", DELTA Working Paper, No. 2003-05.

Bussolo, M. and J. Lay (2005), "Globalisation and poverty changes in Colombia", Globalization and Poverty: Channels and Policy Responses, M. Bussolo and J. Round (eds.), London, Routledge.

Castillo, M. and J. Ramírez (2004), "Modelo de equilibrio general estático para la evaluación del Tratado de Libre Comercio en la economía ecuatoriana y calibración mediante máxima entropía", Cuestiones económicas, vol. 20, No. 3, Quito, Central Bank of Ecuador.

Cockburn, J. (2005), “Trade liberalization and poverty in Nepal: a computable general equilibrium micro simulation analysis", Globalization and Poverty: Channels and Policy Responses, M. Bussolo and J. Round (eds.), London, Routledge.

Davies, J.B. (2004), "Microsimulation, CGE and macro modelling for transition and developing economies", WIDER Discussion Paper, vol. 2004/08, Helsinki, United Nations University/World Institute for Development Economics Research (UNU/WIDER).

Deaton, A. and S. Zaidi (2002), "Guidelines for constructing consumption aggregates for welfare analysis", LSMS Working Paper, No. 135, Washington, D.C., World Bank.

Dollar, D. and A. Kraay (2002), "Growth is good for the poor", Journal of Economic Growth, vol. 7, No. 3.

Fargeix, A. and E. Sadoulet (1990), "A financial computable general equilibrium model for the analysis of Ecuador's stabilization programs", Working Paper, No. 10, Paris, OECD Development Centre.

Fields, G. (1989), "Changes in poverty and inequality in developing countries", World Bank Research Observer, vol. 4, No. 2.

Heckman, J., L.J. Lochner and P.E. Todd (2003), "Fifty years of Mincer earnings regressions", NBER Working Paper series, No. 9732, May.

Hood, R. (1998), "Fiscal implications of trade reforms", Trade Policy Reform: Lessons and Implications, J. Nash and W. Takacs (eds.), Washington, D.C., World Bank.

IMF (International Monetary Fund) (2005), "Dealing with the revenue consequences of trade reform. Background paper for review of Fund work on trade" [online] http:/ /www.imf.org/external/np/pp/eng/2005/021505.pdf.

Internal Revenue Service of Ecuador (2007), "Ley Reformatoria para la Equidad Tributaria en el Ecuador", Quito. (2001), "Ley de Régimen Tributario Interno", Quito. 
Löfgren, H., R.L. Harris and S. Robinson (2002), “A standard computable general equilibrium (CGE) model in GAMS", Microcomputers in Policy Research, No. 5, International Food Policy Research Institute (IFPRI).

Löfgren, H., S. Robinson and M. El-Said (2003), "Poverty and inequality analysis in a general equilibrium framework: the representative household approach", The Impact of Economic Policies on Poverty and Income Distribution: Evaluation Techniques and Tools, F. Bourguignon and L. A. Pereira da Silva (eds.), New York, World Bank/Oxford University Press.

Mayorga, E. (2004), "Petroleum policy", Ecuador: an Economic and Social Agenda in the New Millennium, V. Fretes-Cibils, M.M. Giugale and J. R. López-Cálix (eds.), Washington, D.C., World Bank.

Mincer, J. (1974), Schooling, Experience, and Earnings, New York, National Bureau of Economic Research (NBER).

Morales, C. and others (2005), "Los impactos diferenciados del Tratado de Libre Comercio Ecuador - Estados Unidos de Norte América sobre la agricultura del Ecuador", Economic Commission for Latin America and the Caribbean (ECLAC) [online] http://www.pnud.org.ec/Publicaciones/TLC/ InformeUNDP_CEPLA.pdf.

Perry, G. and others (2007), "Informality: exit and exclusion", World Bank Latin American and Caribbean Studies, Washington, D.C., World Bank.

Ravallion, M. (2001), "Growth, inequality and poverty: looking beyond averages", World Development, vol. 29, No. 11.

Sanchez-Paramo, C. (2005), "Poverty in Ecuador", En breve, No. 71, World Bank.

Savard, L. (2003), "Poverty and income distribution in a CGE-household microsimulation model: top-down/bottom up approach", Working Paper, No. 03-43, Montreal, Centre interuniversitaire sur le risque, les politiques économiques et l'emploi (CIRPÉE).

Tamayo, L.M. (1997), "La evolución del arancel en el Ecuador: 1990-1996", Cuadernos de trabajo series, No. 115, Quito, Central Bank of Ecuador.

Vos, R. and N. De Jong (2003), “Trade liberalization and poverty in Ecuador: a CGE macro-microsimulation analysis", Economic Systems Research, vol. 15, No. 2.

Winters, A. (2002), "Trade liberalisation and poverty: what are the links?", World Economy, vol. 25, No. 9.

Winters, A., N. McCulloch and A. McKay (2004), "Trade liberalization and poverty: the evidence so far", Journal of Economic Literature, vol. 42, No. 1.

Wong, S. (2006), "Impactos del Tratado de Libre Comercio con los Estados Unidos: un análisis de equilibrio general aplicado", Revista Tecnológica ESPOL, vol. 19, No. 1. 
Chapter V

\title{
Poverty assessment from integration and employment policies in Uruguay: A CGE modelling analysis ${ }^{1}$
}

\author{
María Inés Terra \\ Marisa Bucheli \\ Silvia Laens ${ }^{3}$ \\ Carmen Estrades ${ }^{2}$
}

\section{A. Economic overview}

\section{Recent economic performance}

Since the mid-1970s, Uruguay has been gradually adopting reforms to strengthen its relations with the rest of the world, improve the efficiency of resource allocation through market-oriented measures,

This study was supported by a grant from the Poverty and Economic Policy (PEP) Research Network, financed by the International Development Research Centre (IDRC). We are very grateful to Maurizio Bussolo, Nitesh Sahay, Bernard Decaluwe, Nabil Annabi, John Cockburn, Randy Spence and Alvaro Forteza for their useful comments and suggestions. All remaining errors and omissions are our own responsibility. The authors acknowledge the collaboration of Gabriel Katz in various phases of the study.

2 Department of Economics, School of Social Sciences, Universidad de la República, Rodó 1854, Montevideo, Uruguay. E-mail addresses: ines@decon.edu.uy, marisa@decon.edu. uy, carmen@decon.edu.uy.

3 Centre for Economic Research (CINVE). Uruguay 1242, Montevideo, Uruguay. E-mail address: slaens@cinve.org.uy. 
and stabilize macroeconomic variables. Initially, the reforms focused on domestic price deregulation, capital-account liberalization and transformation of the financial sector. In the 1980s, however, the focus shifted towards trade reforms, and tariffs were gradually lowered. Starting from a maximum of $150 \%$ in 1980, by January 1993 the highest tariff had been brought down to $20 \%$.

The 1990s were dominated by the creation of the Southern Common Market (MERCOSUR) -an imperfect customs union encompassing Argentina, Brazil, Paraguay and Uruguay. Trade within MERCOSUR was tariff-free, and a common trade policy was adopted vis-à-vis outsiders. The countries agreed a common external tariff (CET) in 1994 (implemented in 1995), which ranged from 0 to $20 \%$, with an average value of $11 \%$. Nonetheless, many exceptions were allowed and the CET is only being fully enforced in 2010. In particular, tariffs on capital goods and computer and telecommunication products in Argentina, Paraguay and Uruguay would have to increase.

Albeit without an explicit agreement, Uruguay, Argentina and Brazil adopted a similar exchange-rate-based stabilization programme and, as a result, their domestic currencies were overvalued during the 1990s.

The goal of improving competitiveness motivated other important reforms. To begin with, the Government implemented a set of public-sector downsizing measures, including privatization of certain production services, retirement incentives for civil servants and restrictions on new hiring. In addition, two major changes were made to labour-market institutions. First, the government let the minimum wage fall in real terms, so that by the mid-1990s the minimum wage was no longer a binding constraint. Secondly, the rules governing wage and employment negotiations were altered. Following a 12-year ban on labour unions, in 1985 a new democratic government introduced new rules on wage negotiations, whereby both wages and employment conditions came to be set by collective bargaining at the industry level. Then in 1991, negotiations were transferred from the industry to the enterprise level.

As shown in table V.1, Uruguay enjoyed a period of GDP growth lasting until 1998 with only one year of recession (1995). Then, in 1999-2002, the economy suffered a sharp downturn. Between 1998 and 2002 , a cumulative decrease in output of nearly $18 \%$ was recorded.

The recession began when Brazil devalued its currency, which adversely affected Uruguayan exports both directly and indirectly through its impact on Argentina. The share of Uruguayan goods exported to Brazil shrank from over a third in 1998 to just over 20\% in 2001. 
Table V.1

MAIN INDICATORS

\begin{tabular}{|c|c|c|c|c|c|c|c|c|}
\hline Year & GDP a & $\begin{array}{c}\text { Annual } \\
\text { inflation a }\end{array}$ & $\begin{array}{c}\text { Fiscal } \\
\text { balance }\end{array}$ & $\begin{array}{l}\text { Current } \\
\text { account } \\
\text { balance }^{\mathrm{b}}\end{array}$ & $\begin{array}{l}\text { Imports } \\
\text { goods } \\
\text { and serv. }\end{array}$ & $\begin{array}{l}\text { Exports } \\
\text { goods } \\
\text { and serv. }\end{array}$ & $\begin{array}{c}\text { Gross } \\
\text { capital } \\
\text { formation }\end{array}$ & $\begin{array}{l}\text { Unemployment } \\
\text { rate }^{\mathrm{c}}\end{array}$ \\
\hline 1990 & 0.3 & 112.5 & -3.0 & 2.0 & 18.10 & 23.53 & 12.20 & 8.5 \\
\hline 1991 & 3.5 & 102.0 & -1.8 & 0.7 & 17.86 & 20.69 & 15.13 & 8.9 \\
\hline 1992 & 7.9 & 68.5 & 0.3 & -0.8 & 19.63 & 20.45 & 15.38 & 9.0 \\
\hline 1993 & 2.7 & 54.1 & -1.7 & -1.8 & 19.56 & 19.13 & 15.64 & 8.3 \\
\hline 1994 & 7.3 & 44.7 & -2.8 & -2.3 & 20.38 & 19.77 & 15.87 & 9.2 \\
\hline 1995 & -1.4 & 42.2 & -1.5 & -1.3 & 19.10 & 19.00 & 15.41 & 10.3 \\
\hline 1996 & 5.6 & 28.3 & -1.4 & -1.2 & 19.86 & 19.67 & 15.24 & 11.9 \\
\hline 1997 & 5.0 & 19.8 & -1.4 & -1.1 & 20.54 & 20.55 & 15.22 & 11.4 \\
\hline 1998 & 4.5 & 10.8 & -0.9 & -1.8 & 20.58 & 19.85 & 15.87 & 10.1 \\
\hline 1999 & -2.8 & 5.7 & -4.0 & -2.3 & 19.30 & 18.03 & 15.14 & 11.3 \\
\hline 2000 & -1.4 & 4.8 & -4.0 & -2.8 & 20.98 & 19.30 & 13.96 & 13.6 \\
\hline 2001 & -3.4 & 3.6 & -4.3 & -2.6 & 20.04 & 18.35 & 13.77 & 15.3 \\
\hline 2002 & -11.0 & 25.9 & -4.2 & 3.1 & 20.01 & 21.97 & 11.52 & 16.9 \\
\hline 2003 & 2.2 & 10.2 & -3.2 & -0.5 & 24.56 & 26.07 & 12.59 & 16.9 \\
\hline 2004 & 12.3 & 7.6 & -1.8 & -0.8 & 27.94 & 29.65 & 13.29 & 13.1 \\
\hline
\end{tabular}

Source: Prepared by the authors on the basis of data from the Central Bank of Uruguay and National Institute of Statistics (INE).

a Annual cumulative variation.

b Percentage of GDP (current prices).

c Urban areas.

Devaluation and a financial crisis in Argentina in 2002 also affected financial activities in Uruguay. The consequent drain on deposits and the withdrawal of non-resident deposits were aggravated by fraud in three private banks in Uruguay. The Argentine crisis also had a negative impact on Uruguay's foreign sales, with both tourism and merchandise exports declining, by $35 \%$ and $70 \%$ respectively, between 2001 and 2002 (first quarters).

The downturn was compounded by other factors: rising international interest rates and oil prices; a fall in the international prices of key Uruguayan exports (meat, wool and rice); a drought that hit agricultural activity and electricity generation; and the closure of several external markets following an outbreak of foot-and-mouth disease in early 2001.

Recovery began in 2003, fuelled mainly by foreign sales, which grew by $18 \%$. Uruguayan exports obtained an $80 \%$ gain in competitiveness with respect to Brazil and Uruguay's other trading partners as a result of the depreciation of the domestic currency. Total GDP grew by $2.2 \%$ in 2003 and $12.3 \%$ in 2004 . 


\section{Recent trends in the Uruguayan labour market}

Unemployment in Uruguay has traditionally been higher than in other Latin-American countries and has been particularly high among women and young people. During the growth period in the first half of the 1990s, the rate of unemployment held steady at around 9\%. During those years the output/labour ratio rose and the composition of employment changed, mainly due to a decline in manufacturing jobs (De Brun and Labadie, 1997 and 1998).

When GDP shrank in 1995, unemployment increased and, despite the immediate recovery and a period of growth lasting until 1998, it remained at higher levels than in earlier years. Once again, the increase in unemployment stemmed from job losses in manufacturing; but, during those years, services and commerce were unable to take up the slack, and the output/labour ratio rose in most industries (Bucheli, Diez de Medina and Mendive).

With the subsequent recession and crisis, unemployment climbed once again to reach a peak of $17 \%$ in 2002. There was a substantial reallocation of labour among industries over the 1990-2002 period as a whole. The share of manufacturing employment decreased from $21 \%$ at the end of the 1980s to $13 \%$ in 2002, with the textile sector accounting for the largest job losses. In contrast, job creation relied on private services targeting non-resident consumption (UNDP, 2001). ${ }^{4}$ Moreover, as a result of measures geared to public-sector downsizing, the share of public employment declined from $24 \%$ in 1986 to $18 \%$ in 2004 .

Labour-market changes meant wider differences in market outcomes between skilled and unskilled workers; and, in a context of earnings concentration, the education premium widened. In fact, the latter accounts for most of the increase in income dispersion, which has been explained by three factors: (a) the adoption of new technologies -induced by trade liberalization - complementary to skilled labour (Casacuberta and Vaillant, 2002); (b) the change in the wage-bargaining process from a centralized sector-level system to decentralized bargaining at the enterprise level (Arim and Zoppolo, 2000) and (c) the fall in the purchasing power of the minimum wage (Miles and Rossi, 2001).

In addition, the unemployment differential between education levels widened in the 1990s and deepened further during the crisis. Bucheli and Casacuberta (2005) analysed flows from employment to

Services consumed largely by non-residents include hotels and restaurants; transport and storage; financial services; recreational services; personal services and international organizations. 
unemployment in 1991-2002 and concluded that the hazard rate was higher for less educated workers throughout the period. In addition, the education gap in relation to the hazard rate and the probability of being unemployed also widened.

The aim of this paper is to assess the impact of regional integration on the labour market and on poverty in Uruguay. We constructed a computable general equilibrium (CGE) model, in which unemployment was introduced by assuming a wage-curve specification obtained from the econometric estimation of wage-curve elasticity.

\section{B. Methodology}

\section{Labour market specification: wage curve}

In the CGE model, public-sector employment and wages are fixed, and private labour-market closure is made for each category of labour (skilled and unskilled). As the skilled/unskilled employment ratio differs between industries, the unemployment and wage gaps between skilled and unskilled workers are determined by industry-level demand for each type of labour.

In the case of skilled workers (defined as those with at least 12 years of schooling), we assume that economic shocks and fluctuations affect wages, and that unemployment is fixed at a (very low) initial level. The unskilled labour market block proposes a negative relationship between the unemployment rate and the wage level, as discussed in the wagecurve literature. Blanchflower and Oswald (1995) show that a downwardsloping curve in the unemployment-wage space can be interpreted in various ways. For example, the efficiency-wage model argues that firms motivate their workers by offering an attractive wage to elicit effort and/ or reduce the quit rate. When unemployment rises, however, the critical wage needed to raise efficiency decreases. In a trade-union-bargaining model, union power increases when unemployment is low, so the wage rate tends to rise.

We assume that equilibrium in the unskilled labour market occurs when wages and unemployment verify the wage-curve equation estimated for Uruguayan data. The methodology and results of the wage-curve estimation are presented in appendix 1 . We ran several models using data for the period 1991-2004, using two different proxies for wages; and we estimated both micro-data and cell-mean regressions. In addition, we ran the model both for the whole sample and for groups of individuals classified by education level, gender, age and occupation 
-in each case using the overall unemployment rate as an explanatory variable. The results were consistent with the range of values obtained in similar studies for other countries.

Table V.2 reports the estimated unemployment coefficients obtained when running the micro-data regression for the whole sample and for different education levels. The estimation indicates a negative relationship between unemployment and workers' earnings. Specifically, the crosssection micro-data pool gave an elasticity of -0.116 . The parameter is somewhat higher for workers with less than 12 years' schooling and not different from 0 - at the usual significance levels - for skilled workers.

Table V.2

COEFFICIENTS ON THE UNEMPLOYMENT

VARIABLE IN THE ESTIMATION OF A WAGE

CURVE FOR GROUPS OF INDIVIDUALS

\begin{tabular}{ll}
\hline All workers & $\begin{array}{l}-0.116 \\
(7.03)^{\star \star}\end{array}$ \\
\hline Years of schooling & \\
$0-8$ & -0.131 \\
& $(5.82)^{\star \star}$ \\
$9-11$ & -0.158 \\
& $(4.88)^{\star \star}$ \\
12 or more & -0.047 \\
& $(1.32)$ \\
\hline
\end{tabular}

Source: Prepared by the authors.

* Significant at 95\%.

** Significant at $99 \%$.

\section{a) The CGE model}

We used the computable general equilibrium (CGE) model built by Terra and others (2006), with alterations in the labour-market specification, to assess the impact of different regional shocks and specific policies on unemployment in Uruguay. To allow for the possibility of unemployment, we introduced a wage-curve specification for unskilled labour, replacing the efficiency-wage and informal-sector specification of the previous model.

Apart from the wage curve, the structure of the core CGE model is quite conventional in terms of the analysis of trade-related issues. To assess the relevance of considering labour market imperfections, we used two different versions of the model: a wage-curve model and a competitive-labour-market model. 
The main features of this model are presented in Terra and others (2006):

It is a multi-sector model containing 22 sectors, including one special sector which encompasses all activities (mainly, public services and the financial sector), where employment and wages are fixed because institutional arrangements and/or trade unions act as a deterrent to worker lay-offs or wage cuts. Public employment is fixed by law: no new civil servants are hired, and existing employees cannot be laid off. Although trade unions could have been introduced into the model, our intention was to focus on unemployment among unskilled workers. Nonetheless, we decided to include a basic treatment of this sector given its importance in total employment.

We assume that Uruguay has three trading partners (Argentina, Brazil and the rest of the world). The Uruguayan economy is explicitly modelled as a quasi-small open economy (Harris, 1984), while in the case of the other trading partners only the demand for exports is endogenous.

Perfect competition is assumed in all sectors. However, we assume that goods are differentiated by origin using an Armington function.

We assume ten representative households of different income levels (representing deciles of the income distribution).

The Government receives income from tariffs and taxes, purchases goods and services, and makes transfers to households. We assume that the Government has a fixed consumption of goods and services (in physical units), and that transfers to households are indexed to changes in the average wage. ${ }^{5}$ Government savings are obtained as a residual.

On the output side, we introduce a nested production function. At the top level, firms combine intermediate inputs with value-added, under a Cobb-Douglas function. Value is added through a constantelasticity-of-substitution (CES) function that combines capital and composite labour. The latter is obtained by combining skilled and unskilled labour with CES.

We treat Uruguay as a quasi-small economy. ${ }^{6}$ While it faces a perfectly elastic supply curve on external markets for its imports, the country is assumed to face a downward sloping demand curve for its exports. Export demand is a function of relative prices and its tradingpartners' real income, both of which are considered exogenous.

Social security transfers accounted for nearly $83 \%$ of total government transfers to households in 2001. A 1989 constitutional reform established that social security benefits would be indexed to the trend of the Average Wage Index.

6 Following Cox's specification (Cox, 1994). 
Total demand in each sector consists of domestic demand (intermediate and final) plus exports to each trading partner.

The trade balance is fixed. The model's equilibrium is defined by simultaneous equilibrium in both goods and factor markets and in the external sector.

There are three factors of production: capital, and both skilled and unskilled labour (the labour market is segmented by skills). The supply of each factor is fixed and there is no international mobility. The skilled labour market is perfectly competitive while unskilled labour can be unemployed in the wage curve model.

Unemployment is not fixed in this model, so equilibrium in the unskilled labour market is found when the wage and unemployment satisfy the following wage curve equation:

$$
\frac{w u}{p f}=k u \cdot u n^{\theta_{u}}
$$

where $w u$ is the unskilled wage, $k u$ is a constant, $u n$ are unemployed workers and $\theta_{u}$ is the wage-curve elasticity. Although this specification is ad hoc, it is consistent with econometric estimates.?

The model was run using the General Algebraic Modelling System (GAMS).

\section{b) Calibration of the CGE model}

The model was calibrated using a Social Accounting Matrix (SAM) with data for 2000. This was taken from Terra, Bucheli, Laens and Estrades (2006), who had in turn adapted it from Barrenechea, Katz and Pastori (2004) with a number of minor adjustments.

The model first distinguishes between skilled and unskilled labour using data from the 2003 Continuous Household Survey (CHS) collected by the National Institute of Statistics (INE). Workers with twelve or more years of formal education were considered as skilled.

Secondly, it distinguishes between private and public activities, since there are rigidities affecting both wages and employment in the public sector. ${ }^{8}$ This sector combines skilled and unskilled labour, just as the private sector does; but public employment is considered fixed. To separate public from private activities, data were also taken from the 2003 CHS.

This equation replaces equation 9 in Terra and others (2006).

The public sector comprises electricity and water supply, oil refining, communications, the postal service, financial services and education. 
In addition, government final consumption was disaggregated in the new matrix.

Lastly, Argentina and Brazil were separated from the rest of the world, thus creating three foreign agents. In this case, data were taken from national accounts and trade statistics from the Central Bank of Uruguay (BCU).

\section{c) The microsimulation methodology}

The CGE model provides a number of insights into the poverty effects of the shocks and policies that were simulated. Nonetheless, combining these results with a microsimulation methodology yields more precise information about poverty and the income distribution by tracking economy-wide changes at the household level. Several approaches have been developed for this purpose, as discussed in Bourguignon, Pereira de Silva and Stern (2002).

Although the microsimulations are based on household data, there is no need to reconcile these with SAM because the procedure only requires data on changes in wages, employment and unemployment. The method assumes that changes in the labour market can be replicated by a random selection procedure, which imposes counterfactual changes in labour-market parameters calculated for the benchmark year. This approach follows Paes de Barros and Leite (1998), Paes de Barros (1999), Frenkel and González (2000), Ganuza, Paes de Barros and Vos (2002) and Ganuza and others (2004). It was applied for the case of Uruguay by Bucheli and others (2002) and by Laens and Perera (2004). The SPSS (Statistical Package for the Social Sciences) program used in this paper is the same as used in the latter work.

The rationale for using microsimulations is that a CGE model only captures a partial income distribution between families, which makes it hard to visualize the real impact of shocks or public policies on income distribution and poverty. A crucial assumption in this methodology is that an individual's position in the labour market is the main determinant of his or her income and poverty status.

The procedure takes the CGE results as inputs. The structure of the labour market is considered as a function of six parameters: participation rate, the unemployment rate, the wage structure, the overall average wage, the worker's education level and the structure of employment (sector of activity and occupation category). In this study, the participation rate is fixed so it is ignored in the microsimulations. The activity sector is defined as either formal or informal. 
After obtaining the changes in labour market parameters from the CGE results, the microsimulation methodology is applied. The procedure uses random numbers to simulate changes in labour-market structure that are consistent with the parameters introduced. On average, the effect of the random changes will reflect the impact of the new (simulated) labour market parameters. We use a Monte Carlo procedure to estimate the poverty and income distribution indicators and their confidence intervals. Specifically, in each simulation, we estimate changes in poverty and income distribution, the percentage of population under the poverty line, the poverty gap, the Gini coefficient and the Theil coefficient, using data from the 2000 CHS.

Several changes in labour-market structure were simulated for each scenario, first separately and then sequentially. The reason for establishing a sequence is that changes in labour parameters follow an order of some kind, which is not neutral. The commonly accepted sequence is as follows: first the individual decides whether or not to participate in the labour force; then the market decides whether or not he or she will be employed; then the person decides whether to work in the formal or informal sector; and this determines a certain wage level and, in the aggregate, the average wage. Lastly, the structure of the labour market is defined by education level. We applied this sequence in both of the models. As informality is fixed in the model, its rate remains unchanged. The analysis was applied to the whole sequence.

\section{Simulation design and results}

\section{Simulation design}

We designed the simulation in order to show how the main shocks originating from MERCOSUR have adversely affected the Uruguayan economy since 1999. In particular, we focus on how and why the 2002 crisis impacted the Uruguayan labour market, simulating two key components of that crisis: the change in relative prices vis-àvis Uruguay's main trading partners (caused by devaluations in those countries) and the external-savings constraint. To measure the effects of the change in relative prices that occurred when Argentina abandoned its currency-board regime, we simulated a $40 \%$ drop in domestic prices denominated in dollars in Argentina and a 7\% fall in the price of imports from that country (the ARGRP scenario), which was what 
actually happened in Argentina between 2000 and 2002. ${ }^{9}$ To compare the effects of shocks originating in one or other MERCOSUR partner, we simulated an identical change in prices in Brazil (BRARP).

The third simulation related to the foreign savings constraint. In 2000, the Uruguayan current account was running a deficit, which was financed by capital inflows from the rest of the world. In 2002 no capital inflow was forthcoming, so a sharp adjustment was needed to achieve a current account surplus. Accordingly, in this simulation, we set the current account balance (EXTSAV) at zero.

As noted in section 2, MERCOSUR is an imperfect customs union, because the common external tariff has not been fully enforced across the four countries. Nonetheless, we simulated full enforcement to assess its potential effects on the Uruguayan labour market, especially because the rise in tariffs on capital goods might have a negative effect caused by a loss of competitiveness (CET).

Lastly, we simulated a specific labour market policy. Assuming that a reduction in the relative cost of labour might stimulate employment, the study simulated a $10 \%$ direct subsidy on hiring unskilled labour in the formal sector (DIRTAX).

Table V.3 summarizes the five experiments and shows how variables or exogenous parameters are affected. The full model is presented in Terra and others (2006), and is also available from the authors upon request.

The results of these five simulations with the CGE model are presented in tables V.4 (Variation of main macroeconomic variables) and V.5 (Effect on labour market variables).

Table V.3

SIMULATION SCENARIOS

\begin{tabular}{llc}
\hline Simulation scenario & Variable or exogenous parameters & Variation (\%) \\
\hline ARGRP & Domestic price index $\left(\mathrm{DP}_{\text {ARGi }}\right)$ & -40 \\
& Export price from Argentina $\left(\mathrm{PW}_{\text {ARGi }}\right)$ & $-7 \%$ \\
\hline BRARP & Domestic price index $\left(\mathrm{DP}_{\text {BRi }}\right)$ & -40 \\
& Export price from Argentina $\left(\mathrm{PW}_{\text {BRi }}\right)$ & $-7 \%$ \\
\hline EXTSAV & Current account balance $(\mathrm{B})$ & -100 \\
\hline CET & Common external tariff $(\mathrm{t})$ & -10 \\
DIRTAX & Labour taxes (trab) & \\
\hline
\end{tabular}

Source: Prepared by the authors.

9 Data were obtained from the National Institute of Statistics and Censuses of Argentina (INDEC). 
Table V.4

MACROECONOMIC VARIABLES FOR EACH SIMULATION (Percent variation)

\begin{tabular}{|c|c|c|c|c|c|}
\hline & $\begin{array}{c}\text { Relative } \\
\text { price change } \\
\text { with Argentina }\end{array}$ & $\begin{array}{l}\text { Relative } \\
\text { price change } \\
\text { with Brazil }\end{array}$ & $\begin{array}{l}\text { External } \\
\text { Saving } \\
\text { Restriction }\end{array}$ & $\begin{array}{c}\text { Common } \\
\text { External } \\
\text { Tariff }\end{array}$ & $\begin{array}{l}\text { Subsidy } \\
\text { to Unskilled } \\
\text { labour }\end{array}$ \\
\hline \multicolumn{6}{|l|}{ Perfect competition model } \\
\hline Absortion* & -0.4 & -0.2 & -4.4 & -0.2 & 0 \\
\hline Household Consumption* & -0.1 & -0.1 & -0.7 & -0.2 & 1.7 \\
\hline Investment & -2.2 & -1.2 & -31.3 & -0.8 & -10 \\
\hline Exports* & -7.3 & -2.8 & 10 & -3.2 & -0.4 \\
\hline Imports* & -5.9 & -2 & -11.8 & -2.5 & -0.4 \\
\hline Real GDP & -0.5 & -0.3 & -0.5 & -0.3 & 0 \\
\hline Real Exchange Rate & 4.2 & 2.2 & 1.5 & -0.4 & -0.8 \\
\hline Export Price & -0.1 & -0.1 & 0 & 0 & 0 \\
\hline Import Price & -3 & -2.4 & 0 & 0 & 0 \\
\hline Consumer Price & 0.1 & 0 & -0.3 & 0.1 & -0.2 \\
\hline \multicolumn{6}{|l|}{ Wage curve model } \\
\hline Absortion* & -0.7 & -0.1 & -4.7 & -0.3 & 0.8 \\
\hline Household Consumption* & -0.1 & -0.1 & -0.8 & -0.2 & 2.2 \\
\hline Investment & -5.1 & -0.3 & -35.5 & -1.2 & -7 \\
\hline Exports* & -7.7 & -1.1 & 9.7 & -3.3 & 0.1 \\
\hline Imports* & -6.3 & -0.4 & -12 & -2.6 & 0.1 \\
\hline Real GDP & -0.8 & -0.2 & -0.8 & -0.4 & 0.8 \\
\hline Real Exchange Rate & 4.1 & 1.9 & 1.4 & -0.4 & -0.3 \\
\hline Export Price & -0.1 & -0.8 & 0 & 0 & 0 \\
\hline Import Price & -3 & -2.4 & 0 & 0 & 0 \\
\hline Consumer Price & 0 & 0 & -0.3 & 0.1 & -0.1 \\
\hline
\end{tabular}

Source: Prepared by the authors.

Table V.5

FACTOR INTENSITY OF EXPORT BY DESTINATION

\begin{tabular}{lccc}
\hline & Argentina & Brazil & Rest of the world \\
\hline Skilled labour/Unskilled labour & 0.68 & 0.30 & 0.37 \\
Capital/Unskilled labour & 0.94 & 1.47 & 1.82 \\
\hline
\end{tabular}

Source: Prepared by the authors.

\section{Simulations of regional shocks and results}

These experiments illustrate the vulnerability of the Uruguayan economy to regional macroeconomic shocks, which have increased as the physical and economic integration process with the MERCOSUR countries has deepened.

A relative-price change in any of the main MERCOSUR partners causes a decline in GDP in Uruguay, a reduction in exports and imports, and a decrease in investment. The reduction in both exports and imports 
reflects our choice of model closure, which fixes the current account balance. When export demand falls in the wake of a relative-price change with a trading partner, imports decline as well, and adjustment takes place through the exchange rate with a devaluation of the local currency.

The figures suggest that a macroeconomic shock originating in Argentina has a larger impact than one stemming from Brazil. This result should be treated cautiously, however, because it depends on the relative importance of exports to each country. In the benchmark case, exports to Argentina accounted for $24 \%$ of the total, whereas Brazil represented $17 \%$ and the rest of the world 59\%. Those countries' import shares were $26 \%, 18 \%$ and $56 \%$, respectively. If Brazil's relative importance as trading partner for Uruguay grows, the impact of a change of relative prices in that country could increase substantially.

When the existence of a wage curve is assumed, the impact of a change in relative prices in Argentina is greater than under perfect competition. Real GDP falls by $0.83 \%$ in this case, compared to just $0.48 \%$ when neoclassical assumptions are adopted. The change in relative prices with Argentina generates a very significant reduction in investment in Uruguay - as much as $5.1 \%$ in the wage-curve model and $2.2 \%$ under perfect competition. Investment declines because both government and household savings shrink.

In contrast, a Brazilian devaluation has a greater impact on the Uruguayan GDP under the perfect-competition model. This could be explained by the factor-intensity of the goods traded, which is quite different from one country to the other. Trade flows with Argentina are more intensive in skilled labour than those with Brazil (see tables V.5 and V.6). Thus, a loss of competitiveness with Argentina generates a reallocation of resources towards industries that make an intensive use of unskilled labour and capital (see table V.7).

Table V.6

SPECIALIZATION AND FACTOR INTENSITY BY SECTOR

\begin{tabular}{|c|c|c|c|c|c|c|c|c|c|c|c|}
\hline & \multirow{2}{*}{$\begin{array}{c}\text { Skill labour/ } \\
\text { Non-skill } \\
\text { labour }\end{array}$} & \multirow{2}{*}{$\begin{array}{l}\text { Capital/ } \\
\text { Non-skill } \\
\text { labour }\end{array}$} & \multicolumn{3}{|c|}{$\begin{array}{c}\text { Trade Balance } \\
\text { (Mill. of dollars) }\end{array}$} & \multicolumn{3}{|c|}{$\%$ of Exports } & \multicolumn{3}{|c|}{$\%$ of Imports } \\
\hline & & & ARG & BRA & RM & ARG & BRA & $\mathbf{R M}$ & ARG & BRA & RM \\
\hline $\begin{array}{l}\text { Agriculture \& } \\
\text { agroindustries } \\
\text { Other manufacture }\end{array}$ & 0.08 & 0.67 & 1 & 338 & 964 & 11.9 & 55.9 & 66.1 & 12.1 & 14.7 & 9.4 \\
\hline $\begin{array}{l}\text { goods } \\
\text { Services } \\
\text { Total }\end{array}$ & $\begin{array}{l}0.37 \\
1.33 \\
1.00\end{array}$ & $\begin{array}{l}1.33 \\
1.06 \\
1.00\end{array}$ & $\begin{array}{r}-411 \\
434 \\
23\end{array}$ & $\begin{array}{r}-330 \\
-24 \\
-16\end{array}$ & $\begin{array}{r}-1289 \\
-162 \\
-487\end{array}$ & $\begin{array}{r}25.8 \\
62.3 \\
100\end{array}$ & $\begin{array}{r}34.7 \\
9.4 \\
100\end{array}$ & $\begin{array}{r}17.6 \\
16.4 \\
100\end{array}$ & $\begin{array}{r}63.7 \\
24.2 \\
100\end{array}$ & $\begin{array}{l}73.1 \\
12.1 \\
100\end{array}$ & $\begin{array}{r}70.6 \\
20.0 \\
100\end{array}$ \\
\hline
\end{tabular}

Source: Prepared by the authors. 
Table V.7

OUTPUT SHARES AND VARIATION BY SECTOR

(Percentages)

\begin{tabular}{lcccc}
\hline & Agriculture & Manufacturing & Services & Informal \\
\hline Share of sector in total output & 15.4 & 16.4 & 63.8 & 4.4 \\
$\begin{array}{l}\text { Argentina RP } \\
\quad \text { Perfect Comp }\end{array}$ & & & & \\
$\quad$ Wage curve & 5.1 & 2.4 & -0.8 & -0.3 \\
$\quad$ Brazil RP & 4.9 & 2.0 & -1.3 & 0.0 \\
$\quad$ Perfect Comp & -2.9 & -1.6 & 0.2 & 0.1 \\
$\quad$ Wage curve & -2.1 & -1.5 & 0.2 & 0.0 \\
External Saving Restriction & & & & \\
$\quad$ Perfect Comp & 2.1 & 0.8 & -1.5 & 0.5 \\
$\quad$ Wage curve & 2.0 & 0.6 & -1.8 & 0.1 \\
CET & & & & \\
$\quad$ Perfect Comp & -0.6 & 1.2 & -0.1 & -0.1 \\
$\quad$ Wage curve & -0.7 & 1.1 & -0.2 & -0.1 \\
Subsidy to Unskilled labour & & & & -2.3 \\
$\quad$ Perfect Comp & 2.0 & 0.3 & -0.4 & 1.0 \\
$\quad$ Wage curve & 1.8 & 0.7 & 0.5 & \\
\hline
\end{tabular}

Source: Prepared by the authors.

This, in turn, increases the demand for unskilled labour $(0.3 \%)$, which reduces unemployment (by 3.8\%). The opposite occurs when the change in relative prices is with Brazil.

To simplify the problem, we can divide production into two big sectors, defined by their skilled or unskilled labour-intensity. The following graph illustrates the argument:

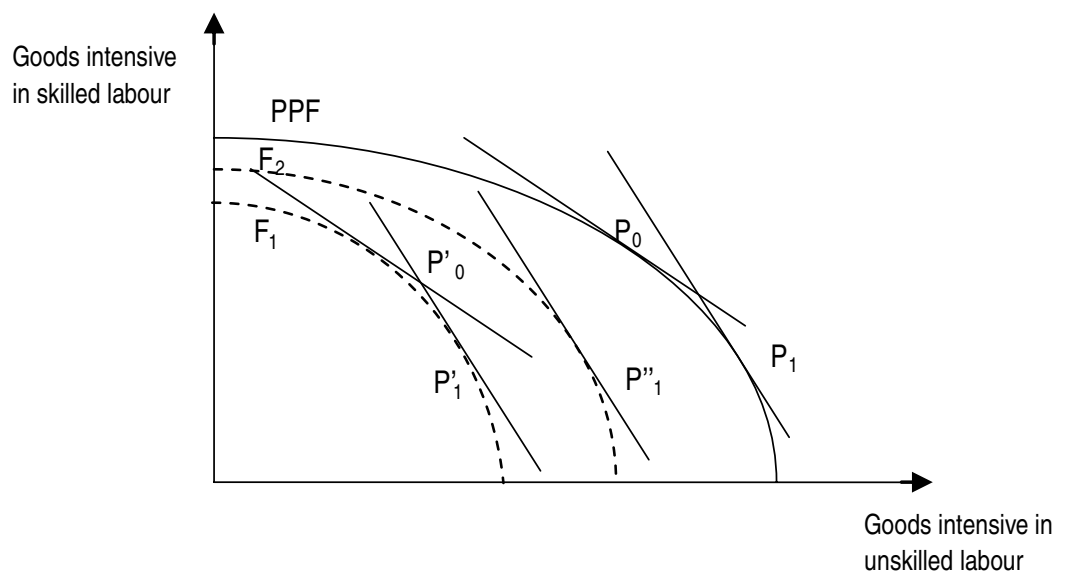


The PPF curve is the production possibility frontier when the labour market is perfectly competitive. When there is a positive level of unemployment, however, the economy cannot reach that frontier. Under the wage-curve assumption, the economy attains frontier $\mathrm{F}_{1}$, which represents the maximum possible output given the stock of capital and skilled labour and the initial unemployment level. $\mathrm{P}_{0}$ and $\mathrm{P}_{0}{ }_{0}$ show the optimal output combinations under perfect competition and under a wage curve for the initial relative prices. The graph shows that as relative prices change, favouring an increase in the production of goods that are intensive in unskilled labour, the production combinations shift to $\mathrm{P}_{1}$ and $\mathrm{P}^{\prime}{ }_{1}$ respectively. When the demand for unskilled labour rises, as happens at $\mathrm{P}_{1}^{\prime}$ the unskilled wage rises and unemployment falls. The frontier $\mathrm{F}_{1}$ shifts to the right to $\mathrm{F}_{2}$, and equilibrium is attained at $\mathrm{P}_{1}^{\prime \prime}$. In our simulations, this represents the case of a change in relative prices in Argentina.

A change in relative prices with Argentina generates a very large reduction in Uruguayan exports, as can be seen in table V.3, and specialization moves towards goods that are intensive in unskilled labour (see table V.6). Consequently, the demand for unskilled labour rises, as does the unskilled wage, thus reducing unemployment under the wage-curve model. In this model unskilled employment and wages increase by more than under perfect competition.

In contrast, a change in relative prices with Brazil has the opposite effect on the labour market. The specialization that occurs is towards sectors that are intensive in skilled labour, specifically services; thus, unskilled employment and wages decline and unemployment rises.

The simulation of an external savings constraint causes a very large reduction in imports and investment, but an increase in exports. More specifically, traditional exports increase, mainly in the primary sector, which are intensive in unskilled labour. Nonetheless, the reduction in investment causes a $25 \%$ drop in the demand for unskilled labour in the construction sector, where $75 \%$ of sector output is destined for investment. This leads to a downturn in the service sector, but concentrated in service activities that are intensive in unskilled labour. The demand for unskilled labour thus falls, causing unemployment to rise. The decrease in external savings also generates a reduction in payments to all factors (see table V.5).

\section{Simulation of MERCOSUR deepening and results}

Full enforcement of the MERCOSUR CET means greater protection in the Uruguayan domestic market. The impact on macroeconomic variables is negative but not significant: absorption, household 
consumption, trade and GDP all fall in both versions of the model. Resources are reallocated towards the manufacturing sector (e.g., chemicals and other import-substituting industries), leading to a more intensive use of capital. Nonetheless, the change in the production structure is slight (see table V.8). The increase in protection causes an anti-export bias, so agricultural output falls. Among services, the sectors that grow are commerce and transportation, while health services, hotels, and gas distribution decline, along with other services.

In the labour market, wages fall, mainly for skilled workers; and, in the efficiency-wage model, unemployment rises (see table V.5). Accordingly, the CET approved by MERCOSUR would not have a positive effect on employment in Uruguay: it would protect workers in the manufacturing sector (where employment rises), but would diminish overall employment. Nonetheless, the impact is much smaller than any of the macroeconomic shocks previously analysed.

\section{Final remarks}

The main findings of this paper are as follows:

- Changes in the shares of Uruguay's main partners in its total trade have different impacts on the labour market. If exports to Argentina grow, the demand for unskilled labour falls and unemployment rises. The opposite happens when exports to Brazil increase.

- Given regional macroeconomic instability, negative external shocks from Uruguay's MERCOSUR partners have a greater impact than any tariff changes that are currently being negotiated with its regional partners. As long as regional instability persists, Uruguay should be cautious with trade integration policies and try to avoid excessive regional dependency.

- It is important to take the existence of labour market imperfections into account. The effects of external shocks are clearly different when we assume a "wage curve" in the unskilled formal labour sector. In this case, when the economy specializes in production that makes intensive use of unskilled labour, there is an efficiency loss. This result underscores the need for appropriate analysis of the labour market.

- Higher unemployment also increases poverty and inequality.

- A subsidy for hiring unskilled labour in the formal sector could help reduce unemployment and therefore boost GDP, although its effects on investment could be negative. 


\section{Bibliography}

Annabi, Nabil (2003), "Modeling labour markets in CGE models", Endogenous Labour Supply, Unions and Efficiency Wages, Québec, Université Laval, Poverty and Economic Policy (PEP) Research Network.

Arim, Rodrigo and Guillermo Zoppolo (2000), "Remuneraciones relativas y desigualdad en el mercado de trabajo. Uruguay: 1986-99“" Montevideo, Faculty of Economic Sciences and Administration, Universidad de la República.

Barrenechea, Pedro, Gabriel Katz and Héctor Pastori (2004), "Construcción de una matriz de contabilidad social para Uruguay para el año 2000", Working paper, No. 20/04, Department of Economics, School of Social Sciences, Universidad de la República.

Blanchflower, David and Andrew Oswald (1995), "Estimating a wage curve for Britain 1973-1990", NBER Working Paper, No. 4770, Cambridge, National Bureau of Economic Research.

Blinder, Alan (1973), "Wage discrimination: reduced form and structural estimates", Journal of Human Resources, vol. 8, No. 4.

Bourguignon, François, Luiz Pereira da Silva and Nicholas Stern (2002), "Evaluating the poverty impact of economic policies: some analytical challenges", Washington, D.C., The World Bank, unpublished.

Bucheli, Marisa (2005), “Uruguay: La cobertura de la seguridad social en el empleo, 1991 - 2002", Protección social y mercado laboral, Fabio Bertranou (ed.), Santiago, Chile, International Labour Organization (ILO).

Bucheli, M. and C. Casacuberta (2005), "Incidencia y duración del desempleo", Uruguay: empleo y protección social: de la crisis al crecimiento, Santiago, Chile, International Labour Organization (ILO).

Bucheli, Marisa, Rafael Diez de Medina and Carlos Mendive (2002), “Uruguay: equidad y pobreza ante la apertura comercial de los noventa. Un enfoque a través de microsimulaciones", Economic Liberalisation, Distribution and Poverty: Latin America in the 1990s, Rob Vos, Lance Taylor and Ricardo Paes de Barros (eds.), Cheltenham, Edward Elgar Publishers.

Casacuberta, Carlos and Marcelo Vaillant (2002), “Trade and wages in Uruguay in the 1990's", Montevideo, Economics Departament, Faculty of Social Sciences, Universidad de la República.

Cassoni, Adriana and M. Fachola (1997), "Non financial services sector: perspectives in view of the openness and integration process", Ministry of Labour of Uruguay, unpublished.

Cox, David (1994), "Some applied general equilibrium estimates of the impact of a North American free trade agreement on Canada", Modeling Trade Policy. Applied General Equilibrium Assessments of North American Free Trade, Joseph Francois and Clinton Shiells (eds.), Cambridge University Press.

Croce, Helena, Luciana Macedo and Patricia Triunfo (2000), "Cost function: an analysis of Uruguayan commercial banks", Working Paper, No. 1/00, Department of Economics, School of Social Sciences, Universidad de la República.

DeBrun, Julio and Gastón Labadie (1998), "Rigidez salarial, precios relativos y ajuste estructural: una interpretación del desempleo en Uruguay", Working Paper, No. 383, Washington, D.C., Inter-American Development Bank (IDB). (1997), “Mercado laboral, apertura y recesión: la experiencia uruguaya de los 
noventa", Mercados laborales en los 90: cinco ejemplos de América Latina, Buenos Aires, Interdisciplinary Center for Latin American Development Studies of the Konrad Adenauer Stiftung (CIEDLA).

Frenkel, Roberto and Martín González Rozada (2000), “Liberalización del balance de pagos. Efectos sobre el crecimiento, el empleo y los ingresos en Argentina - Segunda parte", Buenos Aires, Center for the Study of State and Society (CEDES), unpublished.

Ganuza, Enrique, Ricardo Paes de Barros and Rob Vos (2002), "Labour market adjustment, poverty and inequality during liberalisation", Economic Liberalisation, Distribution and Poverty: Latin America in the 1990s, Rob Vos, Lance Taylor and Ricardo Paes de Barros (eds.), Cheltenham (UK), Edward Elgar Publishers.

Ganuza, Enrique and others (2004), ¿Quién se beneficia del libre comercio? Promoción de exportaciones y pobreza en América Latina y el Caribe en los 90, New York, United Nations Development Programme (UNDP)/Alfaomega Colombiana S.A.

Harris, Richard (1984), "Applied general equilibrium analysis of small open economies with scale economies and imperfect competition", American Economic Review, vol. 74.

Laens, Silvia and Marcelo Perera (2004), “Uruguay: crecimiento de las exportaciones, pobreza y distribución del ingreso", ¿Quién se beneficia del libre comercio? Promoción de exportaciones y pobreza en América Latina y el Caribe en los 90, New York, United Nations Development Programme (UNDP)/Alfaomega Colombiana S.A.

Laens, Silvia and María Inés Terra (2000), "Efectos del perfeccionamiento del MERCOSUR sobre el mercado de trabajo de Uruguay: un ejercicio de simulación usando un modelo CGE", Revista de Economía, Central Bank of Uruguay, vol. 7, $\mathrm{N}^{\mathrm{o}}$ 2, November.

Lorenzo Fernando, Rosa Osimani and Pablo Caputti (1999), "Matriz de insumo producto y contablidad social para la economía uruguaya. Año 1995. Impacto de la apertura comercial del MERCOSUR sobre el mercado laboral uruguayo", Montevideo, Programme on strengthening the social area (FAS), Office of Planning and the Budget, unpublished.

Miles, Daniel and Máximo Rossi (2001), "Wage inequality in developing countries: market forces or government intervention", Working Paper, No. 1001, Department of Economics (dECON), Universidad de la República.

Oaxaca, Ronald (1973), "Male-female wage differentials in urban labour markets", International Economic Review, vol. 14.

Paes de Barros, Ricardo (1999), "Evaluando el impacto de cambios en la estructura salarial y del empleo sobre la distribución de renta", Rio de Janeiro, Institute of Applied Economic Research (IPEA), unpublished.

Paes de Barros, Ricardo and Philippe Leite (1998), “O impacto da liberalizaçao sobre distribuiçao de renda no Brasil", Rio de Janeiro, Institute of Applied Economic Research (IPEA), unpublished.

Saint Paul, Gilles (1996), Dual Labour Markets, The MIT Press.

Shapiro, Carl and Joseph Stiglitz (1984), "Equilibrium unemployment as a worker discipline device", American Economic Review, vol. 74, No. 3.

Tansini, Ruben and Patricia Triunfo (1998a), "Technical efficiency and trade openness in the Uruguayan manufacture sector", Working paper, No. 4/98, Department of Economics, School of Social Sciences, Universidad de la República, Uruguay. 
Tansini, Ruben and Patricia Triunfo (1998b), "Technical change and productivity in Uruguayan industrial firms", Working paper, No. 12/98, Department of Economics, School of Social Sciences, Universidad de la República, Uruguay.

Terra, M. Inés and others (2006), "The effects of increasing openness and integration to the MERCOSUR on the Uruguayan labour market: a CGE modelling analysis", MPIA Working Paper, No. 2006-06.

Thierfelder, Karen E. and Clinton R. Shiells (1997), "Trade and labour market behavior", Applied Methods for Trade Policy Analysis. A Handbook, Joseph F. Francois and Kenneth A. Reinert (eds.), Cambridge, Cambridge University Press.

UNDP (United Nations Development Program) (2001), Desarrollo Humano en Uruguay, 2001, Montevideo. 


\section{Appendix 1}

\section{Estimation of a wage curve}

We used the microdata provided by the Continuous Household Survey $(\mathrm{ECH})$ - a one-shot monthly survey of households - collected by the National Institute of Statistics (INE) between 1991 and 2004. Until 1997 the survey covered cities and towns with more than 900 inhabitants; but since 1998, the sample has been restricted to towns with a population of over 5,000. To ensure similar coverage for the whole period, we dropped the data for small towns in the 1991-1997 surveys. As 12\% of the population live in towns with more than 5,000 inhabitants, we can assume that the results obtained with this sample are representative of the whole country. Nonetheless, the sample underestimates the population engaged in agricultural activities.

In Uruguay, the law sets specific regulations for young workers of between 14 and 18 years old, and the minimum retirement age is 60 . Accordingly, we worked with the subsample of 18-59 years old workers who represent $10 \%$ of the labour force.

With the pool of the annual cross-section data on workers between 18 and 59 years old, we estimate the following wage equation:

$$
\ln \mathrm{W}_{\mathrm{irt}}=\alpha+\beta \ln \mathrm{U}_{\mathrm{rt}}+\delta \mathrm{X}_{\mathrm{irt}}+\varepsilon_{\mathrm{irt}}
$$

where $i$ represents an individual, $r$ is the region, $t$ is the year of the interview; $W$ is the wage (in log form), $U$ is the annual unemployment rate in the worker's region and $X$ is a vector of personal characteristics.

We worked with two different proxies for the wage. The first includes the regular labour income received (both in cash and in-kind) in the previous month, divided by 4.2 (the number of weeks in a month), times the number of hours worked in the previous week. This amount is deflated by the Consumer Price Index to eliminate the effect of price changes through time. We refer to this proxy as the "wage".

In contrast, we use the expression "adjusted wage" when three social benefits are added. First, we assign an estimation of health benefits. In Uruguay, payment of a monthly fee purchases entitlement to medical assistance in the private health system. Under the law, private-sector workers have to contribute to a health fund (DISSE), and this contribution entitles them assistance in the private health system without paying the fee. Although the ECH has not investigated compliance with this regulation - at least before 2001- a number of questions on medical care make it possible to identify most of DISSE beneficiaries. They also make it possible to identify individuals who receive health benefits 
through a collective agreement in their job. We assigned to these workers a benefit equivalent to the price of one ordinary fee. According to Bucheli (2004), these two options allow to identify most in-job private recipients of health benefits but not civil servant recipients, who account for around $50 \%$ of public-sector employment.

The second benefit is the so-called thirteenth wage (an annual payment equivalent to the monthly wage) received by both public- and private-sector wage earners. The $\mathrm{ECH}$ has collected data on this benefit since 2001. Recent data show that, while all civil servants receive the thirteenth, wage, enforcement is weaker in the private sector. In this case, the presence of this benefit is highly correlated with being a healthbenefit recipient. We therefore added an amount equivalent to 1/12 of the monthly in-cash wage to wage earners when they work in the public sector or when they receive in-job health benefits.

Thirdly, the law establishes a specific payment for private-sector wage earners when they take their annual vacation. Although the ECH does not collect data on this benefit, we added an amount equivalent to $2 / 3$ of the monthly in-cash wage when the worker is a private-sector wage earner and receives in-the-job health benefits.

The vector of characteristics $X$ included the following: years of schooling; potential experience (age minus years of schooling minus 6) and the square of this figure; a female dummy; dummies for the relationship with the head of the household (head, wife of the head, or other); dummies for marital status (single, couple, or other); dummies for occupation (private wage earner, civil servant, self-employed with some capital, or self-employed without capital); dummies for industry (manufacturing and energy, agriculture, construction, commerce, services and transport), and a part-time dummy to capture individuals who work less than 30 hours per week.

In addition to these personal and labour characteristics, the explanatory variables include dummies for the year of the interview, regional dummies, and the mean of the annual regional activity rate.

With respect to regional characteristics, Uruguay is a small country divided into 19 political divisions. These divisions were grouped, as follows, according to the INE five-regions-classification: the capital city, the North region (Artigas, Salto and Rivera), the Middle North region (Paysandú, Río Negro, Tacuarembó, Durazno, Treinta y Tres, Cerro Largo), the Middle South region (Soriano, Florida, Flores, Lavalleja, Rocha) and the South region (Colonia, San José, Canelones, Maldonado).

As local unemployment is defined at a more aggregate level than the wage, the estimated standard errors may be biased downwards. 
Following previous studies, we estimate a second model using the average values of the variables.

Apart from the estimation for the whole sample, we run the model for groups of individuals disaggregated by level of education, gender, age and occupation. In all cases we used the overall unemployment rate.

Table 1 reports the unemployment coefficients for the two proposed earnings indicators and for the two models. The estimations show that unemployment has a negative effect on workers' earnings. Specifically, for the pool of the cross-section micro-data we find an elasticity of -0.116 when the wage is used as the dependent variable.

Table 1

UNEMPLOYMENT COEFFICIENTS FROM MICRO-DATA REGRESSIONS AND CELL-MEAN REGRESSIONS

\begin{tabular}{llc}
\hline & Wage & Adjusted wage \\
\hline Micro-data regression & -0.116 & -0.105 \\
& $(7.03)^{\star \star}$ & $(6.17)^{\star *}$ \\
Cell-mean regression & -0.147 & -0.151 \\
& $(4.42)^{\star *}$ & $(4.19)^{\star *}$ \\
\hline
\end{tabular}

Source: Prepared by the authors.

** Significant at 99\%

Table 2 shows the unemployment coefficients estimated for disaggregated groups of workers, with the wage as dependent variable.

We find a higher elasticity for youth (-0.236) than for workers older than 24 years (-0.09). There is also a gender difference: the coefficient is more negative for women than for men. With respect to education, we find a negative elasticity for workers with less than 12 years of schooling; but the pay received by workers with university level education seems not to have been affected by unemployment.

We also find differences when we disaggregate by labour characteristics. Earnings in the public sector seem not to be affected by unemployment. Meanwhile, informal workers with less than 12 years' schooling seem to be the ones affected. 
Table 2

UNEMPLOYMENT COEFFICIENTS FOR GROUPS OF INDIVIDUALS

\begin{tabular}{|c|c|}
\hline All workers & $\begin{array}{l}-0.116 \\
(7.03)^{\star *}\end{array}$ \\
\hline \multicolumn{2}{|l|}{ Years of schooling } \\
\hline $0-8$ & $\begin{array}{l}-0.131 \\
(5.82)^{\star *}\end{array}$ \\
\hline $9-11$ & $\begin{array}{l}-0.158 \\
(4.88)^{\star \star}\end{array}$ \\
\hline 12 or more & $\begin{array}{r}-0.047 \\
(1.32) \\
\end{array}$ \\
\hline \multicolumn{2}{|l|}{$\overline{\text { Age }}$} \\
\hline $18-24$ & $\begin{array}{l}-0.236 \\
(6.31)^{* *}\end{array}$ \\
\hline $25-49$ & $\begin{array}{l}-0.090 \\
(4.41)^{* *}\end{array}$ \\
\hline $50-59$ & $\begin{array}{l}-0.091 \\
(2.24)^{*}\end{array}$ \\
\hline \multicolumn{2}{|l|}{ Sex } \\
\hline Male & $\begin{array}{l}-0.098 \\
(4.82)^{* *}\end{array}$ \\
\hline Female & $\begin{array}{l}-0.148 \\
(5.43)^{* *}\end{array}$ \\
\hline \multicolumn{2}{|l|}{ Occupation } \\
\hline Public-sector wage earner & $\begin{array}{l}-0.045 \\
(1.65)\end{array}$ \\
\hline Private-sector wage earner & $\begin{array}{l}-0.123 \\
(5.64)^{\star \star}\end{array}$ \\
\hline Self-employed & $\begin{array}{l}-0.184 \\
(4.79)^{\star *}\end{array}$ \\
\hline \multicolumn{2}{|l|}{ Formality } \\
\hline Formal & $\begin{array}{l}-0.059 \\
(3.16)^{* *}\end{array}$ \\
\hline Informal & $\begin{array}{l}-0.236 \\
(8.86)^{* *}\end{array}$ \\
\hline \multicolumn{2}{|l|}{ Classification } \\
\hline Public-sector wage earner & $\begin{array}{l}-0.045 \\
(1.65)\end{array}$ \\
\hline $\begin{array}{l}\text { Private sector, with at least } \\
12 \text { years of schooling }\end{array}$ & $\begin{array}{l}-0.045 \\
(0.92)\end{array}$ \\
\hline $\begin{array}{l}\text { Private sector, with less than } 12 \\
\text { years of schooling, formal }\end{array}$ & $\begin{array}{l}-0.034 \\
(1.25)\end{array}$ \\
\hline $\begin{array}{l}\text { Private sector, with less than } 12 \\
\text { years of schooling, informal }\end{array}$ & $\begin{array}{l}-0.263 \\
(9.45)^{\star *}\end{array}$ \\
\hline
\end{tabular}

Source: Prepared by the authors.

* Significant at 95\%.

${ }^{\star \star}$ Significant at 99\%. 

Chapter VI

\title{
CGE lessons on liberalization of trade in services: Argentina, Brazil and Uruguay ${ }^{1}$
}

\author{
Omar O. Chisari ${ }^{2}$ \\ Javier Maquieyra ${ }^{3}$ \\ Carlos A. Romero ${ }^{4}$
}

\section{A. Introduction}

In this paper, we use two computable general equilibrium models to evaluate gains of the liberalization of the trade in services for Argentina, Brazil and Uruguay. We replicate the economies of those countries and simulate several scenarios on the basis of other countries' experiences and suggestions made in the literature.

\footnotetext{
1 A first version of this paper was presented to the meeting organized by the InterAmerican Development Bank (IDB), the United Nations Economic Commission for Latin America and the Caribbean (ECLAC) and the Business School of the Central American Institute for Business Administration (INCAE) in San José, Costa Rica, on 25 and 26 November 2008. The authors are grateful to Julio Berlinski for his comments and ideas on a first draft, and to Inés Terra for providing the data to build the social accounting matrix for Uruguay and her contribution to the summary of the literature. The authors are solely responsible for the information used and any errors that may have occurred. This paper is also based on Chisari, Romero and Maquieyra (2008), prepared for the MERCOSUR Economic Research Network.

2 Institute of Economics of the Argentine University of Administration Sciences (UADE and Argentina's National Council of Scientific and Technical Research (CONICET).

3 Secretariat for Science and Technology (SECYT), Argentina, and UADE

4 Institute of Economics, UADE.
} 
As a guide for policy, computable general equilibrium (CGE) models are a very useful tool for ex ante experimentation. They place the discussion within a context that is neither entirely normative nor completely positive, but intermediate, and make it possible to take into account the structural differences between economies. Not only can they show which industries contract or expand, they also give some hints on the political economy of a trade reform.

We estimate the gains derived from improvements in efficiency, quality and productivity of the service industries, due to more intense competition in the domestic market. One interesting result is that quality advancements lead to gains in welfare of a similar order or even higher than what is expected in the case of productivity improvements. Additionally, we estimate the gains obtained from a reduction in the implicit mark-up of domestic services due to barriers to trade.

We consider two basic cases of liberalization of trade in services: 1) mobility of goods, in which there is mobility of services across borders, as it is the traditional case of exports and imports of goods, and 2) trade presence, that is location in the domestic country of new operators with a new technology for producing services.

To address the second case, a latent technology is defined in situ, and it will be operative or not depending on relative prices. Thus, two technologies will be competing within the same industry and market forces will ultimately determine their market share in the overall equilibrium of the economy. This is especially relevant for the case of telecommunications.

We see that the economy's specific endowment of factors will limit the expected gains of liberalization if the latent technology is unsuitable or incompatible with said factors. For example, if trade presence intensively uses human capital that is unavailable in the economy, the welfare improvements will be less than expected, or will only be possible when the supply of human capital responds to the new requirements.

We will also see that governments may face dilemmas regarding domestic market regulations. If the liberalization of trade in financial services called for a change in regulations, such that the domestic demand for government bonds were to fall, the long-term gains could be overshadowed by the immediate costs. This could occur, for example, if greater trade presence had to be accompanied by less strict regulations on (government-issued) bonds holdings. Hence, the so called "home bias", real or induced by financial regulations, might end up lower after liberalization. 
The results of the computational exercises are presented as changes in: 1) welfare of households (measured in terms of the equivalent variation), for example associated with the breakdown of restrictions (whose magnitude includes estimations from other papers, cf. Berlinski, Celani and Bebzuk (2008) and Dee (2004 and 2005)), 2) rates of profit and the activity levels of industries, 3) prices of goods and factors, ${ }^{5}$ and 4) macroeconomic indicators, such as the net fiscal result and the trade balance, to assess the feasibility of reforms. We attempt to identify the dilemmas and contradictions that the liberalization of trade in services could pose to the economies with respect to the trade surplus, income distribution and the fiscal situation, as well as to illustrate them quantitatively in order to understand their magnitude and relevance.

We employ two CGE models for the calculations. For the Argentine and Uruguayan cases, we apply a model built by the authors (see Chisari and others (2009)), based on the Mathematical Programming System for General Equilibrium analysis (MPSGE) (see, for example, Rutherford and Paltsev (2000)). This kind of model allows for a greater degree of flexibility to design the simulations. For Brazil, our study uses the Global Trade Analysis Project (GTAP) model - adapted by Rutherford (2005) that also works on an MPSGE platform.

The following section presents a brief review of the literature. This helps to identify some of the exercises that must be considered to place our work within the context of the current discussion. Then, the next section develops a simplified version of the economic model. In this context, we highlight the simulation exercises inspired by the literature and those we built from our own analysis based on the structural characteristics of the countries. This reveals the relevance of some macroeconomic dilemmas (such as the way government bonds affect prices given greater financial liberalization) or the development of new industrial organizations in sectors with highly-intensive technology use (for example, when allowing for the trade presence of entrant suppliers of telecommunications). Following that, we classify the main simulations, briefly describing them in isolation or in interaction. The following sections analyse the results for Argentina, Uruguay and Brazil. The paper closes with some lessons and key conclusions. There is also an appendix that describes the model for Argentina and Uruguay. The model for Brazil is the GTAP version.

Note that the said results refer to annual magnitudes. 


\section{B. The literature on the liberalization of services in a computable general equilibrium}

Dee (2003) discusses the special characteristics that models applied to trade in services must take into account and summarizes some methods for quantifying the barriers to trade in services. The study mentions that services are often tailored to buyers, and that this has to do with the regional characteristics of demand or the regulatory framework in which they operate. It also discusses the mobility of production factors starting from capital mobility when barriers to foreign direct investment (FDI) have been eliminated.

Markusen, Rutherford and Tarr (1999) model FDI, stressing the intensive use of skilled labour. Lejour and Rojas-Romagosa (2006) give an overview of the literature on FDI modelling in a general equilibrium. Konan and Maskus (2006) present a model of this kind for Tunisia, a country where the elimination of restrictions on trade in services would have more impact than the liberalization of trade in goods.

Rutherford, Tarr and Shepotylo (2005), within a similar context, incorporate the impact of income distribution and of the liberalization of FDI, indicating that the key component of welfare gains (in the Russian Federation) is associated (as in Konan and Maskus (2006)) with the elimination of the restrictions on FDI in services. To that end, they model the elimination of the implicit mark-up in the prices of services while also considering that productivity changes endogenously via a DixitStiglitz structure, which implies some substitution between the business services and the production factors.

Markusen and Strand (2006) maintain that the increase in the trade in services results from technological change, basically in telecommunications, which allows for gains in the spatial fragmentation of activities. The results of their model show gains for small countries with skilled labour that can export services to larger and more developed countries.

Balistreri, Rutherford and Tarr (2007) employ a Dixit-Stiglitz structure (of variety of goods) for business services, so as to model endogenous productivity gains through the introduction of new varieties (that would grant entry to a higher number of suppliers). The authors model the liberalization of barriers to the trade in services for both domestic and foreign goods.

A crucial element in many of the models cited is the estimation of ad valorem equivalents of the barriers to the trade in services. Table VI.1 presents the estimations used in several of the above-mentioned papers. ${ }^{6}$ ${ }^{6}$ We have based our estimates of ad valorem equivalents for constraints on the analysis
of Berlinski et al (2008). 
Table VI.1

TRADE IN SERVICES: AD VALOREM EQUIVALENT BARRIERS

USED IN THE LITERATURE

(Percentages)

\begin{tabular}{|c|c|c|c|c|c|}
\hline \multirow[t]{2}{*}{ Sector } & FDI barriers & $\begin{array}{c}\text { Type } 1 \text { barriers: } \\
\text { border trade }\end{array}$ & $\begin{array}{l}\text { Type } 3 \text { barriers: } \\
\text { foreign presence }\end{array}$ & $\begin{array}{c}\text { Domestic } \\
\text { firms } \\
\text { mark-up }\end{array}$ & $\begin{array}{l}\text { Multinational } \\
\text { production } \\
\text { mark-up }\end{array}$ \\
\hline & $\begin{array}{l}\text { Rutherford, Tarr, } \\
\text { Shepotylo (2005) }\end{array}$ & \multicolumn{2}{|c|}{$\begin{array}{l}\text { Konan and Maskus } \\
\qquad(2006)\end{array}$} & \multicolumn{2}{|c|}{$\begin{array}{c}\text { Balistreri, Rutherford, } \\
\text { Tarr (2007) }\end{array}$} \\
\hline Telecoms & 33 & 200 & 30 & 12 & 25 \\
\hline Insurance & s.d & 50 & 50 & s.d & s.d \\
\hline Financial services & 36 & 30 & 30 & 8 & 17 \\
\hline Transport & 53 & 50 & 3 & 42 & 57 \\
\hline
\end{tabular}

Source: Prepared by the authors.

Many of the experiments use MPSGE, often contained in a General Algebraic Modeling System (GAMS) environment. Overall, the MPSGE is a self-calibrating Walrasian-type structure. That is, it has the advantage of reducing the cost of programming the calibration every time one wishes to make a slight change in the model, something that is necessary when working with GAMS. GAMS is an optimization programme, which can be adapted to maximize a neutral objective function that is subject to the constitutive equations of the general equilibrium model. However, not all of the Walrasian or general equilibrium structures can be reduced to optimization models. The complementary approach allows us to tackle such cases (for example, minimum wages). Nonetheless, we can work simultaneously with the two, thus taking advantage of both. Such is the strategy that we followed in our model.

Whalley (2004) downplays the conclusions of the quantitative studies, arguing that they do not consider the heterogeneity of service activities. He focuses on the barriers to trade in services in countries and on interpreting the quantitative findings generated by the models, and recognizes that the credibility of the estimations obtained in CGE models depends on the validity of the assumptions and the availability of the data, and that the precision of the estimations may challenge the importance of the computed gains in welfare. However, he claims that the benefit of being able to conduct this exercise is the information obtained and that the resulting externality is to generate a demand for data that can improve future estimations. 


\section{The basic economic model}

To present the counterfactual exercises, we sum up the causal elements in the CGE model in this section. This is a simplified model with a reduced dimension. We also leave aside some markets, as well as unemployment. Appendix A describes the models for the Argentine, Uruguayan and Brazilian cases in greater detail.

For now, let us consider an economy with only one domestic agent, whose utility function depends on domestic goods $c$, services $a$, imported goods $m$ and bonds held by households $b^{F}: u\left(c, a, m, b^{F}\right)$. The equations correspond to the usual optimal conditions, which equal the marginal substitution rate to relative prices given by the quotient between the price of domestic goods in international terms $p^{*}$ and the prices of imported goods $p_{m}^{*}$ :

$$
\begin{aligned}
& u_{c} / u_{m}=p^{*} / p_{m}^{*} . \\
& u_{c} / u_{a}=p^{*} / p_{a} \\
& u_{c} / u_{b}=p^{*} / p_{b}
\end{aligned}
$$

Superscript $F$ indicates the variables corresponding to households. The following equation is the budget constraint of the domestic agent. $w$ represents wages, $L^{0}$ is the endowment of labour, and $\varpi$ and $\varpi_{a}$ are benefits in the industries producing goods and services, respectively. The parameters $\eta$ and $\theta$ represent the participation of domestic agents in each $(0<\eta, \theta<1)$. To simplify, we also assume that the participation in capital ownership coincides with the latter two (the rest of the world retains the complementary shares).

, a time trend, and seasonal dummy variables:

Equation [2] assumes that the consumer only pays taxes on the purchase of domestic tradable goods. This is a simplification given that the model includes all of the taxes in the economy. The last term reflects the initial bonds held by the household.

The production of domestic goods $c$ and exports $x$ in terms of capital and employment is given by:

$$
x+c=F(L, K) \text {. }
$$

The benefits of the tradable industry are:

$$
\pi=p^{*}(x+c)-w L-r^{*} K-p_{a} a^{d}
$$


where $r^{*}$ indicates capital remuneration and $p_{a} a^{d}$ are expenditure on services, assumed in fixed coefficients with the total aggregate value:

$$
a^{d}=\alpha F(L, K) \text {. }
$$

The maximization conditions of benefits are: ${ }^{7}$

$$
\begin{aligned}
& \text { [6] }\left(p^{*}-\alpha p_{a}\right) F_{K}-r^{*}=0, \\
& \text { [7] }\left(p^{*}-\alpha p_{a}\right) F_{L}-w=0,
\end{aligned}
$$

when the levels of capital use and labour are determined optimally. At the level of the services industry, the corresponding equations to define benefits, optimal conditions, and the output function are:

$$
\begin{aligned}
& \pi_{a}=p_{a} \beta G\left(L_{a}\right)-w L_{a}-\theta \beta G\left(L_{a}\right) p^{*}, \\
& a^{s}=\beta G\left(L_{a}\right),
\end{aligned}
$$

10] $\left(p_{a}-\theta p^{*}\right) \beta G^{\prime}\left(L_{a}\right)-w=0$.

The last term represents the use of tradable goods in the services sector (in fixed coefficients given by $\theta$ ). We also assume that the sector only employs labour to produce services. Once again, this is a simplification in this reduced version.

The government has a budget constraint given by:

$$
t p^{*} c+p_{b} b_{0}^{G}=w L^{G}+p_{b} b^{G} .
$$

The left side represents tax and bonds sales. The right side represents the purchases of labour and bonds (so that there is a net position in bonds). Notice that here we assume that the government is not participating actively in the markets for goods or services, although that does not occur in the general model. Here the government collects taxes and mainly uses the proceedings to hire workers and repay debt.

We also include familiar equilibrium conditions in the labour market, services market, and bonds market:

[11] $L_{a}+L+L^{G}=L^{0}$,

[12] $a^{d}+a^{F}-a^{s}=0$.

[13] $b^{G}+b^{F}-b_{0}^{G}-b_{0}^{F}=0$. 
Note that, in this version, the external sector does not buy domestic bonds, which is also a strong assumption that we leave aside in the general model. Given these assumptions, we can obtain an equilibrium in the following current account as:

$$
p^{x} x=p_{m}^{*} m+(1-\eta) r^{*} K+(1-\eta) \pi+(1-\theta) \pi_{a} .
$$

In the above equations we also hypothesize that there are no imports or exports of services that might result from trade barriers or transportation costs, or both.

Once an equilibrium is found, we conduct several counterfactual computational exercises:

\section{Exercise 1: Elimination of barriers on the import of services.}

To explore the impact of eliminating barriers or lowering costs, we take barriers as the equivalent to mark-ups $\lambda$ on the international prices of services $s^{*}$. In addition, we define transportation costs as a percentage of the international price as $c$. Therefore, there is no trade (of imports) because: $p_{a}<s^{*}(1+\lambda+c)$.

Some models in the literature assume that $\beta$ and $\alpha$ are functions of $\lambda$, that is, that a greater liberalization of trade in services stimulates their productivity ( $\beta$ is greater if $\lambda$ is smaller) and improves their quality ( $\alpha$ is lower if $\lambda$ is lower). However, objections also exist in the literature as to how far trade can be liberalized and its impact on $\lambda$, as small domestic suppliers of these services could be replaced by larger foreign firms, with stronger market power to make $\lambda$ rise.

The positive effects of greater trade would thus be conditioned by the degree of competitiveness ex post. A reduction in $\lambda$ owing to the new trade policy would increase the purchase of services to be used as intermediate inputs. Since the observed share of low-income deciles in the capital of firms is small, for the sake of simplification our explorations consider that the excess mark-up is entirely absorbed by the richest decile in the domestic economy, by the rest of the world, or by the government (the latter only being the case for Uruguay).

An increase in $\lambda$ could occur if the liberalization were to create imperfect domestic competition. This could imply that an increase in productivity is associated with a loss vis-à-vis the allocation of resources. Most of the literature assumes that the liberalization of the trade in services would generate a competitive market structure. In contrast, Konan and Van Assche (2006) model the liberalization of telecommunications in Tunisia under the assumption that there will be one sole entrant. They thus define alternative counterfactual scenarios simulating: (i) that the installed firm 
and the entrant compete à la Cournot or establish a cartel, (ii) that the firms confront identical costs or alternative costs that differ from the two firms, and (iii) that the entrant could export remittances of gains or maintain them in the country where the investment is being made. Chisari and others (2003) have already explored this last aspect in the case of regulated public services, showing the choice of alternative regulation mechanisms that influence the performance of the trade balance.

Note that we should take into account the change in condition [14] as a consequence of liberalization. In the case of the above reduced model we can say:

$$
p^{x} x=p_{m}^{*} m+s^{*} a^{*}+(1-\eta) r^{*} K+(1-\eta) \pi .
$$

In this equation $a^{*}$ represents net imports of services, while $s^{*}$ is the international price. An increase in imports will have to be covered by a higher amount of exports, that is, it will have to boost the export effort that the economy will have to make, even though cheaper or better services will become available. The net effect depends on parameter values and should be examined in a general equilibrium.

Exercise 2: Elimination of barriers on the export of services.

As in case 1, the exports of services from Argentina may be subject to a mark-up factor or additional costs that are collected by the rest of the world. Let us call $p_{a}{ }^{*}$ the international price. Domestic producers would therefore see a price $p_{a}^{*}\left(1-\lambda^{*}\right)$ where $\lambda^{*}$ is the markup of the rest of the world prior to liberalization. An international negotiation could mean simultaneously eliminating $\lambda$ and $\lambda^{*}$. This would be an expected positive effect of the opening, most probably based on expectations of reciprocity.

Exercise 3: Gains from improvement in quality, productivity, and efficiency.

The effect on welfare of reducing $\alpha$ is a gain in the quality of domestic services, which help the rest of the industries to reduce their expenses on services per unit of aggregate value. This effect is similar to a positive externality of one output sector over the rest of the output sectors. For example, insurance services could become more agile and the transaction costs or the legal costs from disputes might drop. Meanwhile, increasing $\beta$ corresponds to higher productivity owing to a higher level of competition. This is equivalent to a rise in the total productivity of factors in the services sector, which, following the improvement produces more units with the same endowment of labour (and capital in the general model). Efficiency gains mean that the services sector employs fewer 
intermediate inputs to produce one output unit, thus freeing resources that can be absorbed by the rest of the economy. Equation [8] captures this effect via a reduction in $\theta$.

Exercise 4: Trade presence and technology adoption.

In this case, trade liberalization leads to the entry of new firms with new technology. These entrants contest the incumbents' market share. Therefore, incumbents will see a reduction in the reward of their specific capital. To take into account competition between both kinds of firms it is necessary to modify equation [9] to account for a new supplier and the associated equations. For example, the new output of services will be given as: $a^{s}=\beta G\left(L_{a}\right)+H(K e)$, where $K e$ is the international mobile capital used in the new competitor's output, whose output is given by function $H$. It would also be necessary to consider the new payment of dividends in equation [14]. It is possible to study two sub-cases of this scenario. In one of them, the technology of entrants is the same as that employed by incumbents, with the only difference being that specific domestic capital is replaced with mobile international capital (though the rest of the parameters remain the same). This sub-case is identified with $-\mathbf{T}$ in the simulations that follow below. In Chisari, Romero and Maquieyra (2008), we also studied an additional case, in which we assume that the entrant's technology is the same as that used in the United States. This is not presented here.

Exercise 5: Changes in the preferences for domestic bonds following the liberalization of the financial sector.

Trade presence in financial institutions may make it necessary to modify the regulatory policy of investment (especially the requirements to purchase domestic bonds that are often imposed on financial institutions). In this case, the utility function should be modified, for example, as $u\left(c, a, m, \varepsilon b^{F}\right)$. And the third first-order condition listed in [1] could now be written as $u_{c} / u_{b}=p^{*} / \varepsilon p_{b}$. This change in preference will impact the prices of domestic bonds and could explain the reluctance of some governments to reform the trade of financial services.

Exercise 6: Modifications in the intensity of factor use due to trade presence or the need to compete.

Opening the economy, in particular trade presence, may make it necessary to increase the intensity in the use of scarce factors, like human capital, to supply industries using foreign technology. Some economies may find it difficult to improve the supply of factors quickly, resulting in limited short-term gains. However, this can be seen when different technologies are in competition, as was mentioned for case 4 above; changes in relative prices in favour of scarce factors would place a natural limit on entry. 
Sensitivity evaluations were carried out in relation to the above exercises to examine the changes in the results owing to:

- Modifications in the elasticities of substitution between domestic and imported services, and in the degree of labour and capital mobility between industries (even between services and the rest of the world).

- Different kinds of labour with varying degrees of mobility between industries. A reduction in the mark-up of the rest of the world (barriers) on exports of domestic services.

\section{The nature of liberalization exercises in the trade in services}

The model used in this paper for Argentina and Uruguay is an updated and expanded version of the model built by Chisari and others (2009) for Argentina, 2004. The model has 29 output sectors, which use labour and specific capital in their value-added functions (CobbDouglas, so that these simulations are neutral and guarantee a solution). Intermediate inputs are used in fixed coefficients among themselves and with value added. Each sector is divided into three sub-sectors to capture the differences in tax treatment (especially VAT) for each destination (domestic market, exports and investment). There are ten income deciles, each having a utility function (Cobb-Douglas), a government sector and the rest of the world. The model includes unemployment, given the characteristics of the Argentine and Uruguayan economies. We assume a constant real wage for the simulations. Unemployment is not considered for Brazil, since we use a version of GTAP for that economy.

The two services under analysis -Telecommunications and Financial and Insurance Services - represent a key share of Argentina's GDP $(2.6 \%$ and $4.3 \%$, respectively). Table VI.2 presents data on the production structure, the factoral structure, the input-output relations and the sales structure of these services.

As can be seen, in Argentina, Financial and Insurance Services (F\&I) use proportionally more foreign intermediate inputs than Telecommunications and have a much higher capital/labour ratio (3.5 compared with 1.2). On the demand side, the main destination for both services is intermediate sales.

In the Uruguayan case, the data used to construct the social accounting matrices as of the year 2000 were based on Katz, Pastori and Barrenechea (2004). Telecommunications and Financial and Insurance 
Table VI.2

ARGENTINA, BRAZIL AND URUGUAY: COMPOSITION OF COSTS AND DESTINATION OF SALES

(Percentage of sectoral VBP)

\begin{tabular}{|c|c|c|c|c|c|c|}
\hline \multirow[t]{2}{*}{ Costs } & \multicolumn{2}{|c|}{ Argentina 2004} & \multicolumn{2}{|c|}{ Uruguay 2000} & \multicolumn{2}{|c|}{ Brazil 2001} \\
\hline & $\begin{array}{l}\text { Fin. Serv. } \\
\text { and Ins }\end{array}$ & Telecom. & $\begin{array}{l}\text { Fin. Serv. } \\
\text { and Ins. }\end{array}$ & Telecom. & $\begin{array}{l}\text { Fin. Serv. } \\
\text { and Ins. }\end{array}$ & Telecom. \\
\hline $\begin{array}{l}\text { Raw Materials } \\
\text { Value Added } \\
\text { Employment } \\
\text { Capital }\end{array}$ & $\begin{array}{l}35.0 \\
65.0 \\
29.7 \\
35.3\end{array}$ & $\begin{array}{l}48.6 \\
51.4 \\
11.4 \\
40.0\end{array}$ & $\begin{array}{l}15.5 \\
84.5 \\
19.0 \\
65.5\end{array}$ & $\begin{array}{l}27.2 \\
72.8 \\
26.9 \\
46.0\end{array}$ & $\begin{array}{l}41.9 \\
58.1 \\
44.7 \\
13.4\end{array}$ & $\begin{array}{l}27.9 \\
72.1 \\
23.0 \\
49.1\end{array}$ \\
\hline Sectoral Gross Sales & 100.0 & 100.0 & 100.0 & 100.0 & 100.0 & 100.0 \\
\hline \multirow[t]{2}{*}{ Destination of Sales } & \multicolumn{2}{|c|}{ Argentina 2004} & \multicolumn{2}{|c|}{ Uruguay 2000} & \multicolumn{2}{|c|}{ Brazil 2001} \\
\hline & $\begin{array}{l}\text { Fin. Serv. } \\
\text { and Ins }\end{array}$ & Telecom. & $\begin{array}{l}\text { Fin. Serv. } \\
\text { and Ins. }\end{array}$ & Telecom. & $\begin{array}{l}\text { Fin. Serv. } \\
\text { and Ins. }\end{array}$ & Telecom. \\
\hline $\begin{array}{l}\text { Intermediate Sales } \\
\text { Exports } \\
\text { Final Consumption } \\
\text { Sectoral Gross Sales }\end{array}$ & $\begin{array}{r}72.9 \\
0.0 \\
27.1 \\
100.0\end{array}$ & $\begin{array}{r}63.3 \\
2.8 \\
33.9 \\
100.0\end{array}$ & $\begin{array}{r}32.0 \\
2.6 \\
65.4 \\
100.0\end{array}$ & $\begin{array}{r}56.0 \\
4.9 \\
39.1 \\
100.0\end{array}$ & $\begin{array}{r}49.8 \\
1.2 \\
49.0 \\
100.0\end{array}$ & $\begin{array}{r}47.9 \\
3.1 \\
49.0 \\
100.0\end{array}$ \\
\hline
\end{tabular}

Source: Prepared by the author.

Services account for a significant share of Uruguay's GDP $(10.7 \%$ and $2.6 \%$, respectively), and this explains the relevance of exercises in that industry for the whole economy. We can see that Telecommunications buys proportionally more intermediate inputs than Financial Services. Instead, Financial Services have a considerably higher capital/ employment ratio (3.5) than Telecommunications (1.7). On the demand side, the chief destination of financial services is final consumption, whereas Telecommunications targets intermediate sales.

The data used in the case of Brazil are based on the social accounting matrices elaborated by GTAP as of 2001. The two services considered here (Telecommunications and Financial and Insurance Services) represent divergent shares of Brazil's GDP $(8.1 \%$ and $1.7 \%$, respectively), according to the GTAP database. Table 2 shows that Financial Services buy proportionally more intermediate inputs than Telecommunications. Telecommunications has a substantially higher proportion of capital to labour (2.1) than Financial Services (0.3). On the demand side, the key destinations of the two services are final consumption and intermediate sales (in almost identical proportions). 


\section{E. Counterfactual experiments}

Two general equilibrium models were used to compute the results. For the cases of Argentina and Uruguay, the model used was built by Chisari and others (2009), based on MPSGE by Rutherford (1995). This model offers a greater degree of flexibility to design the simulations. For Brazil, the study uses the GTAP model that Rutherford (2005) adapted to work on an MPSGE platform.

The services included in these estimations are Telecommunications (TEL) and Financial and Insurance Services (F\&I). We consider two types of shocks: quantity including changes in productivity, efficiency, quality, and technology substitution. Price shocks correspond to modifications in the percentage of mark-up on prices associated with the reduction in trade barriers. Furthermore, we simulate the shocks of prices associated with the change in the ad valorem equivalents of the estimated restrictions using Dee (2005). Moreover, we study some cases that combine simulations, for example, decreases in mark-ups with the available technology compared with situations in which technology coexists with other new technology using different or proportionally different factors. Note that the models for Argentina and Uruguay include the bonds markets and the fixed real wage to calibrate the economy to that of the year of reference. ${ }^{8}$

Household living standards are indicated by income level - Poorest Household for lower income households and Wealthiest Household for the counterpart (where the former is an aggregate of the first five deciles and the latter an aggregate of the remaining five deciles). The unemployment rate and government transfers have strong repercussions on the former, while the welfare of the latter depends relatively more on capital remuneration. Both Argentina and Uruguay show transfers from the government to households. The fiscal situation is therefore reflected in household living standards.

\section{A taxonomy of the main simulations in this study}

As we mentioned, service industries studied in this paper are "Telecommunications" and "Financial and Insurance Services" (F\&I), We use $a_{N T}$ and $a_{T N}$ to indicate the amount of said services inputs $N$ purchased by tradable industries $T$ and, similarly, the amount of tradable inputs purchased by the services industries. In line with the previous section, a reduction in the first coefficient will imply greater efficiency in the use

Regarding the latter, the fact that productivity improvements in the economy could induce an increase in the real wage, which would have a negative effect on almost every indicator, cannot be overlooked. 
of services inputs in the tradable industries. However, we also interpret this as an improvement in the quality of the services. In order to obtain an effective unit of the corresponding service, it will be necessary to buy fewer units. Let us make an analogy with the agricultural sector to understand why. An improvement in seed quality will mean that a higher proportion of the "seed"-buying sectors will find themselves in better conditions to sow or produce flour. Likewise, increased efficiency in the use of inputs by the services would be reflected in a reduction of the second coefficient. From both cases, we should expect welfare gains as resources will be freed that can potentially be used elsewhere in the economy.

As mentioned previously, some of the models in the literature assume that the expected changes in these technology coefficients are functions of $\lambda$, i.e. that a greater liberalization of trade in services stimulates efficiency ( $a_{T N}$ is lower if $\lambda$ is lower) and improves quality $\left(a_{N T}\right.$ is lower if $\lambda$ is lower). As we also mentioned in Section II, there are some objections to the idea that trade liberalization is sufficient to reduce $\lambda$. Small domestic suppliers of services could be replaced by other larger international firms with greater market power to raise $\lambda$. The beneficial effects of more trade would thus be conditioned by their ex-post level of efficiency and the ex-post structure of the industrial organization.

Let us now consider the counterfactual exercises used in the models for Argentina, Brazil and Uruguay:

- QUA. The Effect of reducing $\boldsymbol{a}_{N T}$ on welfare. The decrease in this coefficient is similar to a gain in the quality of domestically produced services, which help the rest of the industries reduce their purchases of services per unit of aggregate value. We also evaluate the improvement in the quality of service for customers, who, in turn, have to buy fewer units of the good to obtain an effective unit of the desired service. These savings are used to buy other goods in the economy. These exercises also include all of the industrial demand of the service in question; improvements in quality act as an externality and increase the rate of profit of industries. Since such improvements are implemented by the service sector, but increase the profits of the rest, it is difficult to find incentives to increase quality beyond the forces of competition within the service sector itself. A $10 \%$ reduction in the necessary amount of the service to obtain a unit of output is assumed.

- EFF. Welfare gains by decreasing $\boldsymbol{a}_{T N}$. This corresponds to an increase in productivity owing to greater efficiency. We assume a $10 \%$ reduction in the demand for intermediate inputs by the 
service sectors considered in the analysis. A reduction in this coefficient frees resources to be used elsewhere in the economy. In this case, there are clear incentives to adopt more efficient techniques since they directly increase the rate of profit of the services industry.

- PRO. Improvements in productivity. We consider increases in total factor productivity, understood as reductions in the amount of value added needed to obtain a unit of output. We simulate productivity growth by increasing the output of the services in question by $10 \%$, without increasing the factor demand. As in the previous case, there are attractive incentives for individual firms to adopt new techniques.

- MUP. More intensive domestic competitive conditions. This is represented as a reduction in $\lambda$ owing to the opening to the trade in services, which would lead to an increase in the purchases of foreign services to be used as intermediate inputs or for final demand (unless domestic prices were made to fall in equal proportion). However, as we have mentioned, according to some international literature, trade opening could generate an increase in $\lambda$, rather than a decrease, should liberalization create imperfect domestic competition. This would cause the smallest and most competitive firms to disappear following liberalization and be replaced by other larger and more concentrated firms. This may imply that productivity growth is associated with a loss from the viewpoint of the allocation of resources. In general, we assume a $20 \%$ drop in the mark-up.

- T1 and T2. Competition of technologies. We reconsider the previous simulations to take into account the possibility of competition of technologies due to liberalization. That is, accepting the presence of entrants in the domestic market. They use a new technologythat involves international mobile capital and is more efficient in the use of intermediate goods. In these cases, the model endogenously evaluates the welfare gains derived from allowing the two competing technologies to be operative simultaneously. Hence, we can determine the industrial organization ex post without assuming a mandatory substitution; the scale of operation of each technology will be determined by the market workings and, as both industries produce the same good, competitive costs will explain their market share. Simulations of individual cases can be presented in similar ways. For example, MUP-T stands for mark-up changes due to competition of technologies. 
- LIB and LIB-P. Financial liberalization and changes in regulation. An increase in the presence of international operators in the domestic financial sector may call for a change in the rules and regulations of portfolio composition, and more specifically, in the proportion of government bonds in total holdings. This is tantamount to a change in preferences for domestic bonds, which can (in the short term) offset the main gains resulting from improved quality and efficiency. These exercises are useful for understanding the immediate resistance to reforms that can ultimately generate gains in the long term. We indicate with LIB the case of liberalization of financial services, and with LIB-P the same case when regulations are adapted by the government (we assume it to be equivalent to a $5 \%$ reduction in the price of bonds issued by the public sector).

\section{Productivity (PRO), efficiency (EFF) and quality (QUA) gains due to liberalization.}

For Argentina, table VI.3 shows a striking similarity in productivity and quality gains in terms of domestic product and welfare. That is, a $10 \%$ rise in the total productivity of the factors is almost the equivalent to a $10 \%$ improvement in the quality of the services herein considered. This basically reflects the structural characteristics of the Argentine economy. We also obtain positive results from the 10\% improvement in efficiency in the services sectors, although the magnitude is more moderate because this exercise is mainly reflected in an increase in labour productivity and not in all of the factors. Note that the change in the trade surplus is not always positive and that the activity level of these services is lower than in the quality factor (QUA) because of lower usage of these inputs in the rest of the economy. This is noticeable in the case of Telecommunications. As for the political economy, it is difficult to find sectors or households that have been negatively affected by these changes and that could have disputed the reform, taking into account that it also benefited the government.

Uruguay is a different case. The impact of productivity improvement (table VI.3) and its effects have been greater than in Argentina because Telecommunications and Financial Services activities represent about $12 \%$ of the economy's GDP. In contrast, Argentina registered half as much. Meanwhile, improvements in QUA do not match the productivity level. This implies that the gains derived from domestic improvements in the sectors are more relevant than their externalities, which we did not observe in the Argentine case. Note that, given the 
Table VI.3

ARGENTINA, BRAZIL AND URUGUAY: COMPUTABLE GENERAL EQUILIBRIUM MODEL SIMULATIONS. RESULTS CORRESPONDING TO PRODUCTIVITY, EFFICIENCY AND QUALITY CHANGES

(Percentages)

\begin{tabular}{|c|c|c|c|c|c|c|c|c|c|}
\hline \multirow[b]{2}{*}{ Indicators } & \multicolumn{3}{|c|}{ Argentina } & \multicolumn{3}{|c|}{ Uruguay } & \multicolumn{3}{|c|}{ Brazil } \\
\hline & PRO & EFF & QUA & PRO & EFF & QUA & PRO & EFF & QUA \\
\hline Real GDP & 0.94 & 0.76 & 1.13 & 3.18 & 0.70 & 1.60 & 1.18 & 0.57 & 1.09 \\
\hline Real Investment & 1.12 & 0.72 & 1.09 & 3.23 & 0.67 & 1.51 & 0.37 & 0.20 & 0.03 \\
\hline Trade* (surplus) & -1.09 & -0.82 & 0.19 & - & - & - & - & - & - \\
\hline Trade $^{\star}$ (deficit) & - & - & - & 13.80 & 3.19 & 6.20 & 0.00 & -0.01 & -0.01 \\
\hline \multicolumn{10}{|l|}{ Activity level } \\
\hline Agriculture & 0.19 & 0.08 & 0.17 & 1.97 & 0.30 & 0.87 & 0.16 & -0.06 & 0.43 \\
\hline Industry & 0.54 & 0.25 & 0.57 & 2.15 & 0.35 & 1.27 & 0.87 & 0.01 & 1.40 \\
\hline Services & 0.19 & 0.27 & 0.24 & 1.74 & 0.38 & 0.87 & -0.23 & 0.03 & 2.26 \\
\hline TEL Sector & 6.83 & 0.00 & -3.02 & 7.93 & 0.37 & -2.69 & 6.09 & 0.70 & 2.16 \\
\hline F\&I Sector & 5.52 & -0.13 & -4.75 & 10.16 & 0.11 & -0.26 & 5.39 & 0.91 & 2.55 \\
\hline Household Welfare & - & - & - & - & - & - & 2.18 & 0.87 & 1.71 \\
\hline Poorest Household & 1.42 & 0.84 & 1.30 & 2.43 & 0.53 & 1.28 & - & - & \\
\hline Wealthiest Household & 0.90 & 0.65 & 0.95 & 3.38 & 0.67 & 1.49 & - & - & - \\
\hline Gov't Fiscal Situation & 0.67 & 0.40 & 0.91 & 1.51 & 0.35 & 0.90 & 0.67 & 0.09 & 4.39 \\
\hline
\end{tabular}

Source: Prepared by the authors on the basis of results from O. Chisari, C. Romero and J. Maquieyra, "Evaluación de los efectos del comercio de servicio a través de un modelo de equilibrio general computado para Argentina, Brasil y Uruguay", Ganancias potenciales en el comercio de servicios en el MERCOSUR, J. Berlinski, Montevideo, MERCOSUR Economic Research Network, 2008. PRO: 10 \% productivity increase in services. EFF: $10 \%$ efficiency increase in services. QUA: $10 \%$ quality improvement in services; Chisari and others 2009) is used for Argentina and Uruguay and GTAP for Brazil.

* Note: Percentage changes refer to constant price variations, signs take initial calibration as reference (surplus for Argentina, deficit for Uruguay and Brazil).

relative importance of the selected activities, the deterioration in the trade balance is substantially higher than the similar effect seen in Argentina's PRO and EFF. As for income distribution, the welfare of poor households continues to be linked to the adjustments in the public sector because of the set of transfers that characterize the economy. Among the sectors in the economy and except in the case of EFF, industry continues to benefit most from improvements.

Table VI.3 also presents the findings of the model's productivity simulations calibrated with the Brazilian data. We use a GTAP model with its own database. Unlike the Argentine and Uruguayan cases, this model assumes full employment and the financial transactions are less detailed. The gains in productivity, quality and efficiency (in that order) boost welfare and, as in the previous cases, household gains surpass the government's gains, except in the simulations for Quality. The impact of these experiments on the external sector, however, is practically nil. 


\section{Productivity, efficiency and quality under competition of technologies and international mobility of capital}

We re-examined the above simulations assuming that liberalization implies the domestic installation of a technology using mobile capital with respect to the rest of the world (PRO-T, EFF-T and QUA-T). To perform these simulations we assumed that new producers of services enter the economy, and that they produce perfect substitutes of domestic services. It is also assumed that they employ intermediate consumption and labour in the same proportion as the domestic industries, but that they replace domestic capital for international capital. This exercise attempts to capture the possibility of capital mobility across both domestic sectors and the rest of the world. The industrial structure of TEL and F\&I is endogenously determined with the solution of the model.

The simulated improvements in productivity, quality and efficiency (table VI.4) are assumed to occur only in the new activities, while installed ones must adapt to the change. In general, this happens with a reduction in their participation in the market as a whole and with a decrease in the remuneration of the fixed factor (specific capital). In general, the latter is more significant than the former.

In the Argentine case, the overall standard of living of households rises once again, although this change is not as striking for the Richest Household, because the ownership of specific capital is already concentrated there and it is specific capital that sees a reduction in its reward, due to more intense competition. In the case of Quality, the welfare of the Richest Household shows greater changes than in the cases of PRO-T and EFF-T.

As mentioned, this exercise also shows how the industrial structure is altered in the services sector after a liberalization of this kind. However, the new industry does not generate a significant displacement of the existing one, as the specific capital tends to absorb the decrease in the sector's prices. In each case of technology substitution (for all countries), the share of entrants rises to a range of between $5 \%$ and $11 \%$. Again, the reason for the limited replacement is that the reward of non-mobile capital of incumbents tends to absorb the differences in productivity, quality or efficiency. We should expect a progressive replacement, rather than a sudden change in the pattern of the industrial structure.

The impact on the trade surplus is positive in PRO-T and negative in the other two cases.

In Uruguay, the positive effects on GDP and Investment are higher than in Argentina. We can see that PRO-T diminishes the trade deficit, while the positive results of EFF-T and QUA-T are quite clear. 
Table VI.4

ARGENTINA, BRAZIL AND URUGUAY: COMPUTABLE GENERAL EQUILIBRIUM MODEL SIMULATIONS. RESULTS CORRESPONDING TO TECHNOLOGICAL

SUBSTITUTION AND ITS EFFECTS ON PRODUCTIVITY, EFFICIENCY AND QUALITY CHANGES

(Percentages)

\begin{tabular}{|c|c|c|c|c|c|c|c|c|c|}
\hline \multirow[b]{2}{*}{ Indicators } & \multicolumn{3}{|c|}{ Argentina } & \multicolumn{3}{|c|}{ Uruguay } & \multicolumn{3}{|c|}{ Brazil } \\
\hline & PRO-T & EFF-T & QUA-T & PRO-T & EFF-T & QUA-T & $\begin{array}{l}\text { PRO } \\
\text { (a1) }\end{array}$ & $\begin{array}{l}\text { PRO } \\
\text { (a2) }\end{array}$ & $\begin{array}{l}\text { PRO } \\
\text { (skl) }\end{array}$ \\
\hline Real GDP & 0.48 & 0.74 & 1.06 & 2.38 & 0.78 & 1.35 & 1.15 & 1.12 & 1.16 \\
\hline Real Investment & 0.24 & 0.73 & 1.09 & 1.60 & 0.73 & 1.36 & 0.35 & 0.33 & 0.38 \\
\hline Trade* (surplus) & 2.32 & -1.13 & -0.39 & - & - & - & - & - & - \\
\hline $\operatorname{Trade}^{\star}$ (deficit) & - & - & - & -6.52 & 2.94 & 7.03 & 0.01 & 0.00 & 0.01 \\
\hline \multicolumn{10}{|l|}{ Activity level } \\
\hline Agriculture & 0.13 & 0.07 & 0.15 & 2.17 & 0.38 & 0.64 & 0.18 & 0.20 & 0.14 \\
\hline Industry & 0.37 & 0.22 & 0.51 & 2.34 & 0.43 & 1.03 & 0.91 & 0.95 & 0.83 \\
\hline Services & -0.24 & 0.29 & 0.27 & 0.57 & 0.40 & 0.82 & -0.24 & -0.25 & -0.22 \\
\hline TEL Sector & 1.86 & 0.07 & -2.57 & 3.98 & 0.12 & -2.19 & 6.03 & 5.98 & 6.12 \\
\hline F\&I Sector & 1.86 & 0.13 & -4.12 & 6.81 & 0.06 & -0.06 & 5.25 & 5.08 & 5.46 \\
\hline Household Welfare & - & - & - & - & - & - & 2.17 & 2.16 & 2.16 \\
\hline Poorest Household & 0.60 & 0.84 & 1.23 & 1.10 & 0.57 & 1.18 & - & - & - \\
\hline Wealthiest Household & 0.13 & 0.66 & 0.95 & 1.66 & 0.73 & 1.34 & - & - & - \\
\hline Gov't Fiscal Situation & & 0.38 & 0.85 & 1.02 & 0.39 & 0.80 & 0.67 & 0.68 & 0.70 \\
\hline
\end{tabular}

Source: Prepared by the authors on the basis of results from O. Chisari, C. Romero and J. Maquieyra, "Evaluación de los efectos del comercio de servicio a través de un modelo de equilibrio general computado para Argentina, Brasil y Uruguay", Ganancias potenciales en el comercio de servicios en el MERCOSUR, J. Berlinski, Montevideo, MERCOSUR Economic Research Network, 2008. PRO: 10 \% productivity increase in services. EFF: $10 \%$ efficiency increase in services. QUA: $10 \%$ quality improvement in services; Chisari and others 2009) is used for Argentina and Uruguay and GTAP for Brazil.

* Note: Percentage changes refer to constant price variations, signs take initial calibration as reference (surplus for Argentina, deficit for Uruguay and Brazil).

Additionally, the effect for the Richest Household is higher than for the Poorest Household in all three cases. As in the case of Argentina, the presence of the new technology reduces the welfare gains for all deciles.

For Brazil, we conducted an additional exercise assuming that skilled and unskilled labour are not perfect substitutes, and that the new technology is more intensive in the former. The decreases in the levels of elasticity of substitution between domestic and foreign services show no significant differences with respect to the base case of Productivity (PRO). The last exercise shows that a jump in the productivity of services differs if this industry employs a more intensive use of skilled labour. The post-liberalization demand for 
skilled labour declines due to improved productivity, which, in turn, causes the relative price of skilled labour to fall. The increase in the welfare level of households is maintained and GDP and Investment climb. As for its impact on the trade deficit, we see the same result obtained in table VI.3, i.e. practically zero.

\section{Reduction in the implicit mark-up (MUP) on imports of services. Competition of technologies.}

In this case, we assume that the mark-up is reduced due to competition. That is, the threat of trade in services keeps domestic prices in check, and this is equivalent to a reduction in the implicit mark-up. For the overall results in general equilibrium, it is important to determine who was collecting the revenue produced by the mark-up.

We therefore considered two sub-cases, each with a different assumption of who is entitled to the proceedings of the mark-up. In the first case, the richest decile of the economy receives the excess profits. In the second, the rest of the world has the rights over the revenue. For Argentina and Uruguay, we also assumed that the reduction is due to the presence of a new technology that uses internationally mobile capital.

What are the plausible reductions in mark-up due to liberalization in trade of services?

We adopted the estimates given by Dee $(2004,2005)$ and Berlinski, Celani and Bebczuk (2008). Reductions in Telecommunications included: Argentina 10\% (1989-2005), Uruguay 5\% (1997-2007); in Banks: Uruguay 14\% (1997-2007), Brazil 2\% (2004-2006). ${ }^{9}$ The results are reported in table VI.5. For Argentina, as the estimate of "shadow prices" of constraints are not large, we do not see significant differences in our model. It was observed (not shown in the table) that the activity level of the corresponding domestic service sector falls (and it is replaced with the production of the entrant). Previous simulations showed more significant effects under the assumption of more intense constraints on trade of services. Regarding the impact on the external sector, trade liberalization increases total required surplus slightly, since the trade balance must be compensated for dividends paid abroad. The qualitative results for Uruguay are quite similar. In the case of Brazil, there are no significant effects, and this is again due to the almost negligible level of the implicit mark-up attributed to the constraints (the country was already liberalized in trade of services at the time of the study, as stated by Kume, Piani and Miranda (2008)).

\footnotetext{
9 Based on Berlinski, Celani and Bebczuk (2008), Kume, Piani and Miranda (2008) and Vaillant, Barran and Balseiro (2008).
} 
Table VI.5

ARGENTINA, BRAZIL AND URUGUAY: COMPUTABLE GENERAL EQUILIBRIUM MODEL SIMULATIONS. RESULTS CORRESPONDING TO MARK-UP REDUCTION AND TECHNOLOGICAL SUBSTITUTION BASED ON THE METHODOLOGY OF DEE (2005) (Percentages)

\begin{tabular}{|c|c|c|c|c|c|c|c|}
\hline \multirow[t]{2}{*}{ Indicators } & \multicolumn{2}{|c|}{ Argentina } & \multicolumn{3}{|c|}{ Uruguay } & \multicolumn{2}{|c|}{ Brazil } \\
\hline & $\begin{array}{l}\text { MUP-T1 } \\
\text { (T) }\end{array}$ & $\begin{array}{l}\text { MUP-T2 } \\
\text { (T) }\end{array}$ & $\begin{array}{c}\text { MUP-T1 } \\
\text { (F\&I) }\end{array}$ & $\begin{array}{l}\text { MUP-T1 } \\
\text { (T) }\end{array}$ & $\begin{array}{c}\text { MUP-T2 } \\
\text { (F\&I) }\end{array}$ & $\begin{array}{l}\text { MUP-T2 } \\
\text { (T) }\end{array}$ & $\begin{array}{l}\text { MUP } \\
\text { (F\&I) }\end{array}$ \\
\hline Real GDP & 0.25 & 0.25 & 2.45 & 0.31 & 2.54 & 0.31 & 0.00 \\
\hline Real Investment & 0.10 & 0.12 & 1.28 & 0.22 & 1.61 & 0.24 & 0.00 \\
\hline Trade* (surplus) & 0.68 & 0.52 & - & - & - & - & - \\
\hline Trade* (deficit) & - & - & -11.27 & -0.20 & -7.50 & -0.06 & -0.55 \\
\hline \multicolumn{8}{|l|}{ Activity level } \\
\hline Agriculture & 0.05 & 0.05 & 2.34 & 0.26 & 2.24 & 0.26 & 0.01 \\
\hline Industry & 0.16 & 0.15 & 2.51 & 0.28 & 2.41 & 0.28 & 0.02 \\
\hline Services & 0.00 & 0.00 & 0.55 & 0.05 & 0.66 & 0.06 & -0.01 \\
\hline TEL Sector & -2.43 & -2.43 & 0.79 & -2.99 & 0.75 & -2.99 & 0.01 \\
\hline F\&I Sector & 0.12 & 0.12 & -2.65 & 0.04 & -2.66 & 0.04 & -0.06 \\
\hline Household Welfare & - & - & - & - & - & - & 0.01 \\
\hline Poorest Household & 0.33 & 0.34 & 0.92 & 0.21 & 1.02 & 0.21 & . \\
\hline Wealthiest Household & 0.06 & 0.07 & 1.47 & 0.20 & 1.79 & 0.21 & - \\
\hline Gov't Fiscal Situation & - & 0.14 & 1.00 & 0.14 & 1.06 & 0.15 & 0.00 \\
\hline
\end{tabular}

Source: Prepared by the authors on the basis of results from O. Chisari, C. Romero and J. Maquieyra, "Evaluación de los efectos del comercio de servicio a través de un modelo de equilibrio general computado para Argentina, Brasil y Uruguay", Ganancias potenciales en el comercio de servicios en el MERCOSUR, J. Berlinski, Montevideo, MERCOSUR Economic Research Network, 2008; Argentina: MUP-T1 (T): Markup received by the wealthiest home plus technological substitution (10\%) for Telecommunications. MUP-T2 (T): Mark-up received by the rest of the world plus technological substitution (10\%) for Telecommunications. Uruguay: MUP-T1 (F): Mark-up received by the wealthiest home plus technological substitution (14\%) for Financial Services, MUP-T1 (T): Mark-up received by the wealthiest home plus technological substitution (5\%) for Telecommunications, MUP-T2 (F): Mark-up received by the rest of the world with technological substitution (14\%) for Financial Services, MUP-T2 (T): Mark-up received by the rest of the world plus technological substitution (5\%) for Telecommunication. Brazil: MUP (F): Mark-up reduction of $2 \%$ (by the rest of the world) at Financial Services import prices.

* Note: Percentage changes refer to constant price variations; signs take initial calibration as reference (surplus for Argentina, deficit for Uruguay and Brazil).

\section{Liberalization in trade of financial services (LIB) and regulations in Argentine portfolios}

The assumption in the case of liberalization of trade in financial services and insurance (LIB, table VI.6) is that it is accompanied by the entry of new operators that use capital that are mobile (between domestic activities and the rest of the world) and that are $10 \%$ more productive than those already installed. As was expected, the exercise shows an improvement in aggregate GDP, together with a higher rate of exports to cover the needs of the current account, which is confirmed by the positive change in the trade surplus $(0.56 \%)$. 
Liberalization of financial services for local operation of foreign firms that purchase fewer government bonds (equivalent to a $5 \%$ price reduction) is considered in the LIB-P exercise. That is, a significant entry of new operators requires a change in (or elimination of) regulations. Notice that, in this case, all of the effects on welfare would become negative. In some cases, the government's reduced ability to finance its debt impinges upon the amount of transfers to the poor and affects other deciles, because it indirectly diminishes the activity level of the economy (remember we are assuming constant real wages). On top of that, the increase in the required trade surplus (24.6\%) is notable. This is due to the need to increase the level of exports to offset the reduction in purchases of bonds by the rest of the world. This could be considered a short-run effect to be reversed in the future, but it may explain the reluctance of governments to liberalize financial services.

Table VI. 6

ARGENTINA: FINANCIAL SERVICES LIBERALIZATION

AND REGULATIONS

(Percentages)

\begin{tabular}{lrr}
\hline Indicators & LIB & LIB-P \\
\hline Real GDP & 0.31 & -0.67 \\
Real Investment & 0.17 & -1.75 \\
Trade (surplus) & 0.56 & 24.58 \\
Activity level & & \\
Agriculture & 0.06 & 0.27 \\
Industry & 0.17 & 1.03 \\
Services & -0.17 & $-1,66$ \\
TEL Sector & 0.06 & $-0,36$ \\
F\&I Sector & -5.19 & -4.95 \\
Household Welfare & & \\
Poorest Household & 0.46 & $-3,81$ \\
Wealthiest Household & 0.13 & -1.44 \\
Government Fiscal Situation & $-\mathbf{3 . 4 4}$ \\
\hline
\end{tabular}

Source: Prepared by the authors.

LIB: More efficient new technology (with a productivity increase of $10 \%$ in F\&I), LIB-P: More efficient new technology plus a change of regulations on portfolios (new technology with a productivity increase of $10 \%$ in F\&l and a government bond price reduction of $5 \%$ ). 


\section{F. Main lessons and final remarks}

We used two models to perform experiments in general equilibrium: Rutherford's GTAP version (Rutherford (2005)) for Brazil, and a new version of the Argentine 2004 model based on Chisari and others (2009) and adapted for the Uruguayan case. The latter uses the methodology developed in Rutherford (1995). Among the counterfactual exercises, we examined: improvements in efficiency, productivity and quality of services resulting from liberalization, modifications in competitive conditions due to the threat of entry of competitors, different degrees of substitution between entrants' and incumbents' technologies, inconsistencies of factor endowments with those requested by new operators and modifications in regulations and portfolio composition after liberalization. We considered the simultaneous operation of incumbents and newly adopted technologies, interpreting them as latent technologies, and observed how and to what extent the latter replaced the former.

Overall, we drew the following lessons:

1. There are significant gains in welfare as result of improvements to productivity, quality and efficiency (in that order) in the service industries. Therefore, if the liberalization of trade is expected to increase competition and foster advances in productivity, quality or efficiency, there will be gains of between $1 \%$ and $4 \%$ of GDP, depending on the country and the scenario.

2. The absolutely inclusive relevance of the improvements in quality is striking. If a service shows better quality following the opening, it could have an impact on the economy that is comparable to the habitually estimated gains in factors productivity of the service sectors. This effect is greater in the Argentine case than in the Uruguayan case.

3. If the liberalization of trade in services successfully reduces overpricing (derived from the domestic barriers to trade in services), we consider it reasonable to expect overall improvements in welfare. However, if increased liberalization of trade in services resulted in a higher concentration of domestic service industries (because of the presence of new operators that force the exit of small competitive domestic firms) and overpricing were to rise, the net gains would turn negative yet again, even after taking into account gains in productivity and quality.

4. The above-mentioned findings are confirmed when we use the data on current barriers in Argentina and Uruguay. In Brazil, today's degree of openness is almost at maximum level from 
the viewpoint of overpricing, and our simulations do not show potential residual gains. In Uruguay, however, we can see that a reduction in overpricing benefits the economy and the fiscal situation, even when it is the country's public-owned enterprises that would have to sacrifice their price levels.

5. The results show that, in order to achieve gains from greater trade presence in these service industries, there must be a balanced development between technology adoption and the endowment of domestic resources. Highly-intensive technology in some resources (like human capital) may generate net losses in welfare if the economy is not able to supply them. Likewise, the limited endowment of some factors could act as a constraint on gains from trade presence.

6. When technologies compete, we observed that there is a limited and progressive phase-down of incumbent operators, not a sudden replacement. The reason is that incumbents accommodate the more competitive market conditions through reductions in the reward of their non-mobile, specific capital.

7. The Argentine case illustrates that when the liberalization of financial services must necessarily be accompanied by a deregulation of portfolios, the governments themselves may oppose the reform in the short run because they would see the demand for their bonds drop. Hence, the gains in productivity, efficiency and quality may be limited by the loss of sources of financing.

8. Our results also confirm what we see in the social accounting matrices: changes in the standard of living of the poor are highly correlated with the modification in economic and financial situation of governments. This is due to the fact that said matrices reflect the governments' complex networks of transfers to the poorest deciles (this is clearly the case in Argentina and Uruguay). Therefore, the short-run financial position of governments could also explain the reluctance to adopt reforms.

It is worth mentioning that we also conducted exercises in the other direction: with the rest of the world lowering barriers to trade in services from Argentina, Brazil and Uruguay. We observed that there would be a price increase in domestic services, to align with international prices, and this causes domestic living standards to fall despite an increase of the scale of operation of domestic industries. However, that can be considered as only a first-round effect, and additional gains would probably be observed in a dynamic context. 


\section{Bibliography}

Balistreri, E., T. Rutherford and D. Tarr (2007), "Modeling services liberalization: The case of Kenya", Policy Research Working Paper, N WPS 4544, World Bank, March.

Berlinski, J., M. Celani and R. Bebczuk (2008), "La liberalización del comercio de servicios: telecomunicaciones y bancos en Argentina", Working document, MERCOSUR Economic Research Network.

Chisari, O., C. Romero and J. Maquieyra (2008), "Evaluación de los efectos del comercio de servicio a través de un modelo de equilibrio general computado para Argentina, Brasil y Uruguay", Ganancias potenciales en el comercio de servicios en el MERCOSUR, J. Berlinski, Montevideo, MERCOSUR Economic Research Network.

Chisari, O., G. Lambardi and C. Romero (2007), "Choosing the extent of private participation in public services: a computable general equilibrium perspective", MPRA Paper, $\mathrm{N}^{\mathrm{o}}$ 15358, University Library of Munich.

Chisari, O. and others (2009), Un modelo de equilibrio general computable para la Argentina, Buenos Aires, United Nations Development Programme (UNDP). (2003), "Trade balance effects of infrastructure services liberalization... and of their regulation", Asociación Argentina de Economía Política, 2003: anales de la XXXVIII reunión anual, Buenos Aires.

Dee, P. (2005), A Compendium of Barriers to Services Trade, World Bank. (2004), Services Trade Liberalization in South East European Countries, Australian National University, OECD Commissioned.

(2003), "Modeling the policy issues in services trade", Économie internationale, vol. 2003/3, No. 94-95.

Dimaranan, B. (ed.) (2006), “Global Trade, Assistance, and Production: The GTAP 6 Data Base", Center for Global Trade Analysis, Purdue University, December.

Katz, G., H. Pastori and P. Berrenechea (2004), "Construcción de una matriz de contabilidad social para Uruguay para el año 2000", document No. 20/04, Department of Economics, Universidad de la República, December.

Konan, D. and A. Van Assche (2006), "Regulation, market structure and service trade liberalization", CIRANO Scientific Series, No. 2006s-18, Montreal, September.

Konan, D. and K. Maskus (2006), "Quantifying the impact of services liberalization in a developing country", Journal of Development Economics, No. 81.

Kume, H., G. Piani and P. Miranda (2008), "Liberalização do comércio de serviços: telecomunicações e Bancos no Brasil", Working document, MERCOSUR Economic Research Network.

Lejour, A. and H. Rojas-Romagosa (2006), "Foreign direct investment in applied general equilibrium models", CPB Memorandum, Netherlands Bureau for Economic Policy Analysis, December.

Markusen, J. and B.Strand (2007), "Trade in business services in general equilibrium", NBER Working Paper, No. 12816.

Markusen, J., T. Rutherford and D. Tarr (1999), "Foreign direct investment and the domestic market for expertise", World Bank Policy and Research Working Paper, No 2413, Washington, D.C. 
Rutherford, T. (2005), "GTAP6inGAMS: The Dataset and Static Model", document presented at the Workshop on Applied General Equilibrium Modeling for Trade Policy Analysis in Russia and the CIS, Moscow, December. (1995), Demand Theory and General Equilibrium: An Intermediate Level Introduction to MPSGE, Department of Economics, University of Colorado.

Rutherford, T. and V. Paltsev (2000), "GTAP in GAMS: Global Dataset for Economic Research and Illustrative Models", Working Paper, Department of Economics, University of Colorado.

Rutherford, T., D. Tarr and O. Shepotylo (2005), "The impact on Russia of WTO accession and the Doha agenda: the importance of liberalization of barriers against direct investment in services for growth and poverty reduction", World Bank Policy Research Working Paper, No 3725.

Vaillant, M., F. Barran and G. Balseiro (2008), “Liberalización en servicios. El caso de Uruguay: sector financiero y telecomunicaciones", Working Document, MERCOSUR Economic Research Network.

Whalley, J. (2004), "Assessing the benefits to developing countries of liberalization in services trade", The World Economy, vol.27, No. 8. 


\section{Appendix}

\section{The models}

Two alternative models were used for simulation. A standard version of GTAP for Brazil anda special model developed by Chisari and others (2009) for Argentina (which was also adapted for Uruguay). Here we present a simplified version of the model used in the last case, including only four goods and only one household, although the complete version includes 29 industries and goods, and one representative household for each income decile. The corresponding sub indexes for goods and services are $J=\{1,2, N, R\}$. There are two industries that produce tradable goods, 1 and 2, one industry that produces non regulated services, N, and one sector of regulated services, $\mathrm{R}$ (regulation is limited here to price regulation) All production functions are CES, though value added and intermediate inputs are used in fixed proportions.

\section{Domestic household}

This agent also collects all taxes and grants subsidies. The net welfare of this household will therefore represent social welfare. The domestic agent maximizes the utility function $u\left(c_{1}, c_{2}, c_{N}, c_{R}, m, B D\right)$ subject to:

$$
\sum_{T} p_{T} c_{T}+p_{R} c_{R}+p_{N} c_{N}+p_{m} m+p_{b}\left(B D-B D^{*}\right)=w \bar{L}+\sum_{T_{\langle R} r_{I}} r_{I} \bar{K}_{I}+\theta \pi_{R}^{*}+\theta t p_{R} G\left(L_{R}, K_{R}\right)+T R^{w} v
$$

where $\theta$ is the share of domestic agents in the profits of the regulated sector $\pi_{R}^{*}$. The third term on the right-hand side corresponds to the compensatory transfer from domestic customers $(t>0)$ or to the firm from its shareholders $(t<0)$. Under public ownership, $\theta=1$. In both cases, under price caps, $t$ is computed so that $p_{R}=1 / \mu(1+t)$. The last term corresponds to social transfers. To represent those government programmes, every household is assumed to be endowed with a special good that is required by the public sector. The endowment is represented with $T R^{*}$ and $v$ stands for its price. Households also have an endowment of bonds $B D^{*}$, to be purchased or sold according to their financial condition. Therefore, $\left(B D-B D^{*}\right)$ is the net transaction at prices $p_{B}$.

From utility maximization, we obtain the familiar first-order conditions:

$$
\begin{aligned}
& u_{c_{T}}^{\prime} / u_{m}^{\prime}=p_{T} / p_{m} \\
& u_{R}^{\prime} / u_{m}^{\prime}=p_{R} / p_{m} \\
& u_{N}^{\prime} / u_{m}^{\prime}=p_{N} / p_{m} \\
& u_{N}^{\prime} / u_{B}^{\prime}=p_{N} / p_{B}
\end{aligned}
$$


$c_{T}$ is consumption of domestic tradable goods, $c_{R}$ is the consumption of goods and services under regulation, $m$ are imports (a good produced abroad but not domestically) and $c_{N}$ is consumption of rest of services. $p_{T^{\prime}} p_{R^{\prime}} p_{N}$ and $p_{m}$ are their respective prices. $w$ is the wage rate and $r_{I}$ is the rate of return on capital in each sector. $\bar{L}$ and $\bar{K}$ represent the domestic agent endowments of labour and capital.

The Armington assumption is used to represent imperfect substitution between domestic and imported goods.

The budget condition represents: (1) total expenses in goods, services and taxes; (2) income sources, mainly salaries, capital income and profits, as well as transfers (including pensions) received from the government. Investment goods also enter in the utility function (not shown in this version), for it is the household that determines total savings.

\section{Domestic production sectors}

$Y, H$ and $G$ are the production functions of the tradable, nontradable and regulated sectors, respectively. We assume constant returns to scale in all cases. This enables the separation of each industry in four sub industries with a differentiated tax treatment (especially for VAT) according to destination, without altering the basic structure of the model.

\section{2.a Tradable sectors}

There is one firm that maximizes profits in each tradable sector. The net price for the firm is the price to consumers less the cost of intermediate inputs.

[6] $\pi_{T}=\left[p_{T}-\sum_{j \neq T} a_{J, T} p_{J}-a_{R, T} p_{R}-a_{N, T} p_{N}\right] Y_{T}\left(L_{T}, K_{T}\right)-w L_{T}-r_{T} K_{T}$

for every $\mathrm{T}=1,2$ and where $a_{J T}, a_{N T} \mathrm{y} a_{R T}$ input coefficients

Notice that firms observe the incentive given by the net price after intermediate inputs costs. The maximum profit conditions are:

$$
\left[p_{T}-\sum_{J \neq T} a_{J, T} p_{J}-a_{R, T} p_{R}-a_{N, T} p_{N}\right] Y_{L}=w
$$

$$
\left[p_{T}-\sum_{\nexists \mp T} a_{J, T} p_{J}-a_{R, T} p_{R}-a_{N, T} p_{N}\right] Y_{K}=r_{T}
$$

In both cases, the value of marginal product (corrected for intermediate costs) is equalized to the reward of the factor. Notice that we are not assuming export or import taxes but they can be introduced easily as ad valorem taxes. 


\section{2.b Non-tradable sector}

Services and other non tradable goods are produced using labour and capital. Capital is specialized and non mobile. Equation (9) corresponds to profits definition, and equations (10) and (11) to optimization conditions:

$$
\pi_{N}=\left[\left(1+t_{N}\right) p_{N}-\sum_{T} a_{T, N} p_{T}-a_{R, N} p_{R}\right] H\left(L_{N}, K_{N}\right)-w L_{N}-r_{N} K_{N}
$$

In this last expression we have included a sales tax to non-tradable non-regulated services. This is only for the sake of this simplified presentation, since the general model considers a wide range of different taxes (see Chisari and others (2009)). The maximization conditions are:

$[10] \quad\left[p_{N}-\sum_{T} a_{T, N} p_{T}-a_{R, N} p_{R}\right] H_{L}=w$
$[11] \quad\left[p_{N}-\sum_{T} a_{T, N} p_{T}-a_{R, N} p_{R}\right] H_{N}=r_{N}$

Our model considers the possibility of price regulation in the two basic cases: price-cap and cost-plus. This is done by introducing endogenous mark-ups (see Chisari and others (2009) and Chisari, Lambardi and Romero (2005)).

\section{Rest of the world}

\section{3.a Production sectors}

The rest of the world produces substitutes for our exports and import goods, using a factor of production F. Equations (12) to (17) give an alternative technology available for foreign owners to fulfill their obligation of services, using mobile capital.

$$
\pi_{m}^{*}=p_{m} \alpha\left(F_{m}\right)-w^{*} F_{m}
$$

$$
\pi_{T}^{*}=p_{T} \beta_{T}\left(F_{T}\right)-w^{*} F_{T}
$$

[16] $\quad m^{s}=\alpha\left(F_{m}\right)$

[17] $\quad x^{s}=\beta_{T}\left(F_{T}\right)$ 
$\pi_{m}^{*}$ and $\pi_{T}^{*}$ represent profits in the rest of the world industries that produce import goods and perfect substitutes of tradable goods. The numeraire, $w^{*}$, is the wage rate of the only factor used abroad. $F_{m}$ and $F_{T}$ are factor quantities employed in the corresponding industries. The production functions: $\alpha\left(F_{m}\right)$ and $\beta_{T}\left(F_{T}\right)$ give the total supply in equations (15), (16) and (17). In the case of $\alpha^{\prime}$ and $\beta_{T}^{\prime}$ constants, international terms of trade will be given by $p T / p M=\alpha / \beta_{T}$ (small economy assumption).

\section{3.b Households}

Consumers in the rest of the world receive the rents of foreign factors, including capital installed in Argentina. It maximizes a utility function $v\left(x_{T}, m^{*}\right)$ that depends on the consumption of our tradable goods and of import goods, as well as the demand for bonds. Their budget condition is:

$$
p_{m} m^{*}+p_{T} x_{T}+b\left(B X-B X^{*}\right)=w^{*} \bar{F}+(1-\theta) \pi_{R}+\pi_{m}^{*}+\sum_{T} \pi_{T}^{*}+t p_{R} G\left(L_{R}, K_{R}\right)(1-\theta)
$$

Foreign agents receive profits and capital return from domestic sectors, as well as the wage rate (cost of capital) $F$ and the proceedings of the mark-up factor. $X_{T}$ are exports, namely domestic tradable goods bought by the foreign agent. The last term in equation (18) stands for the endogenous mark-up (positive) or internal subsidy (negative) computed as the difference between the benchmark tariff $1 / \mu$ (as seen by customers) and $P_{R}$.

\section{3.c Public sector}

The public sector is treated as a special agent. It collects tax revenues and buys goods and services (or factors, mainly Labour). It is endowed with a utility function $U G$, and therefore it is possible to estimate its welfare changes. It can issue bonds and also purchases investment goods.

Its initial endowment of bonds is $B G^{*}$, while $\left(B G-B G^{*}\right)$ stands for net purchases. Equation [18] gives the budget condition for the public sector:

$$
T R+L G+I G+G+p_{b} B G=\left[t_{N} p_{N} H\left(L_{N}, K_{N}\right)\right]+p_{b} B G^{*}
$$

Its utility function is assumed to be Cobb-Douglas.

\section{Market equilibrium conditions}

Equations (20) to (22) represent the equilibrium conditions for factors used domestically, and (23) is the equilibrium condition for the foreign factor. Equations (24) to (27) correspond to equilibrium in markets for goods and imports. Equation (28) gives the market condition for what is known as the "market for transfers". While (29) corresponds to the market for bonds. 
[20] $\bar{L}=L_{1}+L_{2}+L_{R}+L_{N}+L G$

[21] $\bar{K}_{T}=K_{T} \quad(T=1,2)$

[21] $\bar{K}_{N}=K_{N}$

[23] $\bar{F}=F_{m}+\sum_{T} F_{T}$

[24] $G\left(L_{R}, K_{R}\right)+q_{R}=\sum_{T} a_{R, T} Y_{T}\left(L_{T}, K_{T}\right)+a_{R, N} H\left(L_{N}, K_{N}\right)+c_{R}$

[25] $Y_{T}\left(L_{T}, K_{T}\right)+x_{T}^{s}=a_{T, R} G\left(L_{R}, K_{R}\right)+a_{T, N} H\left(L_{N}, K_{N}\right)+c_{T}+x_{T}$

[26] $H\left(L_{N}, K_{N}\right)=\sum_{T} a_{N, T} Y_{T}\left(L_{T}, K_{T}\right)+a_{N, R} G\left(L_{R}, K_{R}\right)+c_{N}+G+I G$

[27] $m^{s}=m+m^{*}$

[28] $T R=T R^{w}$

[29] $B D+B G+B X=B D^{*}+B G^{*}+B X^{*}$

A solution is a vector of prices of goods, services, factors, bonds and transfers that clear all markets simultaneously. Under unemployment, wages must be determined following some additional condition (like constant real wages). Under mobility, capital reward is the same across industries. 



\section{Chapter VII \\ World food price increases and Brazil: an opportunity for everyone?}

Joaquim Bento de Souza Ferreira Filho

\section{A. Introduction}

After a period of steady growth, the world economy has recently entered a new phase of instability. A major aspect of this scenario was the recent increase in world commodity prices, which became a source of economic concern for policymakers all over the world. Of particular interest among those commodities is the increase in food prices, which began to rise in 2002 and have accelerated markedly over the last few years (FAO, 2008a). There is an ongoing and intense debate about the causes of this persistent price increase, and it is well established that there are many causes behind this phenomenon, including the rapid rate of economic growth in developing countries, falling food stocks and rising demand, short harvests in some major countries, oil price increases and the devaluation of the United States dollar in relation to most other currencies.

Food price increases can cause strong negative impacts on the wellbeing of a large part of the developing world, which is composed of net food importing countries. The Food and Agriculture Organization of the United Nations (FAO, (2008b)) states that rising food prices are causing severe hardship and suffering among the almost 800 million people who

1 University of São Paulo, Luiz de Queiros Agricultural College. 
are already affected by chronic hunger. However, FAO also points out that "On the other hand, high prices will stimulate a supply side response where the market signals are transmitted to food producers who have capacity to increase production and, where existing transport and market infrastructure allow, to supply the market. This may represent an important opportunity for promoting agricultural and rural development in many low-income countries, provided an enabling policy environment and supportive measures are established quickly".

This latter aspect of the problem has been less analysed, as the issue is dominated by the urgency and gravity of the first effect. As noted by FAO (2008b), however, this food price increase may be an opportunity to help alleviate poverty in other poor countries.

From a Latin American perspective, the situation seems to be better than in general. FAO (2008a) shows that, since the beginning of this decade, growth rates in per capita food production in Latin American and Caribbean (LAC) countries have been higher than both the world average and the average of the developed economies, which would point to a more comfortable situation for the region as a whole. The same study nonetheless refers to the high level of heterogeneity among countries. The Caribbean countries, Mexico and the Bolivarian Republic of Venezuela have food trade deficits, contrary to the majority of the other countries in the region.

Lustig (2008) poses the question of whether poverty increases or falls with higher food prices. According to that author "Since the poor include both net consumers and net sellers of food commodities, a change in their price in either direction will inevitably hurt some of the poor and benefit some of the poor at the same time. Available evidence suggests that among the poorest of the poor, the decline in living standards of net consumers caused by higher food prices outweighs the benefits accruing to net sellers in the majority of countries that have been analyzed so far" (Lustig, 2008).

Brazil, in particular, is one of the countries with a considerable surplus in the food trade balance. In fact, it is a common view in the country that the recent food price increases constitutes an opportunity rather than a threat for Brazil. ${ }^{2}$ Indeed, despite the strong increase in input costs - caused mainly by the increase in world prices of fertilizers and chemical products, which are influenced by the price of petroleum Brazilian agriculture and livestock sectors have shown a steady increase in production in recent years. The availability of agricultural land is

2 The Brazilian President has mentioned this in many recent public speeches. 
still high in the country, even without taking into account the landclearing process in the Amazon region. This makes the country a natural candidate to be a winner in the process, at least at the aggregate level.

The assessment of the importance of food price increases for poverty is further complicated by the fact that it is not only food products that have faced world price increases recently, but also nonfood commodities such as petroleum and mineral products. The effects of these price increases are hard to unravel, and it is conceivably possible that they can act in opposite directions.

Brazil is still a country with a large share of the population below poverty line, even though it is now a middle-income country. This is caused by the country's particularly skewed income distribution. Even though the situation has improved recently, this was mainly due to direct transfers from federal government policies, rather than to structural changes in the economy. This study is an attempt to analyse in greater detail the case of Brazil - an important net food exporter - and address the issue the importance of world food price increases for the country. The effects of the increase in world prices for food and non-food commodities will be examined using a general equilibrium model of Brazil, in order to assess the potential effects that the counterbalancing forces arising from the world food price increases may have on poverty and income distribution in Brazil.

\section{B. Objective}

The objective of this paper is to analyse the potential impacts for Brazil of the recent increase in world food prices. One particular interest is to gain insights into the impact on poverty and income distribution by analysing the net effect on the economy from both the production and consumption sides, in an attempt to isolate the effects of both food and non-food commodity prices increases.

\section{Methodology}

A computable general equilibrium (CGE) model of the Brazilian economy will be used to assess the economic and distributional impact that the recent increase in the world prices of food and other non-food commodities has had on Brazil. The core CGE model is linked to a micro-simulation model of Brazil, and its theoretical structure is based on previous work by Ferreira Filho and Horridge (2006), Ferreira Filho, Santos and Lima (2007) and Ferreira Filho and Horridge (2010). 
The model database used in this paper, however, is a new 2004 database. It is based on the Brazilian National Accounts for 2004 and the Brazilian National Household Survey (PNAD), for the year 2004 (IBGE, 2004a). The following is a description of the main features of the model.

The CGE model used here, TERM-BR, is a static inter-regional model of Brazil based on the TERM ${ }^{3}$ model of Australia (Horridge, Madden and Wittwer, 2005). It consists, in essence, of 27 separate CGE models (one for each Brazilian state), linked by the markets for goods and factors. For each region, industry and final demander, Brazilian and imported versions of each commodity are combined to produce a user-specific constant elasticity of substitution (CES) composite good. Household consumption of these domestic/imported composites is modelled through the Linear Expenditure System, while intermediate demand has a Leontief (fixed proportions) structure. Industry demands for primary factors follow a CES pattern, while labour is itself a CES function of 10 different labour types. These different labour types are classified according to wages, as a proxy for skills. The model distinguishes 42 producing sectors (or industries), among which 41 are single-product industries and the agricultural industry ("Agriculture") distributes its output (according to a CET constraint) among 11 agricultural commodities. Export volumes are determined by constant-elasticity foreign demand schedules.

These regional CGE models are linked by trade in goods underpinned by large arrays of inter-regional trade that record, for each commodity, source region and destination region, the values of Brazilian and foreign goods transported, as well as the associated transport or trade margins. ${ }^{4}$ Users of, say, vegetables in São Paulo state are substituted among vegetables produced in the 27 states according to their relative prices, under a CES demand system. ${ }^{5}$

With 27 regions, 42 industries, 52 commodities, and 10 labour types, the model contains around 1.5 million non-linear equations. It is solved with the GEMPACK software. The CGE model is calibrated with

Versions of TERM have been prepared for Australia, Brazil, Finland, China, Indonesia and Japan. Related material can be found at www.monash.edu.au/policy/term.htm.

4 The dimensions of this margins matrix are: $52^{*} 2^{*} 2^{*} 27^{*} 27$ [COM*SRC*MAR*REG*REG].

5 For most goods, the inter-regional elasticity of substitution is fairly high. To ease the computational burden, we assume that all users of good $G$ in region $R$ draw the same share of their demands from region $\mathrm{Z}$. 
data from two main sources: a 2004 Brazilian Input-Output Matrix, ${ }^{6}$ and some shares derived from the Brazilian Municipal Agricultural Survey (IBGE, 2004b).

On the income-generation side of the model, workers are divided into 10 different categories (occupations), according to their wages. These wage classes are then assigned to each regional industry in the model. Together with the revenues from other endowments (capital and land rents), these wages will be used to generate household incomes. Each activity uses a particular mix of the 10 different labour occupations (skills). Changes in activity level change employment by sector and region. This drives changes in poverty and income distribution. Using data from the Household Expenditure Survey mentioned below, the CGE model was extended to cover 270 different expenditure patterns, composed of 10 different income classes in 27 regions. In this way, all of the expenditure-side detail of the micro-simulation dataset is incorporated within the main CGE model.

There are two main sources of information for the household micro-simulation model: the National Household Survey (PNAD) (IBGE, 2004a), and the Household Expenditure Survey (POF) (IBGE, 2004b). The National Household Survey contains information about households and persons. The main information extracted from the National Household Survey relates to wages by industry and region, as well as other personal characteristics such as years of schooling, sex, age, position in the family and other socio-economic details.

The Household Expenditure Survey, on the other hand, is an expenditure survey that covers 11 metropolitan regions in Brazil. It was undertaken during 2002 and 2003, covering 48,470 households in all states, for the purposes of updating the consumption bundle structure. The main information drawn from this survey was the expenditure patterns of 10 different income classes, for the 11 regions. One such pattern was assigned to each individual household surveyed in the National Household Survey, according to each income class. As for the regional dimension, the 11 regions surveyed for the Household Expenditure Survey were mapped onto the larger set of 27 CGE regions. Here it must be stressed that the Household Expenditure Survey simply provides information about urban areas (the metropolitan areas of the main state capitals). After preparation, the micro-simulation database comprises 283,363 people (above the age of 15) and 121,849 households.

The 2004 Brazilian Input-Output database used in this study was generated by the author based on the Brazilian National Accounting System tables [online] http:/ / www. ibge.gov.br/servidor_arquivos_est/, since the last official Input-Output table published by the Brazilian statistical agency is from 1996. 
The CGE and the micro-simulation (MS) models are run sequentially, with consistency between the two models ensured by matching the micro-simulation model with the CGE model. The CGE model is sufficiently detailed, and its categories and data are close enough to those of the MS model, for the CGE model to closely predict MS aggregate behaviour that is also included in the CGE model (such as household demands or labour supplies). The role of the MS model is to provide extra information about the variance of income within income groups, or about the incidence of price and wage changes upon groups not identified by the CGE model, such as those defined by ethnic group, educational level, or family status. Note that each household in the micro data set has one of the 270 expenditure patterns identified in the main CGE model. There is very little scope for the MS to disagree with the CGE model.

The simulation begins with a set of trade shocks of world export and import prices of commodities. The price shocks are applied, and the results calculated for 52 commodities, 42 industries, 10 households and 10 labour occupations, all of which vary for the 27 regions. Next, the results from the CGE model are used to update the MS model. At first, this update consists basically in updating wages and hours worked for the 283,363 workers in the sample. These changes have a regional dimension (27 regions) as well as a sectoral dimension (42 industries).

The model then relocates jobs according to changes in labour demand. ${ }^{7}$ This is done by changing the National Household Survey weighting of each worker in order to mimic the change in employment. In this approach, there is thus a true job relocation process going on. Although job relocation has very little effect on the distribution of wages among the 270 household groups identified by the CGE model, it may have considerable impact on the variance of income within a group.

One final point should be made about the procedure used in this paper. Although the changes in the labour market are simulated for each adult in the labour force, the changes in expenditure and in poverty are tracked back to the household dimension. A National Household Survey key links persons to households, which contain one or more adults, either working in a particular sector and occupation, or unemployed,

This methodology was termed "the quantum method" in previous work by the authors, and is described in more detail elsewhere (Ferreira Filho and Horridge, 2006). Here, only the main ideas are presented. 
as well as dependents. In the model, it is therefore possible to establish changes in household income from the changes in individual wages. This is a very important aspect of the model, since family income variations are likely to be cushioned, in general, by this procedure. If, for example, one person in a household loses his/her job while another member of the same household finds a new job, household income may change little (or even increase). Since households are the expenditure units in the model, we would expect household spending variations to be smoothed by this income-pooling effect. On the other hand, the loss of a job will increase poverty to a greater extent if the displaced worker is the sole earner in a household.

\section{Poverty and income distribution in Brazil in the 2004 reference year}

Despite the recent improvement, income in Brazil is still very concentrated. If household income is split into ten groups, as displayed in Table VII.1, it can be seen that the first five household income groups (Household Expenditure Survey POF1 to POF5) account for $52.9 \%$ of the population, yet receive only $18.5 \%$ of total household income. The richest households, on the other hand, while accounting for just $10.9 \%$ of the population, receive $43.7 \%$ of total household income.

Table VII.1

POVERTY AND INCOME DISTRIBUTION IN BRAZIL, 2004

\begin{tabular}{|c|c|c|c|c|c|c|}
\hline Household group & $\begin{array}{c}\text { Proportion } \\
\text { of pop. }\end{array}$ & $\begin{array}{l}\text { Proportion } \\
\text { of income }\end{array}$ & $\begin{array}{c}\text { Share bellow } \\
\text { poverty line } \\
\text { (FGTO) }\end{array}$ & $\begin{array}{l}\text { Household } \\
\text { contribution } \\
\text { to FGTO }\end{array}$ & $\begin{array}{c}\text { Average } \\
\text { poverty } \\
\text { gap (FGT1) }\end{array}$ & $\begin{array}{c}\text { Household } \\
\text { contribution } \\
\text { to FGT1 }\end{array}$ \\
\hline 1 POF[1] (poorest) & 14.2 & 2.2 & 0.86 & 0.14 & 0.53 & 0.09 \\
\hline 2 POF[2] & 14.1 & 4.1 & 0.64 & 0.09 & 0.19 & 0.03 \\
\hline 3 POF[3] & 20.9 & 9.9 & 0.20 & 0.04 & 0.03 & 0.01 \\
\hline $4 \quad$ POF[4] & 7.5 & 4.7 & 0.04 & 0.00 & 0.01 & 0.00 \\
\hline $5 \quad$ POF $[5]$ & 11.1 & 8.4 & 0.02 & 0.00 & 0.00 & 0.00 \\
\hline 6 POF[6] & 7.3 & 7.0 & 0.00 & 0.00 & 0.00 & 0.00 \\
\hline 7 POF[7] & 9.8 & 12.7 & 0.00 & 0.00 & 0.00 & 0.00 \\
\hline 8 POF[8] & 5.3 & 9.3 & 0.00 & 0.00 & 0.00 & 0.00 \\
\hline 9 POF[9] & 4.7 & 12.1 & 0.00 & 0.00 & 0.00 & 0.00 \\
\hline 10 POF[10] (richest) & 5.2 & 29.5 & 0.00 & 0.00 & 0.00 & 0.00 \\
\hline National values & 100.0 & 100.0 & 0.28 & Sum $=0.28$ & 0.12 & Sum $=0.12$ \\
\hline
\end{tabular}

Source: Brazilian Geographical and Statistical Institute (IBGE), Pesquisa Nacional por Amostragem de Domicílios (PNAD), 2004. 
The poverty line used in this study was set as one third of average household income. ${ }^{8}$ Based on this poverty line, about $28 \%$ of Brazilian households would be poor in 2004 , or about $15,611,871$ out of $55,707,000$ households $\left(59,531,941\right.$ people). ${ }^{9}$

The figures in table VII.1 also show how each Household Expenditure Survey group contributes to the FGT overall measures of poverty (named after Foster,-Greer-Thorbecke (1984)): FGT0 - the proportion of poor households (i.e. below the poverty line) and FGT1 the average poverty gap ratio (proportion by which household income falls below the poverty line). As shown in table VII.1, the proportion below the poverty line is very high up to the third household income group, and the poverty gap is very high among the poorest household group, around $53 \%$. This household group contributes almost $75 \%$ to the national poverty gap.

The poverty and income distribution figures also display significant regional differences inside Brazil, a large country with considerable regional economic differences. These differences can be analysed using the figures in table VII.2.

As can be seen in table VII.2, the most densely populated regi ons in Brazil are the Northeast region (NE), with $27.83 \%$ of the total population, and the Southeast region (SE), with $42.51 \%$ of the total population. The Northeast and North regions are those with the highest relative poverty levels, or share of regional population below the poverty line. Taking into account the size of the population, however, São Paulo and Minas Gerais, both in the Southeast regions of Brazil appear, along with Bahia, as the main contributors to the national headcount ratio (FGT0) ${ }^{10}$ (see the fifth column in table VII.2). Furthermore, São Paulo is also the most important regional contributor to the poverty gap in the country.

The joint analysis of table VII.1 and table VII.2 provides important information relating to the problem at hand, namely the increase in food prices. Initially, table VII.3 shows the structure of labour use by production sector in Brazil. In this table, the 42 industries have been

8 The criterion used in this study sets the value of the poverty line at $R \$ 184.66$, in 2004 values. Note that this value is not directly comparable to most other studies in the field, since it is computed on an equivalent income basis, and not as the average household income, as in many studies.

9 Rocha (2006), working with a set of regional poverty lines, obtained a 0.332 headcount ratio for 2004, which would amount to $57,698,000$ poor people.

10 São Paulo and Minas Gerais are two of the most industrialized states in Brazil. 
Table VII.2

REGIONAL POVERTY AND INCOME INEQUALITY FIGURES, BRAZIL, 2004

\begin{tabular}{|c|c|c|c|c|c|c|c|}
\hline \multicolumn{2}{|c|}{ Regions } & Macro-regions ${ }^{a}$ & \multirow{2}{*}{$\begin{array}{c}\begin{array}{c}\text { Regional } \\
\text { pop. share } \\
\text { in total } \\
\text { population }\end{array} \\
0.83\end{array}$} & \multirow{2}{*}{$\begin{array}{c}\begin{array}{c}\text { Proportion } \\
\text { of poor } \\
\text { households } \\
\text { in regional } \\
\text { pop. (FGTO) }\end{array} \\
0.26\end{array}$} & \multirow{2}{*}{$\begin{array}{c}\text { Regional } \\
\text { contrib. } \\
\text { to total } \\
\text { FGTO }\end{array}$} & \multirow{2}{*}{$\begin{array}{c}\begin{array}{c}\text { Regional } \\
\text { average } \\
\text { poverty } \\
\text { gap } \\
\text { (FGT1) }\end{array} \\
0.09\end{array}$} & \multirow{2}{*}{$\begin{array}{c}\begin{array}{c}\text { Regional } \\
\text { contrib. } \\
\text { to total } \\
\text { poverty } \\
\text { gap }\end{array} \\
0.00\end{array}$} \\
\hline 1 & Rondonia & N & & & & & \\
\hline 2 & Acre & $\mathrm{N}$ & 0.35 & 0.40 & 0.00 & 0.17 & 0.00 \\
\hline 3 & Amazonas & $\mathrm{N}$ & 1.76 & 0.37 & 0.01 & 0.16 & 0.00 \\
\hline 4 & Roraima & $\mathrm{N}$ & 0.21 & 0.44 & 0.00 & 0.22 & 0.00 \\
\hline 5 & Para & $\mathrm{N}$ & 3.77 & 0.40 & 0.01 & 0.17 & 0.01 \\
\hline 6 & Amapa & $\mathrm{N}$ & 0.32 & 0.39 & 0.00 & 0.17 & 0.00 \\
\hline 7 & Tocantins & $\mathrm{N}$ & 0.71 & 0.34 & 0.00 & 0.13 & 0.00 \\
\hline 8 & Maranhao & NE & 3.32 & 0.58 & 0.02 & 0.30 & 0.01 \\
\hline 9 & Piaui & NE & 1.64 & 0.54 & 0.01 & 0.26 & 0.00 \\
\hline 10 & Ceara & NE & 4.40 & 0.51 & 0.02 & 0.23 & 0.01 \\
\hline 11 & RGNorte & NE & 1.64 & 0.47 & 0.01 & 0.21 & 0.00 \\
\hline 12 & Paraiba & NE & 1.97 & 0.50 & 0.01 & 0.23 & 0.00 \\
\hline 13 & Pernambuco & NE & 4.59 & 0.49 & 0.02 & 0.22 & 0.01 \\
\hline 14 & Alagoas & NE & 1.65 & 0.57 & 0.01 & 0.27 & 0.00 \\
\hline 15 & Sergipe & NE & 1.07 & 0.39 & 0.00 & 0.16 & 0.00 \\
\hline 16 & Bahia & NE & 7.55 & 0.46 & 0.03 & 0.20 & 0.01 \\
\hline 17 & MinasG & SE & 10.47 & 0.26 & 0.03 & 0.10 & 0.01 \\
\hline 18 & EspSanto & SE & 1.85 & 0.25 & 0.00 & 0.10 & 0.00 \\
\hline 19 & RioJaneiro & SE & 8.31 & 0.19 & 0.02 & 0.09 & 0.01 \\
\hline 20 & SaoPaulo & SE & 21.88 & 0.16 & 0.04 & 0.07 & 0.02 \\
\hline 21 & Parana & $S$ & 5.59 & 0.17 & 0.01 & 0.07 & 0.00 \\
\hline 22 & StaCatari & $S$ & 3.19 & 0.10 & 0.00 & 0.04 & 0.00 \\
\hline 23 & RGSul & $S$ & 5.90 & 0.15 & 0.01 & 0.06 & 0.00 \\
\hline 24 & MtGrSul & CW & 1.23 & 0.22 & 0.00 & 0.09 & 0.00 \\
\hline 25 & MtGrosso & CW & 1.52 & 0.20 & 0.00 & 0.07 & 0.00 \\
\hline 26 & Goias & CW & 3.04 & 0.22 & 0.01 & 0.08 & 0.00 \\
\hline 27 & DF & CW & 1.25 & 0.22 & 0.00 & 0.11 & 0.00 \\
\hline Tot & & Brazil & 100.00 & - & 0.28 & - & 0.12 \\
\hline
\end{tabular}

Source: Brazilian Geographical and Statistical Institute (IBGE), Pesquisa Nacional por Amostragem de Domicilios (PNAD), 2004.

a Macro-Regions: $\mathrm{N}=$ North; $\mathrm{NE}=$ North-East; $\mathrm{SE}=$ South-East; $\mathrm{S}=$ South; $\mathrm{CW}=$ Center-West

aggregated to 5, for reporting purposes. The first line shows the upper limit, in Reais of 2004, of the value of each wage class. For example, the OCC2 wage class includes monthly wages ranging from $\mathrm{R} \$ 130$ to $\mathrm{R} \$$ 225 , and so on. The final wage class, OCC10, includes all monthly wages higher than $\mathrm{R} \$ 1,500.00$ in 2004 values. ${ }^{11}$

11 For the sake of reference, the monthly weighted average value of the minimum wage in Brazil in 2004 was $R \$ 253.40$ (4 months at $R \$ 240.0$ and 8 months at $R \$ 260$ ). Roughly speaking, then, OCC 3 is around the limit of the minimum wage value. 
Table VII.3

USE OF LABOR BY EACH AGGREGATED ACTIVITY: SHARES, BRAZIL, 2004

\begin{tabular}{|c|c|c|c|c|c|c|c|c|c|c|}
\hline \multirow[b]{2}{*}{ Sectors } & \multicolumn{10}{|c|}{ Wage classes } \\
\hline & $0 \mathrm{CC} 1$ & 0cc2 & $0 \mathrm{cc3}$ & $0 \mathrm{CC} 4$ & $0 \mathrm{CC5}$ & $0 \mathrm{Cc} 6$ & $0 \mathrm{Cc} 7$ & $0 \mathrm{cc8}$ & $0 \operatorname{ccg}$ & 0CC10 \\
\hline Limit $(\mathrm{R} \$)$ & 130 & 225 & 260 & 300 & 390 & 480 & 600 & 800 & 1500 & open \\
\hline Agropec & 0.502 & 0.478 & 0.169 & 0.213 & 0.172 & 0.128 & 0.107 & 0.075 & 0.051 & 0.059 \\
\hline ExtratMin & 0.004 & 0.007 & 0.010 & 0.012 & 0.011 & 0.013 & 0.014 & 0.015 & 0.013 & 0.019 \\
\hline Manufact & 0.067 & 0.051 & 0.093 & 0.100 & 0.136 & 0.164 & 0.159 & 0.157 & 0.147 & 0.125 \\
\hline Foodlnd & 0.023 & 0.026 & 0.038 & 0.040 & 0.046 & 0.046 & 0.042 & 0.036 & 0.028 & 0.014 \\
\hline Services & 0.401 & 0.435 & 0.689 & 0.634 & 0.634 & 0.646 & 0.677 & 0.719 & 0.76 & 0.784 \\
\hline Total & 1 & 1 & 1 & 1 & 1 & 1 & 1 & 1 & 1 & 1 \\
\hline
\end{tabular}

Source: Brazilian Geographical and Statistical Institute (IBGE), Pesquisa Nacional por Amostragem de Domicílios (PNAD), 2004.

As shown in the table, agriculture accounts for about $50.2 \%$ and $47.8 \%$ of total use (wages) of the less skilled (lowest wages) workers in Brazil (wage classes OCC1 and OCC2, respectively), while the other sectors account for a larger share of workers in the higher wage classes. The Services sector is also an important employer of those types of workers.

Table VII.4 provides information about the income composition of household classes in Brazil (POF1 to POF10, named after the Household Expenditure Survey-), the expenditure units in the model. As we can

Table VII.4

HOUSEHOLD INCOME COMPOSITION ACCORDING TO WORKER'S WAGE CLASS, BRAZIL, 2004

\begin{tabular}{lrrrrrrrrrrr}
\hline & OCC1 & OCC2 & OCC3 & OCC4 & OCC5 & OCC6 & OCC7 & OCC8 & OCC9 & OCC10 & Total \\
\hline POF[1] & 0.244 & 0.333 & 0.404 & 0.019 & 0 & 0 & 0 & 0 & 0 & 0 & 1 \\
POF[2] & 0.098 & 0.142 & 0.119 & 0.196 & 0.213 & 0.231 & 0 & 0 & 0 & 0 & 1 \\
POF[3] & 0.049 & 0.105 & 0.127 & 0.095 & 0.110 & 0.146 & 0.268 & 0.1 & 0 & 0 & 1 \\
POF[4] & 0.028 & 0.063 & 0.102 & 0.070 & 0.091 & 0.134 & 0.215 & 0.249 & 0.048 & 0 & 1 \\
POF[5] & 0.019 & 0.050 & 0.061 & 0.053 & 0.078 & 0.121 & 0.215 & 0.169 & 0.233 & 0 & 1 \\
POF[6] & 0.010 & 0.036 & 0.040 & 0.043 & 0.064 & 0.101 & 0.167 & 0.188 & 0.351 & 0 & 1 \\
POF[7] & 0.004 & 0.017 & 0.022 & 0.025 & 0.037 & 0.064 & 0.114 & 0.134 & 0.427 & 0.156 & 1 \\
POF[8] & 0.002 & 0.011 & 0.013 & 0.014 & 0.024 & 0.040 & 0.085 & 0.095 & 0.350 & 0.368 & 1 \\
POF[9] & 0.001 & 0.004 & 0.006 & 0.007 & 0.009 & 0.019 & 0.041 & 0.052 & 0.235 & 0.627 & 1 \\
POF[10] & 0.000 & 0.001 & 0.002 & 0.002 & 0.003 & 0.005 & 0.011 & 0.014 & 0.073 & 0.890 & 1 \\
\hline
\end{tabular}

Source: Brazilian Geographical and Statistical Institute (IBGE), Pesquisa Nacional por Amostragem de Domicílios (PNAD), 2004.

POF1 is the poorest, POF10 the richest. 
see, the income of the poorest households is mostly composed of wages coming from the poorer workers. The income of the poorest household (POF1), for example, is almost entirely composed of wages coming from the three lowest wage groups, the less skilled workers in the economy.

This illustrates the problem raised before by FAO (2008a) and FAO (2008b), namely the dual effect for the poor of rising food prices: the negative expenditure effect (caused by food price increases themselves) and the income effect (caused by the expansion of the food producing sector fostered by the same price increases). Since agriculture is likely to benefit from food price increases, considering agriculture pays the bulk of the lowest wages in the country and that the income of the poorest families is mostly composed by the lowest wages, the balance of those two effects is a matter of size. The net result of those effects is the main subject of this paper.

\section{E. The simulation}

The simulation comprises the world price increases observed for the main commodities between 2004 (the model's database base year) and July 2008. Although our main interest is in food price increases, other commodity prices must be also included in the scenario due to their importance either as a cost item for agriculture (oil prices and fertilizers, for example) or a "Dutch disease" effect generator in the economy. The shocks to the model therefore involve shocking the world export prices and import prices of the main commodities, according to the model's commodity classification. Most of the price variations were obtained from the International Financial Statistics of the International Monetary Fund..$^{12}$ The original price variations had to be adapted for the model's commodity classification. The resulting shocks can be seen in table VII.5 below.

The shocks were chosen based on the database structure. Products that do not participate in external trade were naturally not included. In the above table, it is worth noting that exports of raw agricultural products are small in Brazil, the only exception being soybeans. On the import side, oil and gas products (mainly gas) are the most important products, based on the share of imports in total domestic use. As can be seen from table VII.5, the price shocks were substantial.

12 Available at www.ipea.gov.br. The price of cellulose refers to type BHKP, short fibre, in Europe. The price of milk and dairy refers to powdered milk in Oceania (data from the United States Department of Agriculture (USDA)). 
Table VII.5

SHOCKS ACCORDING TO THE MODEL COMMODITY CLASSIFICATION

\begin{tabular}{llccc}
\hline Commodity & Description & $\begin{array}{c}\text { Price } \\
\text { variation } \\
\mathbf{2 0 0 4 / 2 0 0 8} \\
\mathbf{( \% )}\end{array}$ & $\begin{array}{c}\text { Share of } \\
\text { exports } \\
\text { in total } \\
\text { production }\end{array}$ & $\begin{array}{c}\text { Share of } \\
\text { imports in } \\
\text { total } \\
\text { domestic use }\end{array}$ \\
\hline Coffee & Coffee beans & 92.160 & 0.010 & 0.000 \\
PaddyRice & Rice (grain) & 97.280 & 0.000 & 0.026 \\
Wheat & Wheat (grain) & 112.070 & 0.213 & 0.518 \\
Soybean & Soybeans & 76.520 & 0.348 & 0.008 \\
Cotton & Cotton lint & 22.830 & 0.000 & 0.000 \\
Corn & Corn (grain) & 96.920 & 0.121 & 0.008 \\
Milk & Raw milk & 107.140 & 0.002 & 0.003 \\
OtherAgric & Other (includes orange juice) & 29.100 & 0.031 & 0.038 \\
MineralExtr & Mineral Extraction (incl. iron ore \& alum.) & 149.500 & 0.450 & 0.119 \\
PetrGasExtr & Oil and gas extraction & 152.830 & 0.143 & 0.337 \\
IronProduc & Iron and steel & 212.820 & 0.259 & 0.064 \\
PaperGraph & Includes cellulose & 76.940 & 0.100 & 0.045 \\
ChemicElem & Chemical products, incl. some petrol. prod. & 180.000 & 0.052 & 0.153 \\
PetrolRefin & Petroleum refined products & 152.830 & 0.065 & 0.115 \\
Textiles & Textiles & 0.940 & 0.105 & 0.064 \\
Coffeelnd & Coffee products & 92.160 & 0.107 & 0.001 \\
VegetProcess & Processed vegetables & 29.100 & 0.302 & 0.103 \\
Slaughter & Meat products in general & 50.540 & 0.243 & 0.012 \\
Dairy & Dairy products & 107.140 & 0.008 & 0.021 \\
Sugarlnd & Sugar & 58.500 & 0.287 & 0.002 \\
VegetOils & Vegetable oils, mainly soybean oil & 62.150 & 0.312 & 0.017 \\
OthFood & Other food products, incl. feedstuffs & 20.420 & 0.034 & 0.039 \\
\hline Soure: Prepan & by the author on the bas of & & &
\end{tabular}

Source: Prepared by the author on the basis of real world price increase.

\section{Model closure}

The closure used for this study has a short-run flavour, considering the four-year time frame involved. On the supply side, national employment by occupation ${ }^{13}$ is fixed for the five higher wage classes (OCC6 to OCC10). In the lower five wage groups labour is mobile, with inter-regional real wage differentials driving labour migration between regions. ${ }^{14}$ The model allows industries to substitute between occupations, driven by relative wages (low elasticity). Capital is fixed at the industry

13 The microdata show substantial unemployment of less-skilled groups in all regions.

14 For a particular occupation and region, the inter-sectoral wage variation was fixed. For the micro-simulation it was assumed that jobs created (or lost) in a region were allotted to (or taken from) households in that region. 
level, with the rate of return endogenous. The land stock in each region (used only in the agriculture and mining sectors activities) is fixed. ${ }^{15} \mathrm{In}$ the mining sectors (mineral extraction and petrol and gas extraction), however, this stock is treated as "natural resources stock", and so is not used to compute the price of agricultural land, which is restricted to agriculture. Since agriculture is an activity that produces 11 products, land is allocated to these competing products through relative prices, allowing the crop mix to change.

On the demand side, real government demands and investment are fixed, while real household consumption is endogenous, and fixed as a share of GDP. ${ }^{16}$ The nominal exchange rate is the model's numeraire, which makes the real exchange rate (the domestic price deflated exchange rate) endogenous. On the export side, the total exports of products not considered in the shocks ( 32 out of 52 products, mainly manufactures and services) remained fixed in real terms at levels observed in 2004. This is necessary since the world economy grew at a rapid rate from 2004 onwards, as Brazil's total exports increased even with the strong exchange rate revaluation observed in the period (see below). This closure, then, takes into account the increase in world demand for those commodities not explicitly shocked.

\section{Results}

Initially, some macroeconomic results from the core CGE model will be presented. These results can be seen in table VII.6, and are presented as a background for results interpretation.

In table VII.6, the results of the shocks are broken down into two parts: the part due to food price increases and the part due to non-food price increases. The total result is also presented (the "All prices" column), and is roughly the sum of the other two. The first point to be noticed in table VII.6 is that, in line with common sense, the price increase shocks actually increase GDP in Brazil by $1.92 \%$ in model results. The closure used, which fixed most of the primary factors supply in the short run,

15 The factor market closure causes the model to generate percentage changes in prices for 10 labour types, capital and land; the price changes vary across regions. Percentage changes in demand for each of the 12 factors vary in addition by sector and region. Each adult in the National Household Survey microdata is identified by region and labour type; those employed are also identified by sector. Changes in microdata poverty levels are driven by wage changes and by the redistribution of jobs between sectors and regions (and hence between households).

16 Fixing the share of household consumption in GDP in real terms is necessary to ensure it continues to rise in the simulation, as observed in the period. Otherwise, consumption would fall markedly in response to price increases. 
Table VII.6

SELECTED MACROECONOMIC RESULTS

(Percentage changes)

\begin{tabular}{lccc}
\hline Macros & All prices & Food & Non-food \\
\hline Real Household Consumption & 1.92 & 1.06 & 0.86 \\
Real Investment & 0.00 & 0.00 & 0.00 \\
Real Government Expenditure & 0.00 & 0.00 & 0.00 \\
Exports Volume & 25.19 & 9.02 & 16.17 \\
Imports Volume & 29.62 & 9.84 & 19.78 \\
Real GDP & 1.92 & 1.06 & 0.86 \\
Aggregate Employment & 0.06 & 0.67 & -0.61 \\
Average real wage & -2.95 & 6.25 & -9.21 \\
Aggregated Capital Stock & 0.00 & 0.00 & 0.00 \\
GDP Price Index & 41.65 & 20.31 & 21.34 \\
Consumer Price Index (CPI) & 36.73 & 17.88 & 18.85 \\
Exports Price Index & 69.67 & 18.94 & 50.74 \\
Imports Price Index & 37.86 & 2.38 & 35.48 \\
Nominal GDP & 44.37 & 21.8 & 22.58 \\
Nominal Land Price & 53.88 & 89.29 & -35.41 \\
\hline
\end{tabular}

Source: Prepared by the author on the basis of model results.

does not allow much variation in GDP. Most of this increase comes from a slight rise in total labour use, around $0.06 \%$, that comes from the five least skilled labour groups which are not fixed in the model. This is in line with the base data information, where there is substantial unemployment in these labour classes in the base year, in all regions.

Model results also show a $1.92 \%$ increase in real household consumption.${ }^{17}$ This happens despite the strong fall in real wages, caused by the $36.73 \%$ increase in the Consumer Price Index (CPI). This increase is less than the GDP deflator, reflecting the simultaneous increase in commodities not directly consumed by households, as is the case of mineral extraction products.

An important feature of the Brazilian economy is that it is not very exposed to external trade, as the domestic market is far larger than trade flows with foreigners. ${ }^{18}$ Since the nominal exchange rate is the model's "numeraire", the real exchange rate defined as the nominal one deflated by the GDP price index showed a $41.65 \%$ revaluation, a movement

17 Considering that the share of consumption in GDP was set as constant, the percentage variation must be the same for both variables.

18 The total value of exports plus imports in 2004 accounted for about $29 \%$ of GDP. In the same year, the trade balance showed a surplus of $0.65 \%$ of GDP. 
close to what was observed in the Brazilian economy in the period. ${ }^{19}$ This exchange movement reduces the transmission of world prices to the national economy, as pointed out by FAO (2008b). Both exports and imports increase substantially in volume and in price, and the net result is that the share of the balance of trade in relation to nominal GDP increase by $4.88 \%$ (not shown in the table).

Land is used only by agriculture, while capital and the five highest wages (types of labour) are fixed nationally, but mobile between sectors. As a result of the simulation, the average (aggregated) capital rental increases. With capital stocks and some types of labour fixed in total, the expanding industries would attract the flexible types of labour from the contracting ones. Those industries those falling capital/labour ratios will see an increase in the marginal productivity of capital, and hence capital returns. The price of agricultural land shows a $53.88 \%$ increase on the national average, reflecting the increase in land demand in every state, as a consequence of the increase in agricultural production.

The respective contributions of food and non-food prices to the national results described above are different. As can be seen in table VII.6, the impact of food price increases on household consumption $(1.06 \%)$ is larger than that of non-food $(0.86 \%)$, as is to be expected. The impact of nonfood price increases on external trade, however, is much more significant than the impact of food prices, reflecting the importance of such a group of commodities in Brazilian external trade. Another interesting result is the impact of both shocks on aggregate employment and real wages. As shown, food price shocks increase employment and real wages, while nonfood price shocks decrease both.

The reason for the abovementioned fact is related to the labour composition in the food (especially in agriculture) and non-food sectors. Agriculture is the largest employer of the less skilled labour groups, of which there is a surplus in the simulation. The non-food sector, on the other hand, is specialized in skilled labour, whose total supply is fixed in the simulation (but not at the industry level). The food price increase causes an expansion in the food and agriculture sectors. Agriculture is the most intensive user of lesser skilled labour in the economy, expanding employment and real wages in order to attract the factor from other sectors.

The non-food price shock, however, strongly increases the production costs in the economy, since these products include oil products. This generates a reduction in the activity level of many labour-intensive

19 From 2004 to July 2008, the Brazilian currency (Real) posted a 44.78\% nominal revaluation compared to the American dollar. 
industries, especially agriculture, reducing both total employment and the real wage in the economy. The real wage reduction effect offsets the increase observed in the case of the food price shock, generating a fall in aggregate real wages in the economy.

National changes in industry output are shown in table VII.7. As shown in this table, most of the expanding industries are those that experienced the largest price shocks (shaded), meaning those producing agricultural, food and mineral commodities. ${ }^{20}$ Manufacturing contracts in general, since for these industries total exports were kept constant in real terms in the simulation. The expanding industries, however, grow at a very high rate, attracting labour from other industries, and reducing their activity level. In particular, the petroleum and gas industry and petrol refineries are extremely specialized in skilled labour in the database, and their expansion is particularly strong in terms of attracting skilled labour from other (contracting) manufacturing industries.

It's interesting to notice that both the vegetable processing (VegetProcess) and the other food (OthFood) industries both contract in aggregate. In the first case, the result is caused by the non-food price shock, whose effect overshadows the positive effect of the food price increase shock, as expected. In the second case, the OthFood industry is not an exporting sector (exports account for only about $4.3 \%$ of this sector's total production in the database) and is mainly consumed by households: the sector accounts for $6 \%$ of total household consumption in the database, being the largest food item in consumption. Besides that, households are responsible for about $56 \%$ of the total use of this sector, where consumption drops due to the price increase caused by the cost push.

The national aggregated values presented above conceal major regional differences inside Brazil. These values, aggregated according to macro administrative regions in Brazil, are presented in table VII.8.

The scheme for regional aggregation into macro regions is the same used in table VII.2, with the exception that here the Southeast region (SE) is further split into São Paulo (SP), the most industrialized state in Brazil, and the Rest of South East (RSE), which includes Minas Gerais, Espirito Santo and Rio de Janeiro. It can be seen from Table VII.8 that São Paulo state shows a different trend in many variables when compared to the other regions. This is the case of real regional household consumption and regional employment, which see a drop. The real wage also shows a larger decrease in São Paulo than in the other regions, which is a 20 The only exception is textiles. In this case, however, the shock is too small compared to
the other shocks, and the final result is equivalent to no shock at all. See table VII.5. 
Table VII.7

Activity level variation by industry

(Percentage changes)

\begin{tabular}{|c|c|c|c|}
\hline Industry & Total shocks & Food shocks & Non-Food shocks \\
\hline Agriculture & 5.18 & 18.62 & -13.44 \\
\hline MineralExtr & 10.21 & -2.90 & 13.11 \\
\hline PetrGasExtr & 19.19 & -3.85 & 23.05 \\
\hline MinNonMet & -8.20 & -0.83 & -7.38 \\
\hline IronProduc & 14.76 & -3.10 & 17.85 \\
\hline MetalNonFerr & -21.37 & -4.18 & -17.19 \\
\hline OtherMetal & -20.31 & -1.59 & -18.72 \\
\hline MachTractor & -33.40 & -4.92 & -28.48 \\
\hline EletricMat & -26.87 & -3.17 & -23.70 \\
\hline EletronEquip & -26.95 & -9.88 & -17.08 \\
\hline Automobiles & -5.53 & 3.07 & -8.60 \\
\hline OthVeicSpare & -30.50 & -4.08 & -26.42 \\
\hline WoodFurnit & -2.36 & -0.33 & -2.03 \\
\hline PaperGraph & 9.90 & -6.62 & 16.52 \\
\hline RubberInd & -22.78 & -0.09 & -22.69 \\
\hline ChemicElem & 15.31 & -2.43 & 17.74 \\
\hline PetrolRefin & 7.10 & -2.45 & 9.55 \\
\hline VariousChem & -28.03 & -1.64 & -26.39 \\
\hline PharmacPerf & -11.87 & -2.99 & -8.88 \\
\hline Plastics & -26.92 & -1.32 & -25.60 \\
\hline Textiles & -15.72 & -4.87 & -10.85 \\
\hline Apparel & 3.73 & 0.17 & 3.56 \\
\hline ShoesInd & -5.51 & -1.82 & -3.68 \\
\hline Coffeelnd & 2.14 & 4.85 & -2.71 \\
\hline VegetProcess & -7.33 & 13.29 & -20.63 \\
\hline Slaughter & 5.45 & 23.29 & -17.84 \\
\hline Dairy & 12.86 & 27.05 & -14.19 \\
\hline Sugarlnd & 3.78 & 11.44 & -7.66 \\
\hline Veget0ils & 3.31 & 11.68 & -8.37 \\
\hline OthFood & -4.18 & -1.33 & -2.85 \\
\hline VariousInd & -6.57 & -0.25 & -6.32 \\
\hline PubUtilServ & -2.62 & -1.53 & -1.09 \\
\hline CivilConst & -2.12 & -1.17 & -0.94 \\
\hline Trade & 6.48 & 2.61 & 3.87 \\
\hline Transport & -4.41 & -1.62 & -2.79 \\
\hline Comunic & -1.61 & -1.27 & -0.34 \\
\hline Financlnst & 0.53 & -0.79 & 1.33 \\
\hline FamServic & -1.48 & -2.96 & 1.49 \\
\hline EnterpServ & -5.35 & -3.75 & -1.61 \\
\hline BuildRentals & 0.04 & -0.15 & 0.19 \\
\hline PublAdm & -0.11 & -0.13 & 0.02 \\
\hline NMercPriSer & 1.92 & -2.84 & 4.76 \\
\hline
\end{tabular}

Source: Prepared by the author on the basis of model results. 
consequence of the large share of manufacturing sectors in this state's GDP. As shown below, these regional differences generate different outcomes in terms of poverty and income distribution inside Brazil.

Table VII.8

SELECTED MACROECONOMIC RESULTS: MACRO REGIONS IN BRAZIL (Percentage change)

\begin{tabular}{lrrrrrr}
\hline Macro regions & N & NE & SP & RSE & S & CO \\
\hline Real Household Consumption & 1.1 & 1.9 & -3.1 & 6.7 & 2.1 & 4.9 \\
Real Investment & 0.0 & 0.0 & 0.0 & 0.0 & 0.0 & 0.0 \\
Real Government Expenditure & 0.0 & 0.0 & 0.0 & 0.0 & 0.0 & 0.0 \\
Exports Volume & 7.2 & 31.4 & 25.3 & 39.6 & 14.6 & 22.8 \\
Imports Volume & 29.9 & 26.0 & 32.7 & 26.9 & 29.2 & 35.1 \\
Real GDP & 1.7 & 2.3 & 0.3 & 3.6 & 1.9 & 3.0 \\
Aggregate Employment & -0.3 & 0.2 & -2.3 & 2.7 & 0.3 & 1.9 \\
Average real wage & -3.2 & -2.6 & -5.1 & -0.6 & -2.7 & -1.3 \\
Aggregated Capital Stock & 0.0 & 0.00 & 0.0 & 0.0 & 0.0 & 0.0 \\
GDP Price Index & 37.0 & 43.9 & 31.1 & 60.5 & 37.9 & 39.1 \\
Consumer Price Index (CPI) & 37.7 & 38.3 & 33.1 & 39.0 & 36.7 & 37.9 \\
Exports Price Index & 46.2 & 87.5 & 56.0 & 107.4 & 53.1 & 62.0 \\
Imports Price Index & 31.3 & 36.7 & 21.7 & 70.5 & 45.6 & 35.2 \\
\hline
\end{tabular}

Source: Prepared by the author on the basis of model results.

\section{F. Poverty and income distribution results}

The impact in model results caused by increased world commodity prices on poverty and income distribution in Brazil can be seen in table VII.9.

As shown in table VII.9, the net result of the shocks on poverty is a $1.04 \%$ increase in the headcount ratio, or FGT0 index. This means that the shock would cause a $1.04 \%$ increase in the number of poor households in Brazil, in aggregate. This number changes to $1.28 \%$ if the calculation is done in terms of the number of people, not households. The GINI index would increase by $0.50 \%$, pointing to a worsening of inequality inside Brazil.

These numbers are substantially smaller than the $11.3 \%$ increase in the number of poor persons in Brazil estimated by the Inter-American Development Bank (IDB, 2008). The present study and the IDB (2008) study, however, are not fully compatible. The IDB (2008) study, for example, "assumed a 30 percent price increase in corn, rice, wheat, 
Table VII.9

POVERTY AND INCOME DISTRIBUTION RESULTS (Percentage variations)

\begin{tabular}{|c|c|c|c|c|c|c|}
\hline \multirow{2}{*}{\multicolumn{2}{|c|}{ Household Income class }} & \multirow[b]{2}{*}{$\begin{array}{c}\text { Average } \\
\text { real } \\
\text { income }\end{array}$} & \multicolumn{3}{|c|}{$\begin{array}{l}\text { Proportion of poor households } \\
\text { (headcount ratio) }\end{array}$} & \multirow[b]{2}{*}{$\begin{array}{l}\text { Average } \\
\text { poverty gap } \\
\text { (FGT1) }\end{array}$} \\
\hline & & & Total & Food & Non-food & \\
\hline 1 & POF[1] & 25.24 & -5.04 & -6.72 & -2.99 & -7.53 \\
\hline 2 & POF[2] & 3.02 & -5.19 & -15.76 & 6.29 & 4.25 \\
\hline 3 & POF[3] & -0.13 & 10.36 & -24.59 & 56.55 & 57.20 \\
\hline 4 & POF[4] & -1.26 & 79.61 & 16.14 & 172.67 & 333.61 \\
\hline 5 & POF[5] & -2.72 & 215.60 & 67.51 & 329.08 & 847.44 \\
\hline 6 & POF[6] & -3.44 & 1803.24 & 664.65 & 2312.16 & 10225.16 \\
\hline 7 & POF[7] & -2.81 & 6137.25 & 2781.69 & 7169.37 & 1004359.38 \\
\hline 8 & POF[8] & -1.60 & 0.00 & 0.00 & 0.00 & 0.00 \\
\hline 9 & POF[9] & -1.36 & 0.00 & 0.00 & 0.00 & 0.00 \\
\hline 10 & POF[10] & -0.40 & 0.00 & 0.00 & 0.00 & 0.00 \\
\hline \multicolumn{2}{|c|}{ Original values (base year) } & - & 0.28 & & & 0.123 \\
\hline \multicolumn{2}{|c|}{ Percentage change } & - & 1.04 & -10.97 & 14.60 & 3.66 \\
\hline \multicolumn{2}{|c|}{ GINI } & 0.50 & -1.43 & 2.73 & & \\
\hline
\end{tabular}

Source: Prepared by the author on the basis of model results.

FGTO: Foster-Greer-Torbecke proportion of poor households index, or headcount ratio. FGT1: poverty gap.

soybean, sugar and beef. They also assumed that international price increases will be fully passed on to consumers, as well as that consumers would not change their consumption habits and that food production will not increase in response to the price signals. It calculated the net impact of the crisis, which is the difference between sectors that gain and lose with rising prices" (IDB, 2008). Apparently, another very important aspect of the problem is not being taken into account in that study, namely the increase in income for workers in the food-production sector. As can be seen in Table VII.9, the simulation generates strong increases in the average real income of the poorest households (POF1 and POF2) (25.24\% and $3.02 \%$, respectively).

As seen previously, the poorest households have their income mainly composed of the lowest wages, and agriculture is responsible for a large share of that wage bill. As a consequence, the headcount ratio falls by $5.04 \%$ and $5.19 \%$ in the two poorest household groups, and increases in the other groups. ${ }^{21}$ The same pattern appears with the

${ }^{21}$ Note that the very high numbers in FGT0 and FGT1 are large variations over very small base values, see Table VII.9. 
average poverty gap variation (FGT1), which is reduced in the lowest household income group, and increases in the rest. The aggregated net effect is an increase in the number of the poor that amounts to 165,028 households (767,523 people).

Notice that food and non-food price shocks have very different effects on poverty and inequality. The food price shock reduces the GINI index, while the non-food price shock increases it. This happens due to the strong increase in the highest wages in the non-food price shock scenario, which are concentrated in some activities directly affected by the shocks. Besides that, the highest wage groups are, under this hypothesis, in fixed supply, which causes the labour market for these workers to adjust only through wages variations.

While the food price shock strongly reduces poverty in the lowest three household income groups, the non-food price shocks only reduces poverty in the first household income group, thereby pushing up the number of poor households in Brazil. Actually, model results show that the food price increase would reduce the number of poor households in Brazil by $10.97 \%(6,503,981$ people), while the non-food price shock would increase it by $14.6 \%(8,601,544$ people). This latter result offsets the first one, giving a positive increase $(1.04 \%$, or 767,523 persons) in poverty, in aggregate terms. These results point again to the importance of the effect of food price rises in Brazil being intensified by an increase in income.

And, finally, figure VII.1 shows the results on poverty and income inequality on regions inside Brazil.

As shown in table VII.9, the results are not in the same direction across all states in the country. Poverty increases more markedly in some states in the Southeast and South regions, as is the case of São Paulo and Santa Catarina. These are the relatively more industrialized regions in Brazil. It increases also in Amazon state, which has a small share of total agriculture and food industry within its GRP, and also has a free importing zone for electronic products.

Poverty falls in most of the poorest states in Brazil, those in the Northeast regions. This raises an interesting issue for policy consideration. The main poverty alleviation programme in Brazil, the Bolsa Familia programme, which is a direct transfer programme from the Federal Government, and which is deemed responsible for a large share of the recent observed fall in the poverty indicators in the country (see, for example, Hoffmann 2006), is mostly concentrated in the Northeast region. However, as model results show, this region would benefit more from the world commodity price increases, due to the higher share of agriculture and food industry in its GRP. The regions most negatively 
affected are those that will benefit less, in relative terms, from the income effect generated by the expanding industries, which, in the model, are mainly those which faced external price increases.

Figure VII.1

REGIONAL POVERTY RESULTS, BY TYPE OF SHOCK (FOOD AND NON-FOOD)

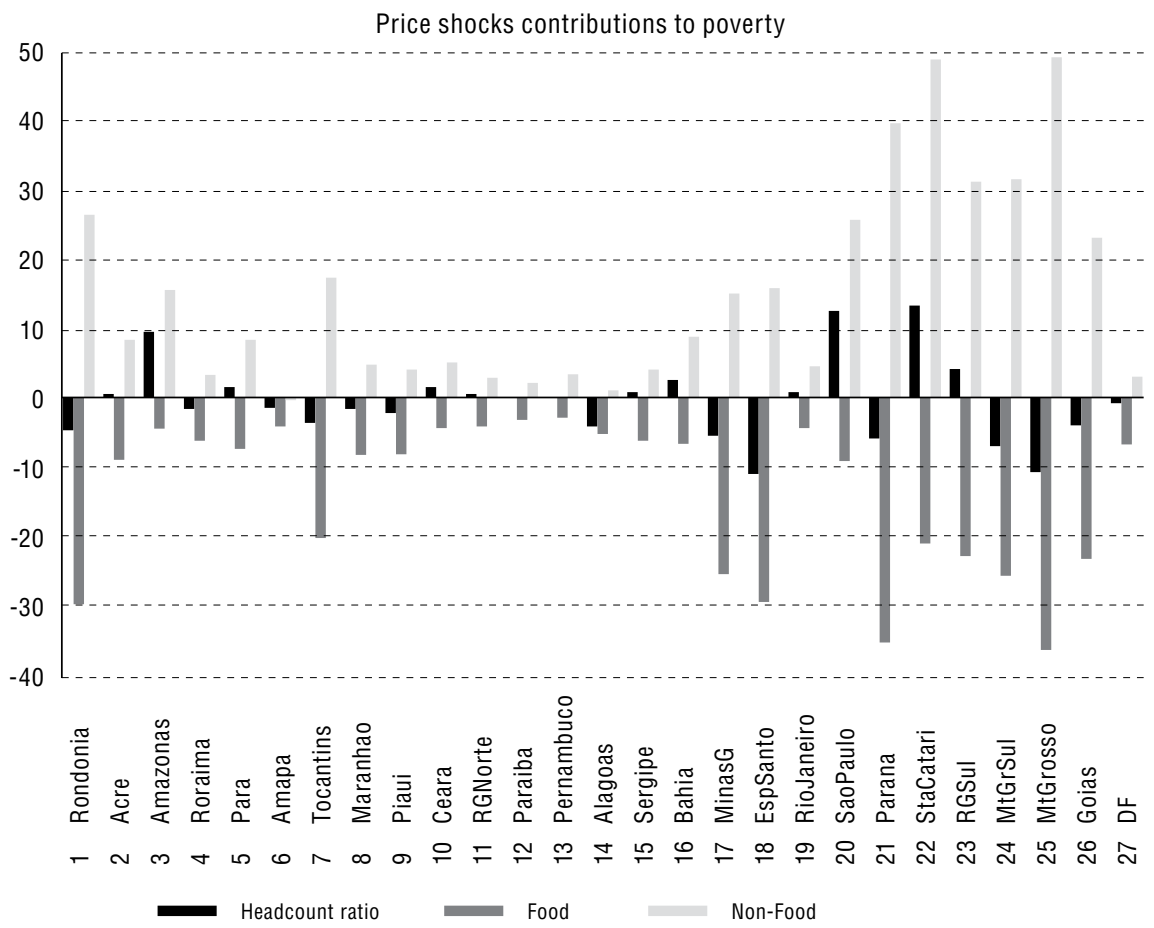

Source: Prepared by the author on the basis of model results.

\section{G. Concluding remarks}

It is possible to infer, then, that the increase in world commodity prices is having a positive effect on the Brazilian economy, when considered in aggregated terms. The country will benefit from the price increases, since it is a net commodity exporter. This will generate an expansion in income, increasing GDP. However, the net effect on poverty is found to be negative in aggregate. This, of course, entails a worsening in income distribution, tending to eliminate part of last year's gains. 
It is also important to notice that model results point to an increase in poverty in regions where the economic activity is more concentrated in manufacturing, which are generally speaking the most urbanized regions. Even though the model does not distinguish between rural and urban households, it is possible to conclude that the poor living in urban areas would be more (negatively) affected by the world price shock increase than those living in rural areas. As these urban households are unable, in relative terms, to benefit from the expansion in agriculture and agriculture related industries, they will have to face the negative expenditure effect, which will cause a strong fall in real wages, and will restrict their consumption.

This is an important effect of the price shocks, and constitutes a change in poverty trends in Brazil. It also suggests that more attention will have to be paid to the allocation of the Bolsa Familia transfer programme if commodity prices continue to rise. 


\section{Bibliography}

Ferreira Filho, J.B.S and J.M. Horridge (2010), "Would world agricultural trade liberalization help the poor of Brazil?", Agricultural Price Distortions, Inequality and Poverty, K. Anderson, J. Cockburn and W. Martin (eds), Washigton, D.C., World Bank.

(2006), "The Doha Round, poverty and regional inequality in Brazil", Putting Development Back into de Doha Agenda: Poverty Impacts of a WTO Agreement, T.W. Hertel and A. Winters (eds.), Washington, D.C., The International Bank for Reconstruction and Development (IBRD)/Palgrave, McMillan.

Ferreira Filho, J.B.S., C.V. Santos, S.M.P. Lima (2007), "Trade reform, income distribution and poverty in Brazil: an applied general equilibrium analysis", MPIA Working Paper, No. 2007-26, Poverty and Economic Policy Network.

FAO (Food and Agriculture Organization) (2008a), "Situación alimentaria en América Latina y el Caribe", Observatorio del hambre, May/June. (2008b), Soaring food prices: facts, perspectives, impacts and acts required. High Level Conference on World Food Security: the challenges of climate change and bioenergy (HLC/08/INF/1), Rome, 3-5 June.

Foster, J., J. Greer and E. Thorbecke (1984), "A class of decomposable poverty measures", Econometrica vol. 52.

Hoffmann, R. (2006), "Transferência de renda e redução de desigualdade no Brasil e cinco regiões", Econômica, vol. 8, No. 1, Rio de Janeiro.

Horridge, J., J. Madden and G. Wittwer (2005), “The impact of the 2002-2003 drought on Australia", Journal of Policy Modeling, vol. 27, No. 3.

IBGE (Brazilian Geographical and Statistical Institute) (2004a), Pesquisa Nacional por Amostragem de Domicílios (PNAD).

(2004b), "Pesquisa de orçamentos familiares 2002-2003" [online] http:// www.ibge.gov.br/home/estatistica/populacao/condicaodevida/pof/2002/ pof200220032aed.pdf .

IDB (Inter-American Development Bank) (2008), “Countries need to spend more to prevent food crisis from deepening poverty" [online] http://www.iadb.org/ NEWS/articledetail.cfm?language $=E N \&$ parid $=4 \&$ arttype $=$ WS\&artID $=4718$.

Lustig, N. (2008), "Thought for food: the challenges of coping with soaring food prices", Working Paper, No. 155, Center for Global Development, November [online] http://www.cgdev.org/content/publications/detail/967250 .

Rocha, S. (2006), "Pobreza e indigência no Brasil: algumas evidências empíricas com base na PNAD 2004", Revista nova economia, vol. 16, No. 2. 



\title{
Chapter VIII \\ Climate change in Latin America: impacts and mitigation policy options
}

\author{
Denis Medvedev and Dominique van der Mensbrugghe ${ }^{1}$
}

\section{A. Introduction}

Climate change is likely to become a major social and economic challenge over the next century. Estimates of damage from climate change, though varying widely across studies, range up to $20 \%$ of global GDP, with the mode at around $1 \%$ to $2 \%$ of GDP. There is also the possibility of tipping points-leading to uncontrollable climate change-such as a sudden release of greenhouse gases (GHG) stored in permafrost, for example, or the collapse of Antarctic ice sheet. Beyond the aggregate effects, the impacts of climate change and policies to mitigate GHG emissions will vary widely across and within countries. Yet, most studies have not included much regional detail, and virtually all have focused on the distributional impacts across rather than within countries.

Economist in the Latin America and the Caribbean region (LCSPE) and Lead economist in the Development Prospects Group (DECPG) at the World Bank, respectively. Address: The World Bank, 1818 H Street, NW, Washington, D.C., 20433, e-mail: dmedvedev@worldbank.org. The authors would like to thank Hans Timmer for many helpful discussions and suggestions, as well as participants of seminars at the World Bank, INCAE Business School, Costa Rica, and the United Nations Economic Commission for Latin America and the Caribbean (ECLAC), Chile. The views and conclusions reported in this paper should not be attributed to the World Bank, its Executive Board or member countries. 
This paper aims to fill the existing knowledge gap by building a global general equilibrium model with a high level of country disaggregation for the Latin America and the Caribbean region and linking the results of this model with a comprehensive compilation of household surveys for the analysis of within-country distributional effects. The paper is organized around four forward-looking scenarios. The baseline runs from 2004 to 2100 and explicitly incorporates damage to agricultural productivity from rising global temperatures. The "nodamage" scenario isolates the adverse impacts of climate change, while two mitigation scenarios explore the costs and benefits of limiting the atmospheric concentration of GHG to below 650 parts per million (ppm). The first mitigation scenario implements an optimal reduction strategy by imposing a globally uniform carbon tax, while the second illustrates the inefficiencies of targeting the same $650 \mathrm{ppm}$ threshold through country-specific taxes.

The paper is structured as follows. Section B provides a brief summary of the methodological approach with a non-technical summary of the macro (general equilibrium) and micro (household survey) models. Section $C$ introduces the four scenarios and describes their macroeconomic impacts. Section D focuses on the distributional impacts of the same scenarios. Lastly, section E offers concluding remarks.

\section{B. Methodology}

\section{a. ENVISAGE: a global computable general equilibrium (CGE) model}

The simulations in the paper are produced with the World Bank's Environmental Impacts and Sustainability Applied General Equilibrium model (ENVISAGE). The detailed description is available in van der Mensbrugghe (2008), while the following paragraphs summarize its most relevant features. The ENVISAGE model is a global, (recursive) dynamic computable general equilibrium (CGE) model, with a 2004 base year. Its standard time frame moves the global economy forward to 2050. While ENVISAGE is a relatively standard CGE model, with a specific focus on the energy side of the global economy, it also contains a simple climate module that makes it suitable for integrated assessment analysis.

Production in ENVISAGE is modelled with a series of nested constant elasticity of substitution (CES) functions that allow for different degrees of substitutability across inputs, which include intermediate inputs, energy, skilled and unskilled labour, different capital vintages, land, and natural 
resources (figure VIII.1). The latter are sector-specific, while land has limited transformation across agricultural uses. New capital vintages and skilled labour are freely mobile across sectors, while the mobility of old vintages is limited. Unskilled workers are freely mobile within farm and non-farm activities, but the movement from farm to non-farm employment is limited with a Harris-Todaro migration function.

The energy bundle is disaggregated into different energy sources using a CES nest, with the top-level bundle composed of electric and non-electric bundles. The electric bundle is further decomposed into electricity produced by coal, gas and oil, nuclear, hydro, and renewable sources. For the first two activities-coal and gas/oil-the model allows for electricity generation using both conventional technologies and more advanced carbon capture and storage (CCS) techniques,

Figure VIII.1

PRODUCTION STRUCTURE NESTING

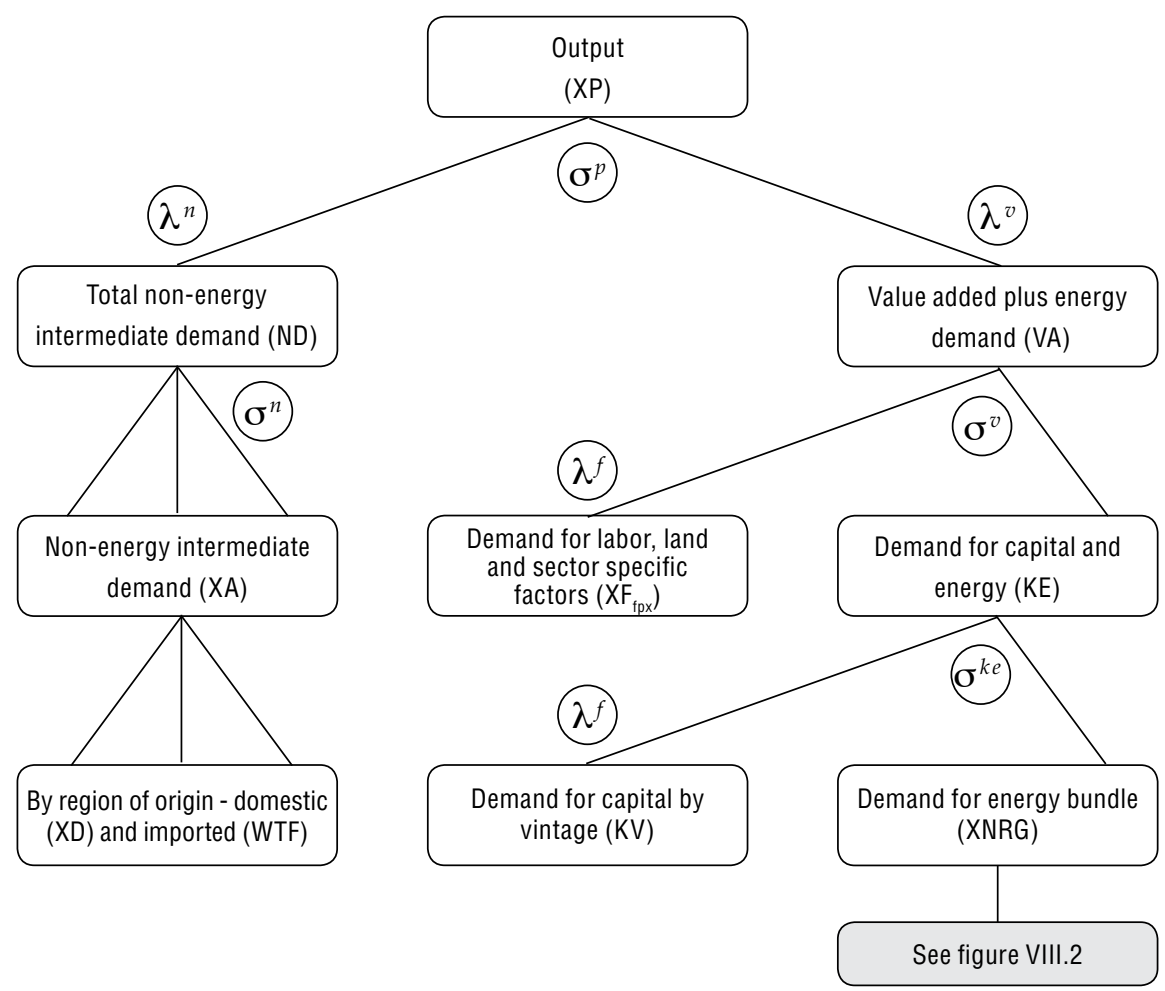

Source: Prepared by the authors on the basis of ENVISAGE CGE model. 
which are more expensive owing to larger capital requirements but also produce just $10 \%$ of emissions generated by conventional technologies. The penetration of these advanced technologies-together with the penetration of electricity generated by renewable sources-starts out at a very low level (between $0.1 \%$ and $1 \%$ of total volume of electricity produced) but gradually increases over time. The penetration of hydrobased electricity is limited to the economically exploitable hydro capacity by country, based on estimates from World Energy Council (2007). The non-electric bundle is decomposed into coal and an oil/gas bundle, with this final bundle decomposed into gas and oil demand (figure VIII.2). The model allows for biofuels to compete with gasoline and diesel, with first- and second-generation biofuels initially calibrated to a $50 \%$ and $400 \%$ markup over gasoline, respectively.

Figure VIII.2

ENERGY NESTING

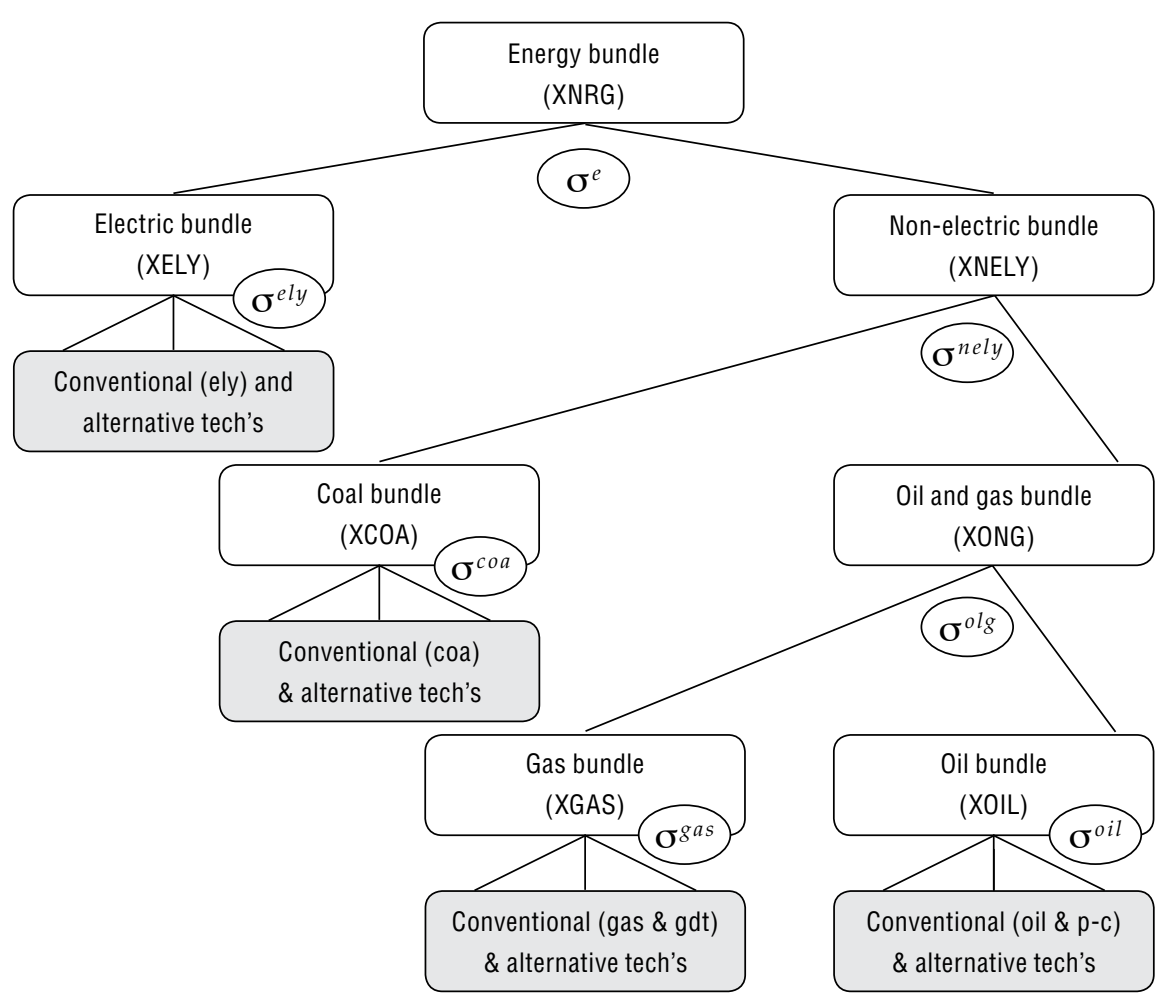

Source: Prepared by the authors on the basis of ENVISAGE CGE model. 
Consumer demand is modelled with a nesting of Cobb-Douglas and constant-differences-in-elasticity (CDE) utility functions (figure VIII. 3). International trade is specified with nested CES and constant elasticity of transformation (CET) functions which allow for limited substitution between domestically produced goods and imports or exports-frequently referred to as the Armington assumption (figure VIII. 4).

The model contains an integrated climate module which links energy-related emissions of $\mathrm{CO}_{2}$ and industrial emissions of methane, nitrous oxide, and fluorinated greenhouse gases (f-gases) to changes in global temperature with feedbacks to agricultural productivity, following the climate module of the model for estimating the regional and global effects of greenhouse gas reductions (MERGE) by Manne

Figure VIII.3

DOMESTIC DEMAND NESTING

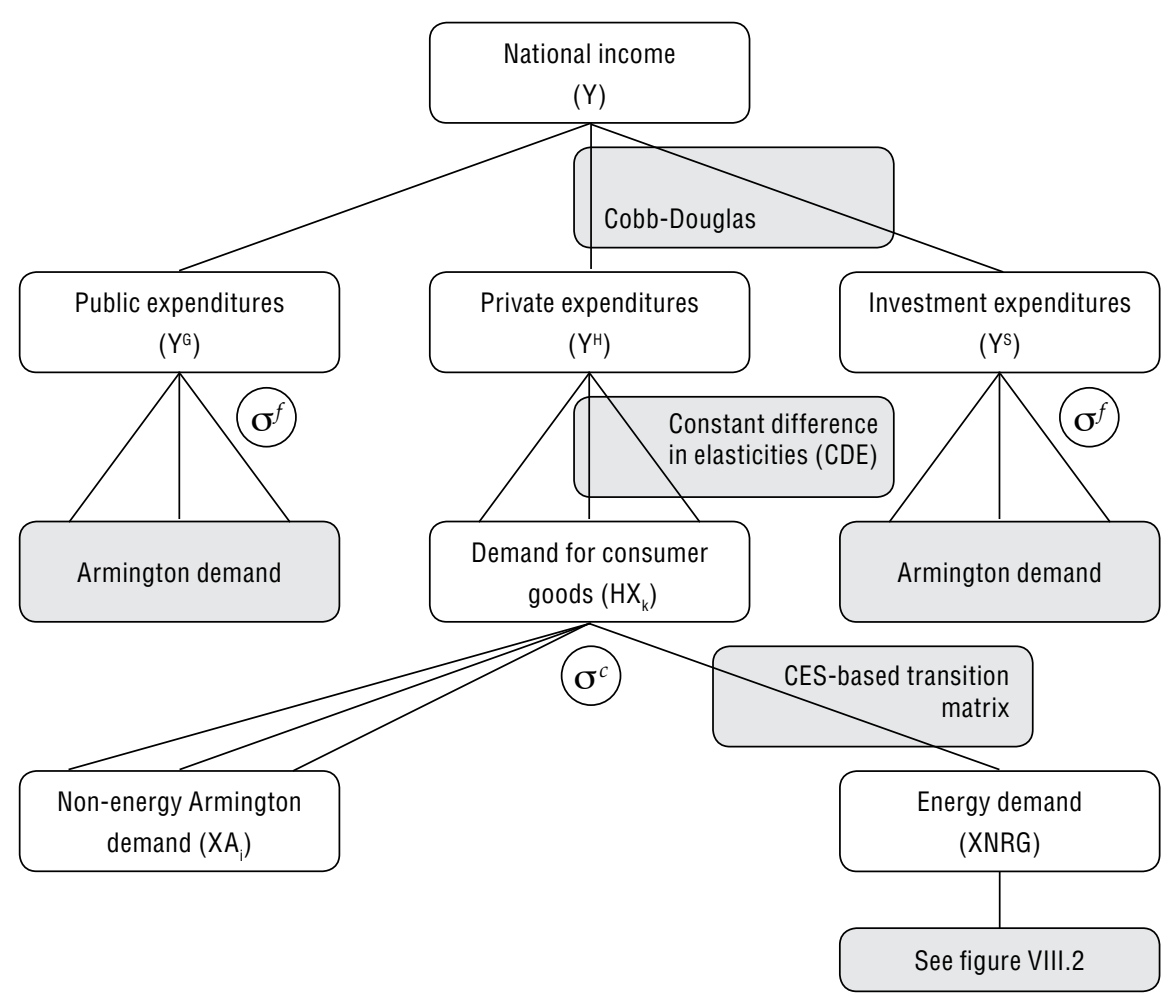

Source: Prepared by the authors on the basis of ENVISAGE CGE model. 
Figure VIII.4

OUTPUT, SUPPLY AND TRADE

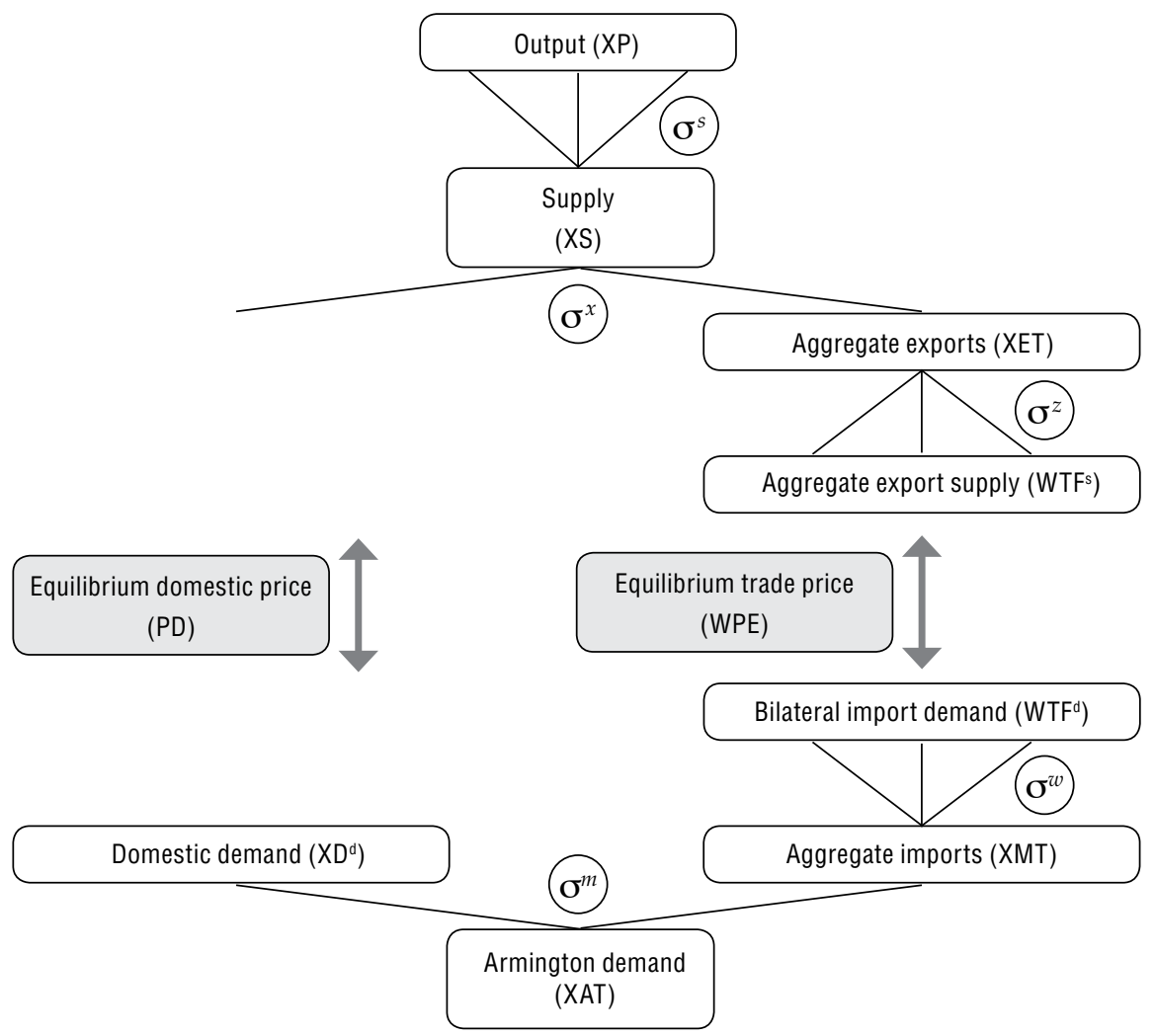

Source: Prepared by the authors on the basis of ENVISAGE CGE model.

and Richels (2004) and calibrated with the average of with- and withoutcarbon fertilization estimates in Cline (2007). Carbon (or $\mathrm{CO}_{2}$ ) emissions emanate from the consumption of fossil fuels in both production and final demand activities. ${ }^{2}$ These are emitted into the atmosphere. A transition matrix approach is used to allocate the stock and flows of carbon and other greenhouse gases across five atmospheric boxes with different rates of transition and decay. The key to climate change is the increase of atmospheric concentration of carbon (and other greenhouse gases). This leads to an increase in so-called radiative forcing whereby more of the sun's energy is absorbed in the atmosphere and leads to rising temperatures.

2 The emissions module adjusts for the transformation of fossil fuels in certain key sectors, for example petroleum refining. 
The model includes an explicit feedback between the change in atmospheric temperature and economic activity, using damage functions. The latter represent sector- and region-specific productivity shocks that are calibrated to estimates available in a limited but growing literature. Hence a rise in atmospheric temperature of $2.5^{\circ} \mathrm{C}$ (relative to 1900) might lead to a decline in agricultural productivity of anywhere between $0 \%$ and $50 \%$ depending on the crop and region. ${ }^{3}$ Some regions may benefit, at least initially, from global warming, such as those lying in the upper latitudes (e.g. Canada and Russia). ${ }^{4}$

The current version of the model is based on the Global Trade Analysis Project (GTAP) database with a 2004 base year, which has been aggregated to 26 country/regions and 22 sectors (table VIII.1) with particular attention to Latin America. The model is solved forward, in recursive fashion, until 2050, with labour force and population growth rates lined up to the medium variant population forecast of the United Nations. Total-factor productivity (TFP) growth in agriculture is set at $2.5 \%$ per annum with no differentiation across sectors or regions,

Table VIII.1

ENVISAGE DIMENSIONS

\begin{tabular}{lllll}
\hline Regions & & Sectors & \\
\cline { 1 - 2 } United States & MENA Energy exporters & & Paddy rice & Other mining \\
Canada & Rest of MENA & & Wheat & Processed food \\
Japan & Brazil & & Other cereal grains & Refined oil \\
Rest of high income & Mexico & Oil seeds & Chemicals, rubber, plastics \\
Western Europe & Colombia & Sugar cane and beet & Energy int. manufacturing \\
China & Peru & Other crops & Other manufacturing \\
Indonesia & Venezuela, R.B. & Livestock & Electricity \\
Rest of Dev. East Asia & Argentina & Forestry & Gas distribution \\
India & Chile & Coal & Construction \\
Rest of South Asia & Bolivia and Ecuador & Crude oil & Transport services \\
Russia & Paraguay \& Uruguay & Natural gas & Other services \\
Rest of ECA & Central America & & \\
Sub Saharan Africa & Caribbean & &
\end{tabular}

Source: Prepared by the authors on the basis of GTAP database.

Cline, 2007 has a comprehensive set of estimates for climate-change impacts on agriculture.

4 There are additional issues related to agricultural productivity and its link to climate change including water availability and the role of carbon fertilization. 
based on estimates in Martin and Mitra (1999). Labour-augmenting productivity growth in the other sectors is endogenized to achieve the World Bank's long-term forecasted growth of real GDP through 2015 and is held fixed at the 2015 level afterwards. The macro closure has government expenditures as a share of GDP fixed at 2004 levels, while a demographically-driven savings function determines the allocation of private expenditures between consumer demand and domestic investment. The manufactured export price index of the high-income countries is the numéraire. Lastly, it is assumed that energy efficiency, otherwise known as the autonomous energy efficiency improvement (AEEI) parameter, improves at an exogenous rate-currently set at $1 \%$ per annum in all regions and for all activities.

\section{b. Global Income Distribution Dynamics (GIDD): a global micro-simulation model}

The distributional analysis is carried out with the World Bank's Global Income Distribution Dynamics (GIDD) model, which applies the existing CGE-microsimulation methodologies-e.g. Bourguignon, Bussolo, and Pereira da Silva (2008), Chen and Ravallion (2003), and Bussolo, Lay, and van der Mensbrugghe (2006) - at the global level and is described in detail in Bussolo, De Hoyos, and Medvedev (2008). The GIDD data set consists of 73 detailed household surveys for low and middle-income countries. These are complemented with more aggregate data on income groups (usually vintiles) for 25 high-income and 22 developing countries. The final sample covers more than $90 \%$ of the world's population (see table VIII.1 below for country coverage). The majority of the surveys (54) use per capita consumption as the welfare indicator, while the remaining surveys -all but one for countries in Latin America- include only per capita income as a measure of household welfare. The data are standardized to around the year 2005 and are expressed in 2005 purchasing power parity (PPP) prices for consistency with the US $\$ 1.25$ and US $\$ 2.50$ a day poverty lines, which are calculated at 2005 PPP exchange rates. ${ }^{5}$

The counterfactual income distribution is obtained by capturing four major changes in the structure of the population and the economy of the aforementioned countries: (a) change in the age and skill composition of the population, (b) change in the allocation of workers across sectors in the economy, (c) change in returns to labour by skill and occupation, and (d) change in the relative prices of food and non-food items in each

See Chen and Ravallion (2008) for a discussion of the new poverty lines adopted by the World Bank. 
household's consumption basket. Although in reality these changes take place simultaneously, in the GIDD framework they are accommodated in a sequential fashion.

The conceptual framework of the GIDD is depicted in figure VIII. 5. The expected changes in population structure by age (upper left part of figure VIII. 5) are taken as exogenous from the population projections provided by the World Bank's Development Data Group. Therefore, we assume that fertility decisions and mortality rates are determined outside the model. The change in shares of the population by education groups incorporates the expected demographic changes (linking arrow from top left box to top right box in figure VIII. 5). Next, new sets of population shares by age and education subgroups are computed and household sampling weights are re-scaled according to the demographic and educational changes above (larger box in the middle of figure VIII. 5). The impact of changes in the demographic structure on labour supply (by skill level) is incorporated into the CGE model, which then provides a set of link variables for the microsimulation: overall economic growth, growth in relative incomes by skill and sector, relative price changes, and the movement of labour between agricultural and non-agricultural activities. The final distribution is obtained by applying the changes in these link variables to the re-weighted household survey (bottom link in figure VIII. 5). ${ }^{6}$

Figure VIII.5

GIDD METHODOLOGICAL FRAMEWORK

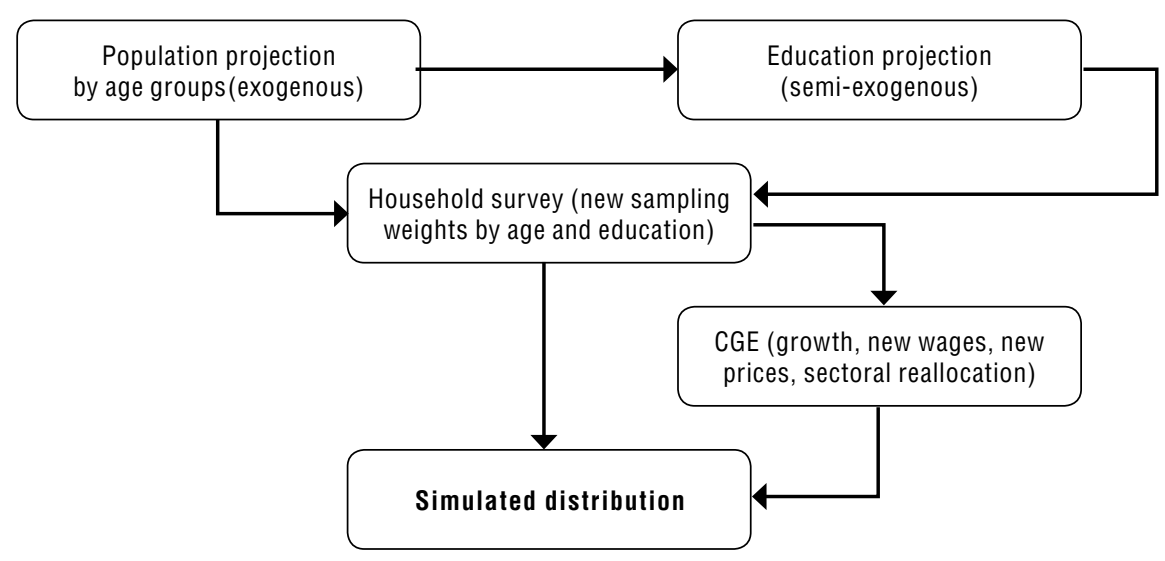

Source: Prepared by the authors on the basis of ENVISAGE CGE model.

6 See Annex B for a detailed description of the GIDD, including the mathematical statement. 
The sequential changes described above reshape the income distribution under a set of strong assumptions. In particular, income inequality within population subgroups formed by skills and sector of employment does not change as a result of economic shocks. Moreover, data limitations affect estimates of the initial inequality and its evolution. Although consumption expenditure is a more reliable welfare measure than income, and its distribution is normally more equal than the distribution of income, consumption data are not available for all countries' surveys. To obtain a global picture, this paper had to include countries for which only income data were available, as well as countries with consumption information. Lastly, measurement errors implicit in purchasing power parity exchange rates, which have been used to convert local currency units, also affect comparability across countries. The resulting hypothetical income distribution should thus not be seen as a forecast of what the future distribution might look like; instead it should be interpreted as the result of an exercise that captures the ceteris paribus distributional consequences of climate change.

\section{Macro results}

\section{Baseline: Business-as-usual (BaU) with climate-change damage}

In the baseline scenario, global emissions rise from 7 gigatons of carbon ( $\mathrm{gtC}$ ) in 2004-10 gt of carbon equivalent once other GHG are considered-to $25 \mathrm{gtC}$ in 2050 and $62 \mathrm{gtC}$ in 2100 (68 gt of carbon equivalent). Under this rapid rate of emissions growth, the atmospheric concentration of carbon increases from $382 \mathrm{ppm}$ to $1218 \mathrm{ppm}$ in 2100, well above the commonly mentioned thresholds of 450/550 ppm (figure VIII.6). Of course the true objective is the overall rise in temperature which increases by $5.0{ }^{\circ} \mathrm{C}$ relative to 2000 levels, driven by rapid increases in radiative forcing.

The main drivers of the emissions path are the carbon intensities of existing technologies, population, and economic growth, all of which vary by region and country. The behaviour of these variables is summarized in table VIII.2, which shows that in 2005, the per capita emissions in Latin America were significantly below not only the per capita emissions of high-income countries, but also the per capita emissions of other regions at approximately the same level of development (e.g. Middle East and Eastern Europe). Although population growth in Latin America and the Caribbean is expected to be on a par with population growth in all developing countries, the low initial carbon intensity of the region 
Figure VIII.6

ATMOSPHERIC CONCENTRATION OF CARBON, RADIATIVE FORCING, AND TEMPERATURE IN BASELINE

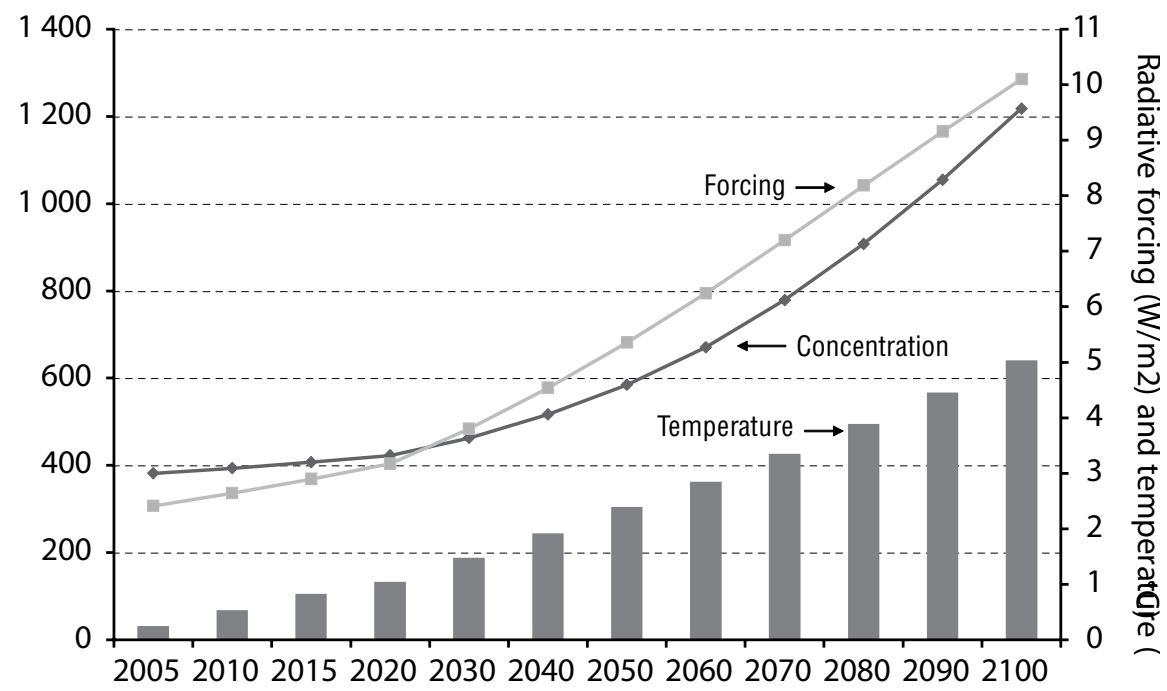

Source: Prepared by the authors.

combined with the less rapid income growth relative to other developing countries means that Latin America is likely to become even less carbonintensive vis-à-vis the world average over time. By 2050, Latin America's carbon emissions per capita are only half of the world average, although the difference shrinks to two-thirds by 2100 as hydro capacity in many countries reaches its maximum and fossil fuels are used to satisfy growing energy demand.

The aggregate development conceals a wide amount of variation within the region. For example, in the first half of the century the per capita emissions in Brazil grow at a slower rate than the per capita emissions of the Bolivarian Republic of Venezuela-despite the similar grow th rates in GDP per capita-owing to the former's heavier reliance on cleaner technologies. Similarly, per capita emissions in Bolivia and Ecuador grow faster than in Central America, despite the similarities in income growth. In the second half of the century, the differences in emissions growth become less pronounced as hydro power generation reaches its capacity, the rate of penetration of cleaner technologies- 


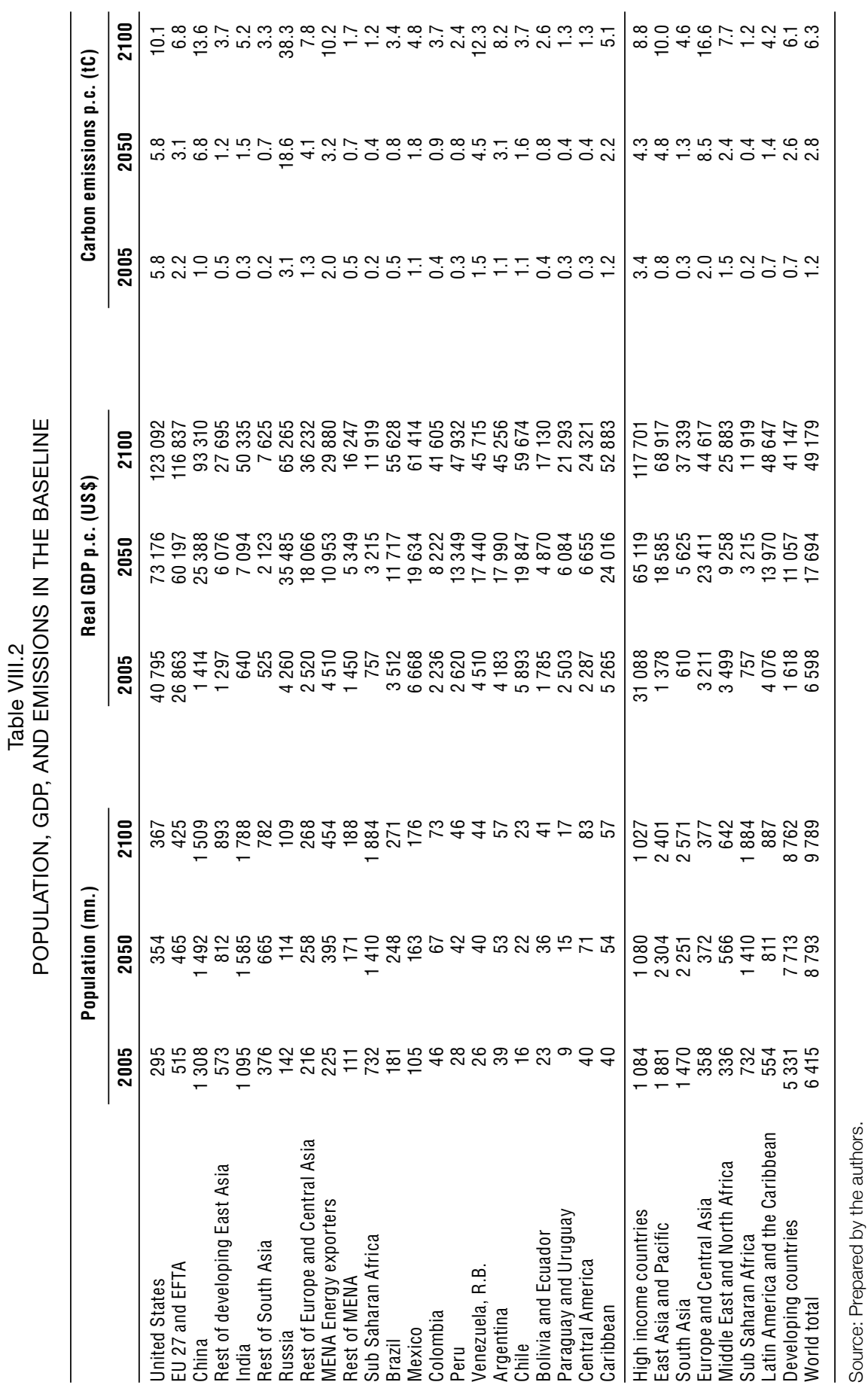


renewables, CCS, and biofuels-slows, and no new technologies become available, all of which lead to greater reliance on fossil fuels at the margin.

The shifting composition of energy demand in Latin America relative to the developing country average is shown in figure VIII.7. While total energy demand grows by approximately $2.6 \%$ per year-0.6 percentage points slower than growth in real GDP reflecting improvements in energy efficiency-the composition of energy demand shifts away from more polluting coal and oil and into cleaner natural gas and biofuels. For the region as a whole, the share of coal in fossiland biofuel-based energy demand declines from 5\% in 2004 to $4 \%$ in 2100 , while the share of oil falls from $58 \%$ to $42 \%$ while gas increases from $35 \%$ to $38 \%$. The major difference-maker is biofuels, the share of which increases from $2 \%$ in 2004 to $16 \%$ in 2100 . These trends are quite different from the average for the developing world, where the rate of penetration of biofuels is half as fast and the reliance on coal increases from $34 \%$ to $47 \%$.

Figure VIII.7

COMPOSITION OF ENERGY DEMAND

(Millions of tons of oil equivalent)

Latin America

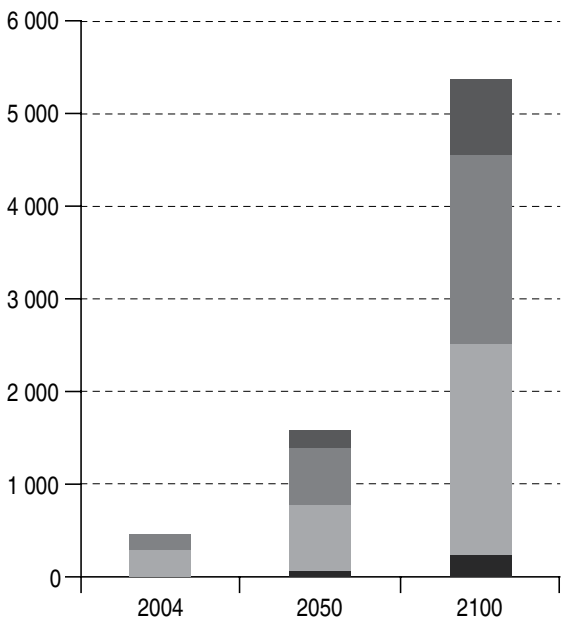

Biofuels Gas
All developing countries

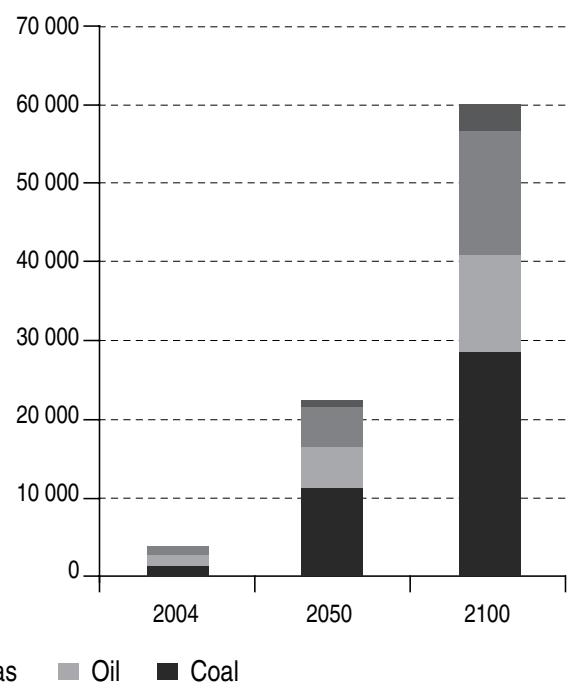


Latin America currently contributes just $5.4 \%$ of the total amount of fossil-fuel generated carbon released annually into the atmosphere. In the baseline scenario, this ratio would fall to $4.6 \%$ by 2050 before climbing back to the 2004 value by 2085 and reaching $6.1 \%$ of global emissions by 2100. However, over the same time period the weight of Latin America and Caribbean in global GDP would rise from $5.3 \%$ to $8.3 \%$, which means that in aggregate as well as per capita terms, the region remains cleaner than the world average.

\section{Baseline with no damage from climate change}

In order to quantify the impact of climate-change damage on output, income, prices and trade, the scenario in this section sets the damage coefficient to zero. This allows us to attribute the differences across the baseline and this scenario exclusively to climate change. Table VIII.3 shows that the real income losses for Latin America are likely to be substantial, rising from $1 \%$ of baseline income in 2030 all the way to $5.2 \%$ of baseline income in 2100 . In proportional terms, these losses are larger than the region's contribution to the global change in temperature: while the region contributes just 5\% to the world's total emissions of carbon between 2004 and 2100, its share of global damage ranges from $8.9 \%$ in 2100 to $12.4 \%$ in 2030 . The disparity between damage and contribution to emissions decreases over time because the region's emissions growth accelerates in the second half of the century at the same time as damage becomes really extensive in the hardest-hit region of South Asia.

In comparison with other developing regions, climate-change damage in Latin America is somewhat below the average. However, damage in the region is on a par with East Asia, which is responsible for $40 \%$ of global emissions between 2004 and 2100, and twice the damage in Eastern Europe, which is responsible for $11 \%$ of global emissions over the same period. High-income countries, despite being responsible for $50 \%$ of the total amount of carbon released into the atmosphere in 2004 and as much as $15 \%$ in 2100 , may actually gain slightly from the warmer temperatures. While the specific damage figures are estimated with some uncertainty and therefore should not be taken as the impacts of climate change, the orders and ranking of magnitude suggest that the climatechange vulnerability of Latin America is high, especially relative to its contribution to global emissions.

Although the main reason for the disproportionate impact of climate change on Latin America rests outside the model-namely, the climate-change sensitivity parameters from Cline (2007)—another 


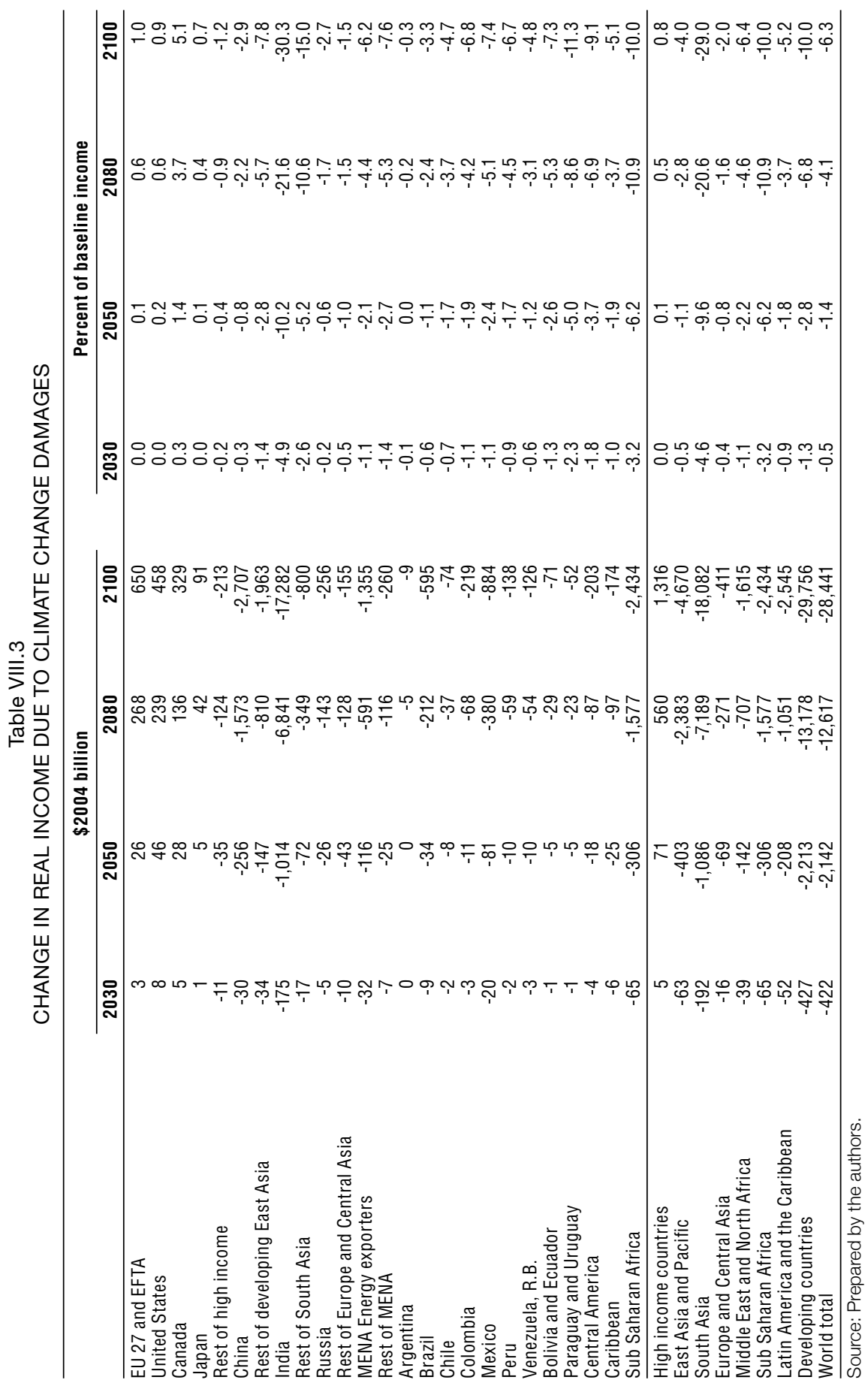


contributing factor is the substantial share of agriculture in total output, which makes the marginal impact of productivity losses larger in aggregate terms. In 2004, Latin America accounted for 19\% of agricultural output in developing countries; this share rises to $23 \%$ by 2050 and $32 \%$ by 2100 . At the same time, the region's share in the population of the developing world would remain roughly stable at just above $10 \%$. While this increased specialization in agriculture magnifies the region's sensitivity to climate-related losses in agricultural productivity, it also makes Latin America less dependent on food imports in an environment of slower growth in global agricultural output. ${ }^{7}$

As agricultural production declines owing to climate-change damage to agricultural TFP while demand for agriculture and food remains relatively stable, agricultural producer prices increase by an average of $6.1 \%$ by 2050 and another $6.5 \%$ by 2100 . The rising prices and reduced domestic food output lead to an increase in the import bill for the majority of countries (table VIII.4). By 2050, rising prices - as opposed to increasing volumes of global trade- are responsible for more than two-thirds of the total increase, and by 2100 the higher prices account for nearly all of change in the import bill. Even though Latin America maintains a comparative advantage in agriculture and therefore experiences terms of trade gains from higher agricultural prices, climate-change damage still results in a loss in net exports of nearly $2 \%$ of GDP in 2100 .

At the country level, the impact of climate-change damage on real income and trade flows varies substantially. On the welfare side, the damage ranges from almost no change in Argentina to $9 \%$ of baseline income in Central America and more than $11 \%$ of baseline income in Paraguay and Uruguay. These large differences are mostly due to the variation in estimated impacts by Cline (2007); the variation is exacerbated because this paper takes the average of impacts that include and exclude the gains from carbon fertilization. In addition to the damage estimates, the impact also varies by the importance of agriculture in GDP; vulnerability is greater when the contribution of agriculture to total output and export earnings is larger. This explains why the Bolivarian Republic of Venezuela, Bolivia and Ecuador, and Paraguay and Uruguay experience progressively larger real income losses despite nearly identical agricultural damage coefficients. 


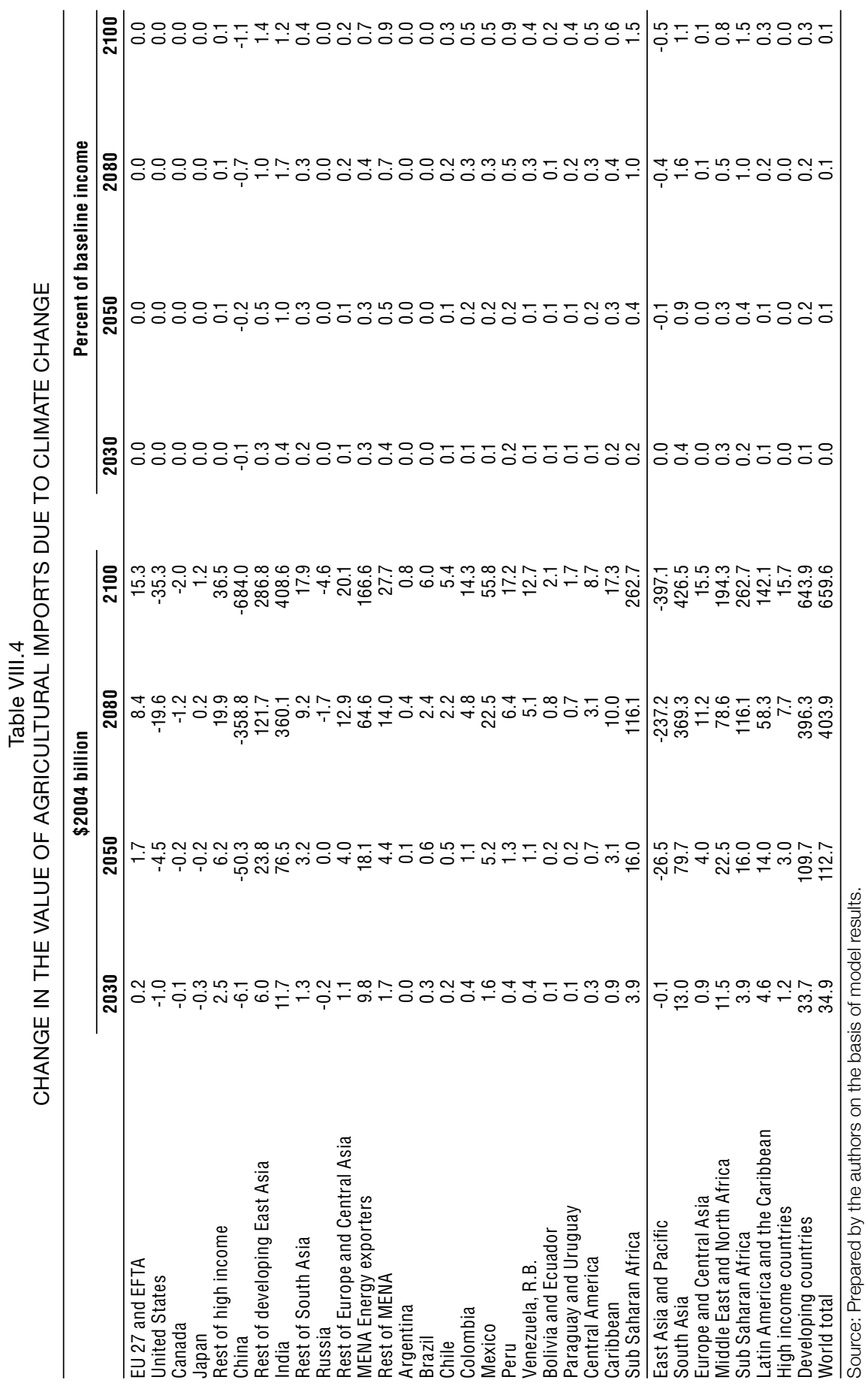




\section{Mitigation policies: country-specific and global uniform carbon taxes}

In order to mitigate the large negative impacts of climate change, a number of proposals have suggested taxing carbon emissions. The scenarios in this section assess the potential impacts of two different mitigation strategies: imposing a country-specific carbon tax, where each country reduces its emissions by the same percentage to achieve a given global reduction, and a global uniform tax, where emissions are reduced more in countries where the cost of doing so is the lowest. Therefore, the first case may be thought of as an "inefficient" solution, while the second is the "efficient" mitigation strategy. ${ }^{8}$ In both cases, the target is to stabilize the atmospheric concentration of GHG below $650 \mathrm{ppm}$, or, equivalently, to constrain the atmospheric content of carbon below 550 ppm. ${ }^{9}$

The reductions in carbon emissions required to achieve this target-which is at the upper range of commonly discussed thresholdsalong with the carbon tax necessary to reach these reductions are shown in figure VIII.8. While there are multiple ways of reaching the stabilization threshold-e.g. front- or back-loading the reductions, minimizing the net present value of damage or the distortions to the economy, etc.- the approach in this paper is to begin reductions in 2012 with a minimal global tax of less than US $\$ 1$ per ton of carbon, gradually accelerate the emissions reductions through 2030, and impose a constant rate of emissions reductions thereafter. ${ }^{10}$ This means that by 2015 , global emissions are reduced by just $5 \%$ relative to baseline; however, by 2050 emissions decline by more than $60 \%$ and by 2100 , emissions fall by $92 \%$ below baseline levels (figure VIII. 8). In aggregate terms, global emissions peak in 2030 at $12 \mathrm{gtC}$; by 2075, emissions fall below their 2004 level of $7 \mathrm{gtC}$ and continue to decline to less than $5 \mathrm{gtC}$ in 2100.

Under this emissions profile, the radioactive forcing is nearly halved from its baseline level in 2100 and the increase in temperature is limited to $3.4{ }^{\circ} \mathrm{C}$-still a highly worrisome increase but more than $1.5^{\circ} \mathrm{C}$ below the baseline spike in temperature. The limited increase in temperature mitigates some of the impact of climate-related damage but does not eliminate them; combined with the adverse effects of the carbon tax on real income growth, incomes in the mitigation scenario are

8 The efficiency refers to minimizing the dead-weight losses of the taxes. This will be explored in more detail in the later parts of the section.

9 This is the upper threshold considered in the climate-change scenarios of the Energy Modelling Forum (EMF).

10 The starting date for emissions reductions is again consistent with the EMF scenario assumptions. 
Figure VIII.8

REDUCTION IN GLOBAL EMISSIONS AND CARBON TAXES IN THE EFFICIENT MITIGATION SCENARIO

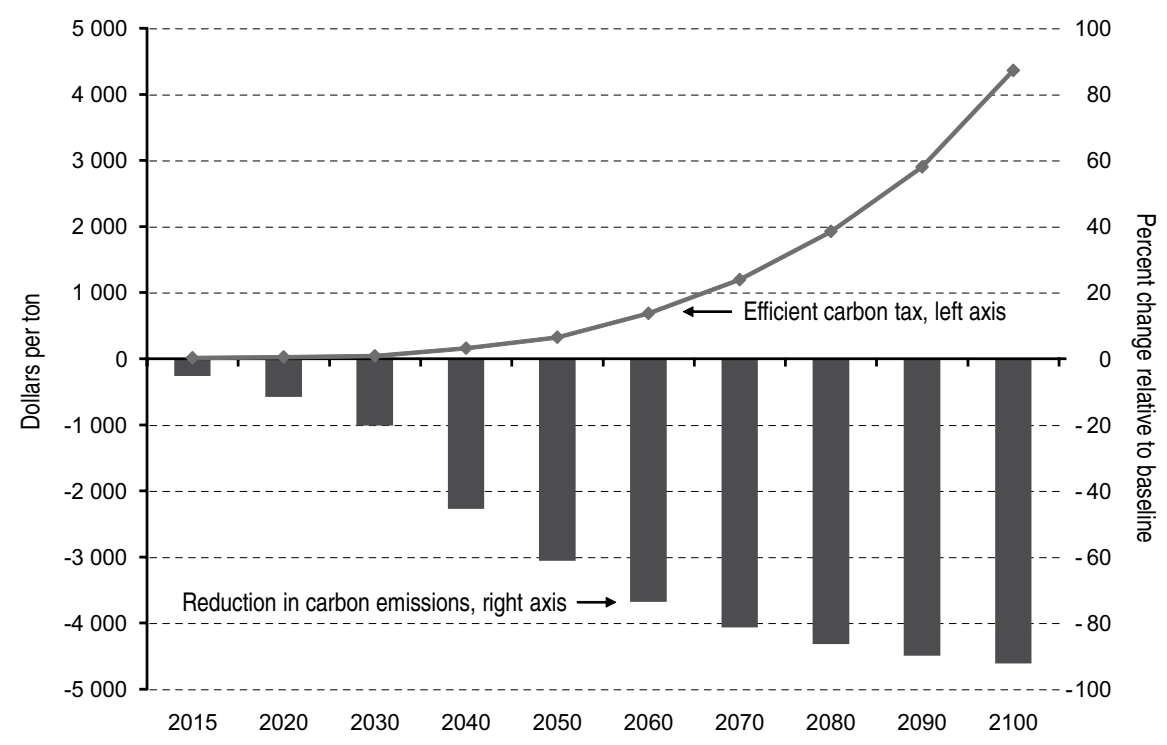

Source: Prepared by the authors.

lower than in the baseline. This does not mean, however, that the costs of mitigation are greater than its benefits because, even though the baseline does not consider the likelihood of catastrophic climate events, their likelihood rises dramatically with the kinds of temperature increases generated in the baseline.

The low carbon intensity of Latin America means that if mitigation is done at the country level, the carbon taxes paid by Latin American consumers would be significantly above the global average. In a very simple partial equilibrium framework, the carbon tax can be summarized by the following formula ${ }^{11}$ :

$$
\pi^{c}=\frac{P N R G}{\rho}\left[(1-R)^{-1 / \sigma}-1\right]
$$

11 See Burniaux, Nicoletti and Oliveira-Martins, 1992. 
In formula (1), $\tau^{\mathrm{c}}$ is the carbon tax, PNRG is the price of energy (for example US\$ per ton of oil equivalent (TOE)), $\rho$ is the average carbon content of energy (for example ton of carbon per ton of oil equivalent), $\sigma$ is the overall elasticity of substitution across factors of production, including energy and $R$ is the level of emissions reduction. Obviously for $R$ equal to 0 , the tax is zero, and the tax approaches infinity as the level of reduction approaches $100 \%$, i.e. equal to 1 . Let us start with an example, where the price is US\$ 50 (per TOE), the average carbon content is $50 \%$, the substitution elasticity is 0.8 and the level of effort is a $50 \%$ reduction. The implied price of carbon is then around US\$ 140 per ton. The formula is highly sensitive with these values. The price of carbon is US\$ 90 for a $40 \%$ reduction in emissions and is US\$ 215 for a $60 \%$ reduction.

The formula summarizes the impacts across regions with three key variables. First, the higher the price of energy, the higher the price of carbon for the same level of reduction. For example, if energy costs on average of US\$100/TOE in countries of the Organisation for Economic Co-operation and Development (OECD), but US\$ 50 in the nonOECD countries, the carbon tax will have to be higher in the former to achieve the same level of reduction. (A tax of US\$ 25/tC has a smaller percentage impact on US\$ 100 than on US\$ 50 assuming the carbon content is the same per unit of energy). At the moment, the lowest prices are in places like China and India, and many of the oil exporters. The second key factor is the carbon content of energy, i.e. $\rho$. The greater the carbon content of energy, the lower the cost. This makes countries like China and India relatively low cost countries as they have a relatively high carbon content of energy. Finally, the third factor is the degree of substitutability in the economy, o. The greater the degree of flexibility, the lower the carbon tax. Again, using the same basic parameters as above, a reduction of the substitution elasticity from 0.8 to 0.6 raises the carbon tax to US\$218. A value of 1 would lower the tax to US\$ 100. Here, substitutability is summarized with a single parameter; in practice, it will reflect a more complex production structure that embodies not only energy's degree of substitution with labour and capital, but also the inter-fuel substitutability. Since the model has vintage capital, the degree of substitution also changes over time. In practice, countries with the overall higher level of savings and investment will tend to have a higher share of 'flexible' capital and this will tend to lower the carbon tax. China again stands out given its currently very high level of investment.

Latin America falls in the middle of the pack in terms of average energy price and degree of substitutability, but has low carbon content relative to other regions. This means that on average, the region would face a higher carbon tax than other parts of the world. For example, in the inefficient country-specific mitigation scenario, the average carbon 
price in Latin America in 2050 is more than three times the average for all developing countries and nearly twice the average for the world (table VIII.5). ${ }^{12}$ There is also a large degree of variation in carbon prices within the region; for example, the 2050 carbon tax ranges from US\$ 400 in Argentina to US\$2,480 in Paraguay and Uruguay. However, even the lowest tax in Latin America is substantially above the price of carbon in China, South Asia, Eastern Europe, or Sub-Saharan Africa.

Another way to illustrate the inefficiency of the country-specific approach in Latin America is to compare the carbon price in this scenario with the globally uniform efficient carbon price. Table VIII.5 shows that for Latin America, the inefficient price is nearly three times larger than the price paid in the efficient scenario all the way through 2050. Beyond 2050, the inefficient scenario cannot be solved because the implied carbon price becomes too high, particularly so in Latin America and high-income countries. This underscores the difficulties in achieving a global target without coordination, but also illustrates the particular vulnerability of the region to a "do it alone" scenario.

Given the high cost of the carbon tax, Latin America is likely to experience substantial income losses under inefficient mitigation. By 2030, real incomes are likely to fall by more than $1 \%$ relative to the baseline, despite the fact that mitigation limits global warming damage to agricultural productivity (table VIII.6). By 2050, the income loss reaches $6.5 \%$, second only to losses in the Middle East, where a sharp carbon-tax-driven increase in energy prices results in a dramatic fall in export earning. For a number of countries in the region, the impacts are even more severe, with Mexico and the Bolivarian Republic of Venezuela experiencing losses of more than $10 \%$ of baseline income. In other countries-such as Argentina and Brazil-the impacts are much more mild but still on a par with the average for all developing countries.

The magnitude of losses is not proportional to the size of the carbon tax: in some countries with small shares of "dirty" industries in output and low consumption of energy-intensive goods, such as Paraguay and Uruguay, the high carbon tax, redistributed in a lump-sum fashion, can somewhat offset the higher production costs and higher energy prices. Still, table VIII.6 shows that the losses for the region are substantial, compared either with losses in other countries/regions or with losses in the region under an efficient mitigation scenario. In the latter, the average income loss for the region is less than half of the country-specific scenario and the distribution of individual country losses around that

12 Because many of the developed economies have low carbon intensities, the carbon tax in high-income countries is higher than in most of the developing world. 


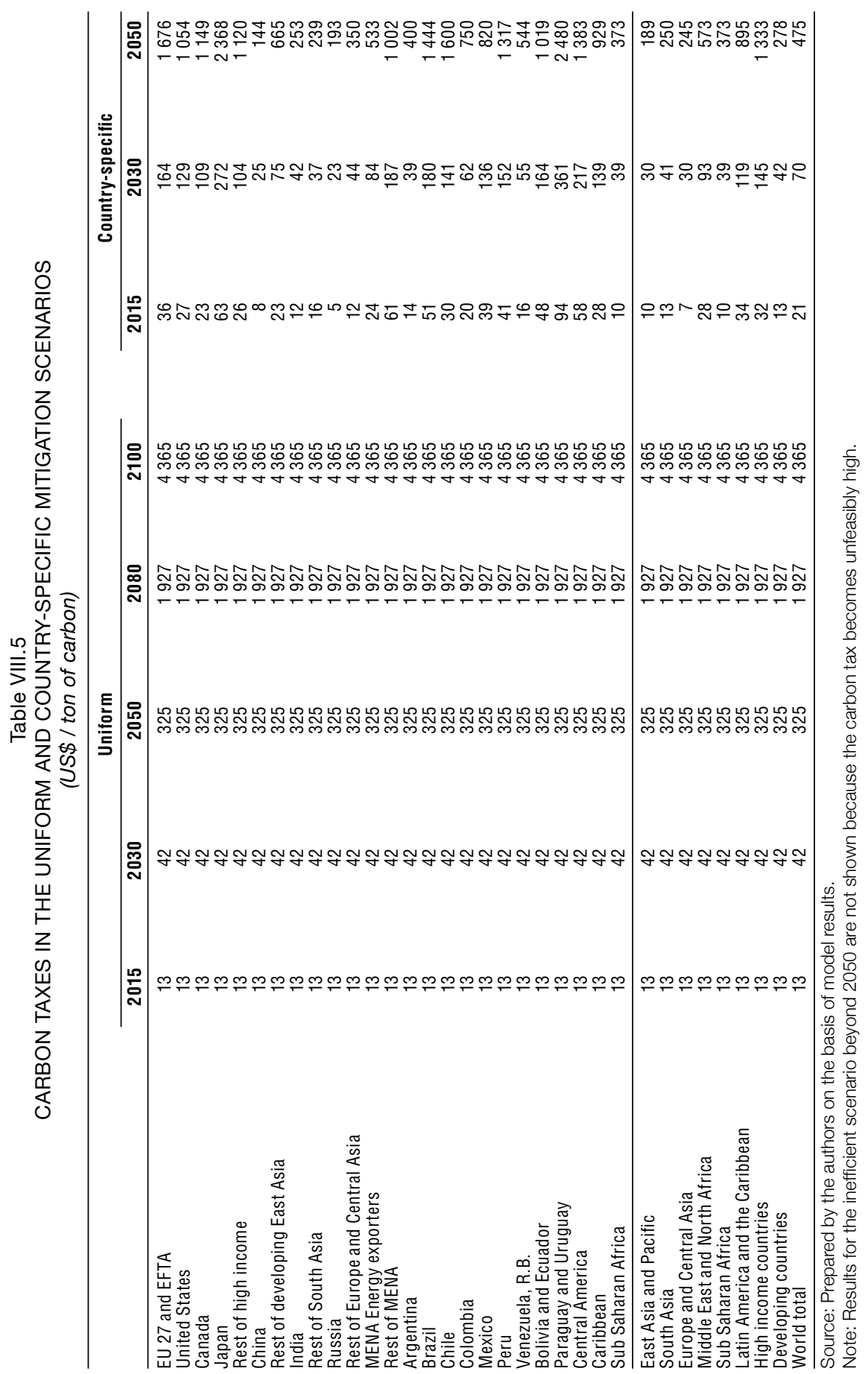




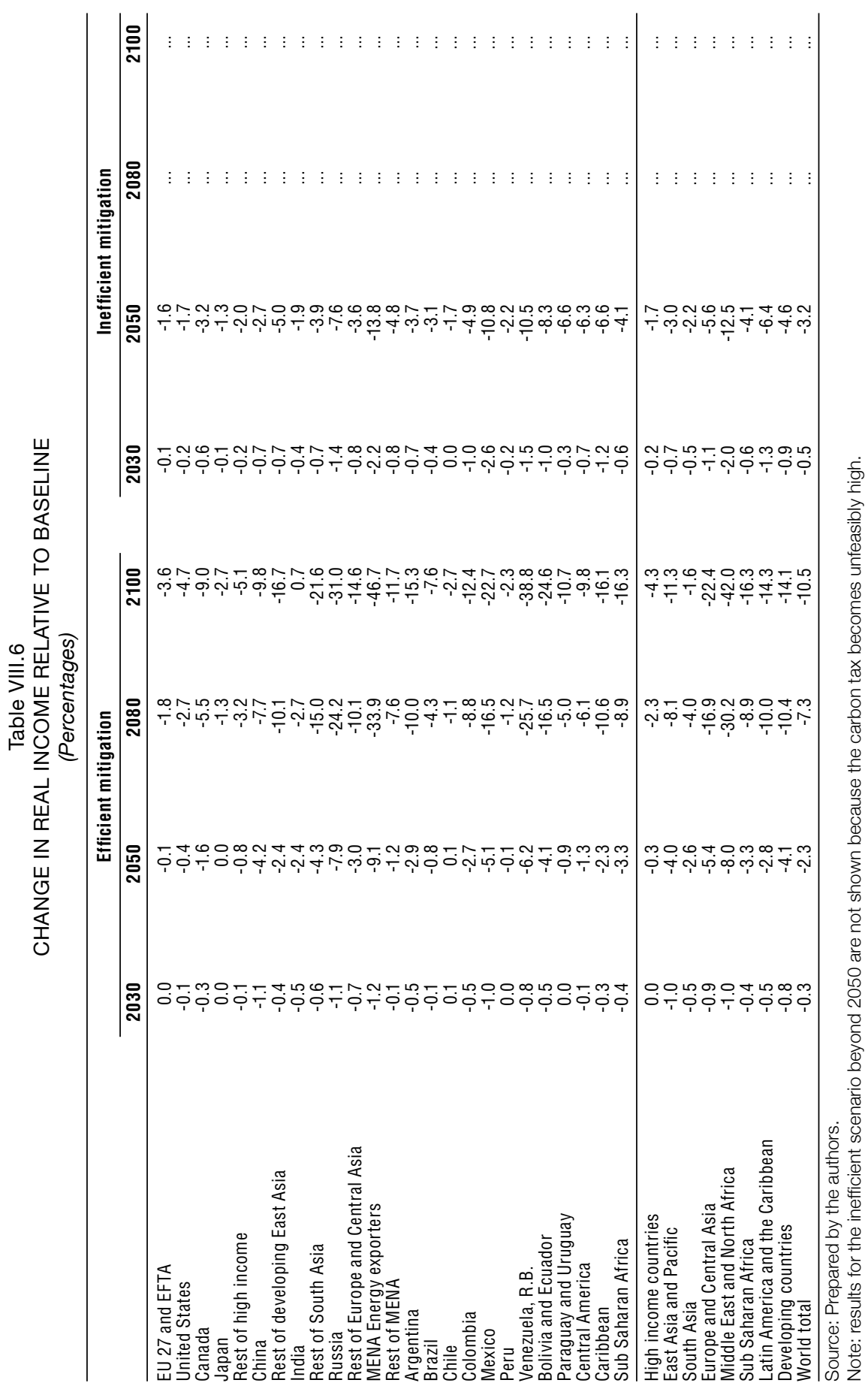


mean is narrower as well. This again supports the idea that, given its high climate vulnerability and low carbon intensity, Latin America has much to gain from a global solution to climate change.

An inefficient mitigation scenario is likely to give rise to a substantial amount of carbon leakage, i.e. the movement of energyintensive manufacturing out of "cleaner" and more expensive Latin American countries, where carbon taxes are expected to be high, and into "dirtier" and cheaper countries like China and India. The value of Latin America's net exports of energy intensive manufacturing falls by US $\$ 13.6$ billion in 2050, which represents a loss of more than $18 \%$ of the region's total net exports under the efficient mitigation scenario. Although the exit of "dirty" industries may be associated with a number of social benefits, this also presents a potential danger of an erosion in the domestic manufacturing base and potentially slower long-term growth due to a decline of high productivity growth industries.

\section{Micro results}

This section analyses the poverty and distributional impacts of climate change within a shorter time horizon than the macro discussion which preceded this section. The micro discussion is limited to 2030 because going out further into the future stretches the stability assumptions on many of the parameters of the micro model and makes the current poverty lines irrelevant as the vast majority of the world earns incomes above today's international poverty line. At the same time, as shown in the previous section, 2030 is far enough in the future to witness both non-trivial climate-change damage and non-negligible carbon taxes in the mitigation scenarios.

In the baseline scenario, poverty falls dramatically between 2005 and 2030 (table VIII.7). For developing countries as a whole, the share of population below the extreme poverty line declines by a factor of ten while the proportion of population below the moderate poverty line declines by a factor of five. ${ }^{13}$ The regions primarily responsible for this impressive achievement are South and East Asia, which together account for $78 \%$ of the total reduction in extreme poverty and $86 \%$ of the reduction

13 This paper uses the new World Bank poverty line of US\$ 1.25 (2005 PPP) per day, and, in accordance with earlier practice, defines the moderate poverty line as twice the extreme poverty line (US\$ 2.50 per day, 2005 PPP). The poverty estimates presented in this paper do not line up to the official World Bank poverty estimates published in World Development Indicators or in Chen and Ravallion (2008) due to differences in country coverage. The extreme poverty statistics in this paper are fully consistent with Chen and Ravallion (2008) at the country level, and are reasonably close at the global and regional level. 
Table VIII.7

POVERTY HEADCOUNT

(Percent of population)

\begin{tabular}{|c|c|c|c|c|c|}
\hline & $\begin{array}{l}\text { Observed } \\
2005\end{array}$ & $\begin{array}{c}\text { Baseline } \\
2030\end{array}$ & $\begin{array}{c}\text { No climate } \\
\text { damages } \\
2030\end{array}$ & $\begin{array}{c}\text { Efficient } \\
\text { mitigation } \\
2030\end{array}$ & $\begin{array}{c}\text { Inefficient } \\
\text { mitigation } \\
2030\end{array}$ \\
\hline \multicolumn{6}{|l|}{ US\$1.25 (PPP) per day poverty line } \\
\hline Developing countries & 23.97 & 2.02 & 1.84 & 2.04 & 2.04 \\
\hline East Asia and Pacific & 15.66 & 0.05 & 0.04 & 0.05 & 0.05 \\
\hline Eastern Europe and Central Asia & 4.27 & 0.04 & 0.04 & 0.04 & 0.04 \\
\hline Latin America and Caribbean & 7.94 & 2.58 & 2.49 & 2.58 & 2.59 \\
\hline Middle East and North Africa & 2.28 & 0.18 & 0.15 & 0.20 & 0.21 \\
\hline South Asia & 39.30 & 0.78 & 0.64 & 0.79 & 0.79 \\
\hline Sub-Saharan Africa & 50.97 & 11.94 & 10.91 & 12.02 & 12.05 \\
\hline \multicolumn{6}{|c|}{ US\$2.50 (PPP) per day poverty line } \\
\hline Developing countries & 57.16 & 11.26 & 10.09 & 11.40 & 11.44 \\
\hline East Asia and Pacific & 51.13 & 2.40 & 2.17 & 2.44 & 2.47 \\
\hline Eastern Europe and Central Asia & 16.53 & 0.69 & 0.67 & 0.71 & 0.71 \\
\hline Latin America and Caribbean & 20.85 & 7.81 & 7.45 & 7.83 & 7.89 \\
\hline Middle East and North Africa & 27.47 & 2.03 & 1.82 & 2.08 & 2.13 \\
\hline South Asia & 85.79 & 14.03 & 11.59 & 14.23 & 14.23 \\
\hline Sub-Saharan Africa & 81.07 & 40.55 & 38.41 & 41.00 & 41.17 \\
\hline
\end{tabular}

Source: Prepared by the authors on the basis of simulations with the GIDD and ENVISAGE models.

in moderate poverty. Although poverty in Latin America also declines substantially over this period, the lower expected per capita growth rates and much higher initial inequality result in the reversal of the region's position vis-à-vis other regions like East and South Asia: although the poverty rate in Latin America is much lower than in these regions, the opposite could be true by 2030.

Climate-change damage increases poverty in 2030 only moderately, with the poverty headcount rising by 0.2 and 1.2 percentage points at the extreme and moderate poverty lines, respectively. However, these relatively small aggregate changes mask a larger degree of regional variation. For example, extreme poverty remains virtually unchanged in Eastern Europe while the headcount in Sub-Saharan Africa increases by a full percentage point. The latter is equivalent to nearly eight million persons slipping below the threshold of extreme poverty. In fact, SubSaharan Africa contributes nearly $70 \%$ to the total increase in the number of extreme poor due to climate change, while Latin America accounts for just $5 \%$ of the increase. In terms of regional rankings, this places the region in the middle of the pack: it accounts for a larger share of the increase than East Asia, Eastern Europe, and the Middle East, but a smaller share than South Asia and Africa. Latin America is slightly 
less vulnerable when moderate poverty is considered: it accounts for just $3 \%$ of the total increase, with smaller changes observed only in Eastern Europe and the Middle East.

The adverse effects of climate change vary significantly by the main source of household earnings. Although climate-change damage is concentrated in agriculture, the agricultural households are not necessarily the most affected. As discussed in the previous section, the prices of agricultural products rise with increasing damage, which helps close the wage gap between earnings in the farm and non-farm sectors. At the same time, the cost of the food basket rises for all consumers, including agricultural households. Moreover, farm households tend to be poorer than average, which means that they devote a larger share of their consumption expenditures to food. Therefore, the ultimate impact of climate-change damage on agricultural households depends on whether the increase in the output price is sufficient to compensate for the welfare loss due to the higher cost of feeding the family.

At the global level, moderate poverty in agriculture increases by 1.6 percentage points while poverty in the non-farm sector goes up by 0.9 percentage points. This is driven primarily by increases in agricultural poverty in Sub-Saharan Africa and South Asia, where farmers are hurt severely on the consumption side. In Latin America, where farmers tend to be somewhat better off and consequently spend a smaller portion of their income on food, the impact is less severe. These developments give rise to the growth incidence curve in figure VIII.9, which shows that the incidence of climate-change damage in Latin America-despite the compensating increase in farmers' incomes-is highly regressive. The poorest $1 \%$ of the population could experience a welfare loss that is nearly four times the loss experienced by the top $10 \%$ of the distribution. Still, the widening of regional inequality due to climate-change damagewhich amounts to 0.1 Gini points-is substantially less than the widening of global inequality, which increases by 0.5 Gini points. This is because the widening of inequality between countries is largely offset by the narrowing of inequality within countries owing to faster growth in the earnings of agricultural households, which tend to be concentrated in the left tail of national distributions.

The inefficiencies of targeting emissions reductions via a countryspecific carbon tax are shown in the final two columns of Table VIII.7 as well as in figure VIII.9. The increase in poverty due to the inefficient tax is negligible at either the extreme or the moderate poverty lines. Furthermore, Sub-Saharan Africa accounts for more than half of the total increase, while in Latin America less than 400,000 people fall into poverty. However, the growth incidence curves in figure VIII.9 show a 
Figure VIII.9

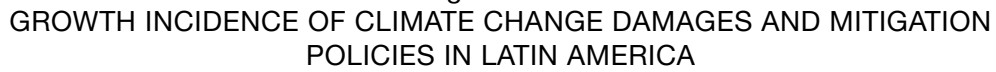

(Percent change in real income or consumption relative to baseline, 2030)

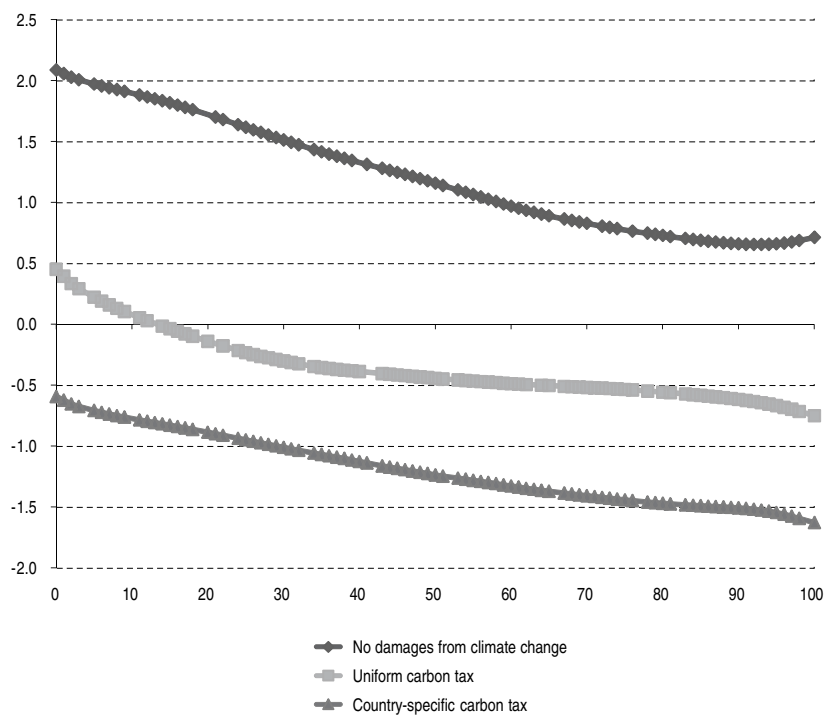

Source: Prepared by the authors.

more nuanced picture. Mitigating the negative effects of climate change is always pro-poor in Latin America, but the efficient strategy reduces the losses significantly and may even benefit-in absolute termsthe poorest households. There are two main reasons for this. First, mitigating damage lowers food prices, which benefits a poor household more than the average. Second, although taxing carbon raises the prices of energy-intensive products, these products are a much more important consumption item for the rich rather than the poor.

\section{Conclusions}

As the global community undertakes the current round of the complex negotiations on a new architecture to limit the damage from man-made global warming, it is abundantly clear that developing countries will play a central role. It is important that each individual country understands the stakes for itself-both in terms of the damage that it could absorb in the absence of mitigation, as well as in the potential 'costs' it could incur from its own mitigation policies-either independently or as part of a broader agreement. 
Latin America, given its current energy configuration, would gain significantly from a global efficient price of carbon. This is because the region is more vulnerable than average to the adverse impacts of climate change but cannot cut emissions as easily as some of the other regions because its carbon intensity is already below the average. Therefore, delaying or not at all addressing the damaging consequences of rising temperatures would disproportionately hurt the region as its share of global losses is likely to exceed its contribution to the global emissions. Similarly, anything less than a global solution is likely to result in the region imposing a carbon price that is much higher than otherwise necessary, suffering income losses and flight of manufacturing industries to countries with lower taxes in the process.

There are still many critical issues that need to be explored-1) to what extent will clean energy technologies (for example biofuels, nuclear, solar, wind, geo-thermal, or carbon capture and storage) penetrate the existing energy mix and what new technologies may become available, particularly in the second half of the century; 2) what role is there for using land and forests to assist in the sequestration of carbon; and 3) what will be the shape of the international solution to climate change and to what extent will this solution place the burden of mitigation on the high-income nations and allow for resource transfers to developing countries (perhaps in the form of cap and trade). 


\section{Bibliography}

Bacon, Robert W. and Soma Bhattacharya (2007), "Growth and $\mathrm{CO}_{2}$ emissions: how do different countries fare?", Environment Department Papers, Climate Change Series, No. 113, , Washington, D.C., The World Bank, November.

Bourguignon, François, Maurizio Bussolo and Luiz A. Pereira da Silva (eds.) (2008), The Impact of Macroeconomic Policies on Poverty and Income Distribution: Macro-Micro Evaluation Techniques and Tools, New York, Palgrave.

Bussolo, Maurizio, Rafael De Hoyos and Denis Medvedev (2008), "Economic growth and income distribution: linking macroeconomic models with household survey data at the global level", document presented at the thirty general conference of the International Association for Research in Income and Wealth (IARIW), Portoroz, Slovenia, August 24-30.

Bussolo, Maurizio, Jann Lay and Dominique van der Mensbrugghe (2006), "Structural change and poverty reduction in Brazil: the impact of the Doha Round", World Bank Policy Research Working Paper, No. 3833.

Burniaux, Jean-Marc and Truong P. Truong (2002), "GTAP-E: an energyenvironmental version of the GTAP model", GTAP Technical Paper, No. 16, Center for Global Trade Analysis, Purdue University, West Lafayette.

Burniaux, Jean-Marc, Giuseppe Nicoletti and Joaquim Oliveira-Martins (1992), "GREEN: a global model for quantifying the costs of policies to curb $\mathrm{CO}_{2}$ emissions", OECD Economic Studies, No. 19, Paris, Organisation for Economic Co-operation and Development (OECD).

Cai, Lixin, John Creedy and Guyonne Kalb (2006), "Accounting for population ageing in tax microsimulation modelling by survey reweighting", Working Papers Series, No. 935, Department of Economics, The University of Melbourne.

Chen, Shaohua and Martin Ravallion (2008), "The developing is poorer than we thought, but no less successful in the fight against poverty", World Bank Policy Research Working Paper, No. 4703, Washington, D.C. (2003), "Household welfare impacts of China's accession to the world trade organization", Policy Research Working Paper, No. 3040, Washington, D.C., World Bank.

Cline, William R. (2007), Global Warming and Agriculture: Impact Estimates by Country, Washington, D.C., Center for Global Development/Peterson Institute for International Economics.

Ferreira, Francisco H.G., Phillippe Leite and Paulo Picchetti (2004), "Can the distributional impacts of macroeconomic shocks be predicted? A comparison of the performance of macro-micro models with historical data for Brazil", Policy Research Working Paper, No. 3303, Washington, D.C., World Bank.

IPCC (Intergovernmental Panel on Climate Change) (2007), Climate Change 2007: Mitigation. Contribution of Working Group III to the Fourth Assessment Report of the Intergovernmental Panel on Climate Change, Cambridge University Press.

Hertel, Thomas W. (ed.) (1997), Global Trade Analysis: Modeling and Applications, Cambridge University Press.

McDougall, Robert (2003), "A new regional household demand system for GTAP", GTAP Technical Paper, No. 20, Center for Global Trade Analysis, Purdue University, September. 
Manne, Alan and Richard Richels (2004), "MERGE: an integrated assessment model for global climate change" [online] http://www.stanford.edu/group/ MERGE/GERAD1.pdf

Martin, Will and Devashish Mitra (1999), "Productivity growth and convergence in agriculture and manufacturing", Policy Research Working Paper Series, No. 2171, World Bank.

Raupach, Michael and others (2007), "Global and regional drivers of accelerating $\mathrm{CO}_{2}$ emissions", Proceedings of the National Academy of Sciences of the United States of America (PNAS), 22 May [online] http://www.pnas.org/cgi/ reprint/0700609104v1.

United Nations (2007), World Population Prospects: The 2006 Revision. Population Database [online database] http://esa.un.org/unpp/.

van der Mensbrugghe, Dominique (2008), "The environmental impact and sustainability applied general equilibrium (envisage) model", Washington, D.C., World Bank, unpublished. (2006), "Linkage technical reference document: version 6.0", Washington, D.C., World Bank.

(1994), "GREEN: the reference manual", OECD Economics Department Working Paper, No. 143, Paris, Organisation for Economic Co-operation and Development (OECD).

Weyant, John P., Francisco C. de la Chesnaye and Geoff J. Blanford (2006), “Overview of EMF-21: multigas mitigation and climate policy", The Energy Journal: MultiGreenhouse Gas Mitigation and Climate Policy, Special Issue.

World Energy Council (2007), Survey of Energy Resources, London. 


\title{
Chapter IX
}

\section{Armington elasticities for Brazil $^{1}$}

\author{
Octávio Augusto Fontes Tourinho² \\ Honorio Kume \\ Ana Cristina de Souza Pedroso ${ }^{4}$
}

In this article we estimate substitution elasticities for goods distinguished by place of production, specifying whether they are imported or produced domestically. These are known as the Armington (1969) elasticities and are widely used to assess the impact on the domestic economy of policy changes in countries' tariff structures; and, in particular, to evaluate the costs and benefits of signing free trade agreements. The sample period for our study is 1986-2002, and the estimation is done separately for each of the 28 industrial sectors specified in the Brazilian input-output table. Special consideration is given to the fact that the data is affected by import restrictions for part of that period, and that foreign trade liberalization

1 This is an English language version of Tourinho, Kume and Pedroso (2007). The authors would like to thank participants in the seminar "Encuentro Regional sobre Modelos de Equilíbrio General Computable: sus aportes em la Formulacipón de La Política Econômica em America Latina", sponsored by ECLAC and IDB, held in Santiago, Chile, in April 2007, for their comments and suggestions.

2 Brazilian Development Bank (BNDES) and University of the State of Rio de Janeiro (UERJ). E-mail: touri@bndes.gov.br

3 Institute of Applied Economic Research (IPEA) and University of the State of do Rio de Janeiro (UERJ). E-mail: kume@ipea.gov.br

4 Institute of Applied Economic Research (IPEA), when involved in the research reported in this paper. E-mail: anapedroso@globo.com 
occurred in Brazil in 1990. The estimation procedure is automated and takes into consideration the stochastic dynamic properties of the quantity and price series, using the appropriate estimation approach in each case. The Armington elasticities we estimate have the correct sign, and are significant at the 5\% level for 20 sectors, at $10 \%$ for two sectors, and at $20 \%$ for two others. In one sector the estimated value is significant, but has the incorrect sign (negative). For three sectors the estimated elasticity is not significantly different from zero; but these represent only $12 \%$ of the average value of total import value in the period 1997-2002. The point estimate of the elasticity of substitution, for the sectors where it is positive and statistically different from zero, varies from 0.16 to 3.6 ; and its weighted average value is 0.93 .

\section{A. Introduction}

Regional free trade agreements are hard to evaluate economically because they affect multiple productive sectors in several different ways, and they impact the performance of the national economy in a complex manner. ${ }^{5}$ Nonetheless, it is possible to assess their main consequences using either a partial-equilibrium approach or, more broadly, computable general equilibrium models (CGEs). In either case, the agreement is represented by the tariff reductions it imposes on the countries signing it. These, in turn, alter the domestic price of the imported good relative to the domestically produced good, and this change affects the proportion of domestic demand that is supplied by imports. To analyse this effect and attempt to forecast its intensity, requires estimating the elasticity of substitution between goods distinguished by place of origin. These are known as Armington elasticities, in honour of the economist who first drew attention to their importance. Moreover, as the substitutability between imports and domestic production varies widely from one product to another, these estimates are needed at a disaggregated product level.

Estimates of Armington elasticities by sector are not readily available for most countries, despite their crucial importance for evaluating the impact of changes in trade policy on foreign trade flows. To deal with this lack of empirical data, studies in this area often make use of elasticity values obtained for other countries, in many cases completely disregarding important differences that may exist between

Brazil is engaged in the negotiation of several trade agreements, of varying scope: multilateral - the World Trade Organization (WTO); free trade agreements with the countries of MERCOSUR and the European Union (UE); and bilateral agreements, with South Africa and India, among others. 
the production and consumption structures of different countries. ${ }^{6}$ As these elasticity values are also not available for Brazil, the aim of this study is to estimate them for our country, using the longest data series available, which runs from 1986 to 2002 . We have adopted the same level of aggregation as in the Brazilian input-output matrix, to make it easy to use the estimates in empirical studies of the country's import basket.

The approach proposed here makes a methodological innovation with respect to the literature in this area, by advocating extensive use of the time-series properties of the series in question, to select the most suitable estimation method and the corresponding equation. Depending on the order of integration of the relative-price and quantity series, we employ one of four approaches: simple regression of the levels of variables, regression of first differences, linear model of mixed equations, or a vector error correction model (VEC). ${ }^{7}$ We also consider the possibility of a structural break occurring in the data series caused by the foreign-trade liberalization which began in Brazil in 1990, together with the possibility of seasonal factors and a time trend. This is done both in the tests to determine the order of integration of the series, and in the estimation itself. Lastly, we also consider the possibility that the demand for imports is affected not only by the level of the relative price of imported goods, but also by its uncertainty .

This painstaking approach to model specification and estimation has clear empirical advantages in the case of Brazil for the period considered, since an attempt to employ simpler methods had led to poor or incorrect estimates. We believe that the approach proposed here will also prove useful in the case of other countries, especially if the sample period includes a trade liberalization episode.

This paper is divided into five sections including the introduction. In section B we briefly review the concept of elasticity of substitution, and introduce the approach used to deal with the impact on the observed data of the foreign-trade liberalization initiative that began in 1990 and lasted through 1993. Section $C$ discusses the tests used to determine the existence of unit roots in the price and quantity series, and the models used in the estimation process. Section D reports the estimates obtained for the 28 industrial sectors of the Brazilian input-output table; and section E summarizes the main conclusions.

6 For example, Sánchez (2001) evaluates the costs and benefits for Mercosur of joining FTAA using the applied general equilibrium model of the Global Trade Analysis Project (GETAP), but it arbitrarily multiplies the original elasticities by six. Harrison et al (2002) analyse the impacts of regional and multilateral trade agreements for Brazil while using elasticities estimated for Hong-Kong.

7 We believe this is a pioneering application of the methods developed by Johansen (1988) to the problem of estimating the Armington elasticity. 


\section{B. Armington elasticity and Brazilian trade liberalization of 1990}

The approach proposed by Armington (1969) to evaluate impacts of changes in trade policy on the volume of imports has been widely used, both in its original partial equilibrium formulation and in general equilibrium models. ${ }^{8}$ The approach assumes that goods are differentiated by country of origin, and that domestic demand for each sector is supplied by a composite good which is a CES (Constant Elasticity of Substitution) aggregation of domestically produced and imported goods. This is represented in equation (1), for sector $i$.

$$
Q_{i}=\bar{Q}_{i}\left[\delta_{i} M_{i}^{-\rho_{i}}+\left(1-\delta_{i}\right) D_{i}^{-\rho_{i}}\right]^{-1 / \rho_{i}}
$$

where $Q_{i}, M_{i}$ and $D_{i}$ represent the quantity index of the aggregate good, the imported good, and the domestically produced good, respectively. The scale parameter is $\bar{Q}_{i}$, and $\rho_{i} \delta_{i}$ are the substitution and the distribution parameters, respectively. The first of these indicates the degree of substitutability between domestically produced and imported goods, and determines the shape of the indifference curve that represents the smooth transition between these two goods in the preferences of the representative consumer. Its role can be clearly seen by noting that, for $\rho_{i}=-1$, the composite good is a linear combination of $M_{i}$ and $D_{i}$ and the indifference curve is linear. The second parameter indicates the shares of imported and domestically produced goods in the composite good.

The solution to the problem of minimizing the cost of supplying total demand, given expenditure and the prices of the imported and domestically produced goods, gives the optimal mix of these two goods in the composite good $Q_{i}$, and is represented by equation (2). This shows that the proportions of the domestic and the imported good depend on the elasticity of substitution $\sigma_{i}=1 /\left(1+\rho_{i}\right)$ and on the ratio of their prices, represented by $P_{i}^{d}$ and $P_{i}^{m}$.

$$
\frac{M_{i}}{D_{i}}=\left[\left(\frac{\delta_{i}}{1-\delta_{i}}\right)\left(\frac{P_{i}^{d}}{P_{i}^{m}}\right)\right]^{\sigma_{i}}
$$

8 A good example is Dervis, Melo and Robinson (1982) which uses the Armington specification in a computable general equilibrium (CGE) model, which has become a standard model for policy analysis. See also Melo and Robinson (1989) for a more detailed discussion of its use in CGEs. For examples of its use in a partial equilibrium framework, see the series of studies to measure the social cost of protection in several countries, started by Hufbauer and Elliot (1994) and sponsored by the Institute of International Economics, Washington, D.C. 
The internal price of the imported good, which is the relevant value for the consumer's decision, is a function of $P_{i}^{e}$, its foreign-currency price on the foreign market, the exchange rate $(X)$, and the import tariff $\left(\tau_{i}\right)$ as shown in equation (3):

$$
P_{i}^{m}=P_{i}^{e} X\left(1+\tau_{i}\right)
$$

It is useful to explore the behaviour of equation (2) for three extreme cases of the elasticity of substitution. If $\rho_{i} \rightarrow \infty$ and $\sigma_{i} \rightarrow 0$, there is no substitution between the two goods, and the ratio of their quantities does not depend on their relative prices. When $\rho_{i} \rightarrow-1$ and $\sigma_{i} \rightarrow \infty$, the two goods are perfect substitutes, ${ }^{9}$ and small changes in the relative prices are sufficient to produce wide swings in the ratio $M_{i} / D_{i}$. Lastly, when $\rho_{i}=0$ and $\sigma_{i}=1$, the CES function in equation (1) reduces to the Cobb-Douglas function, and the ratio of expenditure on the imported and domestically produced goods is constant and equal to $\delta_{i} /\left(1-\delta_{i}\right)$.

Equation (2) also shows that an estimate of the elasticity of substitution, $\sigma_{i}$, can be obtained from the time series for the ratios $M_{i} / D_{i}$ and $P_{i}^{i^{\prime}} / P_{i}^{m}$. Nonetheless, a relatively long time period is required for quantities to fully adjust to price changes. In the short run (a few months) the impact will probably be small, since several years are usually necessary for the quantity imported to fully reflect changes in the relative price of imports. The short-run and long-run elasticities are, therefore, different.

In this study we will estimate the long-run elasticities of substitution, using the argument employed by Gallaway, McDaniel and Rivera (2000) to justify adoption of that time horizon in their study. They point out that Armington elasticity estimates are most often used in comparative static analyses, in either partial- or general equilibrium models. In this type of analysis we compare the results of the controlled experiment to those obtained in the base year, assuming the economy has had long enough to adjust, so that the results of the experiment reflect the total effect of the policy experiment being evaluated.

To build a price series for imported goods that truly reflects the actual cost paid by importers to bring them into the country, a number of peculiarities of Brazilian tariff and import regulations in force between 1986 and 2002 need to be taken into account. The period can be divided into two distinct sub-periods that can be described in stylized fashion as follows. 
Before the unilateral trade liberalization that began in 1990, imports could be broadly classified in two categories:

(a) non-competing imports for which import tariffs were already low, precisely because there was no need to protect the domestic industry. Examples are metallurgy, coal, petroleum, some fertilizers, and capital goods with no close national substitute, etc.

(b) competing imports, for which import tariffs were extremely high. In this case, imports were only an economically viable alternative to domestic products if purchased by agents with access to reduced import tariffs or, in most cases, exemption. This special treatment was extended to agents eligible to claim special tax regimes, such as those applicable to State-owned enterprises, or those associated with special investment projects which, despite being private, were deemed to be of national interest. Examples are projects supported by the Amazonia Development Superintendency (SUDAM), the Northeast Development Superintendency (SUDENE), the Industrial Development Council (CDI), the Manaus Duty Free Zone, etc. This represents a situation of repressed demand, where potential importers were driven out of the import goods market by a combination of a prohibitive tariff and ineligibility for tariff-exempt status. ${ }^{10}$ Consequently, there was a wedge between nominal tariffs, which were very high, and the tariffs that were actually paid, which were much lower because of these exemptions and reductions.

The dichotomy outlined above in the imported goods market was a consequence of the crisis in the Brazilian balance of payments which began in 1983 following a sudden stop in the flow of foreign savings to developing countries, and deepened in 1987 when the country declared a unilateral moratorium on its foreign-debt service. The situation only returned to normality in 2002, when the country signed a wide-ranging foreign-debt refinancing agreement with the international financial community.

After 1990, nominal tariffs were lowered, import restrictions were lifted, and most special tax regimes for imports were removed, except for those relating to the Manaus Free Trade Zone, the drawback regime, the special provisions for imports of computers and computer parts, and those relating to international agreements. As a consequence, the wedge between nominal and effectively paid tariffs, which had been very large, narrowed significantly.

10 According to Kume (1990), about $70 \%$ of imports, excluding oil, benefited from special tax regimes in this period. Competitive imports were also prohibitive because tariff redundancy was widespread. 
The approach we propose captures these two situations, before and after liberalization, in a unified framework, by calculating the equivalent tariff faced by the average importer in each sector, taking into account the dichotomy between the two types of imports that existed before liberalization, as described above. Assuming that imports in each sector were determined by the condition represented in equation (2), but that the tariff faced by some of them was the nominal tariff, while for others it was zero because they were exempt, we can write equations (4) and (5), which determine the relative shares of imports and domestic production in each of these cases, respectively:

$$
\begin{aligned}
& \frac{\alpha_{i} M_{i}}{D_{i}}=\alpha_{i}\left[\left(\frac{\delta_{i}}{1-\delta_{i}}\right)\left(\frac{P_{i}^{d}}{P_{i}^{e} X}\right)\left(\frac{1}{1+\tau_{i}}\right)\right]^{\sigma_{i}} \\
& \frac{\left(1-\alpha_{i}\right) M_{i}}{D_{i}}=\left(1-\alpha_{i}\right)\left[\left(\frac{\delta_{i}}{1-\delta_{i}}\right)\left(\frac{P_{i}^{d}}{P_{i}^{e} X}\right)\right]^{\sigma_{i}}
\end{aligned}
$$

where $\alpha_{i}$ denotes the proportion of imports that pay the full nominal tariff in sector $i$. Equation (6) sums these two types of imports, determined in equations (4) and (5) to calculate the ratio of imports to domestic production in sector $i$.

$$
\frac{M_{i}}{D_{i}}=\frac{\alpha_{i} M_{i}}{D_{i}}+\frac{\left(1-\alpha_{i}\right) M_{i}}{D_{i}}=\left[\left(\frac{\delta_{i}}{1-\delta_{i}}\right)\left(\frac{P_{i}^{d}}{P_{i}^{e} X}\right)\right]^{\sigma_{i}}\left[\left(1-\alpha_{i}\right)+\alpha_{i}\left(\frac{1}{1+\tau_{i}}\right)^{\sigma_{i}}\right]
$$

For estimation purposes, a logarithmic transformation is applied to equation (6), to give equation (7).

$$
\log \left(\frac{M_{i}}{D_{i}}\right)=\sigma_{i} \log \left[\left(\frac{\delta_{i}}{1-\delta_{i}}\right)\left(\frac{P_{i}^{d}}{P_{i}^{e} X}\right)\right]+\log \left[\left(1-\alpha_{i}\right)+\alpha_{i}\left(\frac{1}{1+\tau_{i}}\right)^{\sigma_{i}}\right]
$$

The fact that equation (7) is non-linear in the elasticity of substitution makes the estimation more difficult. To simplify, we take a Taylor series expansion of the second term in the right-hand side of (7) with respect to $\sigma_{i}$, in the neighbourhood of $\sigma_{i}=1$, and obtain equation (8).

$$
\begin{aligned}
\log \left[\left(1-\alpha_{i}\right)+\alpha_{i}\left(\frac{1}{1+\tau_{i}}\right)^{\sigma_{i}}\right] & =\log \left[\left(1-\alpha_{i}\right)+\left(\frac{\alpha_{i}}{1+\tau_{i}}\right)\right]+ \\
& \frac{\alpha_{i}}{1+\tau_{i}-\alpha_{i} \tau_{i}}\left(\sigma_{i}-1\right) \log \left(\frac{1}{1+\tau_{i}}\right)+\vartheta\left[\sigma_{i}-1\right]^{2}
\end{aligned}
$$


Apart from the error term in the approximation, only the second term on the right-hand side of (8) depends on $\sigma_{i}$, and it does so linearly. That term is reproduced in equation (9), which also represents that fact explicitly.

$$
\sigma_{i}\left[\theta_{i} \log \left(\frac{1}{1+\tau_{i}}\right)\right], \text { where } \theta_{i}=\frac{\alpha_{i}}{1+\tau_{i}-\alpha_{i} \tau_{i}}
$$

Using (9) as an approximation for the part of (7) that depends on $\sigma_{i}$, we obtain equation (10), where the constant term $\kappa_{i}$, defined in (11), consolidates terms in which the elasticity of substitution does not appear.

$$
\begin{aligned}
& \log \left(\frac{M_{i}}{D_{i}}\right)=\kappa_{i}+\sigma_{i} \log \left[\left(\frac{\delta_{i}}{1-\delta_{i}}\right)\left(\frac{P_{i}^{d}}{P_{i}^{e} X}\right)\right]+\sigma_{i} \theta_{i} \log \left(\frac{1}{1+\tau_{i}}\right) \\
& \text { (11) } \kappa_{i}=\log \left[\left(1-\alpha_{i}\right)+\left(\frac{\alpha_{i}}{1+\tau_{i}}\right)\right]-\theta_{i} \log \left(\frac{1}{1+\tau_{i}}\right)
\end{aligned}
$$

Lastly, equation (11) can be simplified to yield equation (12), which is similar to equation (2), but with the difference that the term capturing the effect of the tariff is raised to the power $\theta_{i}$.

$$
\log \left(\frac{M_{i}}{D_{i}}\right)=\kappa_{i}+\sigma_{i} \log \left[\left(\frac{\delta_{i}}{1-\delta_{i}}\right)\left(\frac{P_{i}^{d}}{P_{i}^{e} X}\right)\left(\frac{1}{1+\tau_{i}}\right)^{\theta_{i}}\right]
$$

The significance of the exponent $\theta_{i}$ in (12) can be understood by considering its definition in (9) and recalling that $\alpha_{i}$ is the proportion of imports that pay the full nominal tariff $\tau_{i}$. It is then trivial to verify that equation (12) adequately reflects the two polar stylized types of imports that occurred before trade liberalization, because they correspond to the extreme values of $\alpha_{i}$; and that it also correctly describes the intermediate situations existing afterwards.

We first discuss the situation before 1990. When the imported good was non-competing (case (a) described above), the tariff was low and applied to all import operations, i.e. $\alpha_{i}=1$, so $\theta_{i}=1$, and equation (12) reduces to (4). When the imported good is competing (case (b)), the pre-1990 tariff was very high, and the imports that actually entered the country did so under tariff exemption, which implies $\theta_{i}=0$, and reduces equation (12) to (5).

Following trade liberalization, all goods are in an intermediate situation between the two polar cases that existed before 1990. They are also adequately represented by equation (12), whose behaviour can be 
extrapolated by examining a linear approximation for the expression that defines $\theta_{i}$. This is given by equation (13), which is obtained by expanding equation (9) in a Taylor series with respect to $\alpha_{i}, \tau_{i} \in[0,1]$ in the neighbourhood of the origin. This shows that for low values of the tariff $\tau_{i} \rightarrow 0$, when most imports are taxed, $\alpha_{i} \rightarrow 1$, and $\theta_{i} \rightarrow \alpha_{i}$. When only a small proportion of imports pay the nominal tariff $\alpha_{i} \rightarrow 0$, and $\theta_{i} \rightarrow\left(1-\tau_{i}\right)$.

$$
\theta_{i}=\alpha_{i}+\vartheta\left[\alpha_{i}\right]^{2}+\tau_{i}\left(-\alpha_{i}+\vartheta\left[\alpha_{i}\right]^{2}\right)+\vartheta\left[\tau_{i}\right]^{2}
$$

Estimation of equation (12) requires calculating $\theta_{i t}$, for which a measure of $\alpha_{i t}$ is also needed. ${ }^{11}$ This can be obtained by assuming that, in the context of the stylized situation described at the beginning of this section, the observed tariff is a weighted average of the nominal tariff applied to imports in case (b), and the zero tariff, which is relevant for imports in case (a), and where the weighting factor is the estimated value of $\alpha_{i t}$. This is represented in equation (14), where $\bar{\tau}_{i t}$ stands for the mean observed tariff.

$$
\bar{\tau}_{i t}=\alpha_{i t} \tau_{i t}
$$

From (14) we can then obtain an estimate for $\alpha_{i t}$, which is represented by $\bar{\alpha}_{i t}$ in equation (15):

$$
\tilde{\alpha}_{i t}=\bar{\tau}_{i t} / \tau_{i t}
$$

Lastly, we include a dummy variable in the estimated equations to represent the shift in the demand curve for imports, reflecting the possibility that became available to firms after the last quarter of 1990, of importing goods that were previously restricted provided the full import duty was paid. ${ }^{12}$

At this point the reader may be wondering why so much effort has made in these adjustments to allow the use of the data covering the period when foreign trade was restricted, and to take into account the impact of unilateral trade liberalization in Brazil, given that in our study this includes data for only five years (1986 to 1990). The main reason is not the additional degrees of freedom it gives the estimation, but rather to include a period in the empirical analysis where there were large

${ }_{11}$ In the notation for $\alpha_{i}$ we introduced the index $t$ to emphasize that, besides being exogenous, it varies through time.

12 Import restrictions were officially lifted in March 1990 when the new Federal Government took office. Nonetheless, the non-tariff barriers that actually controlled most imports in practice were only eliminated in July of that year. Thus, only in the last quarter did economic agents effectively perceive and benefit from the new freedom to import. 
changes in the relative internal price of imported goods. This is important because the aim of this study is precisely to estimate the curvature of the indifference curve for the CES function in equation (1), which can only be measured correctly if we have a database that includes a wide range of relative prices of domestically produced and imported goods.

At this point we speculate that the adjustments proposed here to make it possible to use a single unified framework for data relating to periods when trade restrictions were in place and for data relating to the liberalization and post liberalization periods, are also applicable to other countries besides Brazil. The reason is that the distortions we address, produced by very large nominal tariffs together with a large number of special import regimes that entail exception and special treatment for certain industries, firms or goods, are likely to arise in other countries that went through periods in which similar protectionist policies were used.

\section{Empirical analysis}

We used quarterly data for each sector of the Brazilian input-output matrix (IBGE - level 50), for the period 1986-2002. The database in electronic format is available to readers on demand, and its construction is described in Annex A. ${ }^{13}$

Estimating equation (12) for each sector requires examining the order of integration of the time series involved in it. A comparison of the stochastic characteristics of these series determined the model to be estimated to obtain the elasticity of substitution. This section describes the methodology used in these two steps of the estimation.

To implement the unit root test systematically with regard to inclusion of the constant and the time trend, we adopted the procedure proposed by Dolado, Jenkinson and Sosvilla-Rivero (1990). In cases where this indicated the existence of a unit root, we also applied the Perron (1989) test for a structural break in the fourth quarter of 1990, using the variant that specifies a break of the type represented by the changing growth

13 The database in this study differs from that used in Tourinho, Kume and Pedroso (2002) because the foreign trade statistics for 1996 were revised in July 2002 (Funcex, 2002). The data for exports did not change significantly, but for several sectors expenditure on imports underwent major revision, mainly due to changes in the physical quantities imported. As the price and quantum indexes estimated by Funcex are chained in time, using 1996 as the base year, all the data were revised. Thus, the change in that year affected the level of the entire series, even though the rates of change were not altered, except for those calculated in relation to 1996. 
model, according to the typology proposed there..$^{14}$ In all cases the level of significance adopted in the tests was $10 \%,{ }_{1}^{15}$ and the Akaike information criterion was used to determine the number of lags to be used. Annex B describes the methodology of the tests in greater detail.

To make the estimation methodology more explicit, we recall that equation (12) represents a long-term relation between $p_{i t}$ and $q_{i t}$, defined in equations (16) to (19):

$$
\begin{aligned}
& \text { (16) } q_{i t}=\log \left(\frac{M_{i t}}{D_{i t}}\right) \\
& p_{i t}=\log \left[\left(\frac{P_{i t}^{d}}{P_{i t}^{e} X}\right)\left(\frac{1}{1+\tau_{i t}}\right)^{\theta_{i t}}\right] \\
& \theta_{i t}=\tilde{\alpha}_{i t} /\left(1+\tau_{i t}-\tilde{\alpha}_{i t} \tau_{i t}\right) \\
& \text { (19) } \tilde{\alpha}_{i t}=\bar{\tau}_{i t} / \tau_{i t}
\end{aligned}
$$

A stochastic version of equation (12) is represented in (20), where, to simplify the notation, we drop the product index $i$. This convention will be followed from now on and is justified by the fact that we apply the same methodology to all sectors. The elasticity is estimated for each of the products in isolation and individually, to be consistent with the Armington hypothesis that specifies zero cross-elasticities between all products.

$$
\begin{gathered}
q_{t}=\mu+\sigma p_{t}+\varepsilon_{t} \text { where } \mu=\kappa+\sigma \log \left(\frac{\delta}{1-\delta}\right) \\
\text { and } \varepsilon_{t} \approx N\left(0, v^{2}\right)
\end{gathered}
$$

14 The Perron test for the changing growth model assumes, in the null hypothesis, the existence of a unit root and a change in the intercept of the stochastic process at the time of the structural break. The alternative hypothesis is that the process is stationary with a change in the slope of the deterministic time trend at the time of the break.

15 The significance level of the ADF test indicates the probability of incorrectly rejecting the existence of the unit root. We adopted the $10 \%$ level as a compromise solution, owing to the well-known low-power property of the ADF statistic, i.e. a bias towards nonrejection of the unit root when in fact is not present. A lower significance level would reduce the power of the test even further in this relatively small sample. 
Each of these series can be integrated. When a unit root is not present, the series may or may not be stationary, but the procedure employed is the same, regardless, and is based on the assumption that the series is I(0). Table IX.1 presents the four possible combinations of the order of integration of the two series, along with the model employed in each case. As can be seen by comparing the lines in table IX.1, it is the order of integration of $q$ that determines whether the estimation is done in terms of levels or first differences, because it is the dependent variable in equation (20).

Table IX.1

DECISION TABLE FOR THE TYPE OF MODEL USED IN ESTIMATION

\begin{tabular}{cll}
\hline \multirow{2}{*}{ Quantities $(q)$} & \multicolumn{2}{c}{ Prices $(p)$} \\
\cline { 2 - 3 } & $\mathrm{I}(0)$ & $\mathrm{I}(1)$ \\
\hline $\mathrm{I}(0)$ & A: levels & C: levels \\
$\mathrm{I}(1)$ & B: differences & D and E: cointegration \\
\hline
\end{tabular}

Source: Prepared by the authors.

All of the models we estimate also include as an exogenous variable the coefficient of variation of the ratio between the prices of domestic and imported varieties of the good. ${ }^{16}$ This allows the uncertainty surrounding that relative price to affect the ratio between the amount imported and the amount produced domestically. The expected sign on its coefficient depends on the net effect of the speculative mechanism affecting imports, which may be positive or negative. For example, firms that depend heavily on imported inputs may react to greater uncertainty in their expected relative import costs by increasing their imports (positive effect) or else by substituting for them (negative effect). One cannot therefore anticipate the significance of this variable in equation (5), or the sign of its coefficient.

We also use control variables to take account of several important exogenous factors, as follows. The first is a dummy variable to capture the stepwise response of the quantity imported following the 1990 foreign trade liberalization. Its value is therefore $d_{t}=1$ for $t \geq 1990: 4$ and $d_{t}=0$ for other periods. The second control variable is a time trend to capture other factors that may have provoked structural changes in the quantum of imports without affecting the relative price of imports. The third is a vector of seasonal dummies $\left(z_{t}\right)$. The inclusion of a time trend and the dummy variable can be rationalized as an attempt to take account of variations in the quality of the goods and the composition of the sector price and quantity

16 The coefficient of variation is the ratio between the standard deviation of the variable and its mean. We chose this measure as a measure of variability because it preserves the non-dimensional nature of equation (2). 
aggregates that could not be adequately considered when constructing the quantity index. Examples include imports of electro-electronic goods and personal computers, which grew strongly in the later years of the period, but for which there was also a significant quality change. Our formulation assumes that part of those changes occurred progressively throughout the period, while others happened suddenly in response to the change in the foreign-trade regime; and it allows the empirical equations to distribute these effects among the variables.

Lastly, the estimated equation is shown in (21), which includes all the effects discussed above.

$$
q_{t}=\mu+\sigma p_{t}+\lambda d_{t}+\xi \cdot \mathbf{z}_{\mathbf{t}}+\gamma t+\varepsilon_{t}
$$

In the estimation of all models mentioned in table IX.1 we start with the most general specification, assuming the maximum number of lags for the price variable; and we progressively eliminate the nonsignificant variables to arrive at the final equation. In the next section we discuss the estimation of each of the models mentioned in table IX.1.

\section{Model A}

The simplest case is when both series are stationary, and we can obtain the long-term elasticity in equation (21) from a regression on the level variables. The equation is initially estimated by ordinary least squares; but, when the Durbin-Watson statistic indicates the existence of first-order serial correlation among the residuals, it is re-estimated using the maximum likelihood method, assuming a first-order autoregressive structure for the errors. This provides estimates of the coefficients and confidence intervals for the parameters of equation (6), and for the parameter of the autoregressive term $(\rho)$, which allows us to calculate the long-term Armington elasticity $\sigma /(1-\rho)$.

In cases where this procedure suggests the possible existence of a unit root on the residuals, i.e. the confidence interval of $\rho$ includes 1 , the equation is re-estimated in first difference terms, in the form of equation (7), which also includes lagged values of the price variable among the explanatory variables. The number of lags included in the equation is the same as used in the procedure to determine the order of integration of the price series, and may be zero. ${ }^{17}$

$$
\Delta q_{t}=\mu+\sigma \Delta p_{t}+\sum_{=0}^{\tau} v_{l} p_{t-l}+\lambda d_{t}+\xi \cdot \mathbf{z}_{\mathbf{t}}+\gamma t+\varepsilon_{t}
$$

\footnotetext{
17 Appendix B shows how we used a sequence of chained tests to endogenously obtain the number of lags used in the ADF test.
} 


\section{Models B and C}

Cases where the order of integration of the two series is not the same are hard to rationalize from an economic point of view. Moreover, these unbalanced equations are quite troublesome to estimate. This difficulty has been noted by other authors, who nonetheless recognize the need to overcome the problem in the best possible way. ${ }^{18}$ Below we indicate how we treat the two unbalanced cases of table IX.1.

When $q$ is $\mathrm{I}(1)$ and $p$ is $\mathrm{I}(0)$, the equation is estimated in terms of first differences, as in (22). This avoids the possibility of spurious correlation, because differentiation produces stationary series. ${ }^{19}$ When $q$ is I (0) and $p$ is I (1), we estimate the equation in terms of levels, including as many lags as those used in the tests of order of integration, plus one, as indicated in equation (23).

$$
q_{t}=\mu+\sigma p_{t}+\sum_{l=0}^{\tau+1} v_{l} p_{t-l}+\lambda d_{t}+\xi \cdot \mathbf{z}_{\mathbf{t}}+\gamma t+\varepsilon_{t}
$$

The asymmetric treatment of these two cases is justified by the need to deal with the "integratedness" of the dependent variable, when it has that property. On the other hand, the differencing operation we perform when it is integrated does not impair the estimation when the price variable is already stationary; and it preserves the possibility of interpreting the coefficient on the price variable as the elasticity of substitution. Any signs of serial correlation among the residuals when estimating equation (23) are dealt with by using the same procedure as in Model A. ${ }^{20}$

When the procedure described above is unable to produce an elasticity that is significantly different from zero, we try to estimate it by using the co-integration model described in the next section. We call this case Model E. This procedure is adopted even though the series have not been classified as integrated; but this can be justified in two ways. The first is that there is a margin of error in the tests of order of integration described at the start of this section and in appendix B, which may have led to rejection of the unit root for one of the series, when it is in fact present. The second argument has already been put forward above: there is no entirely satisfactory procedure available to deal with the case of unbalanced equations; and each of the procedures entails a compromise.

18 See, for example, Maddala and Kim (1998, p. 252): "Should one estimate unbalanced equations? Of course not, if it can be avoided. But if it has to be done, one has to be careful in their interpretation and use appropriate critical values".

19 This procedure is also adopted in Gallaway, McDaniel and Rivera (2003).

20 This procedure is the estimation via quasi-first differences, as described in the previous section (equation (22)). 
In our opinion these arguments justify the attempt to estimate the equation by cointegration methods when the other methods fail to find an elasticity that is significantly different from zero.

\section{Models D and E}

When prices and quantities are integrated, the cointegration relation provides an estimate of the long-term Armington elasticity, for which we use the general formulation contained in Johansen (1988). We write equation (20) in vector notation as equation (24).

$$
\beta^{\prime} \mathbf{x}_{t}-\mu=\varepsilon_{t}
$$

where $\mathrm{x}_{t}^{\prime}=\left(p_{t}, q_{t}\right), \beta^{\prime}=(1,-\sigma)$. This VAR model, can be put in a restricted form as a vector error correction (VEC) model which can be written as equation (25) when there is no time trend and the variables are lagged by just one period,

$$
\Delta \mathbf{x}_{t}=\alpha \cdot\left(\beta^{\prime} \mathbf{x}_{t-1}-\mu\right)+\varepsilon_{t}
$$

where $\beta$ is the co-integration vector and $\alpha$ is a vector that contains the weights applied to components of the cointegration term, and is used to adjust the value of $x$; in other words, it is the vector or coefficients of the error correction term. The vector of residuals $\varepsilon$ must be i.i.d. with mean zero and variance matrix $\Omega$.

The VEC of equation (25) can be generalized and written as equation (26) by including $k$ lags of the first difference of the vector of variables, and including the exogenous variables used to obtain equation (21): a dummy variable that captures the shift in the intercept caused by the trade liberalization, a time trend, and seasonal dummy variables:

$$
\Delta \mathbf{x}_{\mathbf{t}}-\boldsymbol{\gamma}=\boldsymbol{\alpha}\left[\boldsymbol{\beta}^{\prime} \mathbf{x}_{\mathrm{t}-1}-\left(\boldsymbol{\beta}^{\prime} \boldsymbol{\gamma} \cdot(t-1)+\lambda d_{t}+\mu\right)\right]+\sum_{l=1}^{k-1} \boldsymbol{\Gamma}_{l}\left(\Delta \mathbf{x}_{\mathrm{t}-l}-\boldsymbol{\gamma}\right)+\boldsymbol{\varepsilon}_{\mathbf{t}}
$$

In our case, the matrices $\Gamma_{\tau}$ are $2 \times 2$ and contain the weights of the autoregressive components of the process. We chose the number of lags to be included in the equation, represented by $l$, so as to maximize the likelihood statistic for the system of equations. ${ }^{21}$ In equation (26), $\gamma$ is a

${ }^{21}$ The number of lags was reduced progressively starting from a maximum of eight quarters, until the remaining terms were significant. To choose the maximum number of lags we assumed that the effects of a given shock would mostly have been absorbed by the system within two years. 
$2 \times 1$ vector containing the time-trend parameters for the growth of the variables. Thus, $\beta^{\prime} \gamma \cdot(t-1)$ is a scalar term that shows how the time trend of prices and quantities affects the cointegration relation.

Since the cointegration relation was normalized with respect to the quantities (the first dimension of vector $x$ ), one can interpret the term in parentheses in equation (26) as the long-term effect that would occur if the distribution parameter of the CES function in equation (1) had a time trend and were independent of the foreign trade regime. That dependence is captured in our formulation through $d_{t}$, the dummy variable that captures the effect of liberalization; and it is represented by its effect on a generalized distribution parameter of the CES formulation, $\delta_{t}$ which is defined (implicitly) by equation (27).

$$
\log \left[\delta_{t} /\left(1-\delta_{t}\right)\right]=\boldsymbol{\beta}^{\prime} \boldsymbol{\gamma} \cdot(t-1)+\lambda d_{t}+\mu
$$

To summarize, equation (26) takes account of the major shifts that may have occurred in the demand function for imports, based on the hypothesis that the elasticity of substitution $\sigma$ was constant throughout the period.

\section{Results}

We applied the procedure described above to identify the order of integration of the series and to choose the most suitable model to estimate data from the period 1985-2002, for the 28 sectors of the Brazilian inputoutput matrix where imports were positive in 2002, except for agriculture (including livestock) and the service sectors.

Table IX.2 sets out the types of series considered in our classification, in terms of their stochastic properties and the code adopted for each one. We also show, for each variable in the model, the frequency with which each type of series was encountered. Only 16 quantum series and 11 price series do not have a unit root; but, of these, only six quantum series and five price series are stationary. For 10 quantum series and 17 price series, we are able to find evidence of a unit root. ${ }^{22}$ For two quantum series we cannot rule out the existence of a unit root. Lastly, there is evidence of a structural break in the fourth quarter of 1990 for 10 quantum series and six price series.

\footnotetext{
22 It is possible to put forward theoretical arguments against the possibility that a price series is integrated. However, we admit that if they behave like integrated series in our sample, it is preferable to treat them as such in the estimation.
} 
Table IX.2

TYPOLOGY OF QUANTUM AND PRICE SERIES

\begin{tabular}{llcc}
\hline & & \multicolumn{2}{c}{ Number of series } \\
\cline { 3 - 4 } Code & Type & Quantum & Price \\
\hline 1 & Stationary around a non-zero average & - & 3 \\
2 & Stationary around a zero average & 4 & 1 \\
3 & Stationary around a linear trend & 10 & 1 \\
4 & Has a unit root with zero time trend & - & 17 \\
5 & Has a unit root with non-zero time trend & 2 & - \\
6 & The existence of a unit root cannot be rejected & 10 & 6 \\
7 & Does not have a unit root & 10 & 6 \\
\hline- & Evidence of the existence of a structural break in 1990:4 & & \\
\hline
\end{tabular}

Source: Prepared by the authors.

The classification of model types presented in table IX.1 shows that most cases refer to situations where the order of integration of the price and quantity series coincide: this happens in 11 instances of Model A (estimation in terms of levels), and 11 of Model D (cointegration). There are six cases of unbalanced equations, but we estimated four of them using cointegration (Model E) since Models B and C did not produce estimates that were significantly different from zero in these cases. There are also two cases where the estimation through models $B$ and $C$ was satisfactory - one of each type.

The results, in table IX.3, show that the estimate of the Armington elasticity has the correct sign and is significantly different from zero for 20 sectors at the 5\% significance level. For two sectors it is significant only at the $10 \%$ level, and for two others it is significant only at $20 \%$. For one sector the estimated value is significant but its sign is incorrect (negative); and for the three remaining sectors the estimated elasticity is not significantly different from zero.

The coefficient of variation of prices proved significant in just two sectors, and in both cases it is positive, indicating an increase in the share of imports relative to domestic production, in response to greater uncertainty in the relative price of imports. The lack of significance of this variable in most sectors was somewhat surprising, because we had expected it to be significant in several sectors.

The dummy variable that captures the occurrence of a structural break in 1990:4 was significant at the 5\% level in 11 sectors, and at 10\% in one other, thus confirming the importance of the point discussed in 
section 2 regarding the nature of the impact of the liberalization that began in 1990. Its coefficient is positive for eight sectors, where the proportion of imports increased, and it is negative in the other four.

When interpreting the coefficient on this variable it is important to remember that part of the impact of liberalization appears in the equation as a tariff reduction and is therefore already taken into account in the estimated value of the Armington elasticity. The dummy variable captures the rest of the impact of liberalization, which can be attributed to other factors such as the existence of repressed demand for imports, which was revealed when non-tariff barriers were removed on that occasion. ${ }^{23}$

The coefficient of the time trend variable is significant in 20 sectors, and is positive in all cases except one. This is consistent with the interpretation that during the period 1986-2002 there was an increase in the relative demand for imports that is not explained by the other three factors; and it is possibly related to the modernization and internationalization of the basket goods produced and consumed by domestic industry.

Table IX.4 summarizes the values we obtained for the Armington elasticity for the different the sectors, classified as: very high, high, average, low, zero or negative. The range of values in each category is not uniform because the purpose of the classification is to provide an indication of the curvature of the indifference curve between imports and domestically produced goods, for each sector. This curvature does not vary linearly with the elasticity, however, as can be seen in figure IX.1.

Figure IX.1 is also useful for illustrating the difficulty of estimating the Armington elasticity when its value is small and the indifference function has a high degree of curvature. This is the case in the two sectors where the elasticity is classified as low, and in the three cases where it is zero or negative (table IX.4). Considering that, at each point on the plane in figure IX.1, the elasticity of substitution is the ratio between the slope of the indifference curve passing through that point and the slope of the line segment that connects it to the origin of the coordinate

23 The presence of repressed demand is a possible explanation for the sign of the dummy variable in imports of automobiles, trucks and buses, tractors and machinery, other vehicles and autoparts, textiles and clothing. The negative value of that variable can be rationalized for cases where imports did not grow by as much as expected, given the tariff reduction. This may have occurred because of pricing policies implemented by domestic producers to control import penetration in the following sectors: the rubber industry, electronic equipment, miscellaneous chemical products and mineral extraction. 


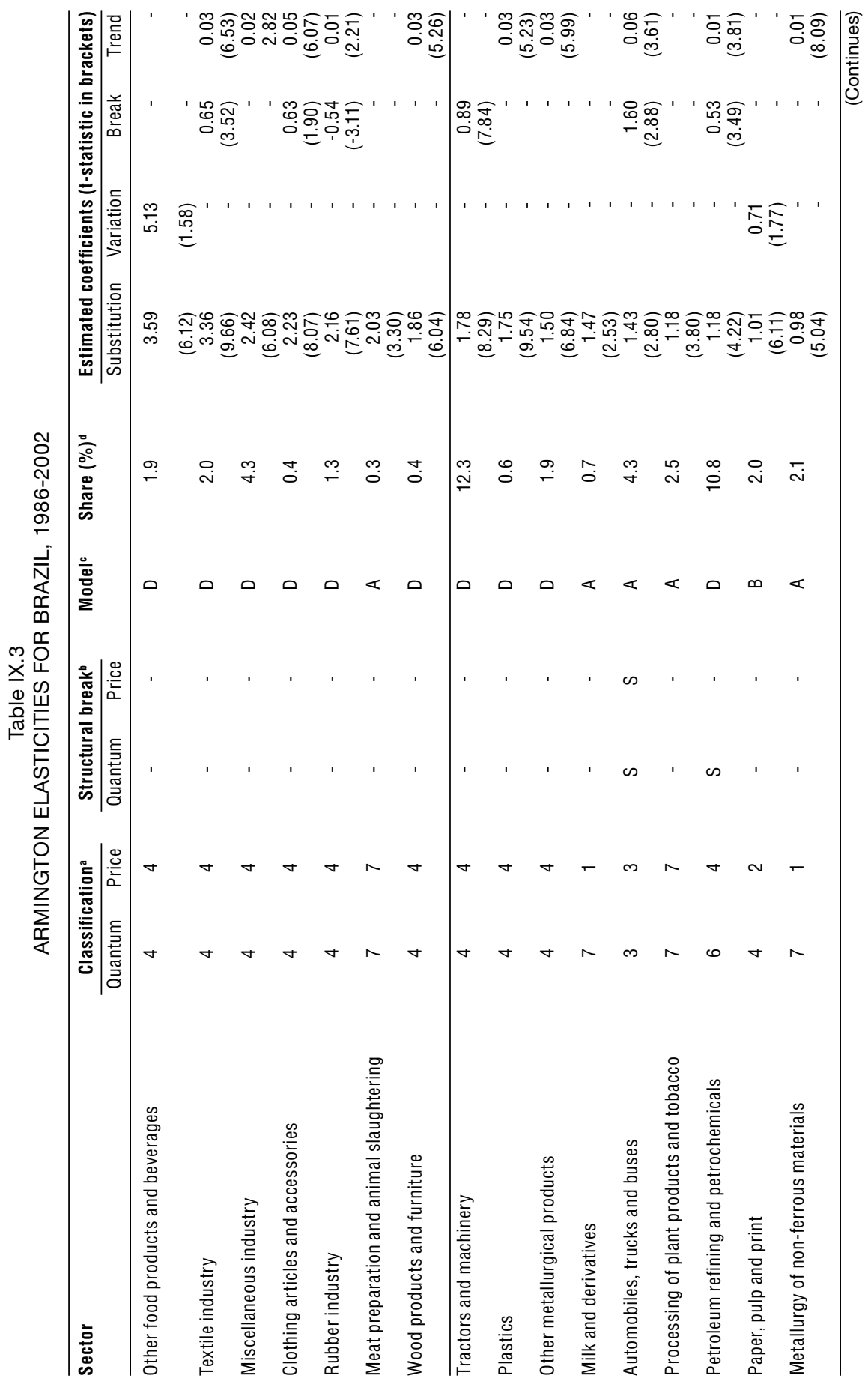




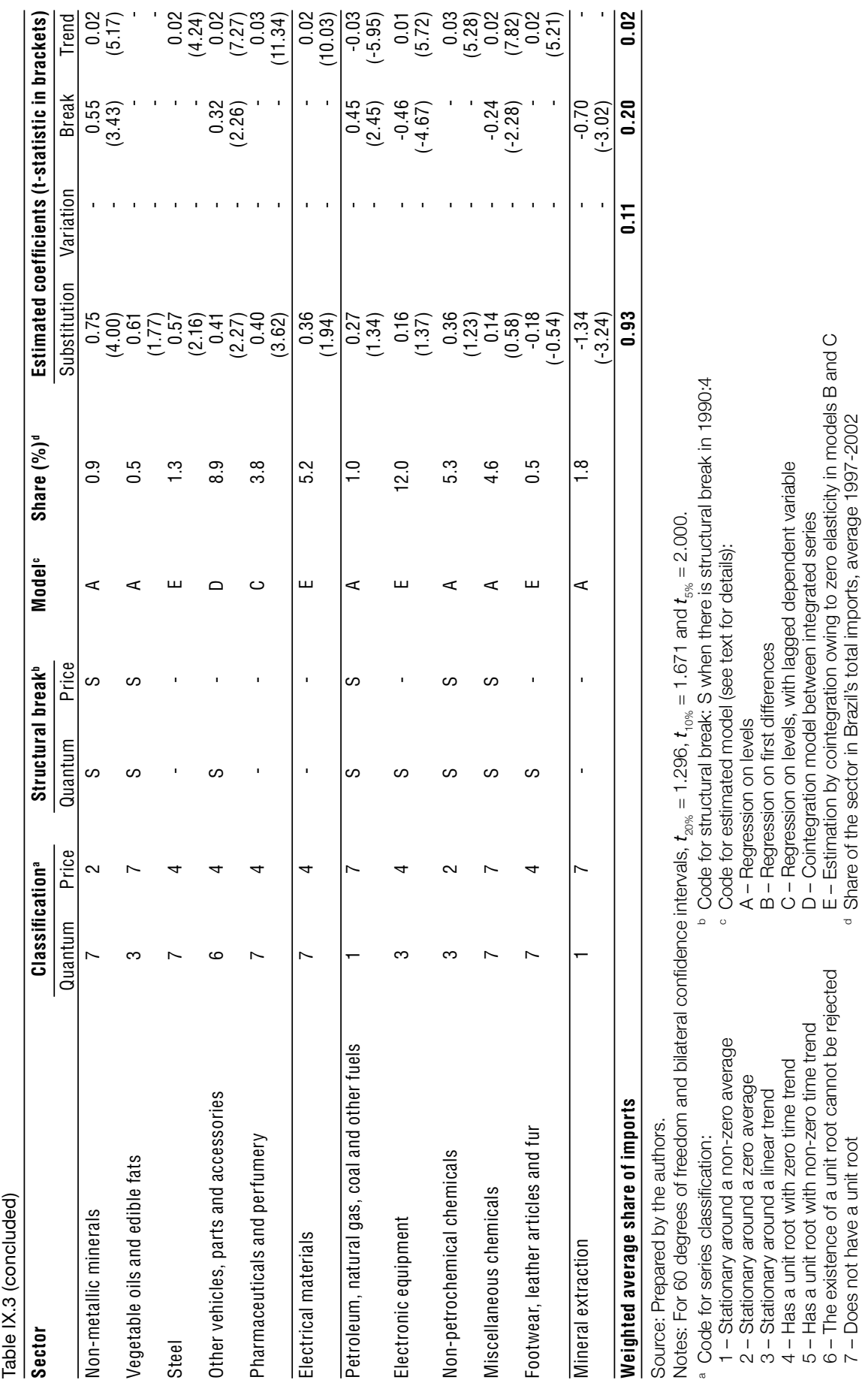




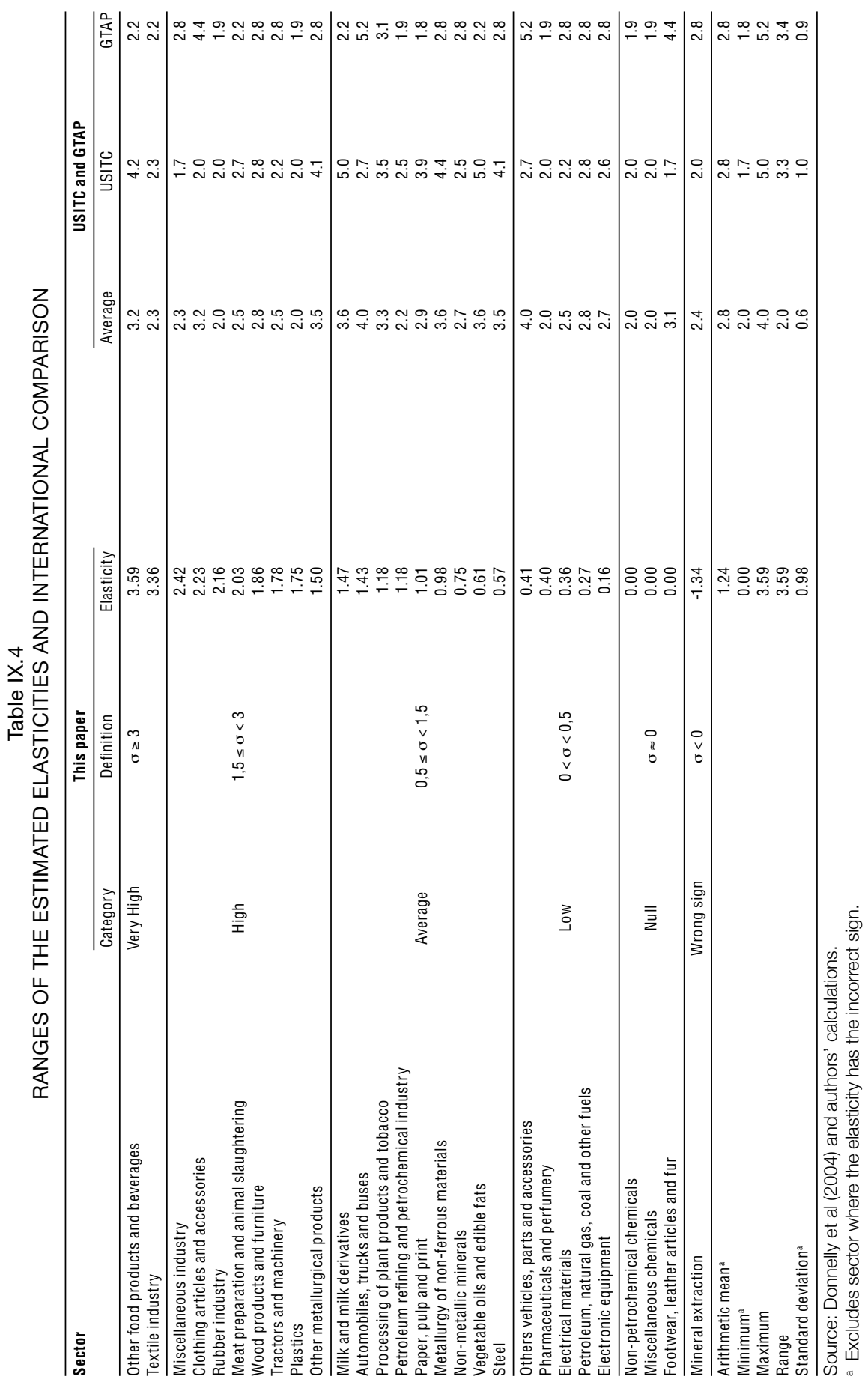


Figure IX.1

INDIFFERENCE CURVES BETWEEN IMPORTS AND DOMESTIC PRODUCTION

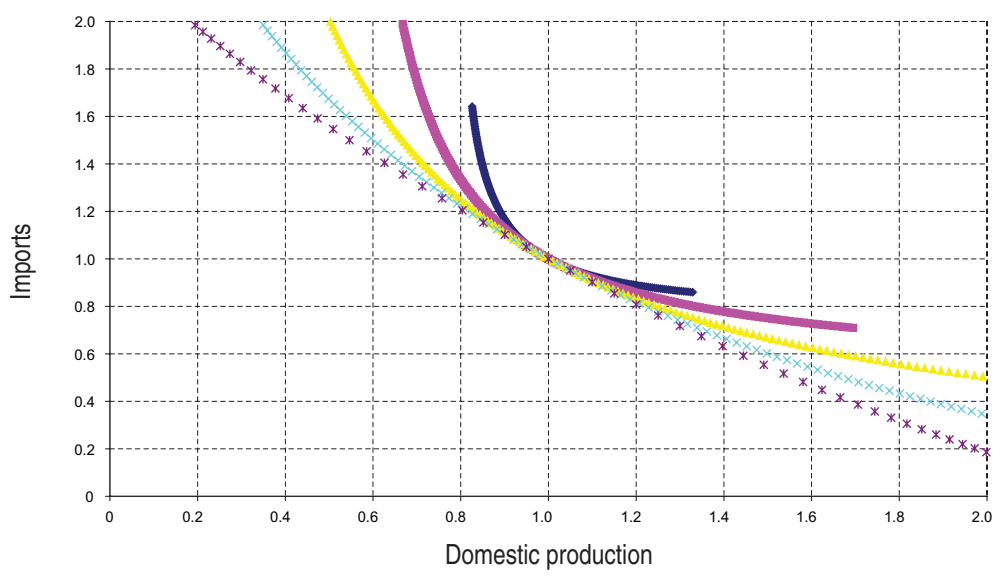

Armington elasticity

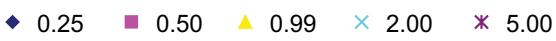

Source: Prepared by the authors.

system, we note that when the curvature is high, only a small segment of the indifference curve is spanned when the relative price changes, even when that change is large. This make the estimation more difficult because large variations in $p$ elicit only small changes in $q$; and in this situation the error term $\varepsilon$ in equation (21) is larger. One might therefore expect a large standard error in the estimate of $\sigma$ in those cases.

Table IX.4 also shows that there are two sectors with very high elasticity $(\sigma \cong 3)$, eight with high elasticity $(\sigma \cong 2)$, nine average $(\sigma \cong 1)$, five low $(\sigma<0.5)$, three zero and one with negative elasticity. The arithmetic mean of the estimated elasticities is 1.24 and their frequency distribution is roughly symmetric.

We now compare the elasticities we estimated for Brazil with those produced by other studies. As noted above, there are no previous estimates for our country; and the difficulty in contrasting them with elasticities for other countries is compounded by differences in the sector classification and the small number of studies available in the international literature. Nonetheless, this obstacle can be partially avoided using the study by Donnelly et al (2004), which presents the Armington elasticities adopted in the applied general equilibrium models of the 
United States International Trade Commission (USITC) and the Global Trade Analysis Project (GTAP), ${ }^{24}$ using a sector classification similar to the one we adopted. ${ }^{25}$

Although table IX.4 compares these three measures of sector elasticities, the comparison may be of questionable relevance in itself, since there is no a priori reason for them to be equal, or even similar, because they reflect country-specific characteristics in the respective consumption and production structures. We proceed with the comparison nonetheless.

Initially we note that the arithmetic mean of the estimated sector elasticities (1.24) is only $44 \%$ of the 2.8 average value of the USITC and GTAP sector elasticities. This suggests that substitution between imports and domestic production is more difficult in Brazil than in the United States, or in other hypothetical "conventional" countries, because, to produce the same relative change in import share the change in relative price needed in Brazil is twice as large, owing to the lower elasticity. This is consistent with the perception that, even after liberalization, Brazil still is relatively closed to international trade. Another possible interpretation of this very large difference in elasticities is that those calibrated by USITC and GTAP are in fact too high for a country with our characteristics, and thus do not represent the behaviour of the import share our case.

On the other hand, this difference in elasticity values does not represent a very significant difference in the curvature of the indifference curve, as can be inferred from figure IX.1 by noting that the curves for $\sigma=1$ and $\sigma=3$, are very close to each other. ${ }^{26}$

As can be seen by comparing the ranges and standard deviations of the sector-level Armington elasticities in our study and those of USITC and GTAP, shown in the bottom lines of table IX.4, the variability of our estimates is similar to those reported by Donnelly et al (2004).

24 The United States International Trade Commission (USITC) developed a CGE model for the United States to evaluate the impacts of changes in trade policy in that economy. Its elasticities refer to the United States, and they were obtained from the literature and later calibrated by sector experts. The Global Trade Analysis Project (GTAP) developed a global-scope multi-regional model which is used to evaluate the global impacts of trade agreements. The generic elasticities obtained from it are used by the model when specific values are not available for a given country. They are derived from the SALTER project of the Australian Industry Commission (Huff, 1997) and other data contained in the literature.

25 In sectors for which we were able to find a direct correspondence with those in our study, we transcribed the values directly. For the other sectors we repeated the values of that study for the broader sector classification.

26 Although the curve for elasticity equal to 3 is not shown in the figure, to preserve clarity, its position can be easily inferred from the curves for elasticities equal to 2 and 5 , as between these two but closer to the former. 
Nonetheless, the fact that the minimum value of the sector elasticities is so high (1.7 and 1.8 for USITC and GTAP, respectively) clearly stands out in comparison to the zero value we found for Brazil. There is also a significant numerical difference in the maximum value of the sector elasticities (3.6 versus 5). Nonetheless, that does not imply a large difference in the curvature of the indifference curve, which is practically zero in both cases, since substitution is near perfect in those sectors, both in Brazil and in the countries represented in those two CGE models.

Lastly, it is important to note that the differences between our estimates and those reported in Donelly et al (2004) may be due not only to the characteristics of the countries, but also to differences in the methodologies used to obtain them. The calibration of elasticities, based on expert opinions expressed in relation to sector studies using the Delphi methodology, may have led the institutions in question to eliminate outlying or uncommon values, as a result of error-risk aversion on the part of the specialists consulted.

We can conclude this international comparison by making a more general assessment of the comparison of sector elasticities, noting that the discrepancies are substantial and more frequent than the coincidences. This eloquent evidence advises against a procedure that is frequently encountered in the literature, whereby the impacts of trade and exchangerate policies are analysed using elasticities calibrated on the basis of values adopted for other countries, on the assumption that differences are insignificant. This procedure is not valid for Brazil, at least for the period we have analysed, and it may easily lead to false conclusions.

\section{E. Conclusions}

This paper has estimated a new set of Armington substitution elasticities for the 28 industrial sectors of the Brazilian input-output matrix, for the period 1986-2002. We develop an estimation methodology that measures the effects on observed data of the trade restrictions that existed before 1990, and the impact of the trade liberalization that began in that year. The methodology also carefully examines and takes into account the stochastic and dynamic properties of the variables involved, and chooses the estimation method so as to be consistent with those properties. We speculate that this methodology could be applicable to other countries that have undergone trade liberalization; and we argue that this is relevant and needs to be included in the estimation data for the trade liberalization period, since it contains information that is very important for estimating the elasticity of substitution and the curvature of the indifference curve between imports and domestic production. 
The Armington elasticities we estimate have the correct sign; and they are significant at the $5 \%$ level for 20 sectors, at $10 \%$ for two sectors, and at $20 \%$ for two others. In one sector the estimated value is significant but has the incorrect sign (negative). Although the estimated elasticity is not significantly different from zero in three sectors, these represent only $12 \%$ of the average total value of imports in the period 1997-2002. The point estimate of the elasticity of substitution ranges from 0.16 to 3.6 in the sectors where it is positive and statistically non-zero; and its weighted average value is 0.93 , the weights being the value of sector imports.

A classification was used to group sectors according to the range of variation of the substitution elasticity. This shows that the Armington elasticity is very high in two sectors, high in eight, average in nine, low in five, zero in three, and negative in one. The arithmetic mean of their value is 1.24 and the frequency distribution of the elasticities is roughly symmetric.

The international comparison shows that the average of the sector elasticities we obtain is only $44 \%$ of those used in the USITC and GTAP general equilibrium models; but this numerical difference in elasticity values only has a small effect on the curvature of the indifference curve between imports and domestic production. Nonetheless, there are large sector differences in elasticity values when the estimates for different sectors are compared individually; and there are also differences in the minimum and maximum elasticities across sectors.

Lastly, we believe that using these elasticities will enable researchers to more precisely evaluate the economic impacts of a change in trade policy, in both partial and general equilibrium models. 


\section{Bibliography}

Armington, P. S. A theory of demand for products distinguished by place of production. IMF Staff Papers, v. 16, n.1, 1969.

Dervis, K., Melo, J. de, robinson, S. General equilibrium models for development policy. Cambridge: Cambridge University Press, 1982.

Dickey, D., Fuller, W. A. Likelihood ratio statistics for autoregressive time series with a unit root. Econometrica, v. 49, July 1981.

Dolado, J., Jenkinson, T., Sosvilla-Rivero, S. Cointegration and unit roots. Journal of Economic Surveys, v. 4, 1990.

Donnelly, W. A. et al. Revised Armington Elasticities of Substitution for the USITC Model and the Concordance for Constructing a Consistent Set for the GTAP Model. Office of Economics Research Note no. 2004-01-A. Washington, D. C.: U. S. International Trade Commission. January 2004.

Enders, W. Applied econometric time series. John Wiley \& Sons, 1995.

Funcex. Boletim Setorial. Rio de Janeiro, Ano VI, n. 3, Jul./Aug./Sep. 2002.

Gallaway, M., McDaniel, C., Rivera, S. Industry-level estimates of U.S. Armington elasticities. North American Journal of Economics and Finance 14 (2003), 49-68.

Hamilton, J. D. Time series analysis. Princeton, New Jersey: Princeton University Press, 1994.

Harrinson, G. W. et al. Politicas comerciais regionais, multilaterais e unilaterais do Mercosul para o crescimento econômico e redução da pobreza no Brasil. The World Bank, May 2002.

Hufbauer, G. C., Elliot, K. A. Measuring the costs of protection in the United States. Washington, D.C.: Institute of International Economics, 1994.

Huff, K. M. et al. GTAP behavioral parameters. In: Hertel, T. W. (ed.) Global Trade Analysis: Modeling and Applications. Cambridge: Cambridge University Press, 1997.

Johansen, S. Statistical analysis of cointegration vectors. Journal of Economic Dynamics and Control, v.12, 1988.

Kume, H. A política tarifária brasileira no período 1980-88: avaliação e reforma. Rio de Janeiro: INPES/IPEA, 1990 (Série Épico, 17).

Maddala, G. S. e kim, I, M. Unit roots, cointegration, and structural change. Cambridge University Press, 1998.

Markwald, R. et al. Índices de preço e quantum do comércio exterior. Working Paper 134, Fundação Centro de Estudos de Comércio Exterior, 1998.

Melo, J. de, robinson, S. Product differentiation and the treatment of foreign trade in computable general equilibrium models of small economies, Journal of International Economics, v. 27, n. 1-2, 1989.

Perron, P. The great crash, the oil price shock and the unit root hypothesis. Econometrica, v. 57, Nov. 1989.

Sánchez, G. Beyond Mercosur: costs and benefits of trade agreements with Northern blocs. Leral de la Fundación Mediterránea, Dec. 2001.

Tourinho, O., Kume, H., Pedroso, A. C. Elasticidades de Armington para o Brasil: 1986-2002. Working Paper 974, IPEA, 2003.

Tourinho, O., Kume, H., Pedroso, A. C. Elasticidades de Armington para o Brasil: 1986-2002. Revista Brasileira de Economia, vol. 61, No. 2, 2007.no. 2, April/ June 2007. 


\section{Annex A}

\section{Source and treatment of the data}

We used quarterly data for each sector of the Brazilian input-output matrix (IBGE - level 50), for the period 1986-2002.

The price and quantum indices $\left(P_{i}^{m}\right)$ and $\left(M_{i}\right)$, respectively, are those produced by Fundação Centro do Comércio Exterior (Funcex), using the methodology described in Markwald et al (1998); they are available in the electronic database system IPEADATA (www.ipea.gov.br). The exchange rate $(e)$ is the monthly average of the official dollar selling price. We approximated the domestic price index $\left(P D_{i}\right)$ by the corresponding wholesale price index, Índice de Preço no Atacado (Oferta Global) calculated by the Getulio Vargas Foundation (IPA-OG-FGV), having reconciled its sectors with those of the input-output matrix described in table A1. We calculate the average price index in cases where an activity of the input-output matrix corresponds to more than one IPA sector, using a weighted average when the necessary data was available, otherwise the simple average.

The coefficient of variation of the relative price $\left(P_{i}^{d} / P_{i}^{m}\right)$ measures the effect of uncertainty and was calculated as the ratio between the standard deviation and the average of this price ratio over a six-month "window" centred on the median month of the period in question.

The domestic sales quantum index $\left(D_{i}\right)$ was estimated by deflating the value of domestic sales for each sector $\left(V D T_{i}\right)$ by the corresponding domestic price index $\left(P_{i}^{d}\right)$.

The sector $V D T_{i}$ was calculated by deducting the value of exports from the corresponding sector-production value $\left(V P_{i}\right)$, which was inferred from its value in the most recent input-output matrix, together with the variation in the production and price indices between the year to which it refers and the date for which the calculation is being made. As data availability prior to 1990 is limited, the procedure was slightly adapted in the earlier period, as follows.

For 1986-1990 the value of total domestic sales $\left(V D T_{i}\right)$ was estimated by equation (A1), which shows that the value for each month was calculated by applying the observed monthly variations in the quantum and price indices to the average value of total domestic sales in 1985, and then deducting the value of exports for the respective month. This uses the domestic production quantum index calculated by IBGE (www.ipea. gov.br) for each sector of the matrix, adjusted to the aggregation used here as described in table A2. 
Table A1

RECONCILIATION BETWEEN THE SECTORS OF THE INPUT-OUTPUT MATRIX AND THE IPA INDUSTRY CLASSIFICATION

\begin{tabular}{|c|c|}
\hline Sector of input-output matrix (level 50) & Sector of the IPA-0G-FGV (column) \\
\hline Mineral extraction & Mineral extraction (28) \\
\hline Petroleum, natural gas, coal and other fuels & Fuels and lubricants (54) \\
\hline Non-metallic minerals & Limestones and silicates $(30)$ \\
\hline Steel & Iron, steel and derivatives (32) \\
\hline Metallurgy of non-ferrous materials & Non-ferrous metals (33) \\
\hline Other metallurgical products & Total metallurgical (31) \\
\hline Tractors and machinery & Machinery and industrial equipment (36) \\
\hline Electric material & Total electric material (38) \\
\hline Electronic equipment & Electric material and others (41) \\
\hline Automobiles, trucks and buses & Motor vehicles (43) \\
\hline Other vehicles, parts and accessories & Motor vehicles (43) \\
\hline Wood products and furniture & Wood (45), total furniture (46) \\
\hline Paper, pulp and print & Paper, paperboard (50) \\
\hline Rubber industry & Rubber (51) \\
\hline Non-petrochemical chemicals & Chemicals and others (58) \\
\hline Petroleum refining and petrochemical industry & Total chemicals (53) \\
\hline Miscellaneous chemicals & Total chemicals (53) \\
\hline Pharmaceuticals and perfumery & $\begin{array}{l}\text { Pharmaceutical products (81), perfumery, soaps } \\
\text { and candles ( } 82 \text { ) }\end{array}$ \\
\hline Plastics & Plastics (56), plastic products (83) \\
\hline Textile industry & $\begin{array}{l}\text { Natural fabrics and yarns (60), man-made fabrics } \\
\text { and yarns (61), knitted or crocheted fabrics (62) }\end{array}$ \\
\hline Clothing articles and accessories & Clothing (63) \\
\hline Footwear, leather articles and fur & Footwear (64) \\
\hline Processing of plant products and tobacco & Plant products (71) \\
\hline Meat preparation and animal slaughtering & Meat and fish (78) \\
\hline Milk and milk derivatives & Milk and milk derivatives (79) \\
\hline Vegetable oils and edible fats & Vegetable oils and fats (74) \\
\hline Other food products and beverages & Salt, animal feed and others ( 80$)$, beverages (66) \\
\hline Other miscellaneous industries & Total manufacturing industry (29) \\
\hline Meat preparation and animal slaughtering & Meat and fish (78) \\
\hline
\end{tabular}

Source: IBGE and FGV. Prepared by the authors. 
where:

(A1) $V D T_{i t}=\left(\frac{V P_{i 85}}{12}\right) \cdot\left(\frac{q_{i t}}{q_{i 85}}\right) \cdot\left(\frac{P_{i t}}{P_{i 85}}\right)-V E_{i t}$

$V D T_{i t}=$ value in $\mathrm{R} \$$ of total sector $i$ domestic sales in month $t$;

$V P_{i t 85}=$ value in $\mathrm{R} \$$ (base price) of sector $i$ production in 1985;

$q_{i t}=$ index of sector $i$ physical production in month $t$;

$q_{i t 85}=$ index of sector $i$ physical production, monthly average in 1985;

$P_{i t}=$ index of sector $i$ domestic price in month $t$;

$P_{i 85}=$ index of sector $i$ domestic price, monthly average in 1985; and

$V E_{i t}=$ value in $\mathrm{R} \$$ of sector $i$ exports in month $t$.

After 1991, the procedure described above for the reference year 1985 was repeated, but using previous year's average values as the base, because the value of domestic production each year is available in the input-output matrix for 1991-1996, and in the National Accounts for 1997-2002.

We used a two-step procedure to calculate the nominal tariff in each sector $\tau_{i t}$. First, we distributed the products and respective tariffs obtained from the foreign trade classification table - the Brazilian Merchandise Nomenclature: Harmonized System (NBM-SH) and the Common Mercosur Nomenclature (NCM-SH) - for each sector (level 80) of the input-output matrix. Next, we calculated the average nominal tariff for each activity in the input-output matrix (level 50), weighted by the value of production of each sector (level 80 ) belonging to each activity (level 50).

The effectively paid tariff series $\left(\bar{\tau}_{i t}\right)$ was calculated as the ratio between tariff revenue and the total value of imports for each category of use, using data obtained from the Brazilian Internal Revenue Service (SRF/MF). This was adjusted to be consistent with the sector classification of the input-output matrix. 


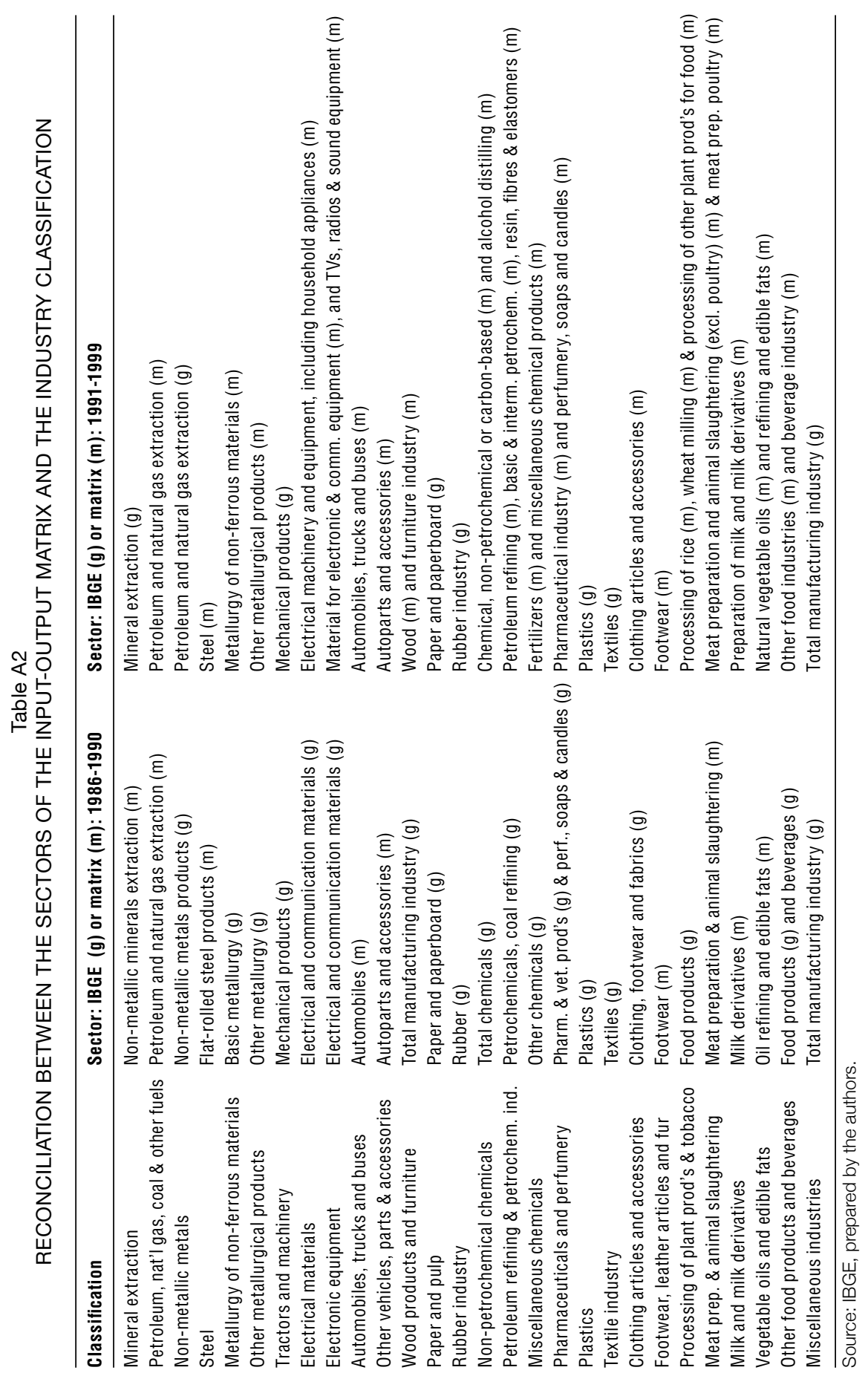




\section{Annex B \\ Determination of the order of integration of the price and quantum series}

We used the methodology proposed by Enders (1995) to determine the order of integration of the price and quantity series involved in the estimation equation, complemented by the Perron (1989) test to deal with the possibility of structural breaks in the series.

We initially estimate equation (B1), which contains a trend, a constant term and autoregressive components; and we test for the existence of a unit root $(\gamma=0)$, using the augmented Dickey-Fuller (ADF) statistic. ${ }^{27}$ If that hypothesis is rejected, we conclude there is no unit root and terminate the search.

$$
\text { (B1) } \Delta x_{t}=a_{0}+\gamma x_{t-1}+a_{2} t+\sum_{i=1}^{p} \beta_{i} \Delta x_{t-i}+\varepsilon_{t}
$$

As this is a low-power test, if the unit root cannot be rejected we must also test the joint hypothesis of its existence and the absence of a trend $\left(a_{2}=\gamma=0\right)$, using the Dickey-Fuller $\phi_{3}$ statistic (1981). If this joint hypothesis is rejected, we test again for $\gamma=0$, using a normal distribution, and the procedure is then ended. If this joint hypothesis cannot be rejected, we assume that we can cast the data-generating process in the form of equation (B2), and we again test for a unit root with the ADF statistic.

$$
\Delta x_{t}=a_{0}+\gamma x_{t-1}+\sum_{i=1}^{p} \beta_{i} \Delta x_{t-i}+\varepsilon_{t}
$$

If the null hypothesis of a unit root is rejected in this specification, we terminate the procedure. If it cannot be rejected, we test for the joint null hypothesis $a_{0}=\gamma=0$ using the Dickey-Fuller $\phi_{2}$ statistic (1981). If joint hypothesis is rejected, we test again for $\gamma=0$, using the normal distribution, and the procedure is completed. If the hypothesis $c_{1}=\gamma=0$ is not rejected, we test for the existence of the unit root in the specification of equation (15), again using the ADF statistic. If $\gamma=0$ is accepted (rejected), we conclude that the series contains (does not contain) a unit root.

$$
\Delta x_{t}=\gamma x_{t-1}+\sum_{i=1}^{p} \beta_{i} \Delta x_{t-i}+\varepsilon_{t}
$$

27 The critical values for the ADF statistics were taken from Hamilton (1994) for a $10 \%$ significance level. 
In equations (B1), (B2) and (B3), the number of lags ( $p$ ) was chosen according to the general-to-simple criterion, starting with a maximum of five. The fifth lag is retained if it is significant at the $5 \%$ level. Otherwise, we re-estimate the equation with four lags, and again assess the level of significance of the last lag. The procedure continues until the coefficient of the last autoregressive component is significant at the $5 \%$ level.

It should be noted that the results of the tests described above may not be conclusive if there is a structural break in the series; in that case the ADF statistic has a bias towards non-rejection of the unit root. To account for this and take into consideration the likelihood of a structural break in the fourth quarter of 1990, we apply the Perron (1989) test to series displaying a unit root. Using the taxonomy proposed by that author, we assume the break is of the type represented by the changing growth model. Equation (B4) describes this model, and accommodates both the null and the alternative hypothesis of the test. In the null hypothesis, a unit root is assumed with a change in the intercept of the process at the time of the structural break. The alternative hypothesis assumes that the process is stationary with a change in the slope of the deterministic trend line at the time of the break.

$$
\text { (B4) } x_{t}=\mu+\theta U_{t}+\beta t+\gamma T_{t}+\alpha x_{t-1}+\sum_{i=1}^{p} \beta_{i} \Delta x_{t-i}+\varepsilon_{t}
$$

where:

$T_{B}=$ date of the structural break;

$D U_{t}=1$, if $t>T_{B}$ and $D U_{t}=0$; and

$D T_{t}^{*}=t-T_{B}$, if $t>T_{B}$ and $D T_{t}^{*}=0$, otherwise.

The null hypothesis imposes the following restrictions on the parameters of equation (B4):

$\alpha=1, \gamma=0, \theta \neq C$

The alternative hypothesis imposes the following restrictions on the parameters of equation (B4):

$\alpha<1, \gamma \neq 0, \theta=\mathrm{C}$

We assumed that the structural break occurred in the fourth quarter of 1990, and the critical values used were those of Perron (1989), with a 10\% significance level. We applied the test sequentially, adding autoregressive components until the hypothesis of residual autocorrelation was rejected in the Ljung-Box test, at a 5\% significance level. 